\title{
LEGISLATING HOME: THE IMPACT OF THE REGULATION OF SMALL HOUSE SETTINGS FOR LONG TERM CARE RESIDENTS IN NOVA SCOTIA, CANADA
}

A Dissertation
Presented to
the Faculty of the Graduate School
at the University of Missouri
In Partial Fulfillment
of the Requirements for the Degree
Doctor of Philosophy

by

EMILY ROBERTS

Dr. Benyamin Schwarz, Dissertation Supervisor

DECEMBER, 2012 
All rights reserved

INFORMATION TO ALL USERS

The quality of this reproduction is dependent upon the quality of the copy submitted.

In the unlikely event that the author did not send a complete manuscript and there are missing pages, these will be noted. Also, if material had to be removed, a note will indicate the deletion.

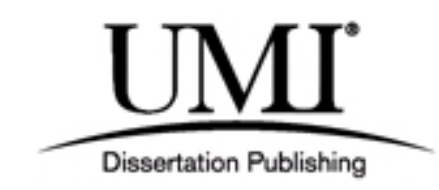

UMI 3537861

Published by ProQuest LLC (2013). Copyright in the Dissertation held by the Author.

Microform Edition () ProQuest LLC.

All rights reserved. This work is protected against unauthorized copying under Title 17, United States Code

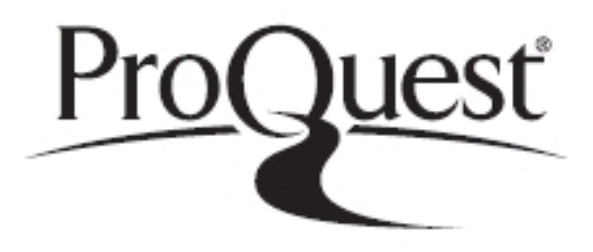

ProQuest LLC.

789 East Eisenhower Parkway

P.O. Box 1346

Ann Arbor, MI 48106 - 1346 
Copyright by Emily Roberts 2012

All Rights Reserved 
The undersigned, appointed by the dean of the Graduate School, have examined the dissertation entitled

\section{LEGISLATING HOME: THE IMPACT OF THE REGULATION OF SMALL HOUSE SETTINGS FOR LONG TERM CARE RESIDENTS IN NOVA SCOTIA, CANADA}

presented by Emily Roberts, a candidate for the degree of Doctor of Philosophy, and hereby certify that, in their opinion, it is worthy of acceptance

Professor Benyamin Schwarz

Professor Ruth Brent Tofle

Professor Newton D’Souza

Professor Myra Aud 
Dedicated to my husband Dennis, And to my children Liam, Holly and Miles;

You are my inspiration,

To the memory of the sisters

Rose and Joan

Who reminded me to always be on the lookout for what's around the next corner,

And to the memory of my father

Dr. David M. Heinz

Whose spirit has been, and will continue to be, a guiding light. 


\section{ACKNOWLEDGEMENTS}

As I reflect back on the past three years, I realize how fortunate I am to have had the support, encouragement, and guidance of several individuals. I am honored and privileged to have worked with Dr. Benyamin Schwarz, who recognized and nurtured my passion for the study of the elderly in long term care; he is a truly unique mentor and instructor. I am deeply indebted to Professor Ruth Tofle, for her endless hours spent in the role of Chair of the Department of Architectural Studies and for personally encouraging me to explore the rich world of environmental gerontology. In addition, I am grateful to Dr. Newton D’Souza, who was the first to read and comment on my work after a 30 year hiatus from writing college papers. Finally, I want to express my appreciation to Professor Myra Aud, whose personal insight into the world of nursing has led me to a deeper understanding of the needs for care for the frail elderly.

This research could not have taken place without the open door which Wyatt and the management and staff at the two communities owned by the Welsh Group afforded me. Their hospitality and focus on outcomes gave me a new appreciation for what nursing care can be. I would also like to thank the faculty at Mt. St. Vincent University Institute on Aging as well as Donna Dill, at the Nova Scotia Department of Health, for helping to clarify a sometimes complex set of provincial guidelines.

Finally, I wish to thank the residents and family members of Ridgemont and Stonebridge, who have made my life richer with their stories, their jokes, and their tears. I will carry your faces and spirits in my heart always. Home for me is spending time with you. 


\section{TABLE OF CONTENTS}

ACKNOWLEDGMENTS _............................................................................................. ii

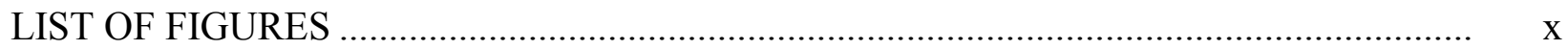

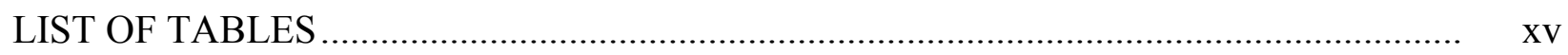

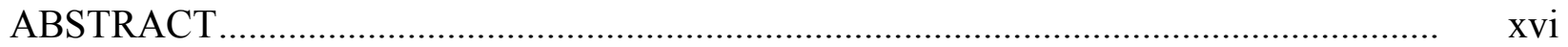

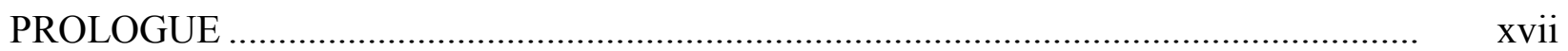

PART I. LEGISLATING HOME

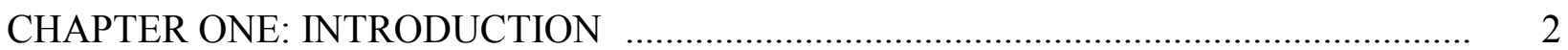

Purpose of Study ............................................................................................... 2

Statement of Problem.............................................................................................

Research Proposition and Questions....................................................................... 8

Limitations of Research ............................................................................... 10

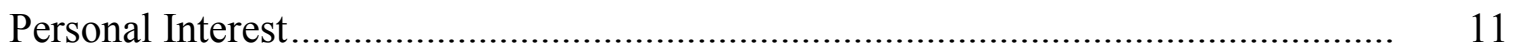

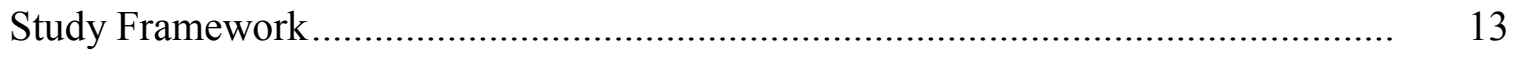

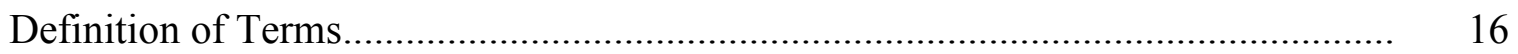

CHAPTER TWO: REVIEW OF LITERATURE .................................................................. 17

Theories of Aging and the Environment.............................................................. 17

The Competence-Press Model ............................................................................ 19

Social Interdependence and Dynamic Systems Theory......................................... 21

The Temporal Perspective …………………........................................................ 23

Social Connection ................................................................................. 23

Place Theory ................................................................................... 24

The Layered Meaning of Home .............................................................................. 26

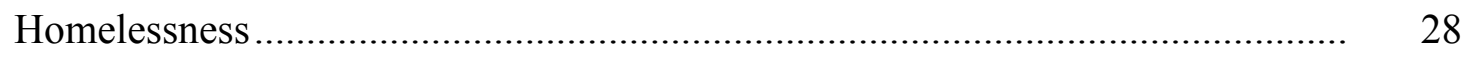

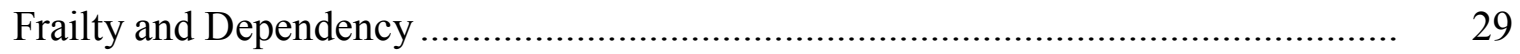


Home, Health, and Care .................................................................................... 30

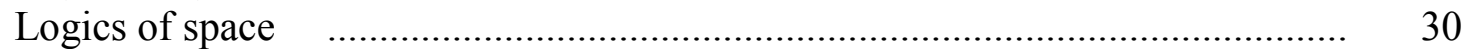

The Small House Model ................................................................................ 31

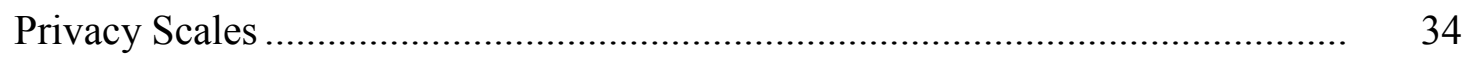

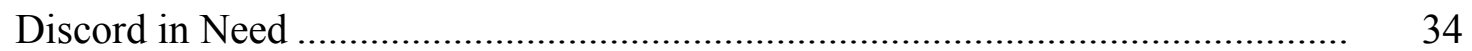

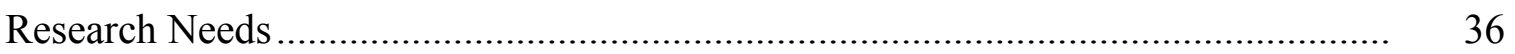

Current Research in the Small House Model ..................................................... 36

CHAPTER THREE: RESEARCH DESIGN AND METHODOLOGY ………...................... 41

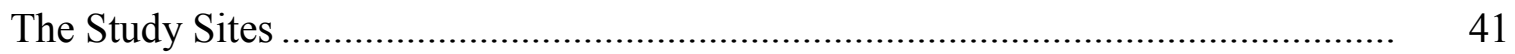

The Case Study ................................................................................................. 47

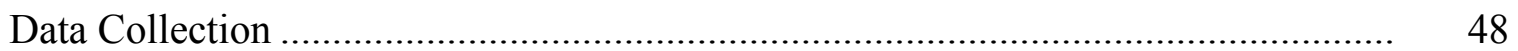

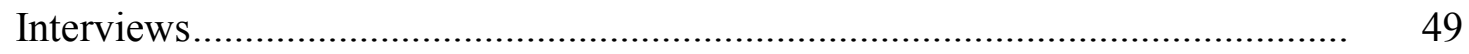

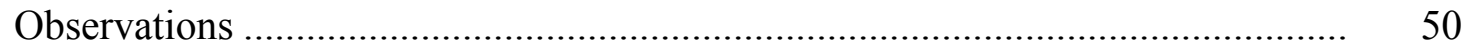

Document Review.................................................................................. 51

Data Analysis ............................................................................................ 51

Validity and Ethical Issues................................................................................. 52

CHAPTER FOUR: LONG TERM CARE IN NOVA SCOTIA …………………................ 54

A Brief History of Halifax, Nova Scotia ................................................................... 54

Long Term Care in Nova Scotia ........................................................................ 58

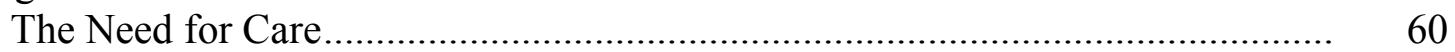

A System in Place ...................................................................................... 62

Changes in Funding Structures ........................................................................ 63

Changes in Assessment Procedures .................................................................... 66

Waiting in Acute Care ..................................................................................... 67

CHAPTER FIVE: RIDGEMONT CONTINUNG CARE COMMUNITY ………….............. 69

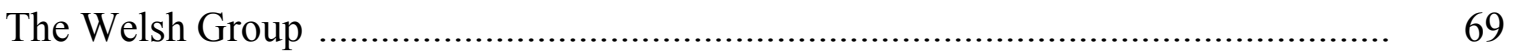

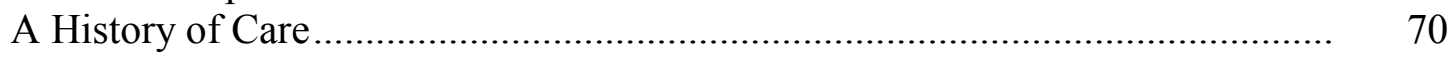

The Nursing Home Renovation ............................................................................ 75

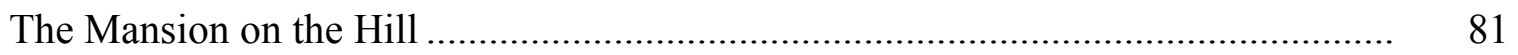

The Demise of the ARC........................................................................................ 83

The Closedown .................................................................................... 85

Transitions................................................................. 87 


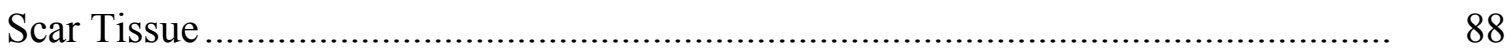

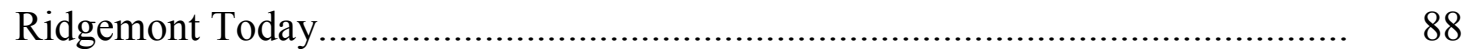

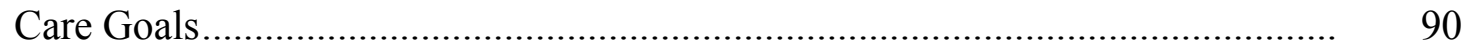

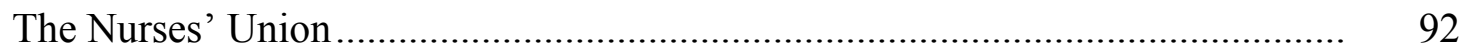

Chapter Summary ..................................................................................... 94

CHAPTER SIX: THE CONTINUING CARE STRATEGY ………………………............. 96

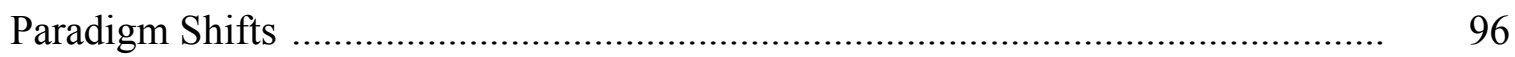

The Continuing Care Strategic Framework Project.................................................. 98

Provincial Design Standards .......................................................................... 99

The RFP Process ……………………............................................................. 102

Making the Pitch Based on Ridgemont …………………………………...... 103

Getting "it" at Saskatoon .............................................................................. 106

Design as a Group Discussion ......................................................................... 108

The Physical Design ..................................................................................... 109

The Fight for the Open Kitchen ...................................................................... 116

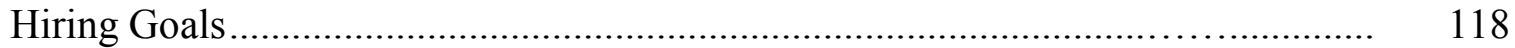

Keeping the Unions Out............................................................................ 120

Chapter Summary ........................................................................................ 121

PART II. FRAMING HOME

CHAPTER SEVEN: STONEBRIDGE CONTINUING CARE COMMUNITY ............... 123

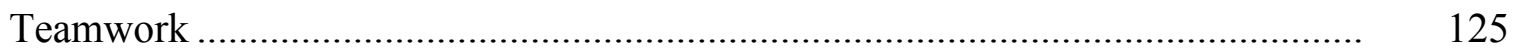

That's Why I'm Here .................................................................................... 126

We Called Them by Their Room Number........................................................ 129

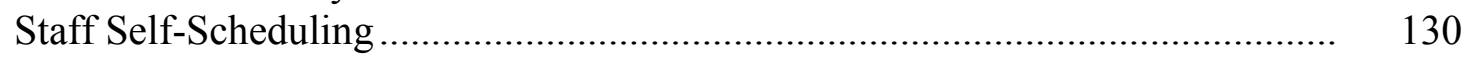

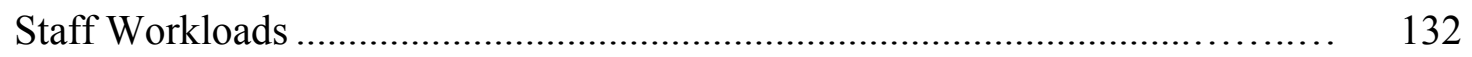

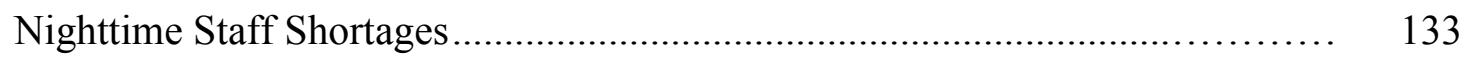

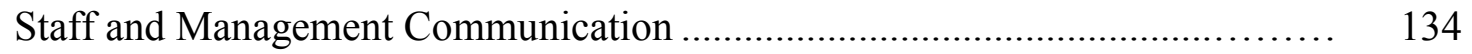

Choice, Risk, and Autonomy-The Triple Edged Sword ..................................... 135

I Don't Have to Go and Wake Them Up ..................................................... 136

Regulating Risk-The RN Perspective .............................................................. 138 
Resident Participation and the Social Environment.................................... 140

Interpersonal Social Connections ............................................................. 140

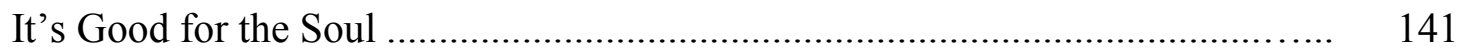

Cottage Proximity to the Community Room ………...................................... 142

Resident Interaction in the Cottages.................................... 143

What Did She do at Home?. ................................................ 147

The Physical Environment .............................................................................. 150

The Secure Environment-Peace of Mind ........................................................ 150

Working in the Open Kitchen.......................................................................... 153

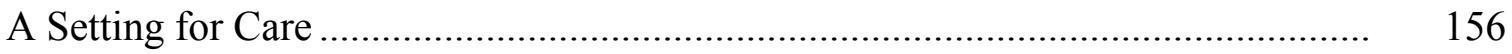

Assessing Care Needs ............................................................................... 156

The Learning Curve in Memory Care .............................................................. 158

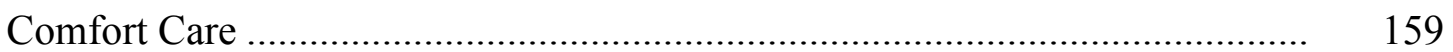

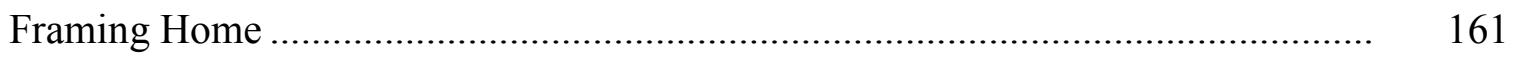

The Power of the Model ................................................................................... 161

I Feel Like I'm Coming into My Home............................................................ 162

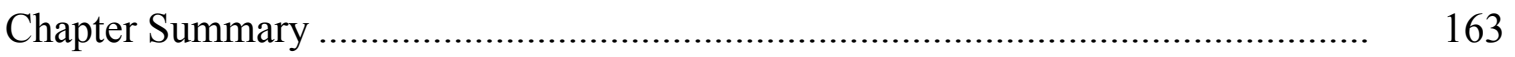

CHAPTER EIGHT: VOICES FROM DOWN HOME ……………………………............ 165

Family Voices-Anger and Guilt: The One-Two Punch ............................................ 166

Ridgemont Family Interviews....................................................................... 168

He Calls Me 10-12 Times a Day........................................................... 168

I'm Not Moving Her Again ........................................................................ 171

He Really Doesn't Know We're Here ........................................................... 174

Caring for Two Parents ........................................................................... 175

Stonebridge Family Interviews ....................................................................... 179

They Sent Him to the Wrong Nursing Home ................................................ 179

She's Well Cared For ........................................................................... 180

There's a Limit to What You Can Do ........................................................ 182

This Location Works ………………………………............................. 185

Resident Voices-Daily Life in Long Term Care.................................................... 187

Daily Life at Ridgemont-Resident Interviews .................................................... 189 
You Can't Go Anywhere Really ................................................................... 191

I Have to Talk to the Head Honcho ............................................................... 193

It's Not Home, but So Far So Good ............................................................ 197

If You Don't Use it, You'll Lose it............................................................... 200

Oh, I Think it's Lovely ......................................................................... 203

You've Got No Other Home, So This is Your Home ...................................... 206

Daily Life at Stonebridge-Resident Interviews .................................................. 210

I Know it's Nice, but it's Not My Cup of Tea .......................... 210

This is Where I'm From ..................................................................... 213

It's Different Having People You Can Depend On ............................... 214

I Don't Think He's Found Me Yet..................................................... 216

It's a Long Way from Being Home .................................................... 218

They Cleaned Out my Apartment ....................................... $\quad 222$

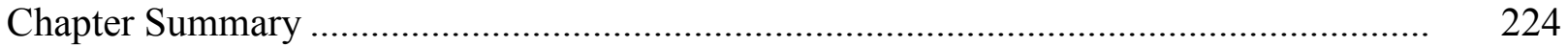

\section{PART III. FINDING HOME}

CHAPTER NINE: CASE STUDY PERSPECTIVES AND ANALYSIS ……………......... 228

The Dynamics of System-wide Change in LTC ……………………………................ 229

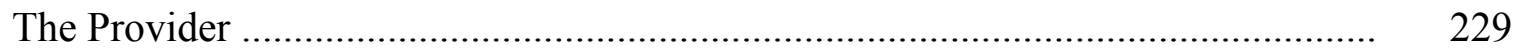

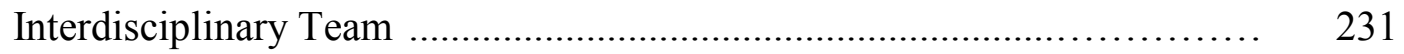

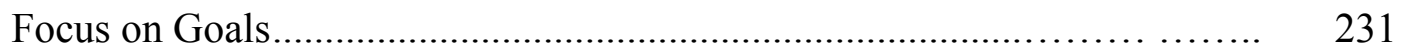

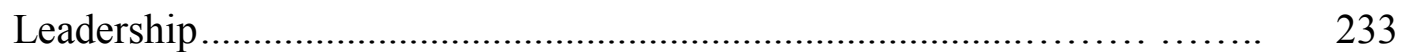

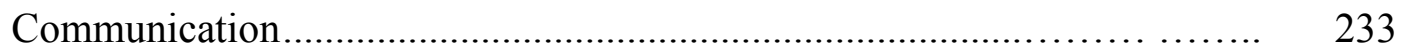

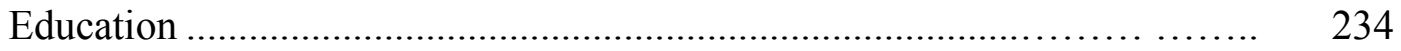

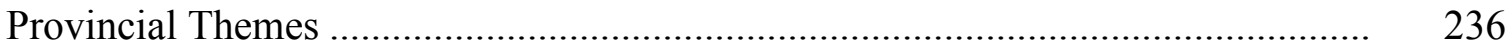

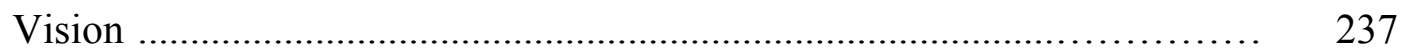

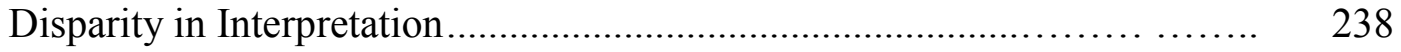

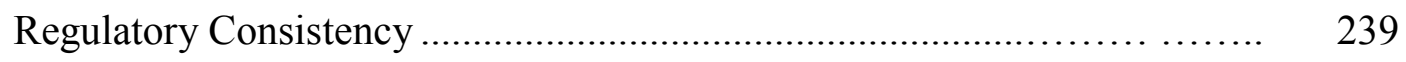

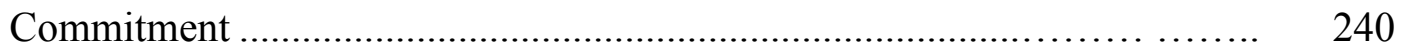

The Dynamics of the Environment in LTC ………………………………….......... 242

The Neighborhood vs. the Cottage ……………………......................................... 243

The Central Parlor vs. the Community Room ………………………………....... 248 
Integration of the Nurses' Area........................................................................... 249

The Open Kitchen (Revisited) ……………………......................................... 250

Private vs. Semi-private Resident Rooms............................................................ 254

The Dynamics of Life Transitions in LTC ………………........................................... 255

The Process of Change for Family Members …………….................................. 256

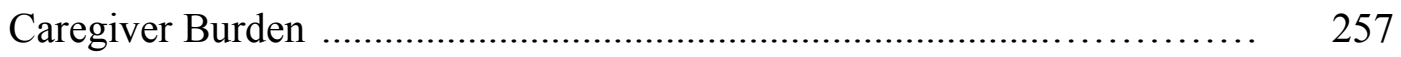

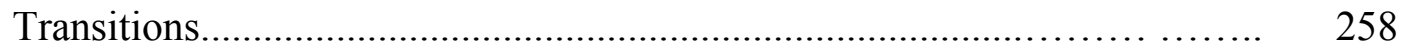

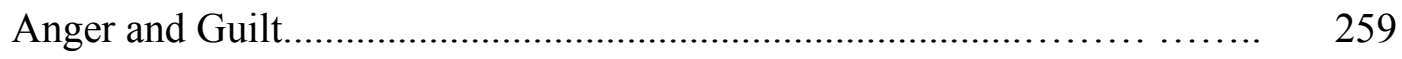

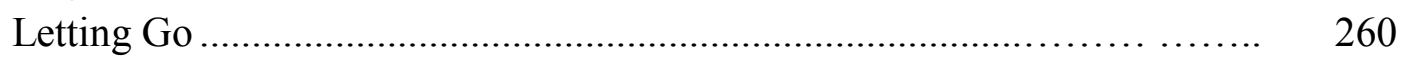

The Process of Change for Residents .................................................................... 260

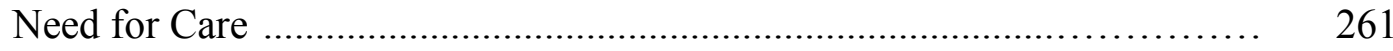

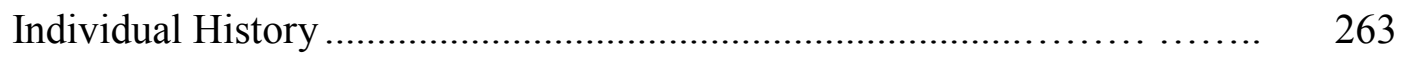

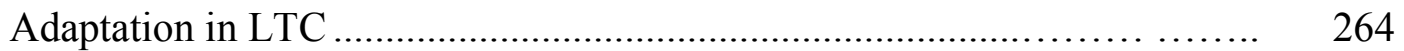

Strength and Vulnerability ............................................................ 265

Autonomy and Choice in the Environment ....................................... 266

Chapter Summary ........................................................................................ 268

CHAPTER 10: FINAL THOUGHTS AND LESSONS LEARNED....................... 270

Research Questions ............................................................................................ 271

Study Orientations ……………………………………………………..... 274

Orientation to Policy-Power Games ................................................................ 276

Consistency in Leadership ....................................................................... 278

Shared Program Expectations .............................................................. 278

Policy Interpretation................................................................................... 279

Orientation to Design-The Center of the Community …………………………...... 282

Community Integration ............................................................................... 284

Orientation to Place- Autonomy and the Social Environment................................ 286

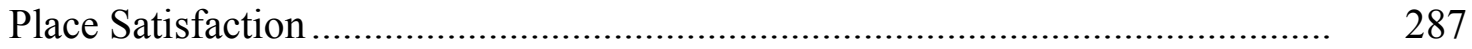

Place Attachment .................................................................................. 288

Orientation to Social and Psychological Processes-Finding Home.......................... 289 


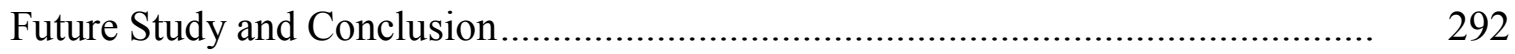

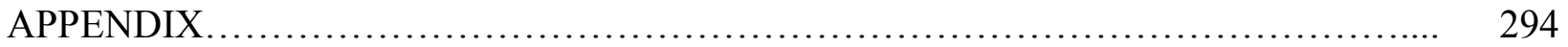

Institutional Review Board Approval ............................................................... 294

Resident/Family Member Informed Consent................................................. 295

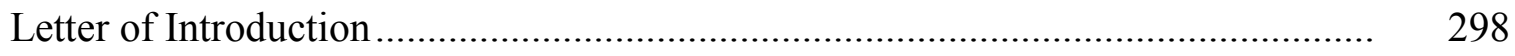

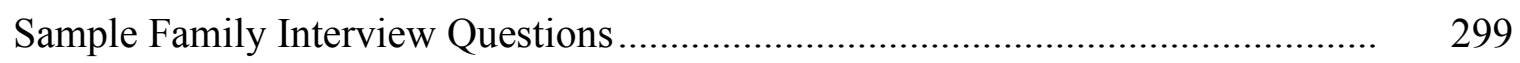

Sample Resident Interview Questions ...................................................... $\quad 300$

Sample Staff Interview Questions ................................................................ 301

Sample Observation Protocol ................................................................... 302

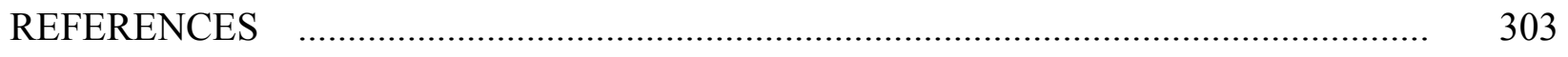

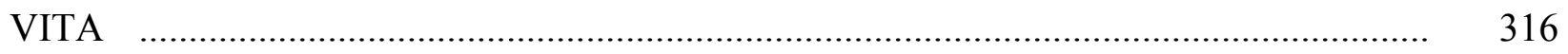




\section{LIST OF FIGURES}

$\begin{array}{lll}\text { Figure Page } & \text { Pan }\end{array}$

Figure 1. Cypress Cottage Interior …………………………................................................ x x

Figure 2. The Competence Press Model ........................................................................ 20

Figure 3. The Historical Nature of Theories of Aging and the Environment ......................... 22

Figure 4. The Small House Model-Opportunities for Privacy or Interaction ........................... 35

Figure 5. Ridgemont- Level One Floor Plan ...................................................................... 43

Figure 6. Ridgemont-Level Two Floor Plan ........................................................................ 43

Figure 7. Stonebridge-Level One Floor Plan ...................................................................... 44

Figure 8. Stonebridge-Level Two Floor Plan ................................................................... 44

Figure 9. Nova Scotia-Canada's Ocean Playground............................................................. 54

Figure 10. Nova Scotia Farmers c. 1900 ......................................................................... 55

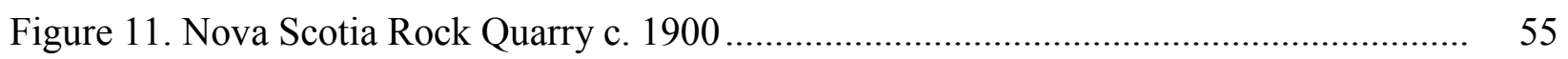

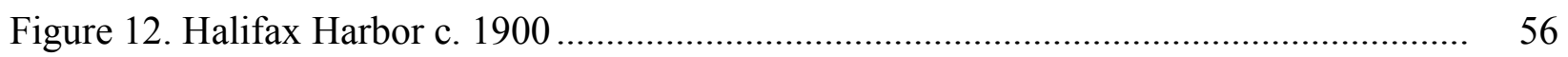

Figure 13. The Bluenose Schooner c. 1920 …………………….......................................... 56

Figure 14. Downtown Halifax c. 1917 ................................................................................ 57

Figure 15. Destruction from Halifax Explosion c. 1917 …….............................................. 57

Figure 16. Halifax Harbor c. 1944 ............................................................................ 58

Figure 17. Bedford Basin at Wartime ………………................................................... 58

Figure 18. Victoria General Ward c. 1910 ....................................................................... 59

Figure 19. Victoria General Waiting Room c. 1920 ……................................................... 59

Figure 20. The Canadian Provinces ...................................................................................... 61

Figure 21. The Canadian Atlantic Provinces ............................................................................. 64

Figure 22. Nova Scotia District Health Authorities' .............................................................. 64

Figure 23. Ridgemont Site Plan ................................................................................... 


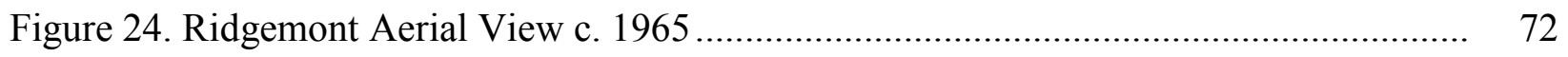

Figure 25. Ridgemont Continuing Care Site Rendering c. 1970 …………………................. 72

Figure 26. Ridgemont Continuing Care Building Entrance .................................................... 73

Figure 27. Ridgemont Continuing Care c. 1990s ……….................................................. 73

Figure 28 Ridgemont Nursing Home Prior to Renovation .................................................... 74

Figure 29. Ridgemont Nursing Home During Renovation..................................................... 74

Figure 30. Ridgemont Nursing Home Renovation with Link to ARC in Foreground ............. 76

Figure 31. Ridgemont Nursing Home Renovation with Link to ARC in Foreground ............. 76

Figure 32. Ridgemont Administrative Level Floor Plan ....................................................... 77

Figure 33. Ridgemont-Level Two Floor Plan .................................................................... 78

Figure 34. Ridgemont Renovated Hummingbird Dining Area................................................. 79

Figure 35. Ridgemont Renovated Nurse's Area ……………............................................ 79

Figure 36. Ridgemont Renovated Entry and Parlor........................................................... 80

Figure 37. Ridgemont Renovated Resident Lounge ……….............................................. 80

Figure 38. Ridgemont Completed Renovation ……………….............................................. 81

Figure 39. Stonebridge Building Site and Millville Aerial View ......................................... 111

Figure 40. Stonebridge Plat Map ……………………................................................. 111

Figure 41. Stonebridge Level One Floor Plan ..................................................................... 112

Figure 42. Stonebridge Level Two Floor Plan.................................................................... 113

Figure 43. Stonebridge Entry Looking East …………………………........................... 114

Figure 44. Stonebridge Entry Looking West ..................................................................... 114

Figure 45. Stonebridge Link for Exterior Egress ................................................................ 115

Figure 46. Stonebridge Level Two Link and Gazebo ........................................................ 115

Figure 47. Stonebridge Open Kitchen-Alderwood Cottage ................................................... 116

Figure 48. Stonebridge Main Street Looking East.................................................................. 144 
Figure 49. Stonebridge Main Street Looking West .............................................................. 144

Figure 50. Stonebridge Community Center-Exterior............................................................... 145

Figure 51. Stonebridge Community Center-Interior............................................................... 145

Figure 52. Stonebridge Cottage Interior …………..................................................... 146

Figure 53. Stonebridge Enlarged Lobby Administration Plan............................................... 151

Figure 54. Stonebridge Front Entrance ………………….............................................. 152

Figure 55. Stonebridge Front Entrance Seating ................................................................ 152

Figure 56. Stonebridge Enlarged Cypress Cottage Plan ............................................................ 153

Figure 57. Stonebridge Charting Area in Cypress Cottage.................................................... 154

Figure 58. Stonebridge Medication Cabinets in Cypress Cottage …………………............. 154

Figure 59. Stonebridge View from Kitchen in Birch Cottage ……......................................... 156

Figure 60. Stonebridge View from Kitchen in Alderwood Cottage ...................................... 157

Figure 61. Stonebridge Cypress Cottage …………….................................................... 160

Figure 62. Tom as a College Freshman ........................................................................ 168

Figure 63. Tom in Military Uniform................................................................................ 168

Figure 64. Tom and his Family ....................................................................................... 169

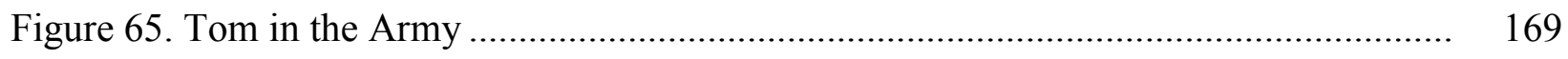

Figure 66. Rose on her Mother's Steps .......................................................................... 171

Figure 67. Rose and Garney ...................................................................................... 172

Figure 68. Rose, her Mother, and Aunt …………………........................................... 172

Figure 69. Ice Skating in Halifax .................................................................................. 173

Figure 70. Frank Fishing .............................................................................................. 176

Figure 71. Frank at Front Right and Alison in Black ............................................................ 177

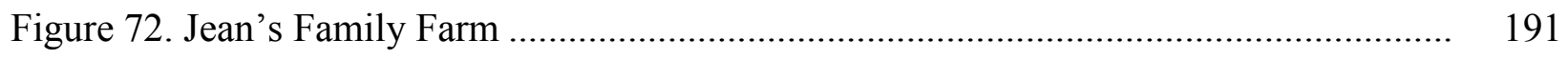

Figure 73. Lumber Mill, Nova Scotia c. 1945 ..................................................................... 192 
Figure 74. Nova Scotia at War

Figure 75. Halifax in Wartime

Figure 76. Steel Gate Across the Entrance to Halifax Harbor

Figure 77. VE Day Riots, Halifax.

Figure 78. VE Day Looter, Halifax

Figure 79. Windsor Train Station, Nova Scotia.

Figure 80. Lumber Truck-Nova Scotia.....

Figure 81. The Aquitania

Figure 82. War Brides Arriving in Halifax

Figure 83. King Street, Bridgewater .

Figure 84. Claire at home in Cape Breton

Figure 85. Danny at Claire's home in Cape Breton.

Figure 86. Cape Breton Picnic

Figure 87. Claire and Danny's Wedding Day.....

Figure 88. Lake View-Nova Scotia

Figure 89. Pond Hockey-Nova Scotia

Figure 90. Edna and James' Wedding Day

Figure 91. Elsie on the Farm-Age 10

Figure 92. Elsie and her Favorite Horse

Figure 93. Spring Garden Road-Halifax

Figure 94. Robert with his Family

Figure 95. Robert's Camping Car.

Figure 96. Robert's Family at Hope Lake

Figure 97. Lady-Robert's Dog

Figure 98. Robert's Mother Alice-Age 20 
Figure 99. Lord Nelson Hotel Lobby-Halifax ………………………………............... 222

Figure 100. The Capital Theater-Halifax............................................................................. 222

Figure101. The McKay Bridge and View of Halifax from Dartmouth ................................. 223

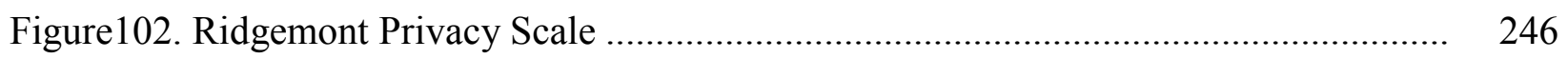

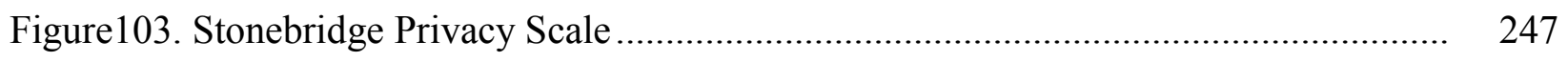

Figure104. View from Nurse's Area to Parlor..................................................................... 249

Figure 105. Hummingbird Dining Area-\#1 ………………........................................... 251

Figure106. Cardinal Dining Area-\#2 ………………................................................... 251

Figure107. Bluebird Dining Area-\#3 .......................................................................... 251

Figure108. Ridgemont Lower Level Kitchen ............................................................... 252

Figure 109. Stonebridge Cottage Kitchen........................................................................... 253

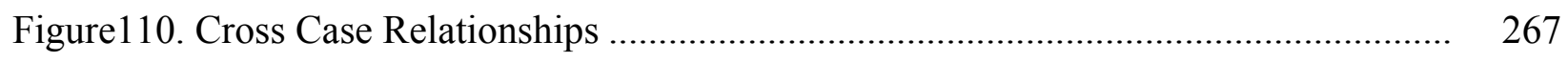

Figure111. Core Study Themes ................................................................................ 270

Figure 112. Finding Home ...................................................................................... 290 


\section{LIST OF TABLES}

Table

Page

Table 1. The Small House Model ................................................................................ 33

Table 2. Resident Demographic Information..........................................................

Table 3. Environmental Features and Relationships.................................................

Table 4. Demographic Projection Nova Scotia 2002 to 2026 ....................................... 60

Table 5. Stonebridge Care Staff Themes ................................................................... 125

Table 6. Family Member Interview Information ..................................................... 166

Table 7. Resident Interview Information ................................................................ 188

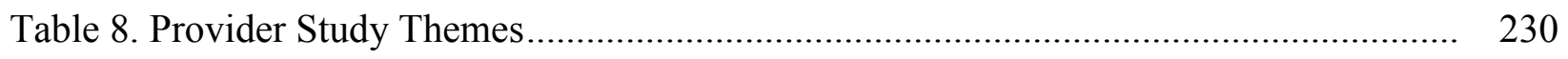

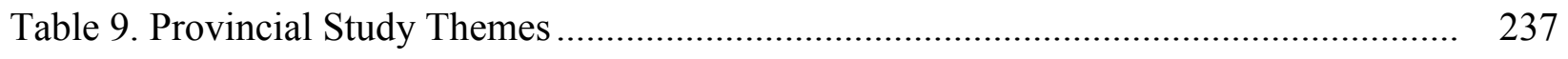

Table 10. Physical Environment Study Themes ...................................................... 244

Table 11. Family Member Study Themes................................................................ 257

Table 12. Resident Study Themes ........................................................................... 262

Table 13. Implementation of the Small House Model of Care ....................................... 280

Table 14. A Change in the Center of the Community ..........................................................283 


\begin{abstract}
Legislating Home: The Impact of the Regulation of Small House Settings for Long Term Care Residents in Nova Scotia, Canada

Emily Roberts, M. Arch-University of Missouri, Columbia

In May 2006, the Province of Nova Scotia, Canada announced a Continuing Care Strategy (CCS) in which issues of home care and long term care were addressed. The strategy is a 10-year plan to enhance and expand Nova Scotia's continuing care system. The CCS covers issues which include home health care, adult day support, respite care, improved access to services, as well as funds to build 1320 new long term care (LTC) beds. As a result of the CCS, the Provincial government has built 11 new LTC facilities to support the vision of "living well in a place you can call home" (CCS, 2006). A key feature within the guidelines is that all of the new LTC facilities be built in the model of the small house $(\mathrm{SH})$ community, with multiple households (cottages) of 12-15 residents each. Each cottage is required to have a living room, dining room, residentially scaled kitchen, and private bedrooms. In addition, implementation of person centered care in which residents are given choices in the daily activities is an operational requirement in the new facilities. In order to gain a better understanding of the implications of a LTC system where resident choice and empowerment are provided for and regulated by legislated policy, a qualitative case study was conducted in early 2012 in two LTC facilities in Nova Scotia. The first facility was designed and built prior to the 2006 CCS regulations $(n=48)$. The second facility opened in 2009 as one of the first in the Province to be built to the new guidelines $(n=49)$. Observations took place for eight weeks at both facilities and interviews were conducted with residents, family members, staff, providers, and legislators. Through place theory and an ecological theoretical framework, key themes emerged relating to the philosophy behind the SH model of care which include the need for shared goals, expectations and consistency in leadership; frontline staff empowerment through the strength of teamwork; and the balance of choice, risk and autonomy for residents in the setting. The physical environment had a direct impact on the social environment in the communities and while the actuality of 'home' was a very personal distinction based on the history and past preferences of each individual, the shared themes between the two study communities were related to the core elements of LTC: the need for and the provision of care.
\end{abstract}




\section{PROLOGUE}

The low winter sun breaks through the late afternoon clouds and lights up the seascape puzzle in front of me. There are sounds, as well as smells, of dinner coming from the next room as the finishing touches on meal preparations take place. Rachael lays down her oven mitts and pops her head into Art's bedroom. "Dinner, Art, are you ready to eat? You don't want to miss my gingerbread for dessert, do you?" Art wheels himself out of his room to the kitchen table. He is 84 years old, and he's tired. Not tired because of his nap, but tired because of a hard life in construction. Due to his age and the fact that he is a little slow in putting his thoughts together, he feels like the people around him treat him like he doesn't know what he's talking about, and because of a loss of a leg due to an accident many years ago, he has said he no longer feels like a whole man. But Art doesn't want anyone to feel sorry for him; he gets up every day, laughs with his friends, and councils some of the young staff on the ways of the world. He is quiet, but has a quick wit, and is usually the winner at Jeopardy played with residents from other cottages down in the community room on Wednesday afternoons.

Art lives with 11 other residents in one of four similar cottages in a long-term care community in Nova Scotia, Canada. I am in Art's cottage, Art's building, community, province and country. I am an outsider, yet I am able to sit down at the kitchen table with Art while he jokes with his buddies Edward and Penny about drinking, women, and life. We can sit with our tea and coffee at the kitchen table on these late winter afternoons and listen to sounds of dinner preparation, toileting negotiations ("We'll take you to the toilet in 20 minutes, Rose, you were just there."), and staff conversations in low tones about necessary medications for one of Art's cottage-mates. Edward asks Art if he is going to go down to hear the music in the Community Center later in the evening: 


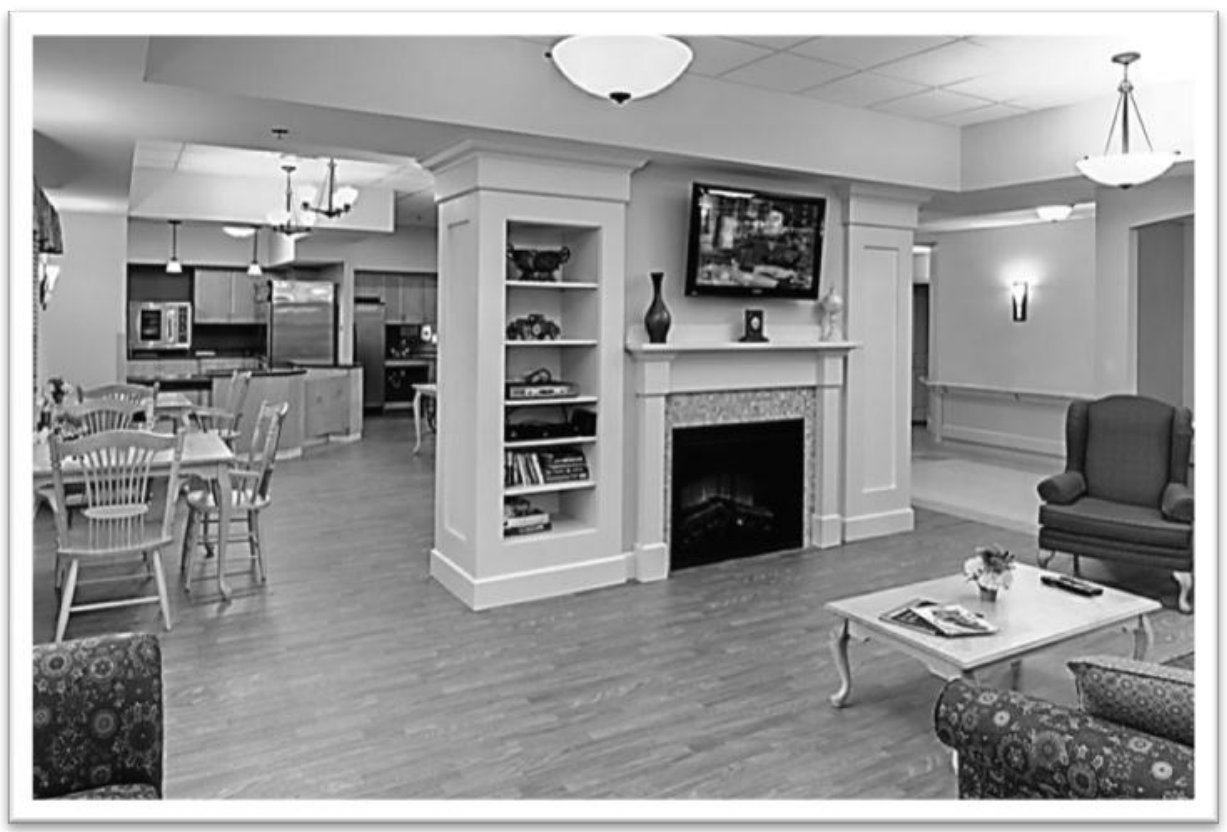

Figure 1.

Cypress Cottage Living Room

Yes, wouldn't miss it. It's something that breaks up the week, the days blend together here, so it's something to look forward to, something special. If I don't have something to look forward to, I might as well just lay down and die. Used to be that I could go to the tavern, and play billiards, you know. Then I'd stop at the store and buy myself a 12 pack, have a beer when I felt like it. I've been here since last April and you know how many drinks I had? One. One beer and they took the rest from me.

Penny seems a little concerned, "Now, you know that might not be such a good idea, Art, considering all the medications you're taking." "I'm willing to take that risk, hey, I'm sittin' down already, right? It's not like I'm going to fall over from too much to drink!" Art and Edward laugh together over that one as I get up and excuse myself. Rachael is on her way over to the kitchen table with dinner for Art and his cottage-mates. 
PART I.

LEGISLATING HOME 


\section{CHAPTER ONE: INTRODUCTION}

Place and participation, health and honor, cannot, of course, be legislated. But legislation and sensible, coordinated action can enhance the opportunities for the aged. Isolation and misery can be prevented or reduced...society, in short, can and must catch up to science. (John F. Kennedy, 1963, in Koff \& Park, 1999, pg.86).

The cottage and community which Art lives in was built with funds provided by his province of Nova Scotia, and his health costs are paid for by the province as well. Yet nearly five decades after President John F. Kennedy delivered his first and only special message on Aging in America in the United States, the field of caring for one of the most vulnerable populations in our country continues to face both fiscal and philosophical challenges. In America, in the year 2012, older, frail individuals like Art, who are unable to care for themselves and do not have the financial resources to live at home with $24 / 7$ care or in a private pay facility are relegated, more often than not, to institutional living in a traditional nursing home. This is due to an inherent absence of options and choices in where and how care is given to the frail elderly in our country. Agich (2003) writes that it is the responsibility of contemporary society to respond to the failures and incapacities associated with old age with compassion and understanding. In other words, society should provide environments that will challenge each individual with extra needs to produce one's best.

\section{Purpose of Study}

The purpose of this study is to focus on the societal implications of a long-term care system in Nova Scotia, Canada, a system in which LTC policy is legislated, funded, and regulated by the province. In 2006, a Provincial Steering Committee created a Continuing Care Strategy (CCS), which resulted in the construction of 11 new long term care (LTC) communities, one of which currently provides a home for Art. The 2006 document contained requirements on 
the guiding principles and philosophies, as well as the physical and organizational structure of the new communities. This study focuses on the outcomes in Art's community, Stonebridge, as well as daily outcomes in an older community, Ridgemont, owned by the same provider.

\section{Statement of Problem}

Increased funding should be considered as another valid means to enhance and improve the physical environment to create dignified living for persons living in a nursing home. Limited funding hampers research in the field of design and the environment, which also diminishes the public's knowledge of the usefulness of environmental interventions and any demand they may make for them. (Brawley in Bowman, 2008, pg. 69)

The design of the physical environment in long term care (LTC) facilities has been shown to have substantial effects on resident patterns of social behavior, and it is widely recognized that social and physical environments can profoundly influence quality of life of older adults (Brawley, 2006; Calkins, 1988; Day, Carreon, \& Stump, 2000; Wood, et al. 2005; Zeisel \& Raia, 2000). Past research has sought to understand the core needs of individuals in continuing care settings and investigated how aspects of the physical and social environments can best meet those needs (Calkins, 1988; Cohen \& Weisman, 1991; Lawton, 2001; Regnier, 2002). Mirowsky (1995) writes that residents in care facilities who feel their environment is responsive to their efforts, choices, and actions tend to enjoy better health than older adults who believe their lives are shaped by forces outside their influence.

Yet the relationship between life in long term care and resident well-being is a complex one. For many residents, the LTC environment is their home and community, and the relationships and social interactions which take place on a daily basis are critical to their coping capabilities (Chaudhury, 2003). While the need to be moved from home into LTC may be necessary for both health and safety reasons, this move can lead to a loss of connections with 
family, friends, and important grounding routines of home, and may sometimes lead individuals to become emotionally and socially detached in the new community due to its size, crowding, and privacy issues. The traditional medical model of care, both in its social and physical aspects, reflects institutional policies and procedures as opposed to the personally meaningful place the resident has left behind (Chaudhury, 2003). In this line of inquiry, we will address these elements of frailty and loss within the context of the home, the community one leaves behind, as well as the challenges of a new setting and community.

For many older adults, the prospect of moving to a nursing or LTC community means leaving behind every positive attribute of home to live in a large building with shared bedrooms, long corridors, and loss of privacy and autonomy. This institutional model and philosophy of care is well known in our country due to policies that have been implemented over four decades. Eckert, et al. (2009) states that LTC management philosophies of care can often be as important as the physical environment for residents, and the operator has a large role in shaping the culture of a specific place. What may be most critical in caregiving environments is not solely who is present or the therapeutic design of the physical environment, but rather, how effectively staff design and enact routine activity situations to use the therapeutic potential of the social and physical environmental features (Wood et al , 2005). Often, in the traditional medical model of care, characteristics observed among the elderly in group settings such as depression, helplessness, and accelerated physical decline have been attributed to restrictive policies and overabundance of services. In addition, limited stimulation or responsibility in the new environment can create habits resulting in boredom and listlessness which can reduce incentive for activity (Thomas, 2003). 
The decision to look to the province of Nova Scotia for this particular research was the result of a chance meeting with Wyatt, the C.O.O. of the Welsh Group and the owner/operator of the Ridgemont and Stonebridge communities. Wyatt and I met at an Environments and Aging conference in Atlanta in the spring of 2011. My conversation with him at the time, and ensuing conversations, led to site visits of the two communities in Nova Scotia in the fall of 2011. It was at that time that I made the decision to use this as an opportunity to study outcomes in a cohesive system of care for the elderly, where staff, operators, residents, and provincial leaders are all working towards the same physical and operational goals. This opportunity would not have been available to me in the United States due to a fractured LTC system.

Just a year before the CCS, at a 2005 CEAL conference in Washington, D.C., policy makers and stakeholders in the United States spoke of their concern about creating a "woodwork effect" in subsidizing research and design of alternatives to traditional nursing facilities. That is, some policy makers did not want to create or expand alternatives to traditional care because they worried that individuals would "come out of the woodwork" to use the services and thus overwhelm states' finances. While research-based information about the true costs and benefits of operating alternative communities could serve as a powerful response to such concerns (CEAL, 2005), U.S. policy makers at the state and federal levels have been hesitant to increase reimbursement rates for alternatives to the traditional institutional model of care. This is due to a lack of evidence about the real costs of operating affordable housing with services, the relationship between costs and quality, and the total cost to Medicaid for residential care. Karen Schoeneman (2007) of the Center for Medicare and Medicaid (CMS) describes this schism in the American LTC system: 
There are many issues involved in changing the environment in nursing homes. There is tradition - what has been acceptable is actually institutional. There are desires on the part of homes to avoid costs, even the very small cost of spackling nail holes. There are Federal regulations, the Life Safety Code, even the Food Code, and there are State and local building codes. The result is a mismatched jigsaw puzzle of often conflicting rules that has innovators stymied in making changes they want to make. There is a lack of research to inform us, and because of this, we are often left guessing what residents want, what is safe, how safe is safe enough, how comfortable and homey they are, how much control over one's daily life is possible within the constraints of living with a group of strangers, each of whom needs some help with their daily lives.

Prior to my research in Halifax, I sat in on a planning meeting with a successful local LTC provider in my community, his hired architect, and the provider's developer (i.e. the money guy). The provider was determined to make a change in the way care is implemented in his communities. He had hired an architect to come up with the "solution" to the problems of resident dissatisfaction and high staff turnover in his communities. While the architect's design displayed shortened corridors, private rooms, and neighborhoods settings, the developer shot down each concept with "but that's not cost effective, that's not the way we do it."

The operator was unable to convince the developer that there were reasons to change the physical setting other than fiscal ones. The architect's design changes were never made and the operator has settled for memory boxes at the doorways of shared bedrooms in his attempt at change in the organizational structure in his communities. Because of the unknowns in the costs and the organizational restructuring it takes to make the change in LTC a reality, this becomes the story for so many providers in our country.

In addition to a lack of incentives for operators to invest in new models of care, traditional nursing home costs in the United States continue to rise, with an annual average cost for a private room at $\$ 74,000$ and $\$ 64,000$ for a semiprivate room (MetLife, 2005). Payment 
may come from private individuals, private insurance, or Medicare for a short time, and when a resident's resources are depleted, Medicaid pays for the remainder of the stay (Konetzka, 2006).

In sharp contrast to the fracturing in United States policy, Canada disperses public health funds to each province which may be applied as they wish, and the Nova Scotia Department of Health $(\mathrm{DoH})$ has used this funding to make a concerted effort to change the way that nursing care is delivered for the elderly in their province. The proportion of Nova Scotia's senior population is higher and growing faster than in other provinces in the country, resulting in a greater demand for a wider variety of housing options. With the expectation of Newfoundland at 14.4\%, the Atlantic Provinces have the highest percentages of seniors in Canada. While the total population of Nova Scotia had been expected to decline by approximately four and a half percent between 2007 and 2033, the senior population (65+) has been projected to increase $86.3 \%$ between 2007 and 2033 (Shiner, et al. 2010).

At the center of the DoH changes in delivery of care is the shift from the institutional model of design prevalent among nearly all long term nursing communities designed in the last 40 years in both the United States and Canada. This older model is based on a medical therapeutic approach to aging that prioritizes treating and caring for symptoms and disabilities. The old method features nursing stations anchoring a unit or wing of 20 to 35 residents, organized along a long corridor. To reach the dining area in the old model involves long-distance treks for marginally mobile residents down long corridors, and sometimes elevators, to central dining facilities. Staff in the old model are organized along hierarchical structures relating to discipline and task as opposed to resident relationships. The traditional model of nursing home care grew out of an institutional model, because care is given, in essence, in the model of the stripped-down hospital (Rader, 1995). Individuals in these communities have been asked to live 
on a long-term basis in a bed in a highly sterile environment with few or none of the amenities of home (Wilson-Brown and Baldwin, 1995) and in arrangements which help the staff carry out necessary tasks in the quickest, most efficient manner possible (Gold, 2002).

Although not new concepts in other countries or other regions in Canada, the 11 new communities built as a result of the CCS in Nova Scotia are based on cottages or households of no more than 12-14 residents each. This small house (SH) care model focuses on a residentcentered living approach. In each household there is a living room, kitchen, dining room, and activity area. Staffing is structured such that some tasks are shared across disciplines, resulting in resident interactions with fewer staff for longer periods of time. Other aspects of the 2006 CCS include certain requirements: private resident rooms, access to substantial outdoor space from each household, and an emphasis on residential décor and atmosphere (Keefe, 2009).

\section{Research Proposition and Questions}

A major benefit of the $\mathrm{SH}$ model of care is the integration of public and private spaces (Wilcocks, Peace, \& Kellaher, 1987). With the range of private, semiprivate, and public spaces, residents may have the ability to exercise control over their daytime location and have the ability to withdraw from public areas to their own rooms when desired. This affords residents more retreat options and places to socialize in smaller groups (Barnes, 2006). While studies have been done on the impact of the small house setting on resident health outcomes and emotional wellbeing (Kane, 2009), the literature on how semi-public and public spaces are used both inside and outside of cottages or neighborhoods is limited and there do not appear to be specific studies in the organizational and social structures of public common areas. This is an important area for study, because for residents in a SH community, any competencies or attachments that may be 
felt in the cottage or households may not translate to the facility public areas. One of the primary benefits of the structure of small house communities is the opportunity for resident choice in privacy or interaction. It is a principle aim of this study to understand the specific impacts of this correlation on resident socialization and connection to place.

There is a slow move in the United States towards legislation for a culture of change and a universal long term care policy which could alleviate some of the cost burdens of the development of new models of care, but the weaknesses of the Medicaid reimbursement program, as well as the gaps in knowledge of facility operators, developers, and lenders into the costs associated with changing long term care systems have been prohibitive. In addition, there are barriers in the United States to financing the development of new models of care by lenders and underwriters because LTC is perceived as being a hybrid of both housing and health care (CEAL, 2005). Participants at the CEAL (2005) conference pointed out that while many assisted living advocates do not support regulatory standardization because they believe it will hinder consumer choice in favor of institutional conformity, other participants suggest that some area of standardization will help lenders to gain a better understanding of what type of assisted living they are financing. This could result in better options for consumers as well. These policy questions could be answered with the study of government supported and subsidized LTC communities.

The goal of this study, therefore, is to gain a better understanding of the workings of the government funded LTC system in Nova Scotia, which promises: "For every Nova Scotian, a place you can call home (CCS, 2006)." While this statement leaves much ambiguity, my intention in this study is to clarify the definition of home for those in long term care, and what it means to truly be 'at home' through the eyes of staff, residents, and family. The conflict 
between the concepts of long term care and to be "at home" appear to be conflicts between dependence and independence, therefore, this study is a search for a consciousness of what creating home means to the principle stakeholder groups in this study. Although each stakeholder creates a set of unique issues, quality of life may be the overarching umbrella in which quality of care and resident satisfaction lie (Stadnyk, 2009). The research questions related to this study include:

I. How do the $2006 \mathrm{CCS}$ policies and guidelines for the small house model impact the philosophy of care, service delivery, and staffing patterns in Nova Scotia LTC facilities?

II. How are staff, facility operators, and legislators transitioning older facilities to meet the challenges of the new LTC programs and services to best meet the needs of the residents?

III. What impact does the physical layout of the public and private spaces in each of the two facilities have on daily operations and resident socialization, as well as staff and resident physical and emotional well-being?

\section{Limitations of Research}

Because LTC communities are living environments with the incorporation of the need and provision of care for residents, the nature and scope of quality concerns may vary considerably with regards to the specific goals of each individual in the setting. While the focus of this research was on the impact of provincial guidelines on the day to day systems in place for the general LTC population in the two communities, it also became very important to understand the history of the operators' philosophy of care and to clarify the common themes of the two communities before I could delineate their differences.

This is a discussion about the characteristics of institutionalization, as well was the process of relocation and the pathways and procedures that lead to a need for full time care. The 
research is about individual and collective goals, and asks the question, can there be an individualistic way of doing something that has collective outcomes? Although this research was confined to a time span of two months, it really tells the story of a province, a company, and a culture of care in transition over several decades. Therefore, this document provides an overview of the impact of provincial changes over several decades with respect to the care and physical design in two long-term care communities. While the scope is broad, it is, in reality, just a sliver of the issues related to what it means to live and work in long term care. My goals in beginning this research were to understand the rather simple questions about how the province of Nova Scotia was able to reach a consensus and group understanding of the need to change in care for the frail elderly. What I found instead were layers of emotion, movement, change, withdrawal, and engagement. While the story is linear, I found myself having to look both forward and backward in time simultaneously in order to understand what was happening in each setting.

\section{Personal Interest}

In mid-2000, about the same time that CEAL convened for their summit in Washington D.C., and the province of Nova Scotia was developing their continuing care strategy, I was experiencing my introduction into the workings of the LTC system in the United States. In 2005, I became guardian for an elderly aunt as a result of her inability to cope with life in a long term care facility. Within the first month of moving from her apartment of 30 years to LTC; due to the size of the facility, walking distances, and the system of care, my aunt was admitted to a psychiatric hospital because of her "failure to thrive". She had locked herself in her room and refused to eat, bathe, or take her medications. She would not allow caregivers to help her and she stopped answering her phone. This was her final grasp at independence; she still had control 
over the decision not to function. This is a woman who had travelled the world as a free-lance photographer in the 1950's and 60s and who had lived alone for 30 years after losing two husbands.

My aunt would move in and out of the facility to psychiatric hospitals three times that year before the LTC facility administrator made it clear that she could no longer to live there and I would need to find other arrangements for her. Faced with the challenge of finding appropriate housing, it quickly became apparent that due to her financial situation, my aunt's housing options were limited to institutional settings in her town of Cambridge, Massachusetts. After visiting a number of large LTC facilities with maze-like corridor systems, I made the decision to find more appropriate housing for her closer to my home.

My aunt ended up living the last two years of her life contentedly, and with dignity, in a residential group home for 12 elderly individuals close to my home in Albuquerque, New Mexico. In this setting, she was just a few paces from the kitchen and the living room that the other residents shared. There were people around all the time so that if my aunt wanted to, she could sit at the kitchen table and have a conversation or a cup of tea. She could sit down on her sofa in her living room and watch TV. She could also close the door and just read in bed. She could basically eat when and whatever she wanted. The other residents all were in different stages of physical and mental capacity, and for the first time, my aunt was part of a community. She could see that she was not the only one with problems; in fact, she was one of the more independent of the residents. She knew their story and they knew hers.

These experiences have led me to this current road of inquiry and it has been my goal since this important period in my life to better understand how the size, configuration, and 
systems of care in LTC impact the frail elderly. In 2009, prior to my admission into the PhD

program at the University of Missouri, I wrote a letter to Dr. Benyamin Schwarz, in which I

asked some of the questions which had been formulating in my mind about small house living:

What lessons can be taken from the environment of a small community and transferred into a large institution? Can they be melded? Who is to say that the norm of a long corridor with similarly sized and shaped rooms off of it can't be transformed into a wing with a "living room" with a few adjacent bedrooms? I understand that institutional kitchen codes prohibit an open setting for food prep, but certainly a small community could share a small dining room, a place to chat with a cup of tea or play cards with 8-10 residents. It would be great if a central kitchen could be adjacent to these dining rooms so that residents could smell a cake baking in the oven. Could the efficient and consistent staffing of these small communities result in familiarity with residents that would result in important bonds being formed? In the case of a nursing facility with a medical staff, could a nurse be responsible daily for one or two small communities, instead of having to rotate throughout the entire facility? In other words, can we design large scale environments that satisfy small scale needs within the confines of a complex fiscal and bureaucratic institution?

My ultimate goal is to be able to use the outcomes from the following study to answer some of these personal questions, while at the same time working toward improved LTC environments for future generations of the frail elderly.

\section{Study Framework}

This research has been conducted within the framework developed by the pioneers of environmental gerontology (E-G) who believed that human understanding and its resulting behaviors are largely based on how perception works within the scope of many differing viewpoints. The individual stories introduced in this research will weave a larger story, which speaks to the universality of being in a place where care is provided, but where the provision of home may never, in fact, be more than an illusion. The document contains ten chapters, which have been divided into three sections in order to define the clear breaking points in the history of 
the two communities, while at the same time describing the chronology of events in provincial legislation.

Chapter 2 gives a broad overview of the theoretical concepts which frame the study of environmental gerontology, and also addresses issues related to frailty and dependency for residents in long term care.

Chapter 3 discusses the key points and considerations in case study research and describes the research design and methodology used in this particular study.

In Chapter 4, for context, I present a very brief history of Halifax, Nova Scotia, as well as background information in the recent developments in the current Nova Scotia LTC system.

Within Chapter 5, I introduce the history of the Welsh Group and Ridgemont Continuing Care Facility. This chapter also includes the background of the current staff's philosophy of care at Ridgemont, because the staff perspective there has been critical in understanding the development of the Stonebridge culture of care.

Chapter 6 addresses the background and approach of the 2006 provincial Continuing Care Strategy. The chapter also discusses how and why the Welsh Group responded to the provincial RFP for Stonebridge, and includes the pertinent issues involved in the design process for the new community.

Chapter 7 discusses the roots of the culture change movement, both in Canada and the United States, presenting the staffs' perspectives of their day to day work in the new model of care at Stonebridge. 
Chapter 8 presents longer format interviews from the current family and residents of both communities. It was important to combine these interviews in one chapter, because the family and resident voices from both communities are strikingly similar. The issues surrounding moving a loved one into LTC, as well as the issues for an individual being moved there, are universal and could not be broken down by care model type.

Based on resident, family. and staff perspectives, as well as Welsh Group management and provincial legislator interviews, Chapter 9 is an analysis of the outcomes of the government run long term care programs at both Ridgemont and Stonebridge. It also discusses the correlations between the physical environments in the two communities and their implications.

Chapter 10 discusses the outcomes and lessons learned from the study through an environment and behavior framework. It also addresses the universal issues of paradigm shifts in social thought, with a discussion the impact of the provincial regulations on residents' day to day lives. 


\section{Definitions of Terms}

Activities of Daily Living (ADLs): Everyday tasks that are required for people to live on their own, such as the abilities to feed oneself, go to the toilet, take a bath, and get out of bed.

Centers for Medicare \& Medicaid Services (CMS): A branch of the U.S. Department of Health and Human Services. CMS is the federal agency which administers Medicare, Medicaid, and the Children's Health Insurance Program.

Continuing Care Assistant (CCA): Individuals providing direct care and support services in Nova Scotia Department of Health and Wellness funded nursing homes and home support agencies. CCA's also work in a variety of other health care settings, including hospitals. CCA's are not licensed as Registered Nurses and therefore cannot practice medical procedures of any kind, but can be certified to dispense medications.

Continuing Care Strategy (CCS): The CCS is a 10-year plan to enhance and expand Nova Scotia's continuing care system. By building on current community support, increasing local solutions, and ensuring care options are available when and where they are needed, the strategy aims to create a system that supports Nova Scotians in their desire to live well as they age.

Department of Health (DoH): The Department of Health and Wellness provides health care for Nova Scotians and their families by offering programs and services that protect and promote health and treat illness. The Department was formed in 2011 when the Department of Health Promotion and Protection and Department of Health merged. The merger recognized health care as a continuum that requires a focus on both prevention and treatment.

Long Term Care (LTC): A variety of services which help meet both the medical and non-medical needs of people with a chronic illness or disability who cannot care for themselves for long periods of time.

Nursing Home (NH): A place of residence for people who require constant nursing care and have significant deficiencies with activities of daily living. NH may also be referred to as Skilled Nursing Facility (SNF).

Registered Nurse ( $R N)$ : In Nova Scotia, a registered nurse must hold a valid license to practice nursing. Duties include the administration of medications, observing and monitoring patient vital statistics, and recording information for review of the principle doctor in charge.

Residential Care Facility (RCF): In Nova Scotia, any building or place, or part of a building or place, where supervisory care or personal care (but without professional nursing care) is provided for four or more people who are ambulatory. 


\section{CHAPTER TWO: REVIEW OF LITERATURE}

To understand the influence of the group living settings in LTC, it is necessary to examine the social and coping resources used to adapt to stressful circumstances and consider the new social context of the resident and the changes that have occurred in their new setting. Golant (1998) explains that when older people evaluate changes in their shelter and care setting, they are telling us a great deal about themselves: what's important about their lifestyles, how happy they are, how mentally and physically vulnerable they are, and how well they deal with change.

In order to describe the relationship between the environment, social structure, and the physical and emotional needs of older adults in LTC, this research draws its conceptual framework from ecological psychology. In physical ecology, organisms are studied and observed within a network or framework and exist due to a series of interconnected relationships. Likewise, the relationships or connections between two or more humans are fundamental to the study of social ecology. Social ecological psychology's entry point for the examination of psychological issues is the dynamics of ongoing, environment-person relationships. Identification of this relationship as the principal unit of analysis highlights the primacy of relational, temporally dependent phenomena of a psychological nature. These phenomena clearly reveal the fact that psychological processes are situated processes, never fully isolatable from their context (Heft, 2001).

\section{Theories of Aging and the Environment}

The theories and frameworks which have shaped much of today's current thinking around the impact on the physical environment and aging originate from M. Powel Lawton (1923-2001), who began his work on aging and the environment in 1963 when he joined the Philadelphia 
Geriatric Center (Calkins, 2003). This is the same year that President Kennedy gave his speech on society's responsibility to the aging population, and Lawton entered the evolving field of Gerontology because new federal programs for purposely designed housing for older people and age-segregated public housing had just begun development (Schwarz, 2003). It was through Lawton's work at the center that many of the basic conceptual frameworks of environmental gerontology (E-G) were formed, and where basic assumptions about nursing home design and structure were challenged with the opening of the Weiss Pavilion at the Philadelphia Geriatric Center in 1978. The unit was designed for only 40 residents and traditional institutional hallways were eliminated in favor of a large, open, central space (Calkins, 2003).

The fundamental premise of Lawton's conceptualization of quality of life is recognition of the breadth and depth of older adults' lives and their inherent meanings. Subjective perception of quality of life was a central dimension in Lawton's quality of life model, and he believed that quality of life conceptualizations, behavioral competence, psychological well-being, perceived quality of life, and the objective environment interrelate to give form and shape to behavior, environment, and experience (Chaudhury, 2003). Others were writing about the importance of the physical environment in LTC during that decade as well. In 1976, Koncelik wrote that:

The most essential ingredient and one most thoroughly excluded in nursing homes is providing a sense of residency. The reason that there are so many poorly designed institutional settings is that design does not penetrate as an activity to the level where it touches the lives of the residents of the facility.

Koncelik continued that in care communities, there are frequent references to "homelike" quality, but these are usually just attempts to provide a visible veneer of appointments and artifacts that relate to the concept of home (Koncelik, 1976). 
Koncelik's reference to "homelike" quality in nursing care is an understandably difficult concept to grasp. What does "homelike" refer to? Is it the physical setting, the social setting, or a personal sense of being in a space? By viewing psychological processes as person-environment functions (as opposed to taking individuals as isolated units of analysis), the research agenda of the field of E-G has been focused on these questions since its inception in the early 1970s and 1980s. The focus of E-G is the description, explanation, and optimization of the relation between elderly persons and their sociospatial surroundings (Wahl \& Weisman, 2003), and has a theoretical tradition stretching back to the classic ecology of the Chicago School of urban sociology in the 1920s, the environmental psychology of Barker, (1968) and the high-water mark of Lawton's environmental press in the 1970's (Kendig, 2003).

\section{The Competence Press Model}

There are several reasons why E-G is important to housing research for aging populations. While other research in sociology or psychology may examine either physical or social residential outcomes, the aim of E-G is to understand both of these aspects of the housing environments, and it is focused on the impact of the environment on the perceptions, attitudes, and behaviors of individuals (Moos, 1976). There is a study not only of an individual's different reactions to their environment based on experience, preferences, or individual differences, but also how these reactions further impact what will take place in the environment. Finally, this approach to research has an explicit value orientation, and Moos (1976) argues it is not simply an approach for science; it is also a humanistic approach by which to benefit Mankind.

The most relied upon theoretical formulation in E-G relationships is inspired by the interactional paradigm or Competence-Press Model (Lawton \& Nahemow, 1973). 


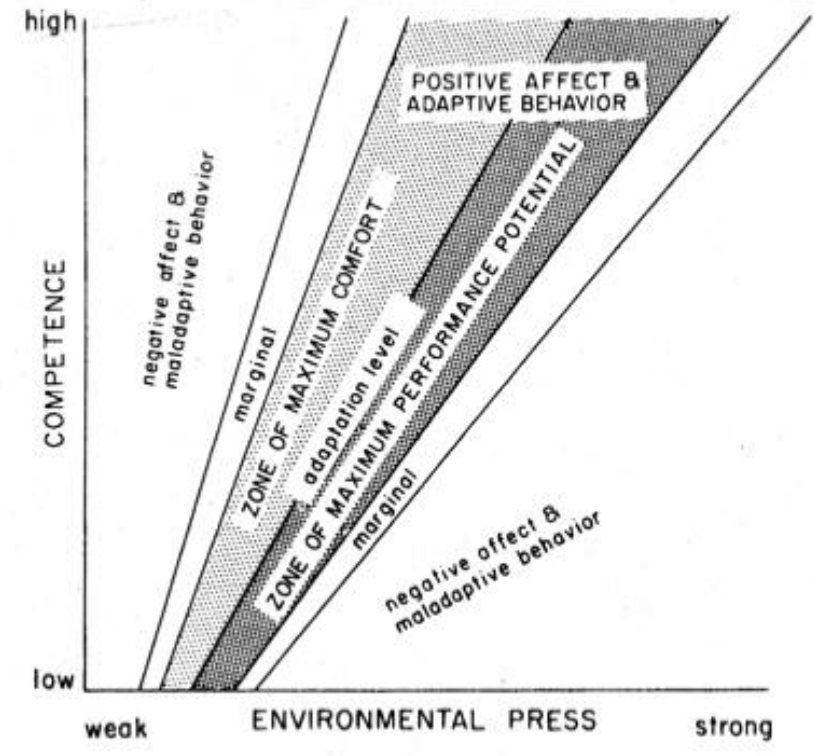

Figure 2. The Competence-Press Model (CPM) originally suggested by Lawton and Nahemow (1973

This model may be the only in E-G to be called a paradigm and it is recognized as one of the most prominent middle-range theories in the field (Schwarz, 2003). Human-environment interactions are dynamic and active processes which lead to the physiological and psychological impact that the environment will have on the individual. If an individual feels lost due to the size of the building, or overwhelmed by the number of people that need to be dealt with on a daily basis, then environmental press may come in to play.

Lawton and Nahemow (1973) define environmental press as a demand character of the environment, i.e., how much an environment demands of a person (Figure 2). Those demands may take the form of stressors and they need to be coupled with the individual's set of competencies ( health, cognitive skill, motor functioning, etc.) to define competence-press for that person and their resulting competence in their environment. Therefore, an individual's competence is a function of press (summation of stressors) $\mathrm{X}$ person, a continuously shifting and 
mutually causal interchange between person and environment. These conclusions are reflected in Lawton's adaptation of Lewin's (1951) original ecological equation, $\mathrm{B}=\mathrm{f}(\mathrm{P}, \mathrm{E})$, with the addition of a PXE interactional term $\mathrm{B}=\mathrm{f}(\mathrm{P}, \mathrm{E}, \mathrm{PXE})$. Therefore, an individual's behavior will change as often as their perceived response to their environment changes, and perhaps more importantly, the more an older person understands their environment, the less its perceived press, and more autonomy is possible for a given level of competence (Scheidt \& Norris Baker, 1998). Within this framework, it is assumed that individuals can thrive and develop within some settings and can face challenges that limit or curtail their development within others.

\section{Social Interdependence and Dynamic Systems Theory}

The environment is viewed as being rich in features with functional significance, and a focal point of human evolution has been the exploitation and subsequent elaboration of meaningful functional resources in the environment. Environmental features, both inanimate and animate, and operating at multiple levels of complexity, have perceivably meaningful properties for action. Individuals function to discover and sometimes to create these meanings, and they act in concert with these features (Heft, 2001). A framework related to Lawton's competence-press theory with roots in Gestalt psychology is social interdependence theory. This theory is based on the premise that the ways in which participants' goals are structured determine how they interact, and these interactions determine the outcomes of the situation (Figure 3) (Heft, 2001). Gestalt psychology dictates that as individuals learn about environmental structures, they in turn sustain these products through their actions and sometimes contribute to their transformation. This view is traceable to writings of Marx, as reflected in the quote, "Men make their own history, but they do not make it just to please...but under circumstances directly encountered, given and transmitted from the past (Marx quoted by McLellan, 1975, pg. 43).” 


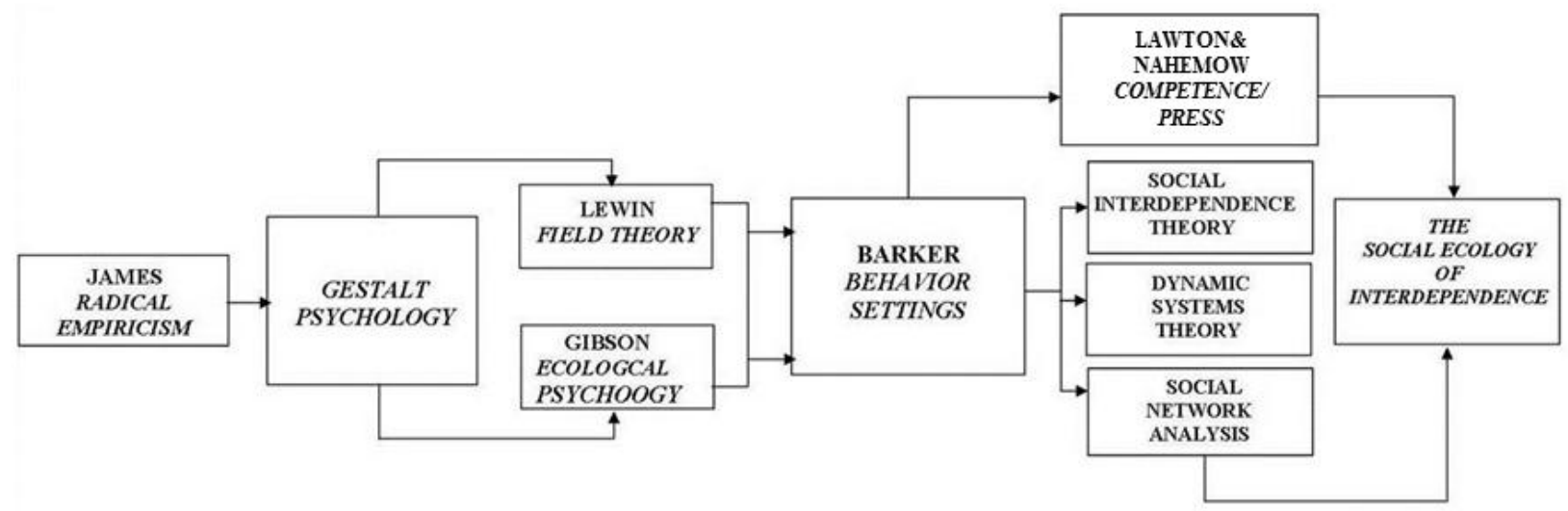

Figure 3. The Historical Nature of Theories of Aging and the Environment

In environmental design research, the environment is not seen as having a direct impact on people and groups; rather, it has an impact via people's perceptions and conceptions of it (Moore, Tuttle \& Howell, 1985). In LTC, residents are at home, and staff are at work, inherently implying differing participant goals. Within this context, cause and effect can go both ways, depending on the understanding that the staff and the residents have of their role in a particular setting. Similarly, dynamic systems theory defines the time-dependent order that emerges from complex interactions in physical and biological processes. Patterns and structures in the natural world are viewed as being determined, sustained, and layered over time by the interplay of numerous factors (Heft, 2001). One resident's response to a situation may change due to others' responses in the same setting because of the multiple, reciprocal influences at work. If there is an attempt to understand the contribution of any single component of the system, it is then necessary to consider it in the context of the system as a whole, because to isolate a component for closer scrutiny, is in fact, to examine that component in a different context (Heft, 2001). Therefore, it is critical to look at the workings of a LTC facility for what it is, a complex system 
defined by the physical environment, the organizational and social structure, and the physical and emotional needs of the residents and staff.

\section{The Temporal Perspective}

Other frameworks relating to congruence are temporal inquiries, which may be thought of as more compatible with transactional paradigms and which focus on events and holistic phenomena involving the confluence of people, space, and time (Altman \& Rogoff, 1987, Rubenstein \& Parmelee, 1992). The temporal perspective is designed to explain personal and environmental outcomes experienced by older adults following changes in their shelter and care setting. Emphasizing a temporal perspective that recognizes the individuality of each person in a new setting and the congruence of this setting with the person's needs, this framework attempts to go beyond models that have previously dealt with the consequences of a move to a LTC setting. This is an attempt to delineate a complex construct of particular characteristics that direct an individual's assessment of their care setting (Schwarz, 2003). Personal resident reflections about their past, as well as the organizational history of the provincial continuing care system and the history of the Welsh Group, will help define a temporal perspective in this study.

\section{Social Connection}

Researchers have suggested that healing and recovering from emotional wounds arises out of connecting both within oneself and with others (Hogg \& Frank, 1992), and many factors that affect quality of life of elderly long term care residents are associated with social connectedness. Good health and psychological well-being in the elderly are an attribute of self, an invisible thread rather than physical or concrete phenomena, and is best described as a human's cognitive and physical attachment and attitude towards others. Low levels of social contact with friends, 
family, and the outside world may have negative impact on the ability of residents to cope with living in long-term care and also with their overall quality of life (Buckley\& McCarthy, 2009). The life we lead and the social connections we've created help ground us in our personhood, connecting us to our world. Connectedness seems to buffer against social isolation, perhaps through the individual's increased willingness to take interpersonal risks (Townsend \& McWhirter, 2005).

Hagerty, Lynch-Sauer, Patusky, \& Bouwsema (1993) describe a state of connectedness as occurring when a person is actively involved with another person, object, group, or environment, and that involvement promotes a sense of comfort, well-being, and anxiety-reduction. This definition is clear and also suggests that the construct of connectedness is an intricate and multidimensional one. Kearney (1998) described empowered connectedness as a sense of having a safe place within a community and a meaningful role to play.

\section{Place Theory}

The aging population, according to Koncelik (2003), especially the oldest among us, has a greater attachment to their personal environment than other age groups, and another important attribute of connection in LTC is the ability to have a sense of connection or attachment within a physical setting. Place theory can be described as a collection of symbolic meanings and attachments with spatial settings held by an individual. Massey (1994) suggests that places are not essences, but processes. Places do not necessarily mean the same thing to everyone because attachments are partially formed by the experiences and cognition in places that have a role in the regulation of a person's emotional balance and self-experience (Korpela, 2001). An individual's sense of place is both an emotional and biological response to the surrounding 
physical environment in all ways of knowing (sight, sound, smell, touch, and taste), which makes it powerful as a source of memory (Hayden, 1995). It is a process through which a person is enabled to change his or her way of being in the world, and especially of relating to others (Kitwood, 1997).

To the extent that LTC is based on institutional values, policies and procedures, residents face the potential of losing their self-identity (Chaudhury, 2003), and the traditional LTC community symbolizes withdrawal from a previous setting and institutionalization of physical dependency. Rubenstein and Parmelee (1992) examine aspects of place attachment in the later life of the elderly, and they have defined place attachment as a set of feelings about a geographic location that emotionally binds a person to that place as a function of its role as a setting for experience. Surveying various literatures on place attachment, Rubenstein and Parmelee (1992) observe that for older people, that attachment is a way to keep the past alive, in order to maintain a sense of continuity, fostering of identity, protection from change, developing a positive selfimage, enacting independence, and continuing competence. They also observed that attachment to place becomes more compelling when one links to it significant life events, key developmental themes, and identity processes within the environment. In other words, attachment to place may also represent attachment to time and is more of a process than a state of mind.

Massey (1994) has also pointed out that places are not isolated, but they should always be regarded in relation to the outside world. What makes a place special is not necessarily any intrinsic qualities of the locale itself, it may also be the particularity of lineage to that 'outside' which is therefore itself a part of what constitutes the place. Thus, places appear as points of intersection, integrating the local and the global. For the institutionalized older person, 
reminiscence of significant places from the past could have powerful meanings in remembering one's life course. This may be particularly salient for people with dementia who have difficulties in maintaining their sense of self in the face of the continuing erosion of identity associated with this progressing disease (Chaudhury, 2003).

\section{The Layered Meanings of Home}

It can now be understood that personal attachments can be created between a place and the person (Stokols, 1988). How we view our place in the world structures the way that we behave in a LTC setting, and relocation may involve reinterpretation of past place identities and changes in the roles. The French philosopher Bachelard (1964) writes about attachment to a home as a place in our 'corner of the world':

But the related problems are many if we want to determine the profound reality of all the subtle shadings of our attachment for a chosen spot. These shadings must be taken as the first rough outlines for a psychological phenomenon. The shading is not an additional, superficial coloring. We should therefore have to say how we inhabit our vital space, on accord with all the dialectics of life, how we take root, day after day, in the "corner of the world." For our house is our corner of the world. As has often been said, it is our first universe, real cosmos in very sense of the world.

For many, the home is center stage for human life and fulfillment. The creation of a home is a response to, and a reflection of our world. Our lives revolve around the security and protection that it provides. The roles that are taken on at home: the sorting, folding, stacking, and mending tasks that are performed every day are attempts to create order in our lives and help to define the internal and external picture of who we are. The role of home, in fact, has many layers of meaning. 
Lewin (2001) describes home as a composite concept. He uses the following analogy by Vikko (1996):

The concept of home can be seen in a twofold sense. On one hand, the home is a residence and thereby a source of an environment for daily routines. As a resident, the home creates a frame for how (we) manage everyday tasks and for meaningful activities in general. On the other hand, we can see the home as being charged with symbolic meaning: The home...refers to mental and social well-being, the home is a totality of meaning-charged activity and the home is an experienced space.

Dahlin-Ivanoff (2007) characterizes home as having two key categorical meanings:

Home means security, wherein we are living in a familiar neighborhood, can carry out everyday functions and have memories that are associative, and home means freedom, comprising a place for reflection, a social meeting-point and leaving one's own mark.

The relationship to physical possessions comes in to play as well. Csikszentimihayli \& Rochberg-Halton (1981) cite that material possessions are signs of the self. Rochberg-Halton (1981) continues this concept by examining the relationship of the person to the significant personal possessions, usually part of the home environment field. He views the home environment as a 'socializing sign-complex' and the relationship of the person with personal possessions or objects in and around the home as a form of developmental cultivation of self. Vikko (1996) describes how expressions such as 'to be at home in the world', 'have the world as my home', and 'to be like home' constitute cultural patterns of thought and expression that are used when assessing life. 


\section{Homelessness}

Often a move into LTC indicates a crucial incision and rupture into every "normality" of what makes the practices of (a) feeling at home with oneself as well as (b) with one's surroundings, specific and stable (Schillmeier \& Heinlein, 2009).An authentic home provides individually meaningful experiences of choice, mastery, refuge, relationship and selfreconciliation (Molony, et all, 2011).

Counter to this ability to feel at home, often residents in LTC will have a sense of homelessness, which Carboni (1990) writes about with respect to nursing home care. She defines home as the experience of a fluid and dynamic intimate relationships between the individual and the environment:

Elderly residents in nursing homes face non-personhood; identity becomes murky because they no longer have a special bond with a place that held a significant, personal meaning. Within the nursing home, there is a pervasive sense of up rootedness and nonbelonging, as well as confused feelings about self and identity... the roots that fed each informant's identity and provided nurturance were more than merely pulled up; it seemed that the roots were actually severed. For example, how can one recover the roots of one's house if it is sold, how can one identify with a place that is no longer there? When possessions are dispersed among relatives or sold, they are no longer available to the individual for interaction and meaning; the relationship with objects and their memories become severed.

The elderly individual wandering the streets is easily identified as homeless, yet there is an entire population of elders who suffer silently, enduring the painful state of homelessness within the confines of the total institution of the nursing home. To view as homeless these individuals who are, in fact, sheltered and fed seems incongruent; however, when one acknowledges these unrecognized homeless, the increased understanding can direct us in the discovery of ways in which we can alleviate or reverse the process.

Homelessness, therefore, can be defined as the experience of the negation of home, where the relationship between the individual and the environment loses its intimacy and becomes 
severely damaged. This shattering of the highly significant relationship is perceived as an insult to the individual's meaningful existence (Carboni, 1990)

\section{Frailty and Dependency}

Because LTC is an intersection of home and health care, it becomes important to understand the implications of physical dependency in aging. Thomas Cole (1992) writes that aging symbolizes spiritual integrity and wisdom. This might be considered a myth or a truism, depending on the circumstances that surround an individual's life journey. For those who are lucky enough to maintain a home, relationships, and a connection to their surrounding environment, the doors of life remain open and there is a symbiotic relationship between self and the world. Others become more mentally and physically fragile as they try to navigate the course of their lives due to illness or disease, and there is a need to move to a LTC setting.

Characterization of the physiological basis of frailty has been described as one of the most important research endeavors in medical gerontology, yet 'frail' and 'frailty' are often under defined (Rockwood, 1994). Frailty is defined as a dynamic state affecting an individual who experiences losses in one or more domains of human functioning (physical, psychological, and social), which is caused by the influence of a range of variables and which increases the risk of adverse outcomes (Gobbens, Luijkx, Wijnen-Sponselees, \& Schols, 2010). Frailty has become synonymous with vulnerability and is a state cause by many factors including disability, recurrent infection and multiple co-morbidities (Wallce, et al, 2012).

Partidge, Harari, \& Dhesi (2012) define frailty as a lack of physiological reserve seen across multiple organ systems and is an independent predictor of mortality, morbidity and institutionalization. The high correlations between physical frailty and psychological adverse 
outcomes (e.g., psychological quality of life) and social adverse outcomes (e.g., social quality of life), suggest that physical frailty is the most important frailty predictor of adverse outcomes (Gobbens, van Assen, Luijkx, \& Schols, 2010).

\section{Home, Health, and Care}

We have an intrinsic need for a home - our dreams are around it, they are pretty central to us. Why, when you need one the most, do you suddenly not have one? Wherever you reside and live has to be home, period. ( Sheilds in Bowman, 2008, pg. 7)

\section{Logics of Space}

When a frail individual moves into LTC, the value systems and logics of home are entangled with the healthcare organizational system, in essence, the reason that the care recipient is in this setting in the first place. This progressive entanglement of the logics of home and those of the healthcare system produce an ambiguity of place for recipients, therefore, there needs to be a deeper understanding of the relations that contribute to care recipients' experiences of home and the care they receive. For care recipients, these interconnecting relations form processes of place that are reflected and enacted in limitations as well as satisfaction in the setting.

Individuals who seek long term care have three distinct needs: housing, assistance with activities of daily living (ADLs), and chronic disease management (Rabig, 2009), yet past models of care have not created environments that support these frail individuals. The nurses' station, central dining room, kitchen, laundry, bathing rooms, and supply areas of past models have been configured to serve large numbers of individuals in assembly line style (Rabig, 2009). Double-loaded corridors designed to maximize efficiency practically mandate wheelchair dependence and encourage incontinence. Double occupancy rooms and shared bathrooms create stress due to a lack of privacy. While skilled nursing facilities were originally conceived of to 
care for the health needs of the frail elderly, this care has been called into question due to ensuing high likelihood of depression, incontinence, and urinary tract infections in this model of care (MetLife, 2005).

\section{The Small House Model}

Amos Rapoport (2000) defines housing as a system of settings within which systems of activities occur. These relations link bodies, feelings, and things in a way that they generate a meaning of home as tranquilized self-assurance of everyday familiarity that generates and maintains the self-sufficiency of the everyday way of taking care of things. The practices that constitute the very feeling to be, or not to be, at home are fragile bodily, emotional, spatial and temporal achievements (Heidegger, 1996).

The E-G principles and models which have been written about, researched, and documented over the past four decades have become themes for care approaches that have, as their primary mission, the support and maximizing of resident strengths (Cohen and Eisdorfer, 2001). The visionary theories and research that has invigorated efforts at LTC reform all share a desire to improve the quality of life for residents and staff by doing nothing less than changing the nature of the relationships with LTC communities (Ronch, 2002). In the 1991 book Holding on to Home, Cohen and Weisman provide systematic approaches and principle to the design of facilities for people living with dementia. While the purpose of the book is to suggest that the physical setting can have a therapeutic role in the care of people with dementia, the themes resonate just as well for all cognitively or physically frail older adults. One theme that permeates the text is the importance of "homelike," "domestic," or "noninstitutional" environments and the 
therapeutic importance of creating such settings for vulnerable ageing populations (Cohen and Weisman, 1991).

In sharp contrast to past models of care, the small house ( $\mathrm{SH}$ ) model has been associated with these therapeutic principle and the use of the terms 'culture change' or 'person centered care,' because this model changes the philosophy, architecture, and organizational patterns of institutions of the past (Rabig, 2009). The SH model serves as a generic term for deinstitutionalized model of LTC. Other terms that reference this model include a social or the household model, group living, Green Houses, and small-scale living (Verbeek, et al., 2009).

One pioneer in the de-institutionalization of nursing homes was William Thomas, a Harvard trained geriatrician who founded the Eden Alternative philosophy of care in 1996 and later the Green House model of SH nursing homes (Kane, 2009). The Eden Alternative was designed to counter loneliness, helplessness and boredom in nursing homes and embraces the philosophy of companionship and the opportunity to create a pathway to a life worth living. Major systematic changes took place with this model at all levels; meal times, relationships and the place of work for staff. Flattening of the traditional staff hierarchy allowed more opportunities for caregivers to get to know the residents in order to understand and meet their needs (Thomas, 2003).

The Green House model is the most well-known of this care community type in the United States, with over 100 of these facilities open across the country in 2011. Some other examples of SH communities currently in place in the United States include: the Providence Mount St. Vincent in Seattle, Washington; Evergreen Retirement Community in Oshkosh, Wisconsin,; Parc Provence in St. Louis, Missouri; The Corrine Dolan Center in Chardon, Ohio; Meadowlark Hills in Manhattan, Kansas, and Asbury Place in Mount Lebanon, Pennsylvania 


\begin{tabular}{|c|c|c|}
\hline Definitions of the Small House Model & Benefits & Current Barriers \\
\hline \multicolumn{3}{|l|}{ Physical Environment } \\
\hline $\begin{array}{l}\text { Small Grouping (8-12)-Cottages or } \\
\text { Households }\end{array}$ & $\begin{array}{l}\text { Fostering self-directed and } \\
\text { relationship based living }\end{array}$ & Cost unknowns \\
\hline $\begin{array}{l}\text { Residential scale and spatial provision for } \\
\text { privacy or interaction }\end{array}$ & $\begin{array}{l}\text { Improved hierarchy of } \\
\text { transitions }\end{array}$ & Inflexibility in environment \\
\hline All activities of daily living in one setting & $\begin{array}{l}\text { Variety of spaces and } \\
\text { potential for interaction }\end{array}$ & $\begin{array}{l}\text { Lack of appropriate spatial } \\
\text { configuration }\end{array}$ \\
\hline $\begin{array}{l}\text { Residential kitchen and meals prepared } \\
\text { in the cottage }\end{array}$ & $\begin{array}{l}\text { Home cooked meals in a } \\
\text { residential setting }\end{array}$ & $\begin{array}{l}\text { Cost/ Fire safety and food } \\
\text { handling regulations }\end{array}$ \\
\hline Private bedroom and bath & Personalization of space/ & Cost/economy of scale \\
\hline \multicolumn{3}{|l|}{ Culture of Care } \\
\hline Person Centered & $\begin{array}{l}\text { Focus one the individual } \\
\text { resident and their needs }\end{array}$ & Staff/Task Orientation \\
\hline $\begin{array}{l}\text { Autonomy and choice for residents in their } \\
\text { daily activity }\end{array}$ & $\begin{array}{l}\text { Control and flexibility in } \\
\text { daily living }\end{array}$ & $\begin{array}{l}\text { Safety seems to be the } \\
\text { antithesis of independence }\end{array}$ \\
\hline \multicolumn{3}{|l|}{ Organization } \\
\hline Flattened Hierarchy & Increased staff satisfaction & $\begin{array}{l}\text { Questions about leadership } \\
\text { boundaries around } \\
\text { management }\end{array}$ \\
\hline $\begin{array}{l}\text { Deinstitutionalized and decentralized } \\
\text { clinical resources }\end{array}$ & $\begin{array}{l}\text { Nurses area integrated } \\
\text { into each cottage }\end{array}$ & $\begin{array}{l}\text { Staff communication and } \\
\text { care planning }\end{array}$ \\
\hline $\begin{array}{l}\text { Empowered self-led care teams cross- } \\
\text { trained and supported by the organization } \\
\text { and management }\end{array}$ & $\begin{array}{l}\text { Low staff turnover and } \\
\text { staff self-scheduling }\end{array}$ & $\begin{array}{l}\text { Increased workloads and } \\
\text { staff shortages }\end{array}$ \\
\hline
\end{tabular}

Table 1.

The Small House Model

Table 1 describes the common elements in the small, domestic -style care settings with a breakdown of spaces into neighborhoods or households resulting in self-contained small homes where 8-12 residents live who have their own full kitchen, living room, and dining room. 
Bedrooms are private and staff work areas are integrated into resident common living areas, eliminating the need for a medication cart or nurses' station (Kane, 2009).

Because SH households are residential in layout and scale, residents have the opportunity to participate in activities and familiar tasks they associate with a residential setting, normal daily activities that occur in any household, (i.e. cooking, cleaning, socializing in the kitchen), which can bring well-being through purpose (Regneir, 2002). This therapeutic approach to program development which works effectively with resident as they are making a contribution and relates to social variables like roles, family, kinship, social networks, and status when work life and home life are merged (Rabig, 2009). This is consistent with Lawton's environmental press model because both behavior and emotions are the result of environments that produce the right levels of support and stimulation (Kane, 2003).The SH may be a single stand-alone residence, as in the Green House model of care, or multiple households in a single building licensed as a nursing home or part of a nursing home. When licensed as a skilled nursing facility, the organization must adhere to regulatory requirements, practices and standards of the specific region.

\section{Privacy Scales}

Privacy may be viewed as a system of both interactions and withdrawals, occurring at varying degrees and linked to spatial order and physical separations (Altman, 1977). A specific outcome in the configuration of the $\mathrm{SH}$ model is a change in spatial ordering from the traditional nursing home. By their nature, institutions are larger than private homes, bringing more people 


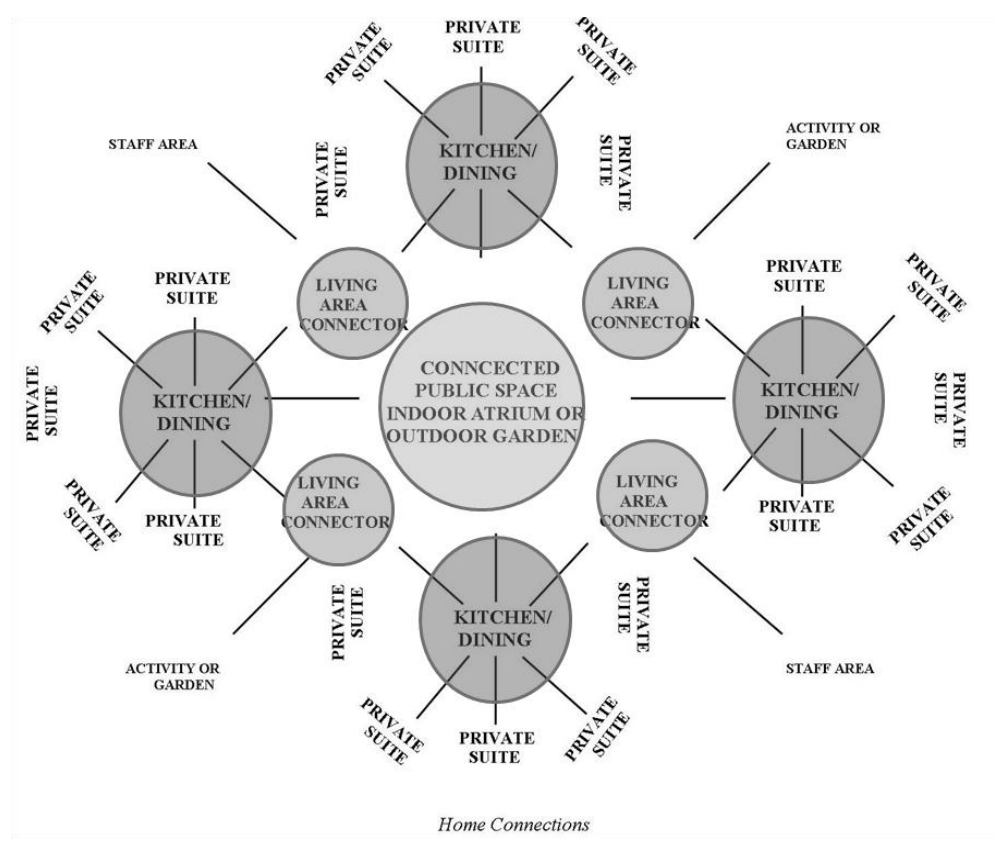

Figure 4.

The Small House Model- Opportunities for Privacy or Interaction

together than within a residential setting. The ability to control access to the individual and group becomes difficult as the access to the collective whole overrides the needs of the individual (Kaup, 2007).

Figure 4 shows diagrammatically the opportunities for privacy or interaction in the SH model, with the resident bedroom allowing the highest level of privacy; the kitchen/dining area in each household as a semi-private area, small connecting areas as semi-public areas, all of which connect to a larger public area which can be a shared community indoor or outdoor spaces. This reduction in scale and change in spatial configuration supports the traditional privacy hierarchy of home, and can be a powerful piece within the organizational and social constructs of a planned care setting (Kaup, 2007). 


\section{Discord in Need}

Because care recipients and care providers are locally situated at the intersection of domestic and healthcare worlds in the SH setting, they may participate in confused relations of social and occupational emplacement (Angus, et al., 2005). Each world provides its participants with a way of looking at and understanding daily life. Each has its own logic, own ideals, sense of justice and fair treatment, method of expedience, prescribed duties, rhetorical style, and proper mode of making decisions (Gubrium, 1975). When moved into LTC, the frail elder becomes dependent to others in a way that is atypical for most normal adults. This situation leads to experiences of loss of hope and mistrust, while accommodating the incapacity and the dependence on caregivers (Bergsma and Thomasma, 1982). Sickness frequently forces an examination of what is so commonly termed one's values, and the world exerts its inexorable demands and places limits on the scope of meaningful action. The problem is less an issue of dependence than a matter of the meanings that dependence imposes on the particular elder (Agich, 2003).

For a caregiver in the traditional medical model of care, while the private or semiprivate bedroom or apartment is considered the residents' private domain, the rest of the facilitycorridor, dining area, and nurses' station-are considered a part of the caregivers work environment. In a SH setting, the cottage is considered home for the residents. This creates a major shift of roles for the caregivers; they are, in essence, coming into a home, rather than an institution as work place. This holds the potential to completely change the dynamics of both patterns of work for caregivers and patterns of living for residents. Regulating risk, freedom of action, and autonomy in decision making become problems shared by both caregivers and residents, and can become the subject of tensions and constant negotiation. The resident may 
have the perspective that 'this is my home, I may do as I please' and the caregivers may have the perspective that 'this is where I work, you are my responsibility.' Therefore, within the SH model, the logic of home, its social relations and structures continue to be linked with relations of power, inclusion, and exclusion in the organizational aspects of caregiving. A new question arises; what if normalcy of the setting has nothing to do with the physical environment, the staffing organization, or an open kitchen? What if normalcy is, in fact, an internal individual setting?

\section{Research Needs}

There is much we do not know. There is more evidence about what does not work then what does. Every design project is a hypothesis, designers and providers believe configuring the space in a certain way will lead to a certain set of outcomes. What is often missing, however, is any systematic evaluation of how well the setting actually achieves the hypotheses. (Calkins, 2005 pg. 68)

\section{Current Research in the Small House Model}

Much has been written about scale, layout, and configuration of SH communities, focusing on the internal scale and residential qualities of the environments, with prescriptive literature revolving around the concept of the homelike qualities of these facilities, the staff, and the organizational aspects of caregiving (Day, Carreon \& Stump, 2000; Kane et al., 2009, Rabig, et al. 2006, Thomas, 2003). Studies which have been conducted in SH nursing facilities have addressed the complex relationships which have emerged between perceived self-care ability and functional performance. Lum, Kane, and a team of researchers (2007) from the University of Minnesota have written about the first Green House homes in Tupelo, Mississippi, collecting information from the residents, primary family caregivers, and staff. These Green Houses were established by Methodist Senior Service of Mississippi and they have run the new houses on a 
cost-neutral basis and have seen occupancy rates increase from $85-92 \%$ before Green House to $95-100 \%$ with a waiting list. The study shows that residents have received equal or better quality of care than they did in comparable nursing homes. They also reported a higher quality of life. There were fewer declines of ADL's, staff turnovers were less than 10\%, and there was less prevalence of depression and less incontinence without a toileting plan. Finally, there was less use of anti-psychotics without a relevant diagnosis in the facility. Both staff and family members of those living in Green Houses also reported that they were more satisfied as well (Lum, et al., 2007).

Imamoglu (2007) has examined how the SH place type is represented in terms of its visual and verbal attributes and in comparison with the well-established schema of home and nursing home. Results indicated that home and nursing home are conceived in opposite terms and were discussed in the possible merging of newly developing and well-established place types (Imanaoglu, 2007). Molony et al. (2011) have addressed a meta-synthesis of the meaning of home and writes that the SH setting is both a place-based experience and a process of personenvironment integration. Achieving this meaningful experience of choice, mastery, refuge, relationship, and self-reconciliation involves a relationship with dynamic interaction within and between the intrapersonal, interpersonal, physical, and transpersonal environment. In their 2011 study of $\mathrm{NH}$ residents who moved to a $\mathrm{SH}$ model, the $\mathrm{SH}$ environment was described by the residents as "normal", " more relaxed", and "more private (Molony, et al, 2011)."

In 2008, Rahman \& Schnelle took a retrospective approach to the critique of the research base underlying the nursing home culture change movement. The context was to propose research agendas aimed at strengthening the movement's empirical base, thereby facilitating culture-change interventions as well as helping the movement navigate the 
next steps in its evolution (Rahman \& Schnelle, 2008). Despite this past research, there is still little known in both the United States and Canada about the effects of small-scale and homelike environments on residents, family, and caregivers (Verbeek, et al, 2009). With respect to researching new models of care, Brawley (2006) writes:

Some ideas work, some work differently than what we anticipated and can be adapted or used for another purpose, and some, sadly, just don't work. Too often, we have been guilty of promoting ideas without testing or research to determine search for better and more productive solutions.

There is concern that a weak empirical base could undermine the credibility of the SH model and limit its effectiveness (Rahman \& Schnelle, 2008). This is important because many providers become discouraged to pursue innovative ideas due to regulatory requirements they believe to be unreasonable and/or unknown expenses, and they worry that what they build will be subsequently found to be out of compliance (Bowman, 2010). Culture change advocate Brian Purtell spoke at a 2010 working group about the SH model and impact of regulatory bodies on culture change in the United States:

I think the key is to address regulations because provider suffer from regulatory paralysis. I have administrators who will call me with a question that has a common sense answer; they are paralyzed by regulatory fear and fear of change can lead to missteps. We have to address regulations in order to have an effect (UWM, 2010).

Additional research into the SH model will help providers understand potential implementation pitfalls based on real data rather than speculation (Rahman \& Schnelle, 2008). It is therefore the goal of this research to address the outcomes in the model in Nova Scotia, not only for the individual residents, their families, and the staff in the communities, but in order to inform providers in other provinces and countries who are considering the transformation of the way that they provide LTC. This is critical to the understanding of the impact of government 
intervention in legislation and funding. As a faculty member at the Nova Scotia Institute on Aging expressed , "The province has put a lot of money into these 11 new communities, I think it's fairly important that we find out what the outcomes are, don't you?" 


\section{CHAPTER THREE: RESEARCH DESIGN AND METHODOLOGY}

\section{The Study Sites}

The two study sites for this research are located outside of Halifax, the capitol of Nova Scotia. The Ridgemont Continuing Care Center was originally built as a military barrack on the outskirts of a small town near Halifax, and went through many uses until a major renovation in 1997 brought it to its current form (Figure 5-6). The interior layout has three neighborhoods with accommodations for 51 residents. At the time of the study, there were 48 residents living there. There are both private and semi-private resident rooms. This facility has a semi-traditional institutional layout, with a large kitchen which dispenses the food to the three dining areas. Each neighborhood has a dining area and a small lounge, though these spaces are not adjacent to each other. The central lobby area has a nurse's station and a community room with an adjoining sitting room. All resident rooms and social spaces are located on the upper level, and the support areas like the kitchen, offices and the laundry area are located on the lower level. There are two or three small outside seating areas, but due to damage from weathering and lack of upkeep, these areas are not safe for use by residents. The philosophy of care, service delivery, and staffing patterns at Ridgemont are based on DoH requirements that were put into place prior to the 2006 LTC requirements, and the organization and staffing continue to be run as a traditional nursing home, with well-defined staff hierarchy and specific job descriptions.

Stonebridge Continuing Care Center was built for 50 residents and opened in 2009 as one of the first of 11 new communities in the province under the 2006 CCS requirements for LTC (Figure 9-10). At the time of the study, there were 49 residents living there. The facility is located on a well-travelled street in a suburban area about 20 minutes between Halifax and Ridgemont. 


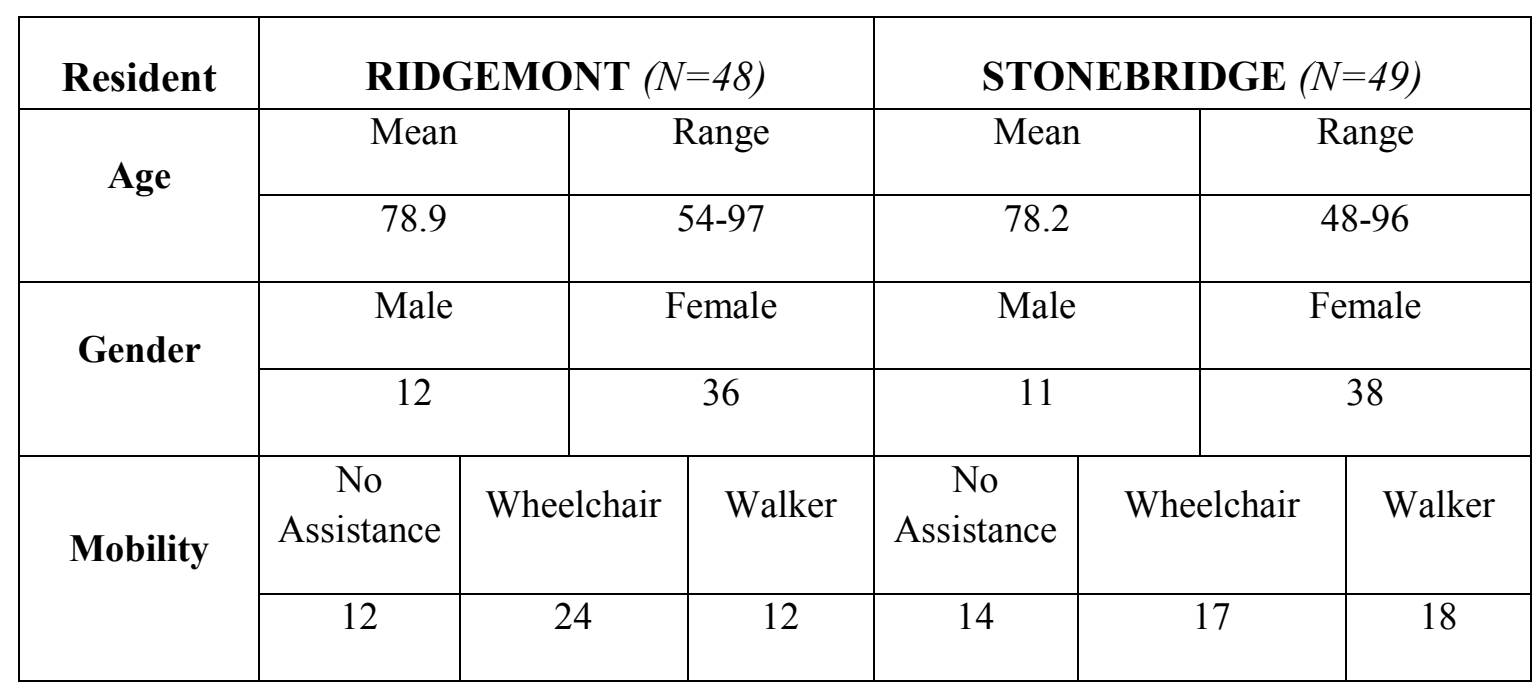

Table 2 .

Resident Demographic Information

Within the two-story building, there are four self-contained cottages, each for 12 to 13 residents. Every cottage has a living room, dining room, and residentially scaled kitchen, and all resident rooms are private. Level one has two cottages, one of which is a memory care unit for residents with dementia. There is central lobby with amenities like a community center for large group activities, a beauty parlor, and a small general store, as well as administrative offices and storage. Level two has two cottages, one of which is a residential care facility (RCF) for residents with lower levels of need. There are walking areas and a gazebo at the back of the building, although the walkway between the upper and lower levels is relatively steep. The philosophy of care, service delivery, and staffing patterns are based on the 2006 CCS requirements.

The resident populations in the two communities are very similar demographically. The average resident age in Ridgemont is 77.8; in Stonebridge, the average age is 78.9. Women outnumber men in both communities by about 3:1, and approximately half of the Ridgemont residents use wheelchairs, while about $35 \%$ of residents in Stonebridge require a wheelchair (Table 2). 


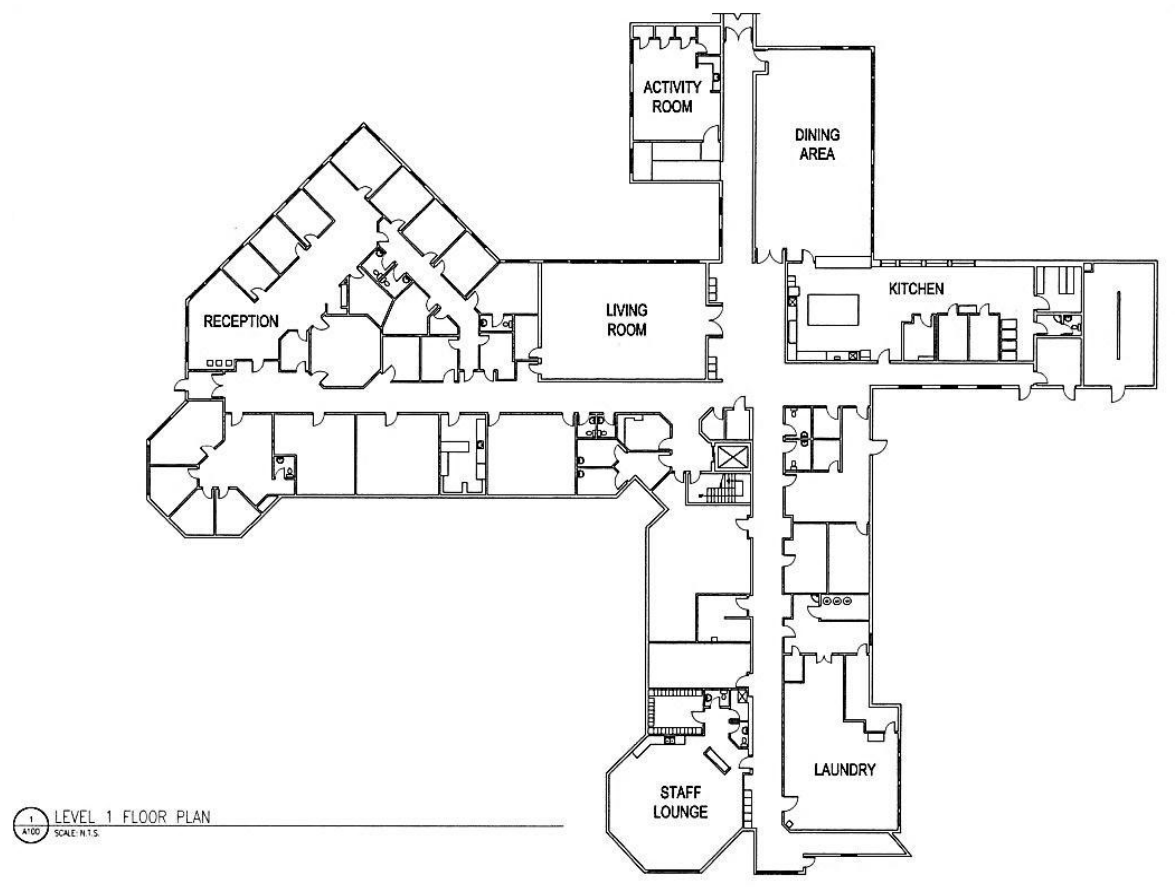

Figure 5. Ridgemont - Level One Floor Plan

Total Building Square Footage 44,000 sq. ft

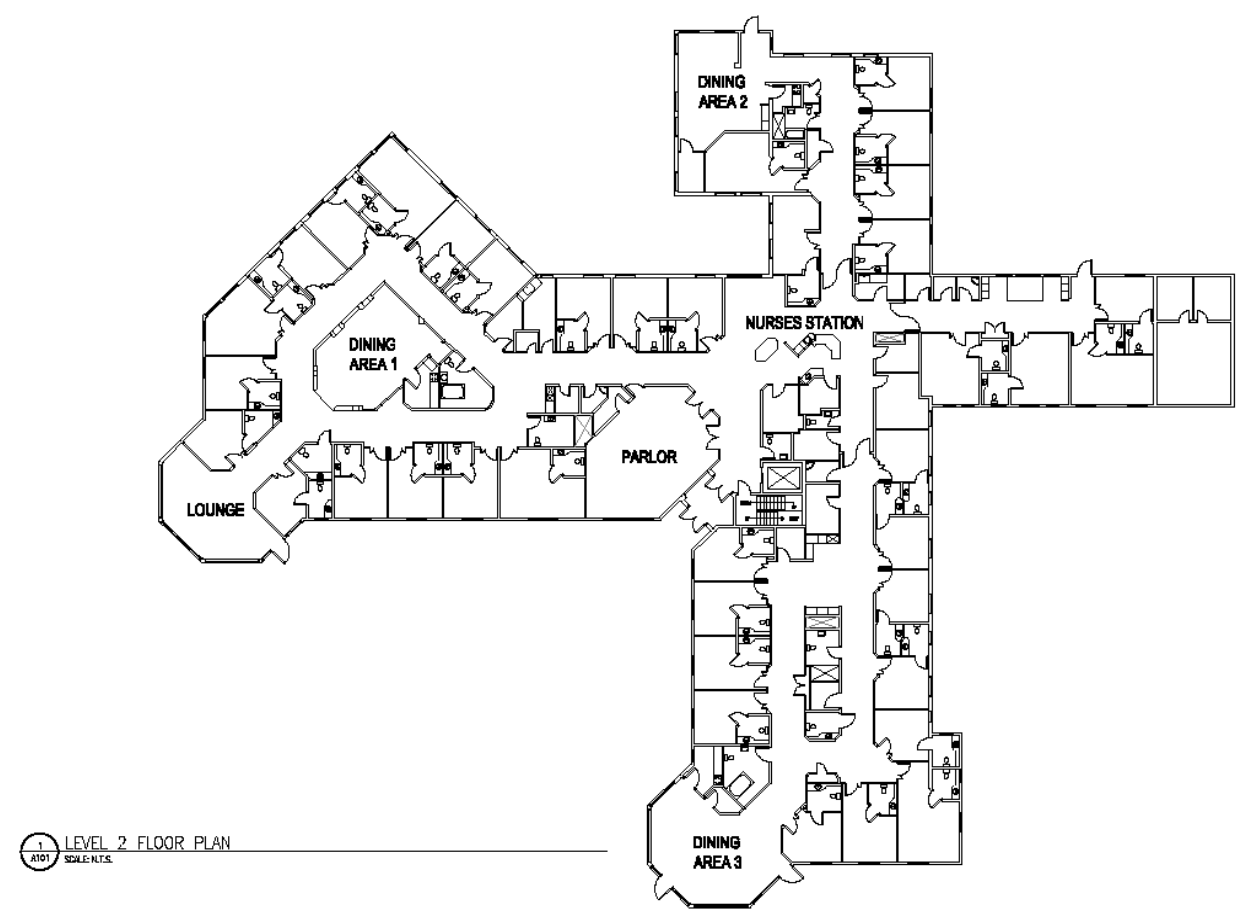

Figure 6. Ridgemont- Level Two Floor Plan 


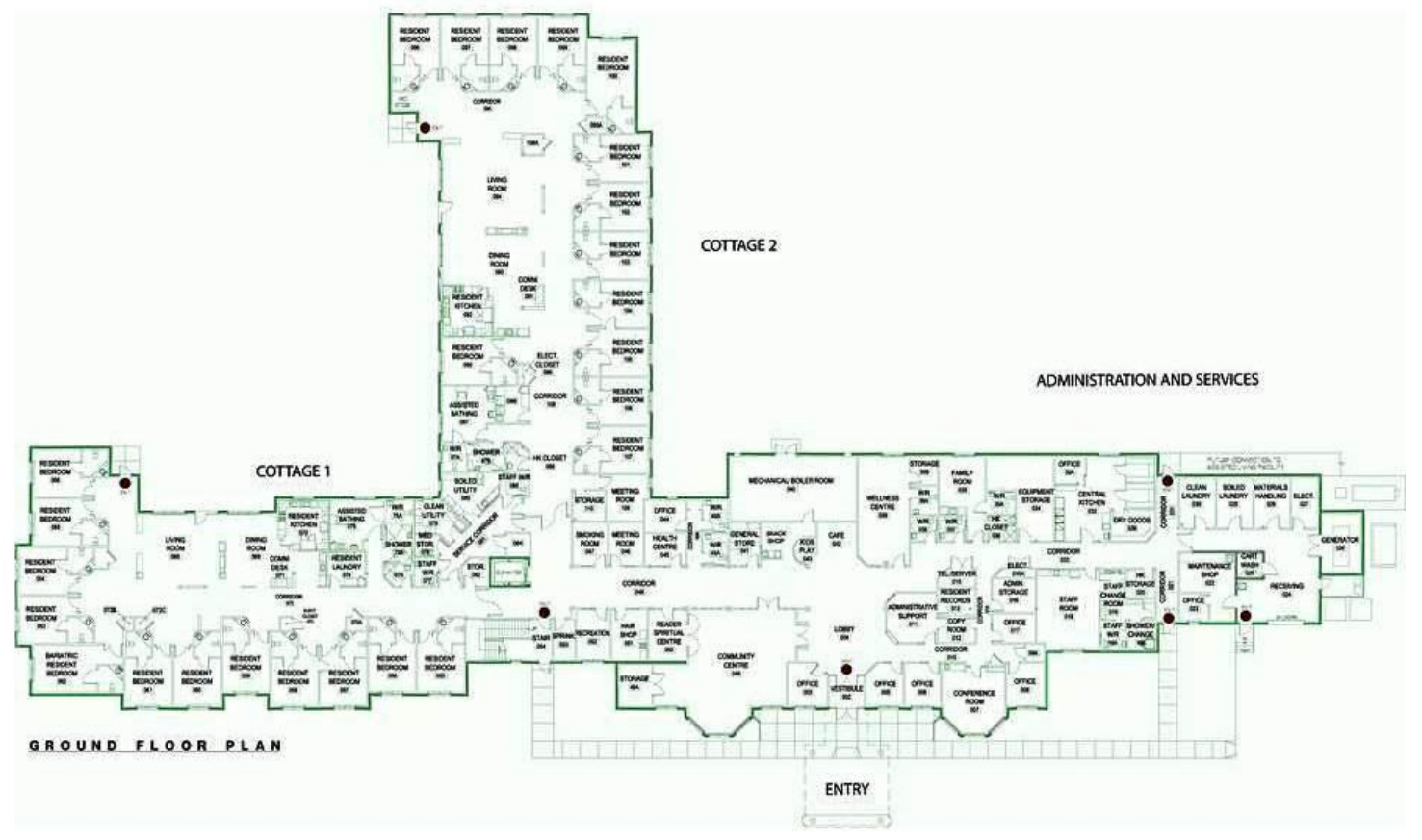

Figure 7. Stonebridge Level One Floor Plan

Total Building Square Footage-47,000

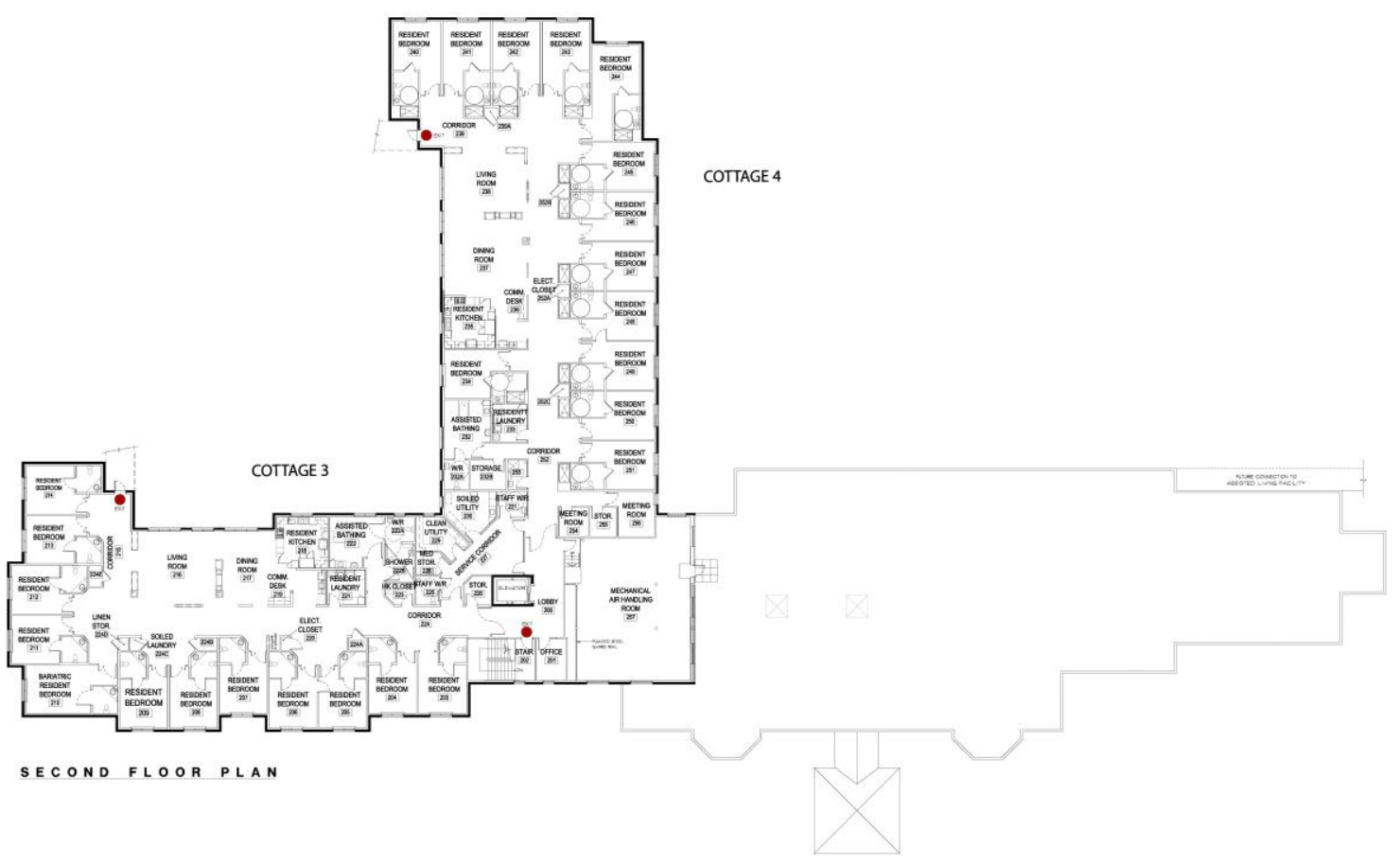

Figure 8.

Stonebridge Level Two Floor Plan 


\begin{tabular}{|c|c|c|}
\hline FEATURE & RIDGEMONT & STONEBRIDGE \\
\hline $\begin{array}{l}\text { Building Type/Age } \\
\text { of Building }\end{array}$ & $\begin{array}{l}\text { Former army barracks-renovated } \\
\text { in } 1997\end{array}$ & $\begin{array}{l}\text { Purpose-built long term care facility } \\
\text { opened in } 2009\end{array}$ \\
\hline Care Type & $\begin{array}{c}\text { Skilled Nursing, Residential Care } \\
\text { Facility (RCF) }\end{array}$ & $\begin{array}{c}\text { Skilled Nursing, Residential Care } \\
\text { Facility (RCF) }\end{array}$ \\
\hline Philosophy of Care & $\begin{array}{c}\text { Staff/ Union Centered } \\
\text { Regimented Meal times } \\
\text { Staff have specific job (i.e. dietary, } \\
\text { CCA, cleaning staff) }\end{array}$ & $\begin{array}{c}\text { Resident Centered } \\
\text { Flexible meal times } \\
\text { CCAs perform all tasks in cottages } \\
\text { except for nursing }\end{array}$ \\
\hline Square Footage & 44,000 sq. ft. & 47,000 sq. ft. \\
\hline $\begin{array}{l}\text { Capacity/Cottage } \\
\text { size }\end{array}$ & $\begin{array}{l}51 \text { residents; } 20,16 \text { and } 15 \\
\text { resident in } 3 \text { neighborhoods ( } \mathrm{N}= \\
48 \text { at start of study) }\end{array}$ & $\begin{array}{c}50 \text { residents; } 12 \text { residents in } 2 \\
\text { cottages, } 13 \text { residents in } 2 \text { cottages } \\
(\mathrm{N}=49 \text { at start of study) }\end{array}$ \\
\hline $\begin{array}{l}\text { Designated } \\
\text { Dementia Unit }\end{array}$ & 1 neighborhood; $\max 15$ residents & 1 cottage; max 13 residents \\
\hline Resident's Room & $\begin{array}{l}13 \text { shared rooms, and } 25 \text { private } \\
\text { rooms }\end{array}$ & All private resident rooms \\
\hline Washroom & $\begin{array}{l}\text { Shared washroom in shared } \\
\text { resident rooms }\end{array}$ & All private washrooms \\
\hline Dining Room & $\begin{array}{c}\text { Dining area for each } \\
\text { neighborhood. Kitchenette for } \\
\text { storage behind closed door }\end{array}$ & $\begin{array}{l}\text { Dining area for each cottage, directly } \\
\text { linked to open kitchen }\end{array}$ \\
\hline Kitchen & $\begin{array}{l}\text { Meals prepared in large kitchen on } \\
\text { lower level, brought up on meal } \\
\text { cart and served from trays to } \\
\text { dining table. }\end{array}$ & $\begin{array}{l}\text { Meals warmed or prepared in cottage } \\
\text { kitchen and served directly from } \\
\text { kitchen to dining table }\end{array}$ \\
\hline $\begin{array}{l}\text { Living Room/ } \\
\text { Lounge }\end{array}$ & $\begin{array}{l}\text { Lounge at the end of two } \\
\text { neighborhoods, third } \\
\text { neighborhood dining room is used } \\
\text { as lounge between meals }\end{array}$ & $\begin{array}{c}\text { Each cottage has a living room } \\
\text { directly linked to the kitchen/dining } \\
\text { area }\end{array}$ \\
\hline
\end{tabular}

Table 3.

Environmental Features and Relationships 


\begin{tabular}{|c|c|c|}
\hline FEATURE & RIDGEMONT & STONEBRIDGE \\
\hline Nurses' Station & $\begin{array}{c}\text { Central Nurses Station incorporated } \\
\text { into resident central lounge. } \\
\text { Smaller nurses' desk in two } \\
\text { neighborhoods }\end{array}$ & $\begin{array}{l}\text { No central nurses' station, although } \\
\text { there is small office/conference area } \\
\text { in each cottage, as well as a main } \\
\text { nurses' office in the administrative } \\
\text { section of the building }\end{array}$ \\
\hline Medication area & $\begin{array}{c}\text { Medication cart is used within each } \\
\text { neighborhood }\end{array}$ & $\begin{array}{l}\text { Cupboard for medications kept in } \\
\text { each cottage }\end{array}$ \\
\hline Outdoor Space & $\begin{array}{l}\text { Limited access to small patios from } \\
\text { two neighborhoods }\end{array}$ & $\begin{array}{l}\text { Access from each cottage to shared } \\
\text { outside area, with the designated } \\
\text { dementia unit access gated }\end{array}$ \\
\hline Community Room & Parlor for group activities & $\begin{array}{l}\text { Community center for group } \\
\text { activities }\end{array}$ \\
\hline Furnishings & $\begin{array}{c}\text { Foyer: Two chairs and fish tank } \\
\text { Nursing Area: conference table and } \\
\text { small seating area adjacent to } \\
\text { parlor } \\
\text { Parlor: Multiple seating areas, } \\
\text { central table and chairs, book } \\
\text { shelves, lg TV, stereo system, baby } \\
\text { grand piano, small alcove for } \\
\text { church services with worship } \\
\text { cabinet } \\
\text { Small Lounge in each } \\
\text { neighborhood with small seating } \\
\text { area in each, one with a couch, TV } \\
\text { and fish tank }\end{array}$ & $\begin{array}{l}\text { Foyer: Small seating area, }+2 \text { small } \\
\text { patio tables with chairs } \\
\text { Community Room: } 1 \text { seating area } \\
\text { with } 2 \text { chairs and a couch, } \\
\text { bookshelves, } 4 \text { tables with chairs, } \\
\text { baby grand piano, Large closet } \\
\text { opens for church services } \\
\text { Cottage Living Room: Couch and } \\
\text { multiple seating areas. Coffee table } \\
\text { and side tables. } \\
\text { Cottage Dining Room: } 4-5 \text { square } \\
\text { kitchen tables w/4 chairs each, hutch } \\
\text { for storage }\end{array}$ \\
\hline Shower/Tub Room & $\begin{array}{c}\text { Shower and tub room for each } \\
\text { neighborhood }\end{array}$ & $\begin{array}{l}\text { Shower and tub room for each } \\
\text { cottage }\end{array}$ \\
\hline Resident Laundry & $\begin{array}{l}\text { Large laundry facility downstairs } \\
\text { One washer/dryer at resident level }\end{array}$ & Shared laundry facility at each level \\
\hline
\end{tabular}

Table 3. (Cont.)

Environmental Features and Relationships 


\section{The Case Study}

This research was conducted as a qualitative comparative case study, using multiple sources in data collection to provide an in-depth picture of the daily life and social patterns in the two continuing care communities. Cresswell (1998) describes a case study as an exploration of a bounded system or a case over time, through detailed, in-depth experiential data collection involving multiple sources of information rich in context. The case study is an opportunity to understand how the people being studied see things and it evolves in time, often as string of concrete and interrelated events that occur at such a time, in such a place (Flyvbjerg, 2006). The two communities studied in this research, Ridgemont and Stonebridge (both pseudonyms, as are all other names of people and places in this study), are both owned by the Welsh Group, a family of companies with construction and building material arms located in the Halifax area. The two LTC communities are similar geographically; they are within 20 miles of one another and similar in size, as both have accommodations for about 50 residents. This study was conducted for approximately eight weeks, with time divided between the two communities, and therefore was to be bounded by time (two months) and place (two sites).

Case study research holds a long distinguished history across psychology, medicine, law, and political science (Cresswell, 1998). A case study can be a person, an event, or a program or organization. A statewide or national project may spin off an innovative local program that is of special interest to decision makers, thereby indicating the appropriateness of conducting a case study of that particular program (Patton, 1990), and it can be particularly helpful to decisionmakers to have detailed case description of how programs are operating. This may include description of program facilities, staff selection procedures, the nature of the services offered to residents, descriptions of actual service delivery activities and descriptions from clients about the 
nature and results of their experiences (Patton, 1990). As a province-wide project, the 2006 Continuing Care Strategy guidelines defined an innovative program that is of special interest to decision-makers in the LTC arena, both in the United States and Canada, thereby warranting the evaluation of staff, resident, and organizational outcomes.

Flyvbjerg (2006) defines case studies as information-oriented, as cases are selected on the basis of expectations about their informational content and particular cases are selected for study because they are of particular interest, given the study's purpose. Case studies are particularly valuable when the evaluation aims to capture individual differences or unique variations from one program setting to another (Patton, 1990). In the case of this research, the outcomes of provincial guidelines applied at Ridgemont and Stonebridge were studied, exposing the multiple realities of staff, residents, family members, facility operators, and provincial legislators, and sometimes contradictory views of what is happening in each of the communities. While the two communities were chosen for this study because they are similar both demographically and geographically, the physical environment and operations of each of the facilities are indicative of very different models of care and service delivery (Table 3).

\section{Data Collection}

In many qualitative studies, inquirers collect multiple forms of data and spend a considerable amount of time in the natural setting (Creswell, 2009). Data collection steps in qualitative case study research include setting the boundaries for the study, collecting information through unstructured or semi-structured observations and interviews, documents and visual materials, as well as establishing the protocol for recording the information (Patton, 1990). 
Yin (1994) recommends six types of information: documentation, archival records, interviews, direct observations, participant observation, and physical artifacts.

In this study, a total of eight weeks were spent in the two facilities, and the principle methods of data collection were participant observation, pre-arranged staff, family and/or resident interviews, as well as interviews with facility administrators and policy legislators. There was also a gathering of information from the legislative documents of the 2006 CCS and the archives at the Welsh Group.

The time in the two communities was equally divided during the two month period. The majority of weekdays were spent in both communities, as they were about a 20 minute drive from one another, although there were some occasions when an entire day was spent at one community. In addition, there were at least two weekend days and three evenings spent at both communities.

\section{Interviews}

Humans are meaning makers; meaning is identified through experience. Qualitative interviewing is one of the best ways of coming to understand meaning through examining experience (Rubenstein, 2002). Interviews are useful in gathering historical information from the participants, and allow the researcher control over the line of questioning (Creswell, 2009). In qualitative interviews, the researcher conducts face-to-face interviews with participants, interviews by telephone or focus group interviews.

In this particular study, face-to-face interviews were conducted in an open format. Interviewees were made aware through the staff that the study was taking place and care staff made a list of potential interviewees available based on their knowledge of their willingness and 
competencies. At Ridgemont, the total number of interviews conducted was $\mathrm{N}=19$, (seven staff, five family member and seven residents). At Stonebridge, the total number of interviews conducted was $\mathrm{N}=23$, (eleven staff, five family members and seven residents). Finally, there were pre-scheduled interviews with the facility operators $(\mathrm{N}=1)$, support $\operatorname{staff}(\mathrm{N}=2)$, architects

$(\mathrm{N}=1)$, and provincial legislators $(\mathrm{N}=2)$, which provided insight into the goals, implications, and roadblocks in bringing the 2006 CCS strategy to reality.

An interview protocol was used which included the following components: a heading defining the date, place, interviewer, and interviewee; the questions beginning with a general questions followed by subsequent questions that relate to the general case study questions; probing questions that asked individuals to explain their ideas in more detail or elaborate on that they have said. All interviews were pre-arranged with the interviewee and facility administrators and were audio-recorded, lasting for approximately 30-45 minutes.

\section{Observations}

Qualitative observations are those in which the researcher takes field notes on the behavior and activities of individuals at a particular research site. In these field notes, the researcher records in an unstructured or semi-structured way (Cresswell, 2009). An ongoing interpretive role of the researcher is prominent in qualitative case studies and observations work the researcher toward a greater understanding of the case (Stake, 1995). The goal of the observations in the two study facilities was to understand the physical and social interactions between residents, caregivers, and visitors. In the Ridgemont community, these interactions took place in the community areas such as the parlor and the dining rooms. In the Stonebridge community, these interactions took place in the four cottages and community center. Field notes 
were taken daily and included general impressions of observations and notation of the areas used by residents for public social activities. An observation protocol was used to record the information in this research, with sections available for recording descriptions of the physical setting, accounts of a particular event or activity, description of particular participants, and reconstruction of dialogue (Creswell, 2009). Based on Patton (1990), much of the observational data was represented within the following categories: (1) chronology, (2) key events, (3) various settings, (4) people, (5) processes, and (6) issues. These categories helped to create an initial framework for managing the data collected during the fieldwork.

\section{Document Review}

Many hours were spent going through the archived documents that are kept at the Welsh Group offices relating to the history of Ridgemont and Stonebridge. In addition, historical photographs of Nova Scotia and Halifax were obtained with permission from the library archives at the Dalhousie University. Other personal photos were provided by family members and residents at both Ridgemont and Stonebridge.

\section{Data Analysis}

Cresswell (1998) defines the case study in four sections: the problem, the context, the issues, and the lesson learned, which are derived through multiple sources of information. After the initial interviews were transcribed, the interviews, observational field notes from the facilities, and data collected from a document review were assessed, leading to a fracturing, or rearranging, of the data into categories which aided in the development of theoretical concepts. This coding or labeling was used to assign meaning to the data compiled (Miles \& Huaberman, 1994). A detailed description of the two cases, analysis of themes, and interpretations or 
assertions were then developed, and reoccurring themes were interconnected into story lines and developed into a theoretical model. Themes were analyzed for each of the two individual case studies as a within-case analysis, followed by a thematic analysis across the cases, which is called a cross-case analysis. Findings of this cross-case analysis were then assessed through a chronology of events, detailed discussion of several themes, and dissemination of interconnecting themes, which describe a province, provider, and culture of care in transition. Through this cross-case analysis, the importance of the history of Ridgemont became apparent, warranting discussion, because the Welsh Group learned from their experiences at Ridgemont over the past four decades, and those experiences have a hand in outcomes in both communities today.

\section{Validity/Ethical Issues}

In qualitative methods, validity hinges to a great extent on the skill, competence, and rigor of the person doing the fieldwork (Patton, 1990). Validity, therefore, depends heavily on the relationship of the researcher's conclusions to the real world, and there are no methods to assure that one has adequately grasped those aspects of the world being studied (Maxwell, 1996). Yin (1994) recommends that qualitative researchers document as many of the steps of these procedures in their case studies as possible, and Creswell (2009) suggests the use of multiple strategies to assess the accuracy of findings and highlights several primary strategies. The strategies used in this study were (1) spending a total of eight weeks in the field in order to develop an in-depth understanding of the phenomenon under study; (2) an understanding of personal bias brought to the study; (3) a triangulation of methods by comparing field notes, staff, family, and resident interviews, and data collected from existing legislative documentation. It 
was the goal of this multi-method approach to increase both the validity and the reliability of the evaluation of the data.

While it is important to point out that though case study research may allow more room for the researcher's subjective judgment than other methods, the advantages of this method are that case studies can "close in" on real-life situations. Flyvbjerg (2006) writes that the case study allows for a testing of views directly in relation to phenomena as they unfold in practice, therefore contains no greater bias toward verification of the researcher's preconceived notions than other methods of inquiry. On the contrary, Flyvbjerg argues that the case study contains a greater bias toward falsification of preconceived notions than toward verification

Although the similarities and differences in the two communities came through clearly in this case study, it is important to point out that this study was not meant to be a post occupancy evaluation of either community. While there may be validity issues with respect to a comparative study between two facilities which were built decades apart, because of the history that the provider had with provincial leaders at Ridgemont, the groundwork was laid for the decisions that were made by the same provider in the new community at Stonebridge. This correlation became very important in clarifying many of the study outcomes and will be a continuous thread through the ensuing discussions. 


\section{CHAPTER FOUR: LONG TERM CARE IN NOVA SCOTIA}

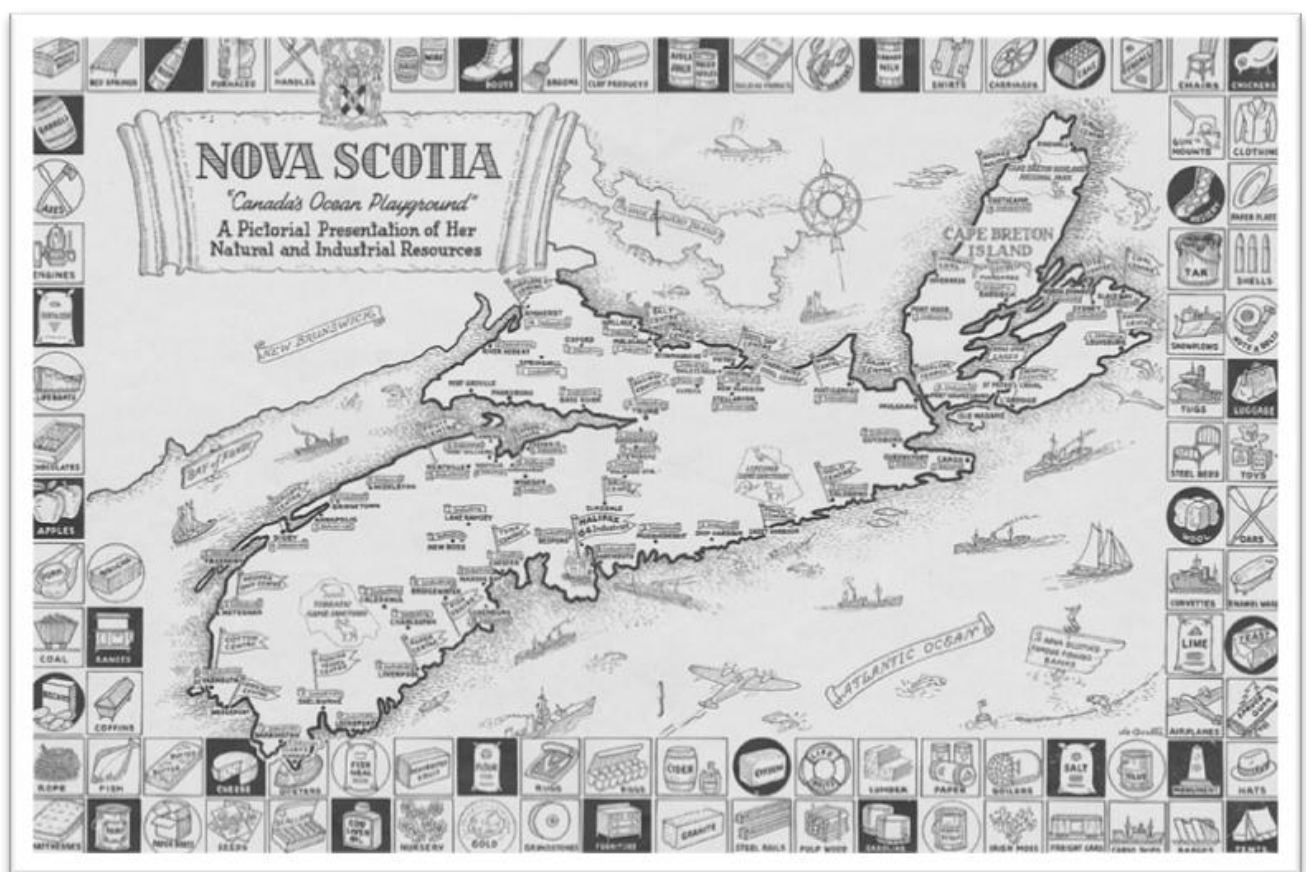

Figure 9 .

Nova Scotia-Canada's Ocean Playground

\section{A Brief History of Halifax, Nova Scotia}

There are nights in the full moon of October when darkness is a kind of silver daylight, when the sea is a sheet of twinkling lights, the shadows of barn and fence and apple tree black and incredible, the air vibrant and alive but still as a dreamless sleep. (Bruce, 1988, p. 3)

The total area of Nova Scotia is 21,300 sq. miles, and in 2011 , the population was 921,727. Originally settled by $18^{\text {th }}$ Century Europeans looking for a better life, the population of Nova Scotia has remained small and there has been a steady exodus from this province which dates back to the mid- $19^{\text {th }}$ century. In order to place in context the discussion about health and aging in a province with roughly the geographical size of the state of West Virginia and the population of the state of Montana, it is important to look at who these people are in this easterly province in Canada (Figure 9). This background history is an important element in this 


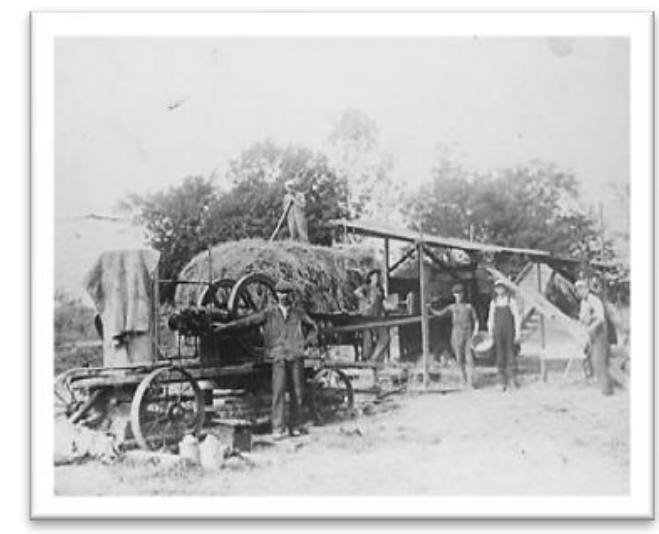

Figure 10. Nova Scotia Farmers c. 1900

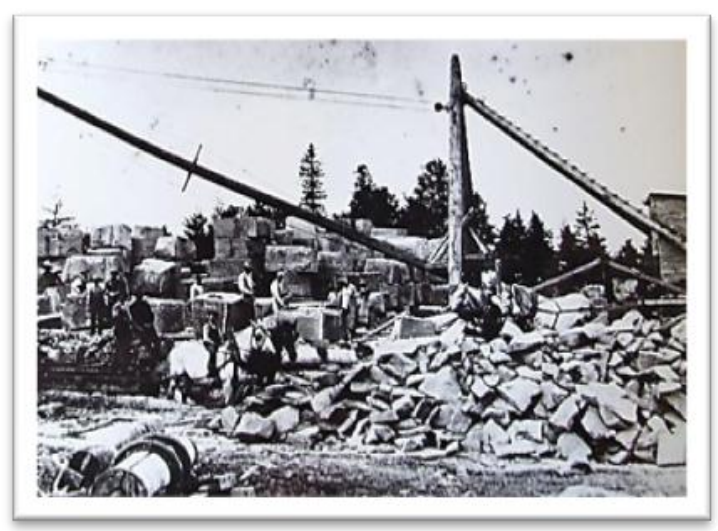

Figure 11. Nova Scotia Rock Quarry c. 1900

dissertation because it sets the stage for the economic factors which have shaped the finacnial needs of the population and their dependance on the govenrment for social progams. Originally from Scotland, Ireland, England, and France, the settlers had moved onto this peninsula in order to escape religious persecution, drought, and hunger. Ensuing generations found that it was, in fact, as difficult and, in some cases, more difficult, to live on this land, and many returned to their homelands. In his book, Down Home: Notes of a Maritime Son, Harry Bruce writes extensively about the history of the struggles of the Nova Scotians:

The exodus began right after the plotters of Confederation had seduced the Maritimers. By 1870, more than 6,200 Nova Scotians had already settled in Boston alone, where they routinely greeted fresh loads of hopeful Maritimers who came by schooled steamships directly from Halifax, Yarmouth, and St. John. In the next thirty years, a quarter-million Maritimers, $40 \%$ of all those in the region in 1870, moved away, mostly to the United States; and in the half-century between 1881-1931, more than 600,000 people left the region. By the 1960s, hundreds of thousands of Maritimers were living in central and Western Canada, and the human tide from Down Home to the United States still flowed strong. The result of the exodus and the feebleness of the immigration flow, was that in the first eight decades of this century, the population of those who stayed Down Home did little better than double (from 894,000 in 1901 to 1,666,000 in 1981), while the population in Canada as a whole almost quintupled.

The families that remained in the province were hearty and dedicated to making their work despite difficult living conditions (Figures 10-11). Bruce (1988) continues: 


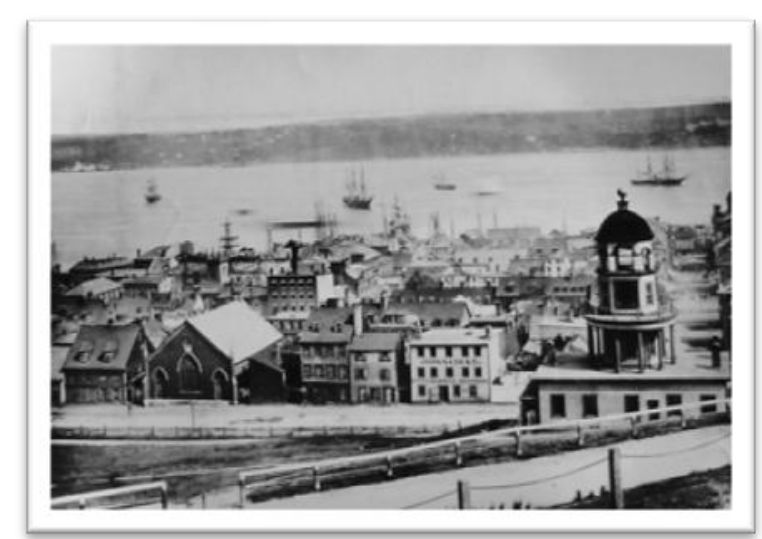

Figure 12. Halifax Harbor c. 1900

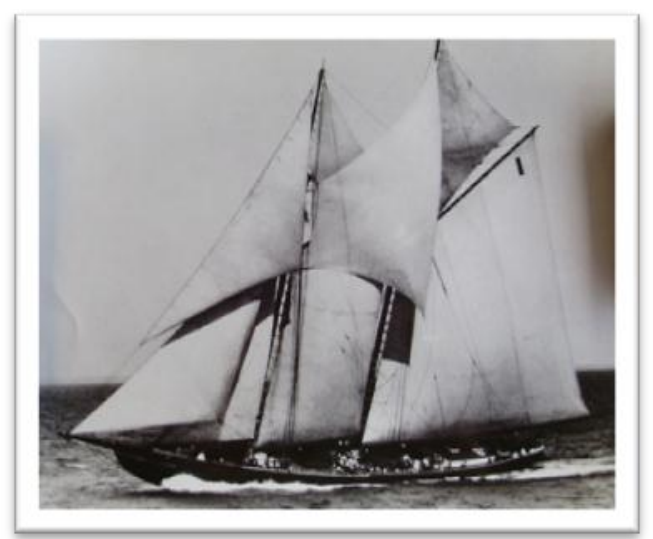

Figure 13. The Bluenose Schooner c. 1920

Maritimers as a whole, have no common history to call their own. Geography and the sea isolate communities from one another. Your friends were the folks who lived along your own road, helped you haul your nets, and pitched in at haying time. Subsistence farming and fishing were hard ways to fend off starvation and they nurtured attitudes of fierce independence, rather than the promotion of anything so distant and abstract as regional identity. At the heart of the Maritime character lie loyalty and defensiveness about exactly where you come from. This story is about those who refuse to leave Down Home, about those who stuck like rockweed to the seaside provinces, that, too often, richer and more politically powerful in landers have dismissed as the shag end of Canada. Most families on the bay shore were hard up and they endured cradle to grave frugality. By subsistence farming, a spot of fishing, cutting their own firewood, and doing their own carpentry and some of their own blacksmithing, by spinning their own yarn and helping one another out, they managed to scratch out a living. In spite of all this, my Aunt Zoe wrote in her 90th year, "Of course, we didn't know that we were underprivileged."

Located at an easterly midpoint of Nova Scotia, the Halifax Harbor is the second largest natural harbor in the world (Figure 12-13), and at the beginning of the $20^{\text {th }}$ century, became a principle world port, playing a critical role in the European war efforts in WWI and WWII. Erickson (2004) writes of the impact of the heavy use of the harbor at the turn of the $20^{\text {th }}$ century and the devastation from one of the world's worst shipping disasters in 1917 (Figure 14-15). Ironically, 150 Titanic victims had been brought back to Halifax for burial just five years earlier: 


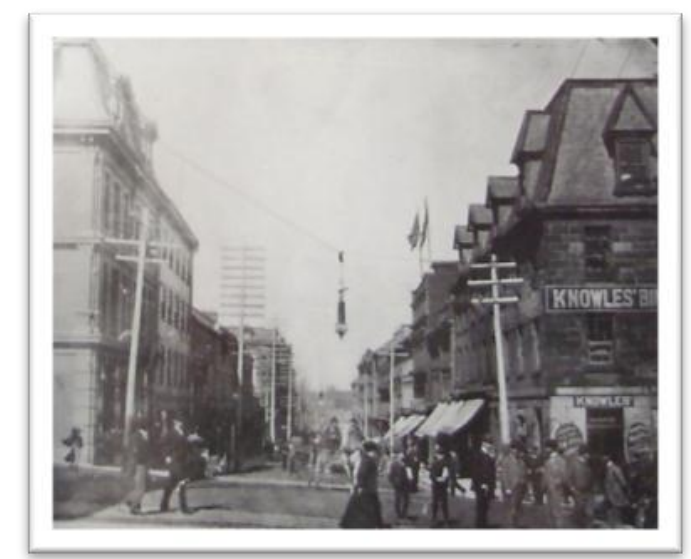

Figure 14. Downtown Halifax c.1917

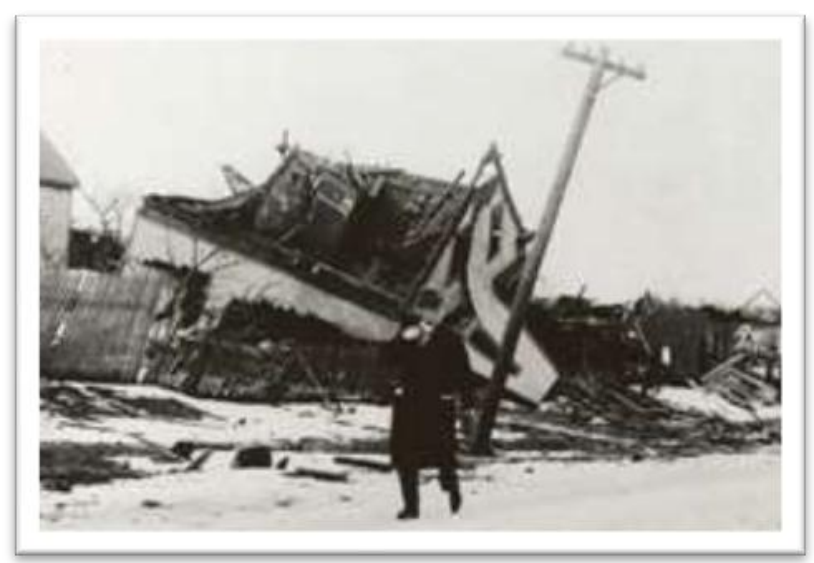

Figure 15. Destruction from Halifax Explosion c. 1917

Throughout the $19^{\text {th }}$ century, the British Navy used the Halifax Harbor, and in 1910, Canada created its own navy using the harbor as its main port. During WWI, the city of Halifax became one of the busiest ports in the world, handling 15 million tons of cargo. Due to the heightened traffic in the harbor, on December 6, 1917, a collision occurred between the French freighter Mont Blanc and the Norwegian ship Imo in the Halifax Harbor. This explosion caused an enormous amount of destruction because Mont Blanc was carrying a cargo of 35 tons of flammable materials and 200 tons of TNT. One summary of the destruction from the Halifax Explosion is 2,000 deaths, 1,600 destroyed buildings, 12,000 damaged buildings, 6,000 homeless people, 25,000 people with damaged homes, and \$35 million worth of property damage. Until the Trinity test explosions of the atomic bombs, the Halifax Explosion was the largest man-made explosion in recorded history.

Halifax spent several years re-building from the damage of the 1917 explosion. At the same time, the Canadian Navy was growing, as was the ship building industry. During WW II, the principle job of the Canadian navy, which is based in Halifax, was to patrol the North Atlantic and make it safe for convoys carrying supplies and troops to and from Europe (Figure 16-17). Erickson (2004) writes about the impact of WW II on the Haligonians:

During the Second World War, 368,000 Canadian army men and women crossed the North Atlantic on a hundred different ships, and almost all of these ships left Canada from Halifax. At the time, the dockyard at Halifax was to become home to the third-largest naval fleet in the world. The Halifax Shipyards built ships for Canada and repaired ships from around the world, many of them crippled by German torpedoes. During war time, exempt from the ban on bright nighttime 


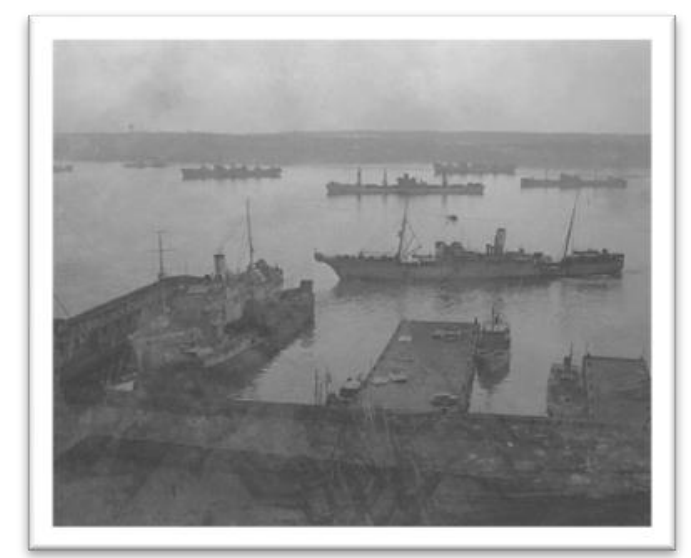

Figure 16. Halifax Harbor c. 1944

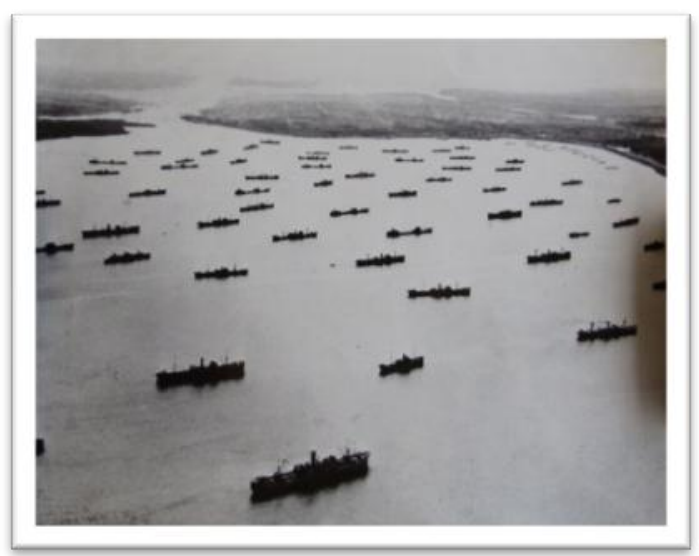

Figure 17. Bedford Basin at Wartime

lights, the shipyards shone eerily far out to sea, seen by lurking German submarines, from which Haligonians contemplated imminent attack. The wartime stresses and strains on Halifax exceeded those of any other city in North America and the population of the peninsula more than doubled in places. While Halifax never saw battle, the threat of attack from sea and air was omnipresent. The harbor was protected by submarine booms, and in order to supply departing ships with water, the supply to homes was often cut off. Throughout the war, the extent of the threats and deprivations remained unknown to most Canadians, who, with censorship and secrecy, received news about Halifax only as the anonymous "An East Coast Port."

The impact of Naval and post-war ship building in the Halifax Harbor has

continued to be an important element of the Nova Scotian economy, as well as logging, fishing, and the oil business, yet the per capita income in the province remains low. Nova Scotians are hardworking, determined people, but require and depend on government assistance in a number of areas, and one of the primary areas of need is healthcare.

\section{Long Term Care in Nova Scotia}

As with the other Canadian provinces, the health care in Nova Scotia is funded by the federal health care system, a predominantly publicly-financed, privately-delivered system, based on an interlocking set of provincial and territorial health insurance plans. Known to Canadians 


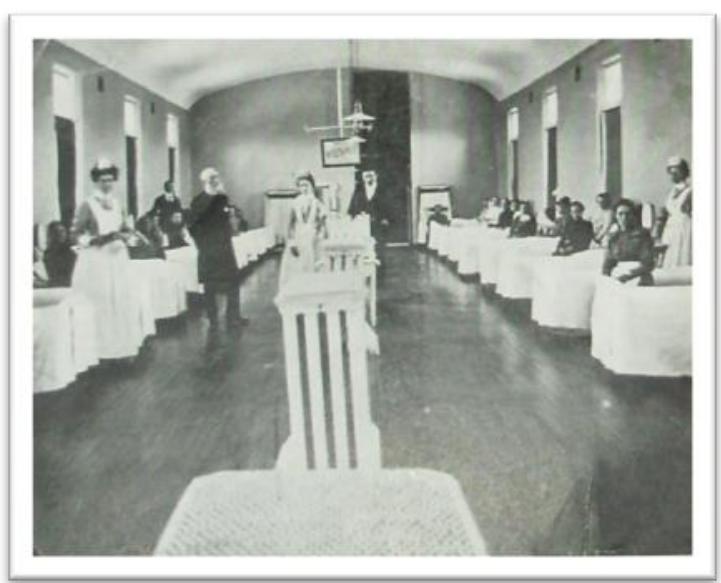

Figure 18. Victoria General Ward c. 1910

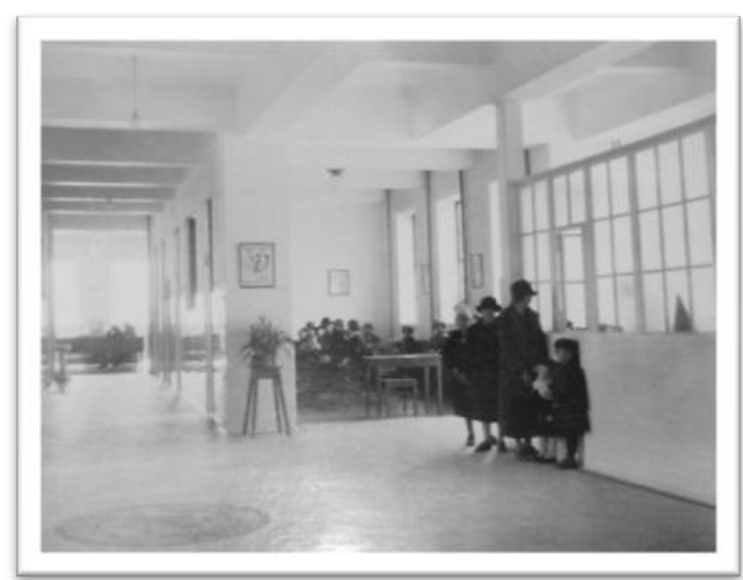

Figure 19. Victoria General Waiting Room c. 1930

as "Medicare", the system provides access to universal, comprehensive coverage for medically necessary hospital, in-patient, and out-patient physician services. The system is referred to as a "national" health insurance system, in that all principal/territorial hospital and medical insurance plans are linked through adherence to national principles set at a federal level, and the management and delivery of health services is the responsibility of each province or territory (Banjerjee, 2002). The original two insurance acts, the Hospital Insurance and Diagnostic services Act (1957) and the Medical Care Act (1966) had the objectives of ensuring that every Canadian had access to all medically necessary services regardless of ability to pay, and to ensure that Canadians would not suffer financial hardship from having to pay medical bills (Kirby, 2002).

The Canada Health Act (1984) stipulates the criteria that principle health insurance plans must meet in order to qualify for full federal transfer payments. The following five criteria are known as the "principles" of Canada's national health care system: public administration, comprehensiveness, universality, accessibility, and probability (Banjerjee, 2002). The framework has, at its core, a shared vision statement and a set of principles that seniors and governments 


\begin{tabular}{|c|c|c|c|c|}
\hline & Age group & 2002 & 2026 & $\%$ growth \\
\hline \multirow[t]{5}{*}{ Male } & $65-69$ years & 17.5 & 35.4 & $102 \%$ \\
\hline & $70-74$ years & 14.2 & 29 & $104 \%$ \\
\hline & $75-79$ years & 10.3 & 22.1 & $115 \%$ \\
\hline & $80-84$ years & 7 & 12.3 & $76 \%$ \\
\hline & $85-89$ years & 3.2 & 5.7 & $78 \%$ \\
\hline \multirow[t]{2}{*}{ 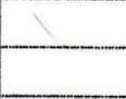 } & 90 years and over & 1.2 & 2.7 & $125 \%$ \\
\hline & Total Male & 53.4 & 107.2 & $101 \%$ \\
\hline \multirow[t]{8}{*}{ Female } & $65-69$ years & 18.5 & 38 & $105 \%$ \\
\hline & $70-74$ years & 17 & 32.5 & $91 \%$ \\
\hline & $75-79$ years & 14.8 & 26.5 & $79 \%$ \\
\hline & $80-84$ years & 12.1 & 16.9 & $40 \%$ \\
\hline & $85-89$ years & 7.5 & 9.9 & $32 \%$ \\
\hline & 90 years and over & 4.3 & 8 & $86 \%$ \\
\hline & Total Female & 74.2 & 131.8 & $78 \%$ \\
\hline & Grand total & 127.6 & 239 & $87 \%$ \\
\hline
\end{tabular}

Table 4. Demographic Projection Nova Scotia 2002 to 2026

across Canada endorse. This vision states that Canada, a society for all ages, promotes the wellbeing of seniors, recognizes their valuable contributions, and reflects the goals of elimination of ageism in all sectors (DAS, 2002).

The Need for Care

In 2001-2002, the federal government spent over \$27 billion dollars on issues related to seniors and transferred an estimated $\$ 34.6$ billion to the provinces under the Canada Health and Social Transfer (CHST). This is a block fund dedicated to providing financial assistance to provinces to use at their discretion for health care (including health care for seniors), postsecondary education, and social programs (DAS, 2002). The fastest growth in the seniors' population is occurring among the oldest Canadians. In 2001, over 430,000 Canadians were 85 years of age or older, twice as many times as in 1921, and the proportion of Canadians aged 85 


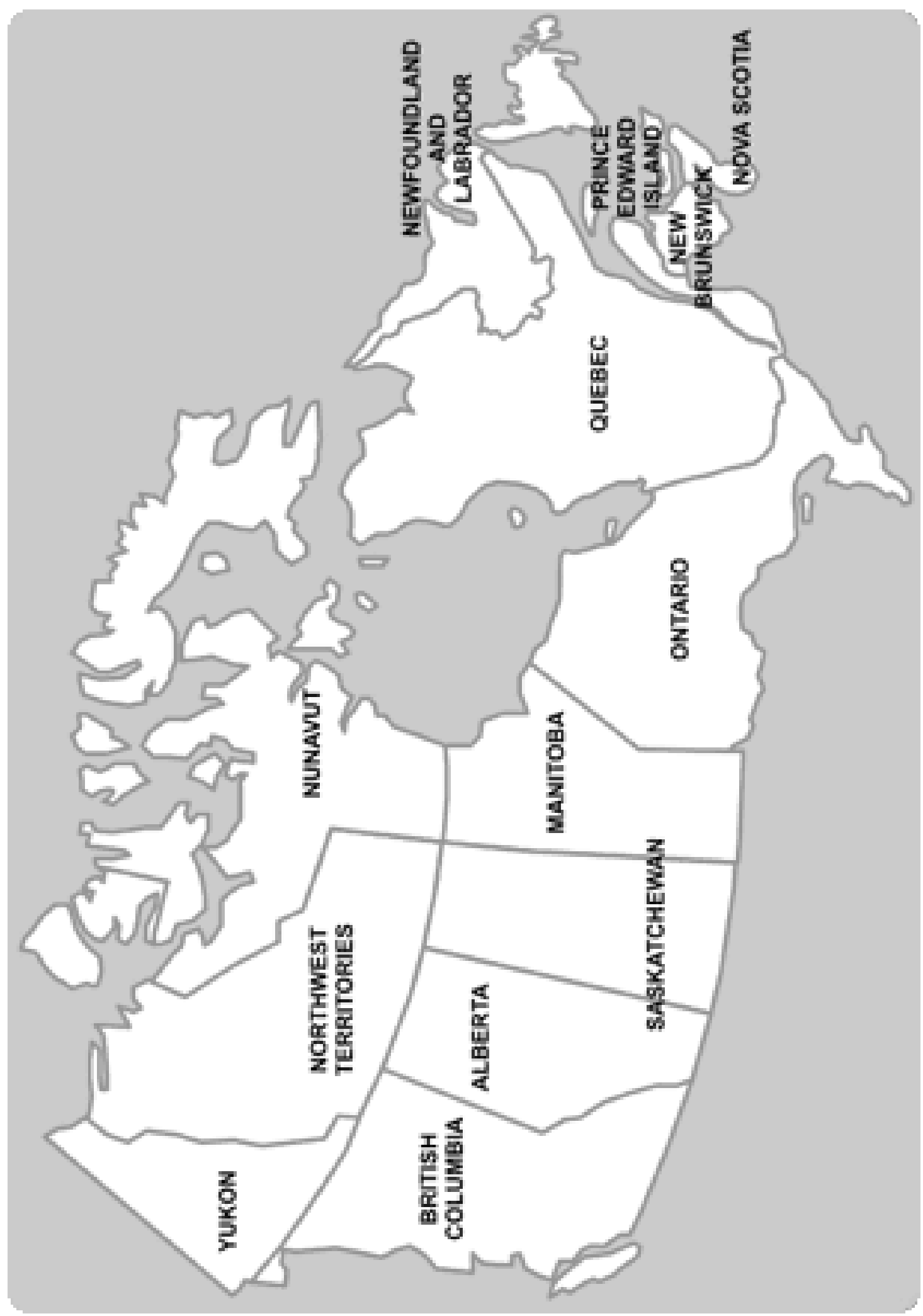

Figure 20.

The Canadian Provinces 
or more is expected to grow to 1.6 million in $2041-4 \%$ of the overall population (Banjerjee, 2002).

In the Province of Nova Scotia, the proportion of the region's senior population is higher and growing faster than in other provinces (Table 4). With the expectation of Newfoundland at 14.4\%, the Atlantic Provinces have the highest percentages of seniors in the country. In addition, while the total population of Nova Scotia is expected to decline by approximately four and a half percent between 2007 and 2033, the senior population (65+) is projected to increase $86.3 \%$ between 2007 and 2033 (Shiner, et al. 2010).

By 2021, the life expectancy in the Province of Nova Scotia is projected to increase to 78.2 for men and 83.9 for women, and the percentage of seniors in Nova Scotia is to rise to over $21 \%$ of the population. Shiner et al. (2010) explain that despite increasing life expectancies, there are currently province-wide health issues which need to be addressed in Nova Scotia, which include:

- An increasing number of people with cognitive impairment and dementias

- The lowest disability-free life expectancy in the country

- The highest death rates in Canada from cancer and respiratory disease

- The highest rates of arthritis and rheumatism in Canada

- The second highest rate of diabetes in Canada

\section{A System in Place}

In the 90s it was homecare, homecare, homecare. Everybody is going to be cared for in their homes, we hadn't opened up a new nursing home in decades. ( Noreen-Activity Director at Stonebridge)

In the mid-1990's, there was a high demand for acute care in the province, however a large number of hospitals were shut down as a result of the formation of District Health Authorities, and between 1991/92 and 1999/00 the number of hospital beds in Nova Scotia 
declined by $37 \%$, from 5149 to 3135 . Wyatt, the C.O.O. of the Welsh Group remembers the changeover in the hospital sector:

Back then, we had individual CEOs in all the hospitals because they were regionalized 20-30 years ago into health regions. We went through that in the early and mid-90s here, and I remember the day they let go 13 CEOs of all the hospitals to create these health boards, four health boards at that time. That was pretty bad, but now you don't have hospitals competing for the same services. It's now all one region and one payer, so they can say this community or that community needs more funding and they can move the money around.

In 1995, in conjunction with the implementation of the District Health Authorities, there was a transfer of operational responsibility for nursing homes and LTC to the newly appointed district health authorities, and legislative responsibility went to the Department of Health (Figure 21-22). The nine district health authorities deliver health care services to residents and are responsible for all hospitals, community health services, mental health services, and public health programs in their districts (DHA, 2007).

\section{Changes in Funding Structures}

Currently, there are three types of long-term continuing care homes in Nova Scotia operating under the jurisdiction of the DoH. These include nursing homes $(\mathrm{NH})$, residential care facilities (RCF), and community-based options (CBO) (DOH, 2007). CBOS and RCFs are intended for residents with similar health capacities (DOH, 2007) and a typical RCF or CBO resident is someone who has care needs that cannot be safely provided at home. While they generally have decreased physical and/or mental abilities, they are mobile (with or without the assistance of canes, wheelchairs, walkers), do not require the supervision of an onsite $\mathrm{RN}$, and do not require more than 1.5 hours a day of supervision or personal care. 


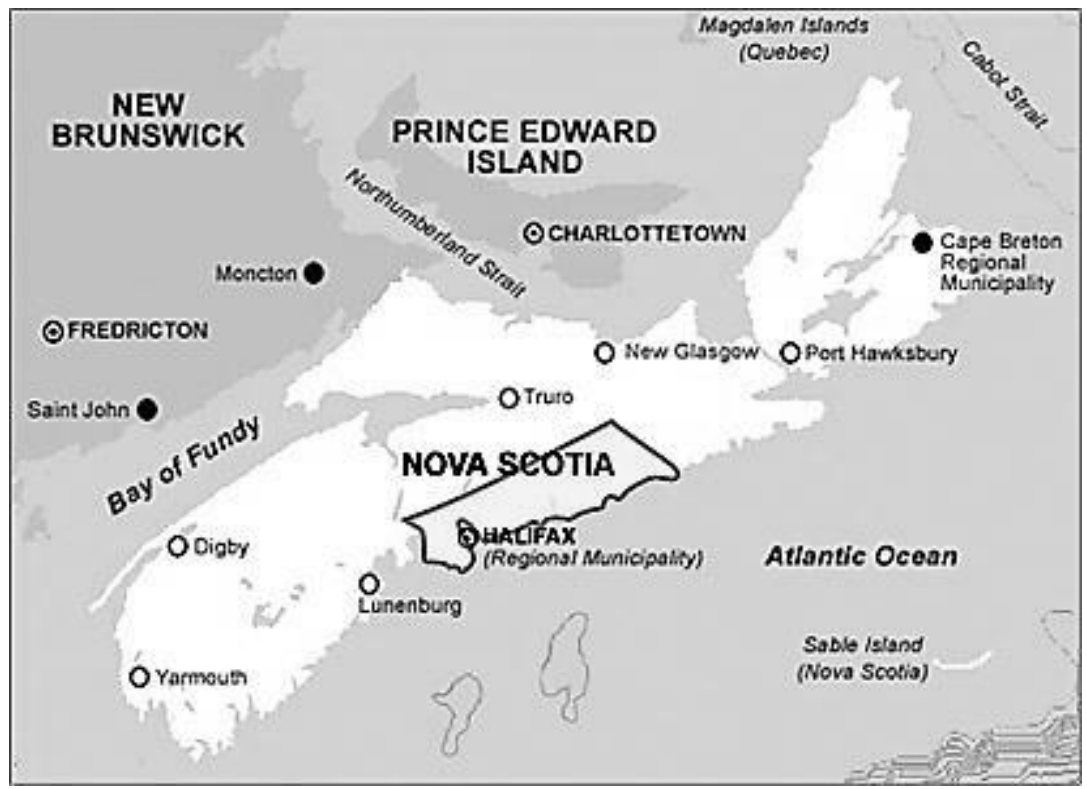

Figure 21. Canadian Atlantic Provinces

Source: DHA gov.ns.ca

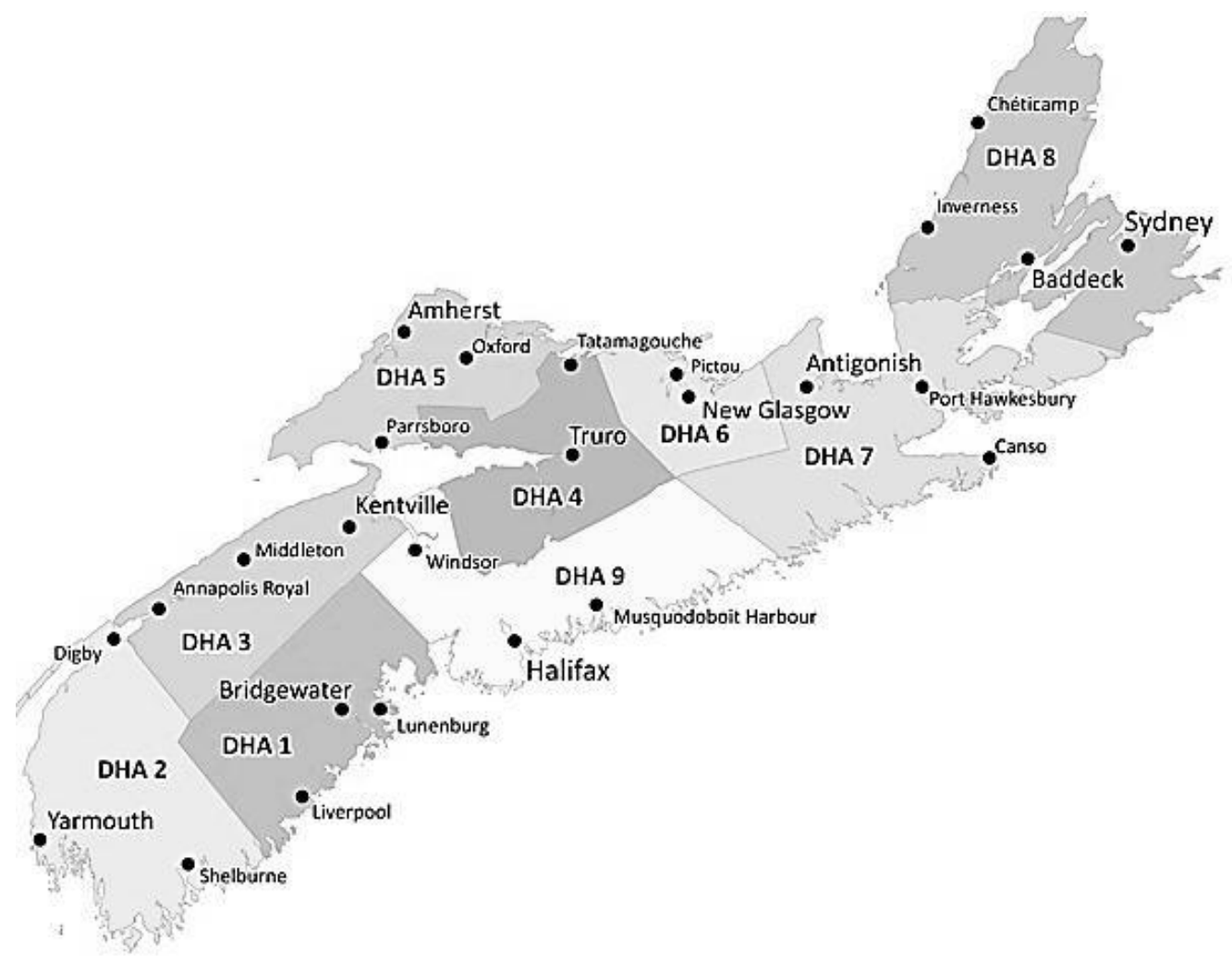

Figure 22.

Nova Scotia District Health Authorities 
The hospital sector has depended heavily on strong linkages with primary care providers, the LTC and NH sectors (NSDH, 2000), because the single largest barrier to timely and appropriate discharge for hospitalized elderly from acute care has been access to LTC beds. Hospital beds had become a very expensive resource due to the restructuring in the 1990s, and health care administers, planners, and professionals have had to make sure that the hospital beds are used as efficiently as possible. In 2000, the occupancy rates in nursing homes in Nova Scotia were consistently high; there is a strong demand for beds, and resident care needs had been stretched the capacity of the LTC sector. This had the combined effect of contributing to a "gridlock" in both the acute and LTC sectors of care (NSDH, 2000 ). Wyatt remembers the gridlock in the system in the early 2000s:

What we had really wasn't that good, because what happened is, if you had money or were private pay, you got into a home. And the homes were actually able to charge more than the standard rate, and chances are that resident didn't even need that level of care. Each home had their own waiting list. They could charge more and then people with money went in over the ones who really needed it. So, what that did, was people went in to these facilities that didn't even need to be there, even though there were other options available. This created a false demand for beds and so by keeping out those who were not private pay, $\mathrm{DoH}$ didn't have to build new beds for years, they instead put money into homecare.

Ultimately, changes began to take place in the way that LTC residents paid for the care. Previously, nursing home care was a government subsided and means tested program, based on income and assets and tax returns examined three years back for evidence of divestment (Stadnyk, 20010). LTC residents were responsible for payment of both health care and accommodation costs, but there was a sliding scale fee schedule. Under the Cost of Care Initiative, launched in January 1, 2005, residents of NHs, RCFs, and CBOs under the DoH mandate are no longer required to pay for their health-care costs. In addition, resident payment for accommodation costs are no longer assessed based on assets, only on their current incomes. 
As a result of the Cost of Care Initiative, the provincial government now covers all health care costs for each resident in LTC. These costs may be related to the salaries, benefits, and operations costs of nursing and personal care, social work services, recreation therapy and physical, occupational, and other therapies. Residents are expected to pay the accommodation charges, which include salaries, benefits, and operation costs of maintenance, dietary services, housekeeping, management and administration departments, capital, and return on investment. Accommodation costs, which came into effect November 1, 2007, are $\$ 79$ day for NHs, $\$ 50.50$ for RCFs, and $\$ 46.50$ for CBOs. Reduced accommodation charges are available, though a yearly needs assessment is required. Personal expenses must be paid by resident (e.g. clothing, eyeglasses, hearing aids, dental services, pharmacy co-pay, and transportation) (DoH, 2007).

\section{Changes in Assessment Procedures}

In addition to changes in funding structures, admission to all three types of LTC in Nova Scotia is now centralized through the Single Entry Access System of the Continuing Care Branch. The DoH is now in charge of assessing the level of care required and determining the most appropriate type of institution for each individual in need. Wyatt discusses the transitions from the old system of entrance into nursing homes in the region:

Now, there were a few homes where over half the people there were private pay, because of the communities that they were in, they wanted to be in there, they were more affluent communities. They were really hard hit because all of a sudden they found out you couldn't pick and choose. For our staff, it wasn't that much of a change, but the other homes went through a shocker. So the single entry has really worked, because now there's one gatekeeper, the DoH prioritized the whole system and there's no messing with it. Before that, it was the board chairs or whoever would make their calls to get someone in, now, you can call the premier and he'll say, "I'm not involved." You can call the director, I know people who have done this because they were desperate, and they were told, "We're not involved, get in line." It's a much fairer system, more objective, you know. Here you get to live in a nice place whether you have money or not, it's 
completely irrelevant how much money you have. Previously you had to go to all these homes, now you call a 1-800 number and your problems are solved; DoH comes in and does the assessments, your financial assessment and your care assessment. With continuing care, they also look after home care and nursing care, so it's all figured out for you.

It is important to point out that health costs will only be covered for residents who enter LTC through the provincial single entry access system, but there also continues to be private pay opportunities in the province. But as Wyatt explains it, why pay a lot of money when you can get into a nice nursing home now for a fraction of the cost? He describes why he feels that the new system is working for everyone involved:

You can't get into a nursing home unless you are assessed. You can go to private assisted living and pay for private services. But for the cost of that with unionized nursing, you need nursing care when you are in an assisted living, you are going to pay a lot of money. The only problem is, to get in to the nice new ones, you may have to do some time in the not too nice ones. You have to break your way through the system. A long time ago, if you got into a home you didn't like, as long as you are out of their area, you were forgotten. Now if you are in the system, and you want to get moved to your favorite choice, they will honor that. You don't have to call them, they will call you when that's available. The system really works. It used to be years ago, out of sight out of mind, unless you were going to make calls every day, you were left. So it really does work, the system is working, it's pretty awesome, really.

\section{Waiting in Acute Care}

One of the principle elements of the single entry access system is that when there has been a determination of need for care, the individual moves into the first available $\mathrm{NH}$ bed in order to receive care until a bed becomes available in the community of choice. As we will see in future chapters, the process may in itself lead to stress for the family members and the resident may decompensate at an accelerated rate as they wait for that desired location. They have three chances to bypass the move to wait for their preference, but if at the end of that time they have not moved, they go back to the bottom of the list. That's when the move is from home, but due 
to back-ups in the hospitals, someone waiting in the hospital will need to take the first available

bed offered to them. A DoH administrator explains the assessment system in a little more detail:

But if I'm in the community, and I can't wait for support any longer, there can be a variance to get them in faster, critical situations, like my caregiver died, or I've had a stroke. Then I get bumped up, something like adult protection. Adult protection has top priority over everybody. Because of back-ups in the hospital, individuals moving to LTC from the hospital need to take the first available bed, most of the time we do not give priority to the hospitals, although there is an ability to do a variance because the hospitals are so backed up. We try not to, although at first the districts thought that that was the way to go, to give hospitals first choice, they quickly realized that that fills the beds with somebody who needs more care. So more work, more cost, they were coming in through emergency.

She also discusses the assessment system for someone who is in a private pay facility and wants to move into a new facility. The focus in that case continues to be on the necessity for care:

They go onto the same list, in fact, where you were living before doesn't really matter. Our concern is that you need to get the care that you need, but you don't need to be in the hospital anymore, as long as you are going to be placed somewhere where you will be cared for.

While the current cohesive system in place appears to be a benefit for families and residents needing LTC services, in the following chapter we will look back at some past lessons learned from a time when LTC providers in Nova Scotia were working under multiple umbrellas of provincial funding. 


\section{CHAPTER FIVE: RIDGEMONT CONTINUING CARE COMMUNITY}

Often when a resident says "I want to go home" they are not necessarily referring to the house they came from, but rather to a state of being that was comfortable, ordered, and fundamentally orienting. They want to return to a place that makes sense, where they can feel comfortable and not threatened by a myriad of things they cannot understand. (Calkins \& Marsden, 2000 pg. 9)

\section{The Welsh Group}

The Welsh Group of Companies has been involved in nursing care since the 1960's, when they purchased the site and buildings of the Ridgemont Continuing Care Community from the Canadian Government. Ridgemont is located outside of Halifax, Nova Scotia, and is the home of a former military base which was built in the 1950's. During the decade of the 1940's up until the mid-1950's, when Halifax was a center of war and post-war activities, the land in Woodside surrounding the Ridgemont site was a radar base, originally financed by the United States Air Force. The location of the site is far removed from urban life of Halifax, and sits on a ridge of hills which are high enough that they have their own weather patterns.

For the past four decades, the Welsh Group has been a part of a larger firm with interests in construction and building materials. The Welsh Group purchased the Ridgemont property in 1965 with onsite buildings which included a care facility for both the elderly and the physically and mentally handicapped, as well as 129 affordable rental homes (relics of WW2 barrack housing), a school, fire hall, church, store, gymnasium, and other support buildings. Up until 2001, the community was operated as a 45 bed licensed nursing home for the frail elderly and a 165 bed licensed Adult Residential Care (ARC) facility for adults with mental handicaps and disabilities (Figure 23). An office administrator remembers the size and complexity of the community: 
Back then we had the Manor and Vista wings of the ARC, as well as the nursing home, which meant about 200 residents total that were here. There was a lot more work back then and a lot more staff, there were 11 of us in the office back then, including the administrator. We had our own educator, our own social worker, our own director of care, director of support services, dietary staff; there was a financial person in the office, a full time scheduler. Then there would be the director of finance that would be watching over us and scheduling payroll.

Wyatt also discusses the scope of the larger community when he began working there as the director of maintenance in the 1970's (Figures 24-27):

Back then we had 15 people in maintenance, because we had 120 houses on the hill. We had a school, and we had a church, there was a big fire hall, a restaurant, a store, and big gymnasium. We actually donated the use of the gymnasium to the Woodside community for over 40 years.

The culture of the community is based on generations of workers who grew up with either a parent or a spouse working at Ridgemont. While the current administrator, Anna, was not working there at that time, she understands that the history of Ridgemont is built on the bonds created by the culture of the community:

I think a lot of staff grew up here; it's a multi-generational work force. There are daughters who are working with parents, spouses working with spouses. Some are married to somebody else's brother. They have a sense of ownership of the building, they had the houses behind us, this is part of their culture, they define themselves by this place, a lot of them. They got their education here, they might have met somebody here, you know what I mean? This nursing home doesn't have a large population to choose its staff from, so a lot of them know each other, unlike staff in one of the city nursing homes who might not know each other.

\section{A History of Care}

Wyatt has been the C.O.O. of the Welsh Group since 1997; prior to that, he was an administrator at Ridgemont for seven years, though he originally began there as the Director of Maintenance. When Wyatt began his work in maintenance in 1977 , he remembers that there 


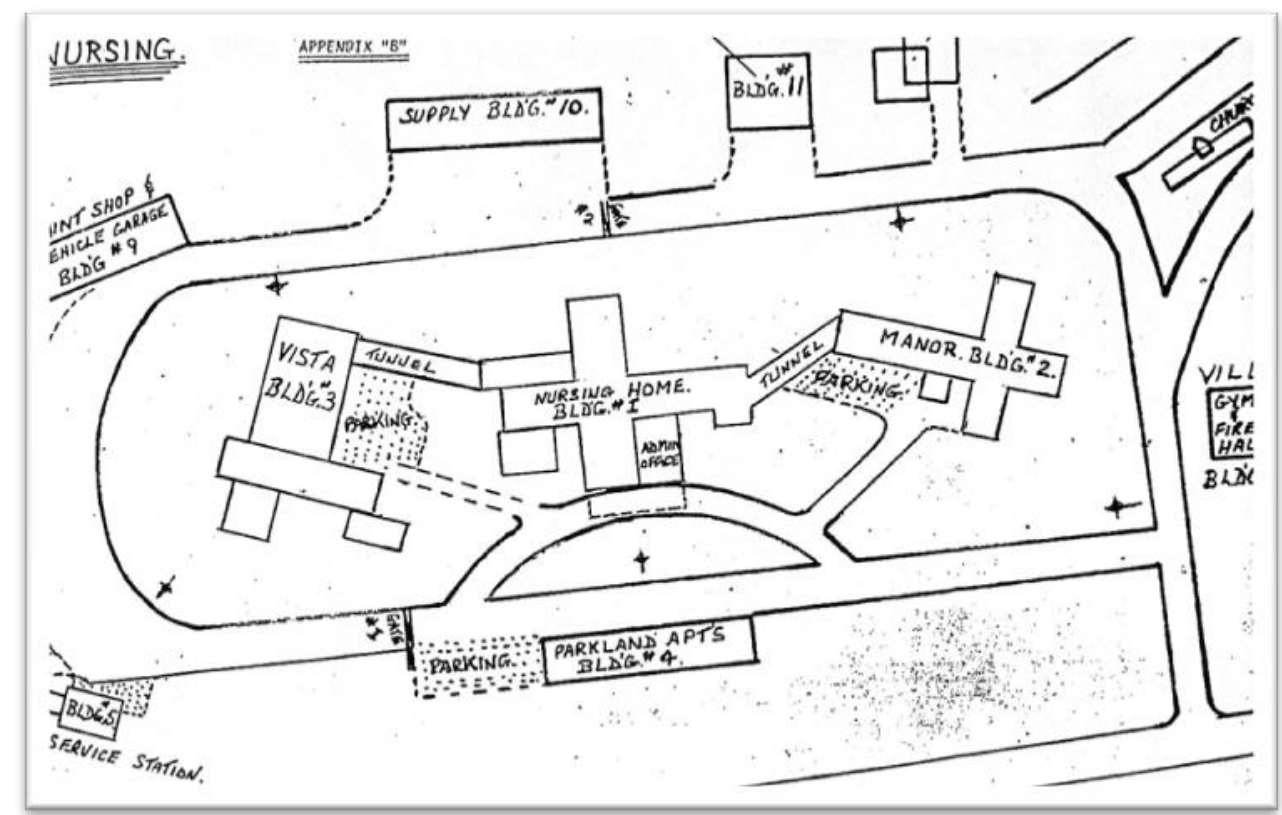

Figure 23.

Ridgemont Site Plan

were some independent residents who were able to drive and the population was

comprised of more than just the elderly. He learned quickly that working at Ridgemont

had its ups and downs, partially due to the dual provincial funding structure of the community:

When I started there in 77 , it was old, really old. We were the only facility at that time that was dually funded. The Department of Health funded the nursing home, Community Health Services funded the ARC. After I'd been there about eight or nine months, the administrator left because he was having an affair with the director of care. That was a bad time, there were many bad times in Ridgemont history. The director of nursing was hoping to get the administrator's job, but that didn't happen, so she left shortly after that. That's how I ended up with that job. We've had history, where way back in the 70s one of the directors of care actually married one of our residents. That was good for a scandal. We have a lot of history at Ridgemont.

Because the buildings were originally built as army barracks, Maureen, a nurse who has worked at Ridgemont for over 30 years, remembers the demands of the job at the time, and that staff were often judged by the outward appearance of the buildings rather than the quality of care that was given to residents: 


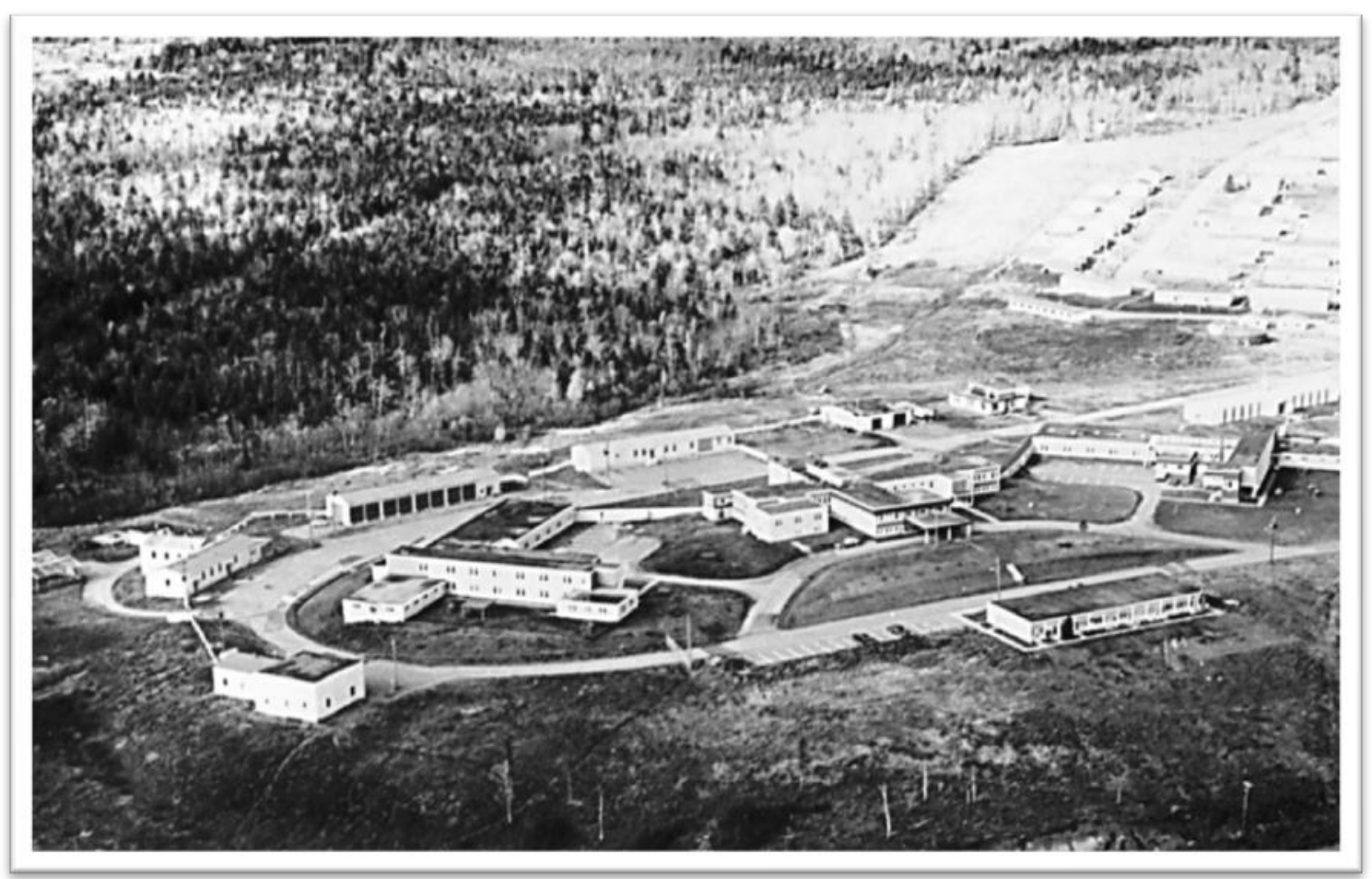

Figure 24.

Ridgemont Continuing Care Aerial View c. 1965

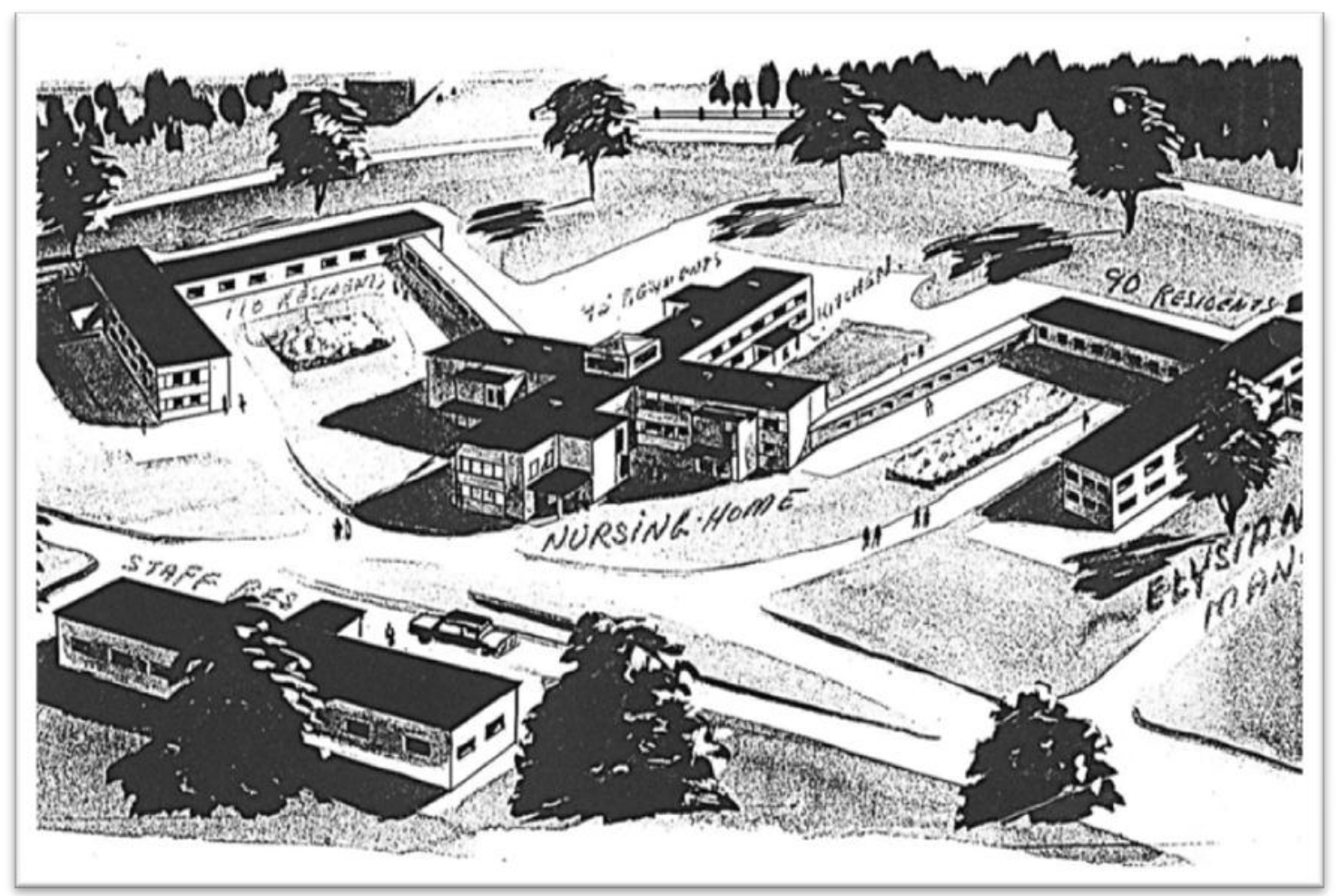

Figure 25.

Ridgemont Continuing Care Site Rendering c. 1970 


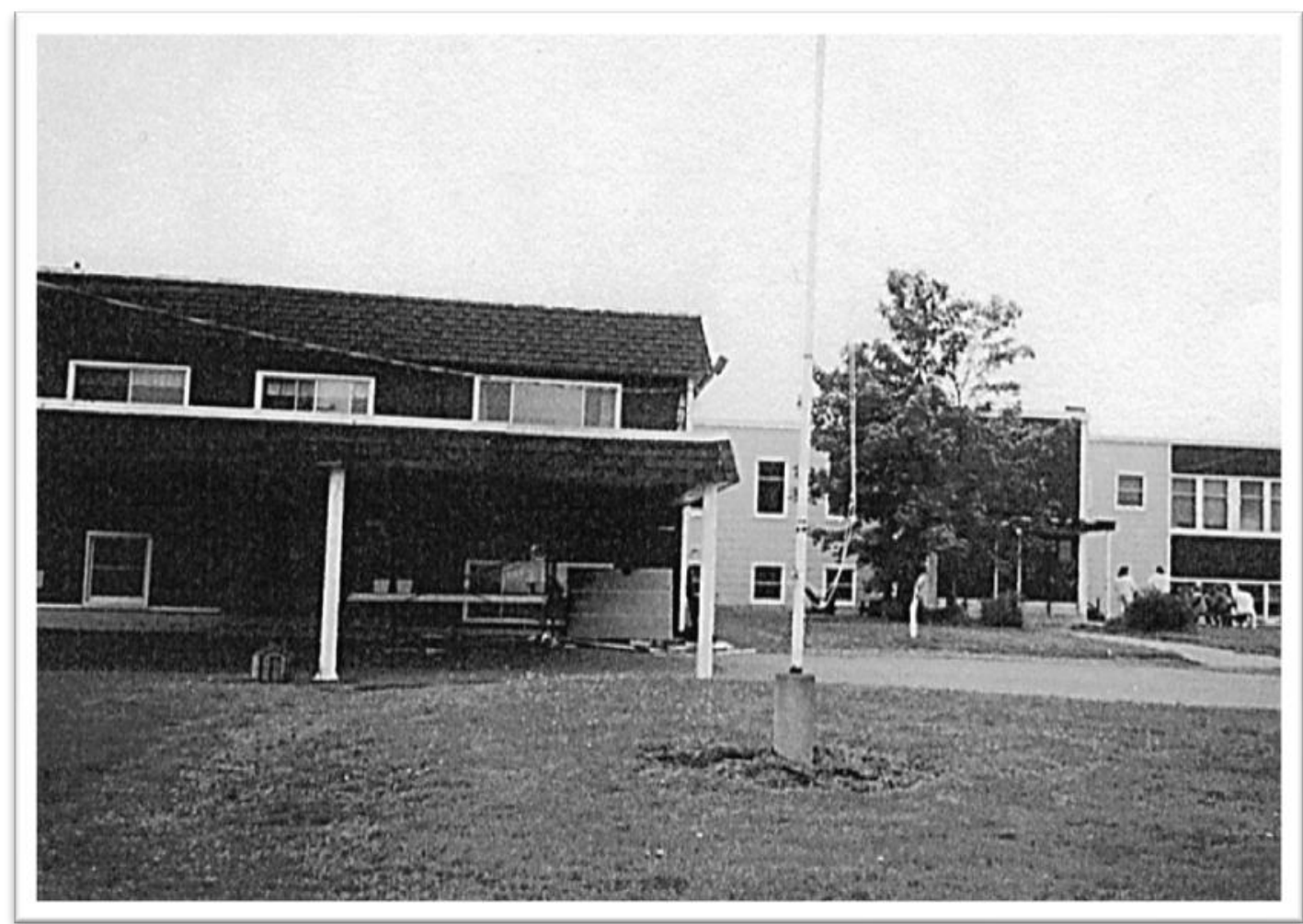

Figure 26.

Ridgemont Continuing Care Building Entrance

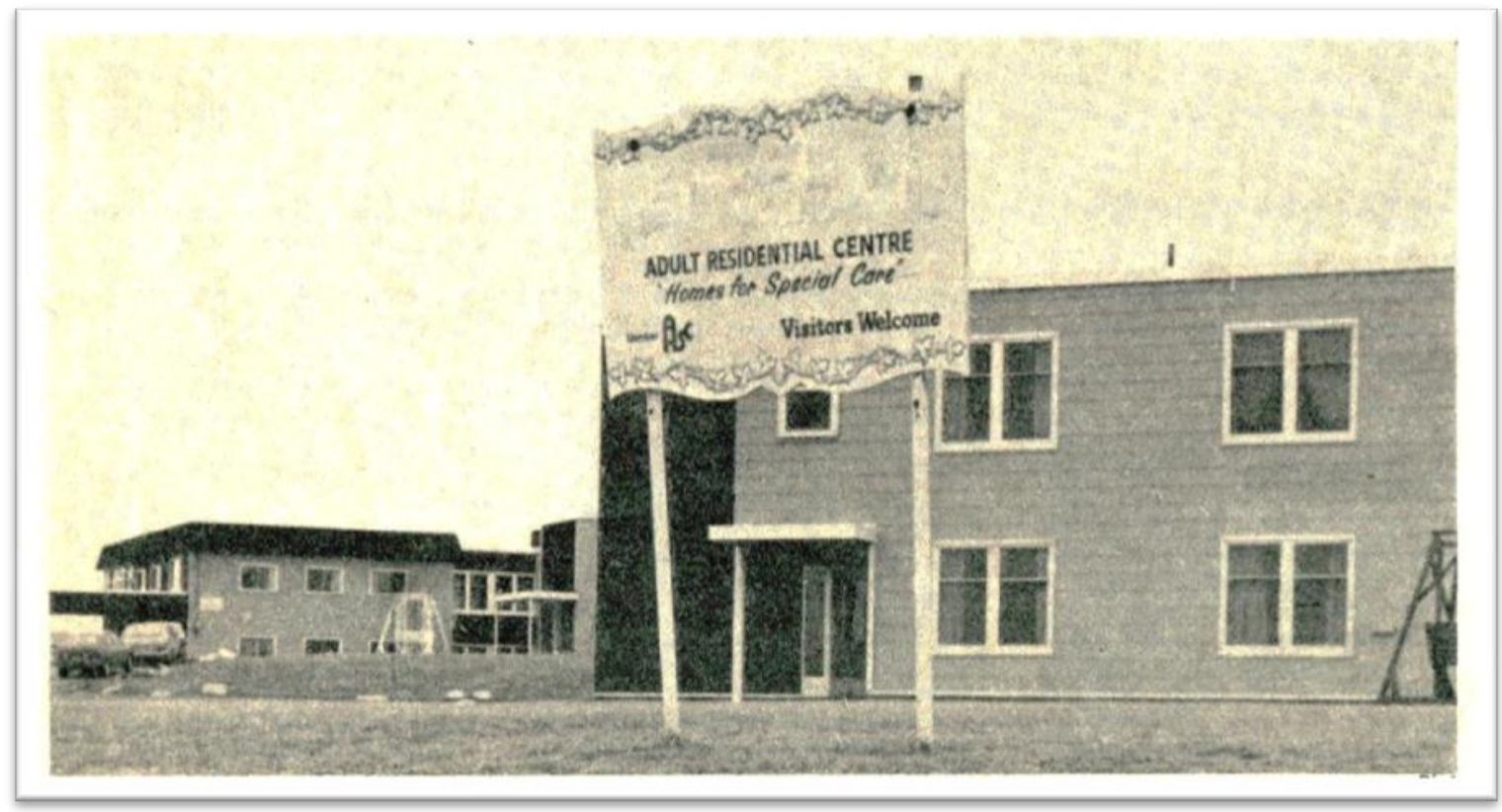

Figure 27.

Ridgemont Continuing Care Circa 1990s 


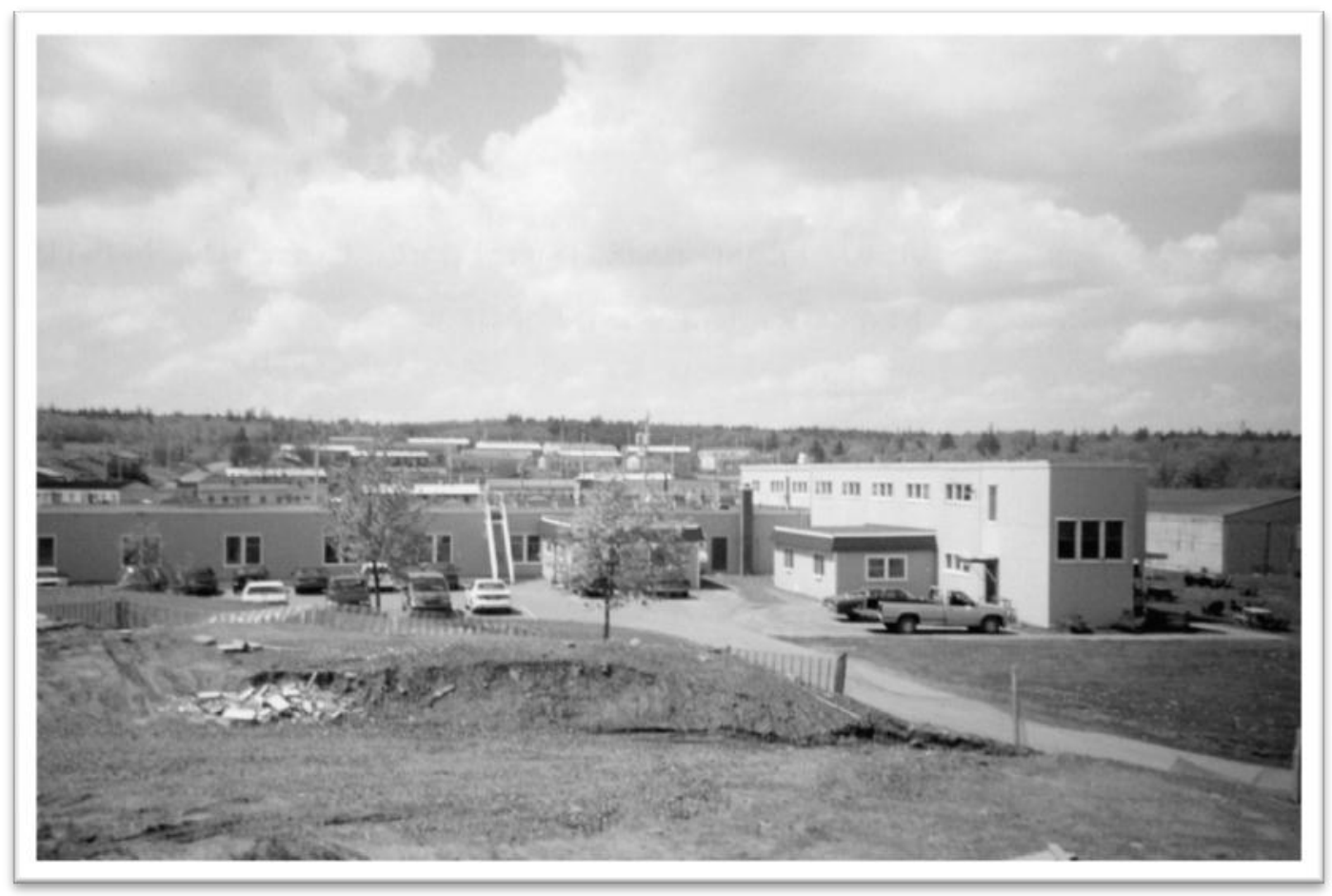

Figure 28.

Ridgemont Nursing Home Prior to Renovation

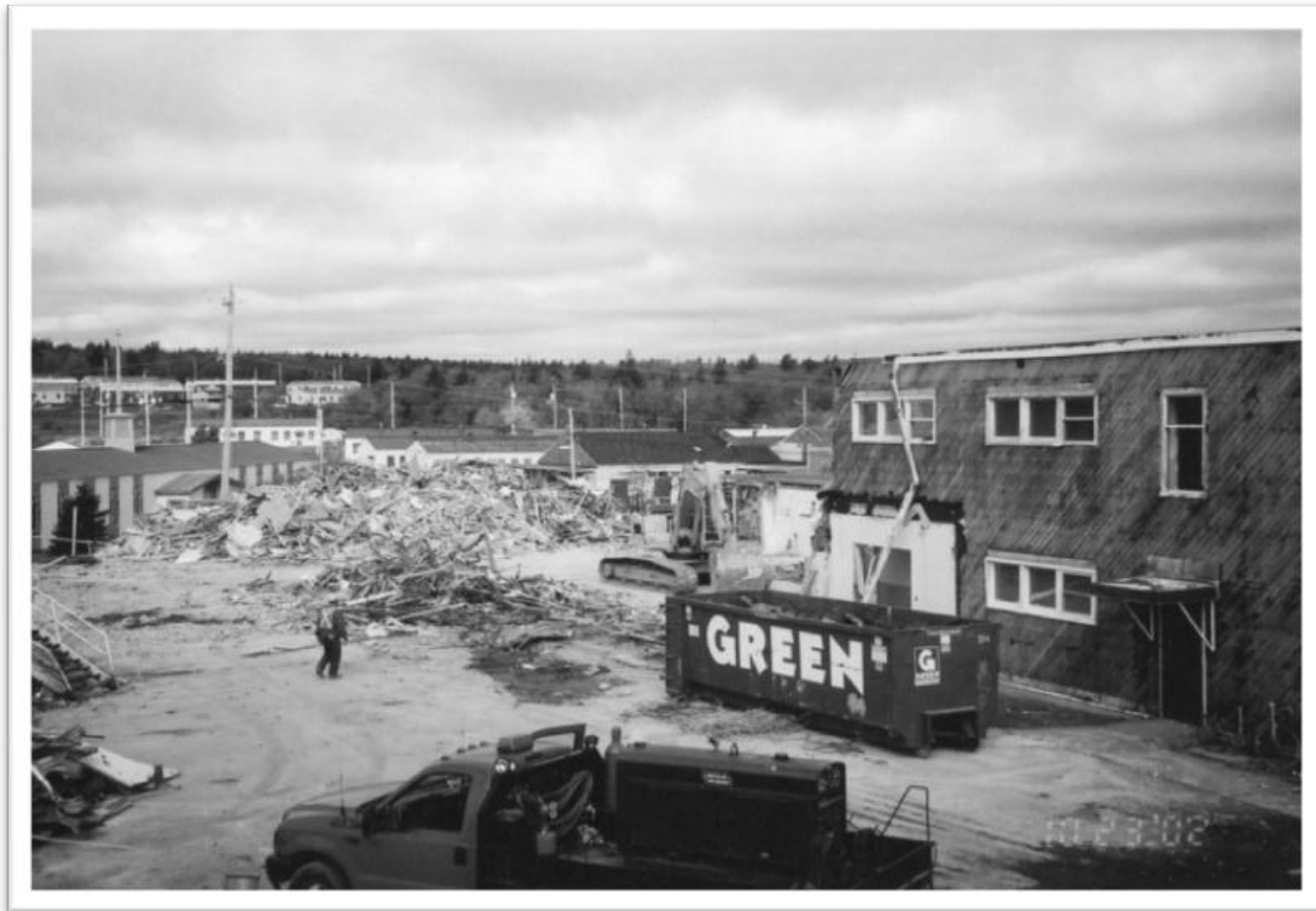

Figure 29.

Ridgemont Nursing Home During Renovation 
The outside of the building looked bad. One lady who brought her mother here from down in the valley, they were having the hardest time making the decision whether to bring her in because the outside of the building looked so drab. I said to the lady, "Don't worry about the outside of the building, it's the inside that counts, the quality of care is excellent." So she finally had to straighten one of her sisters out, they brought her mother in. We had no sitting rooms back then; the residents would sit around the front desk.

When you'd come in and see all of these people sitting around the desk asleep, that was sad for a lot of people to see, especially people from the outside. For residents' baths and stuff, we had to go out into the hall, and get a basin full of water, we used to have to go down and get the water, bring it up, wash the person, and then do it again for the next person because they didn't have bathrooms in their rooms. There were just curtains between the beds.

Wyatt began working with a local architect on plans to alleviate some of the crowding and privacy issues at Ridgemont. Although he had never been trained in design, his experiences with the community led him to an understanding of how much of an impact the physical environment can have on both the staff and residents in LTC.

\section{The Nursing Home Renovation}

Ridgemont is sporting a new look this spring. Phase 1 Renovations to the Nursing Home are moving along on schedule with the new wing now being roof tight, with windows intact and room partitions in place. Our clients continue to be the focus of our programs and services. At Ridgemont, we use a client centered approach to planning, problemsolving and decision making. Teams comprised of direct care staff, support services staff, management and client representatives regularly address such issues as special events, new programs, management of risks, continuing education, and individual care plans. (Ridgmont Community News-May 1998, pg. 2)

In 1997, as a result of Wyatt's leadership, the Welsh group was funded by the DoH to

perform a 5.5 million dollar renovation in the nursing home, almost doubling the square footage from 25,000 to $44,000 \mathrm{sq} \mathrm{ft}$. (Figures 28-33). The redesign included the division of the main

floor plan into three 18,16, and 11 bed neighborhoods, the smallest being the Alzheimer's wing.

The renovation created 29 new single rooms with private washrooms, three decentralized dining 

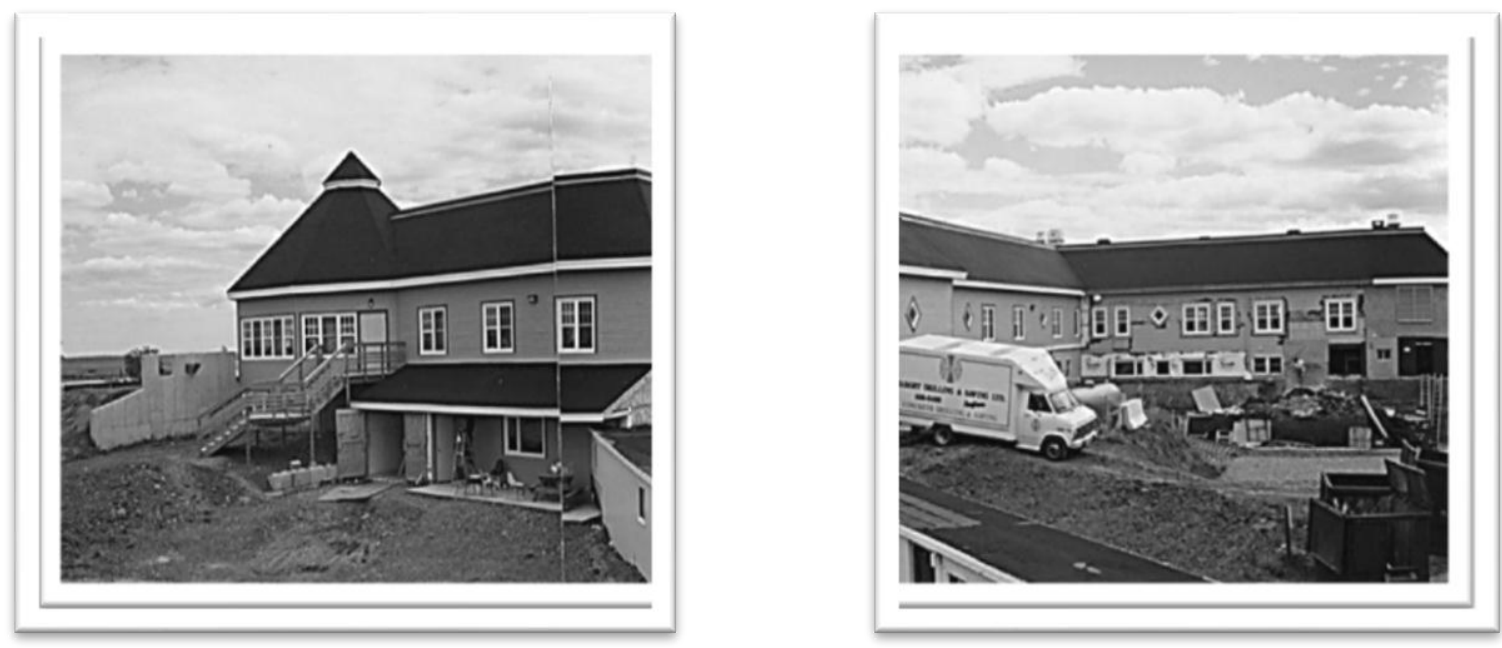

Figure 30. \& 31. Ridgemont Nusing Home Renovation with Link to ARC in Foreground

areas with enclosed kitchenettes, six lounges, and three exterior terraces.

The DoH administrator remembers that the neighborhood model had not been tested in Nova Scotia prior to this; "That one and Annapolis Royal were probably the first ones that we funded and built like that. We really wanted a more residential home-like environment." As administrator, Wyatt worked with the architect and several staff members to design the core of the new facility to be more open for resident/staff interactions. The existing enclosed nursing area was removed and a new nursing area was incorporated into the primary lounge area, with a large, kitchen sized table, chairs, and residentially scaled cabinetry. Wyatt explains the introduction of an entirely new design concept to the nurses at Ridgemont:

I got the idea for the team station from one of the design magazines. We were dealing with nurses at the time who had never heard of anything like that, so we had to develop a whole planning team around that. And working with the RN who wanted dividers, I said, "We don't want to have dividers, we want to all work together here." It took a whole planning committee (of nurses and management) to design the nurses' area. 


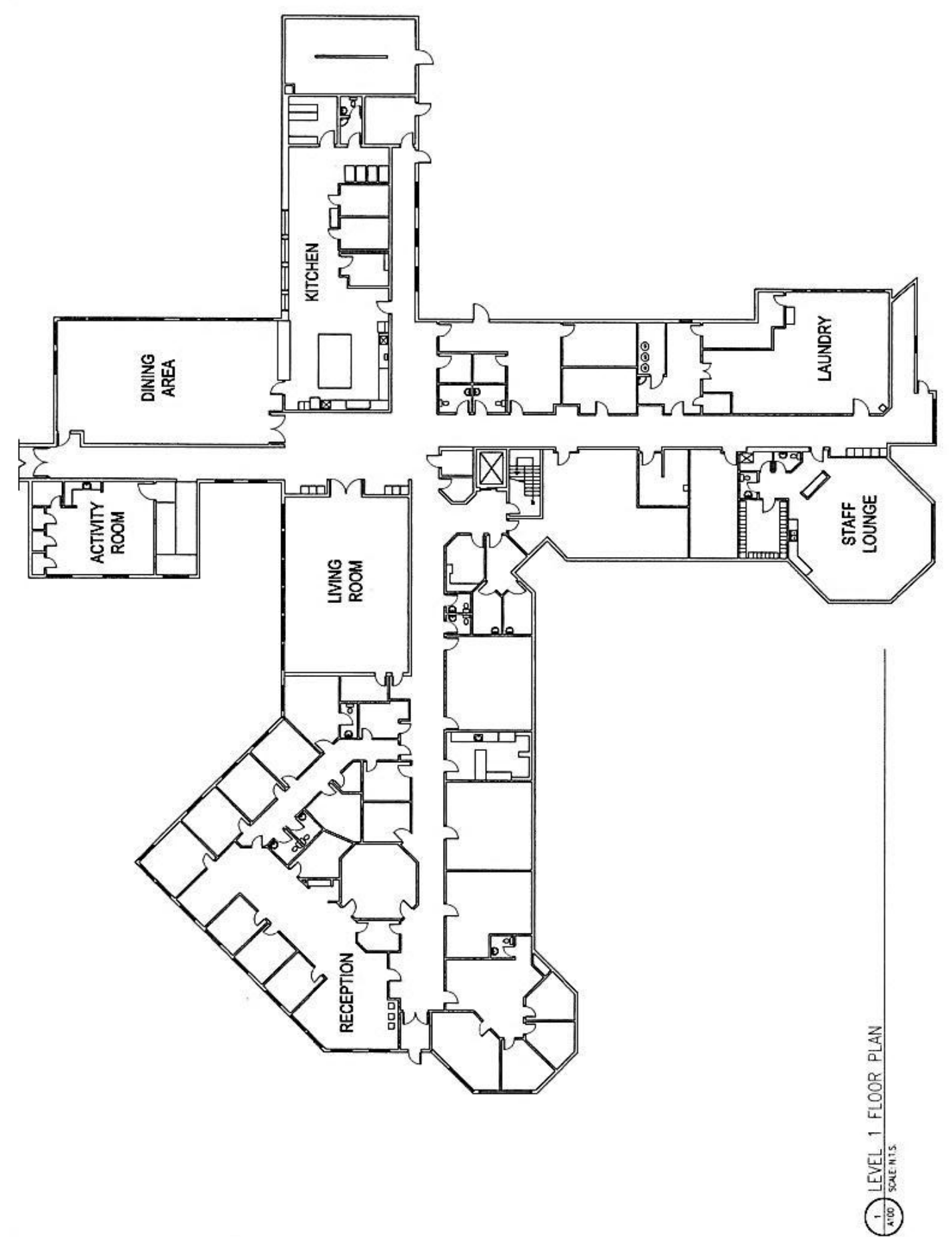

Figure 32.

Ridgemont- Administrative Level Floor Plan 


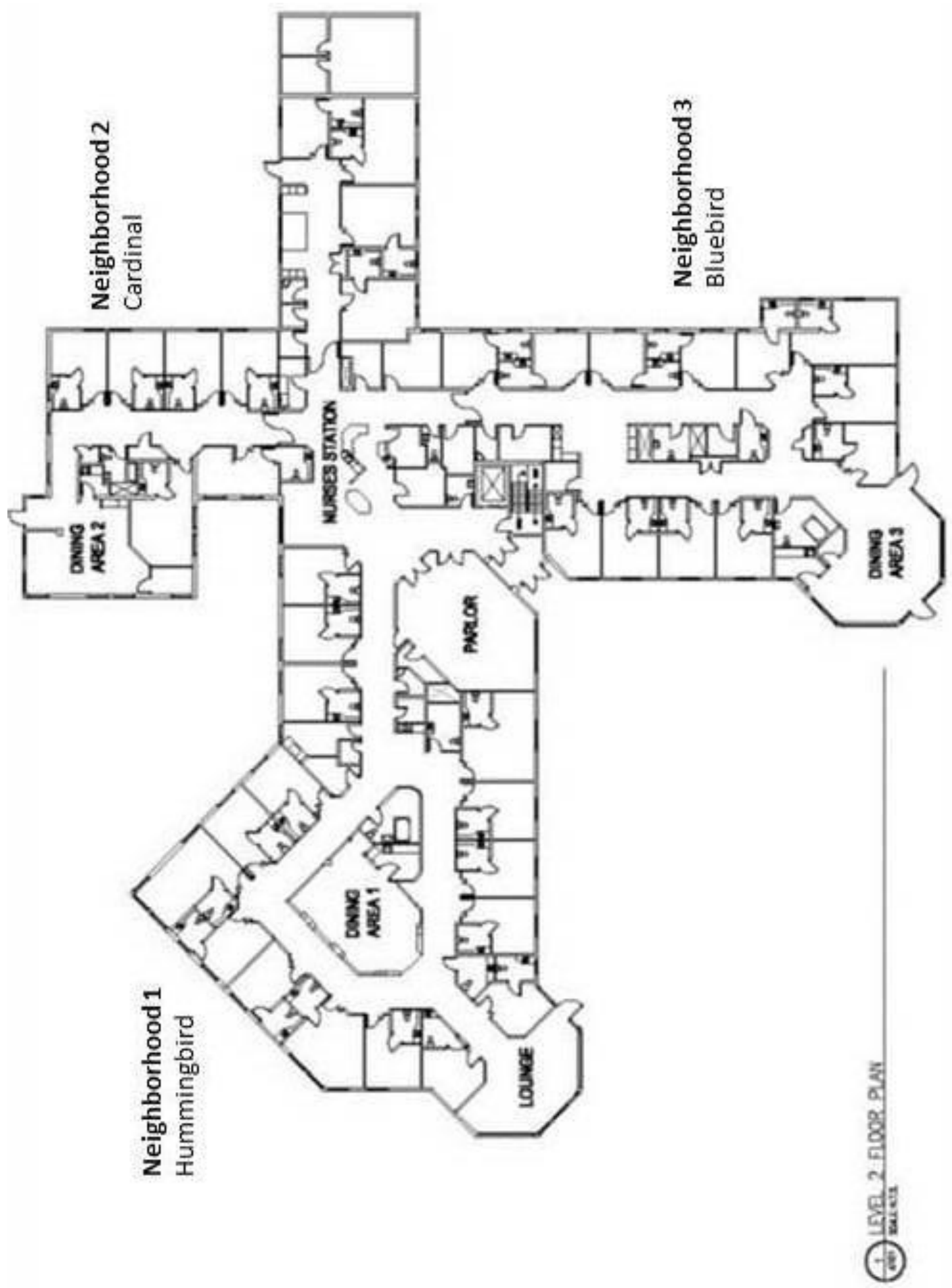

Figure 33.

Ridgemont Level Two Floor Plan 


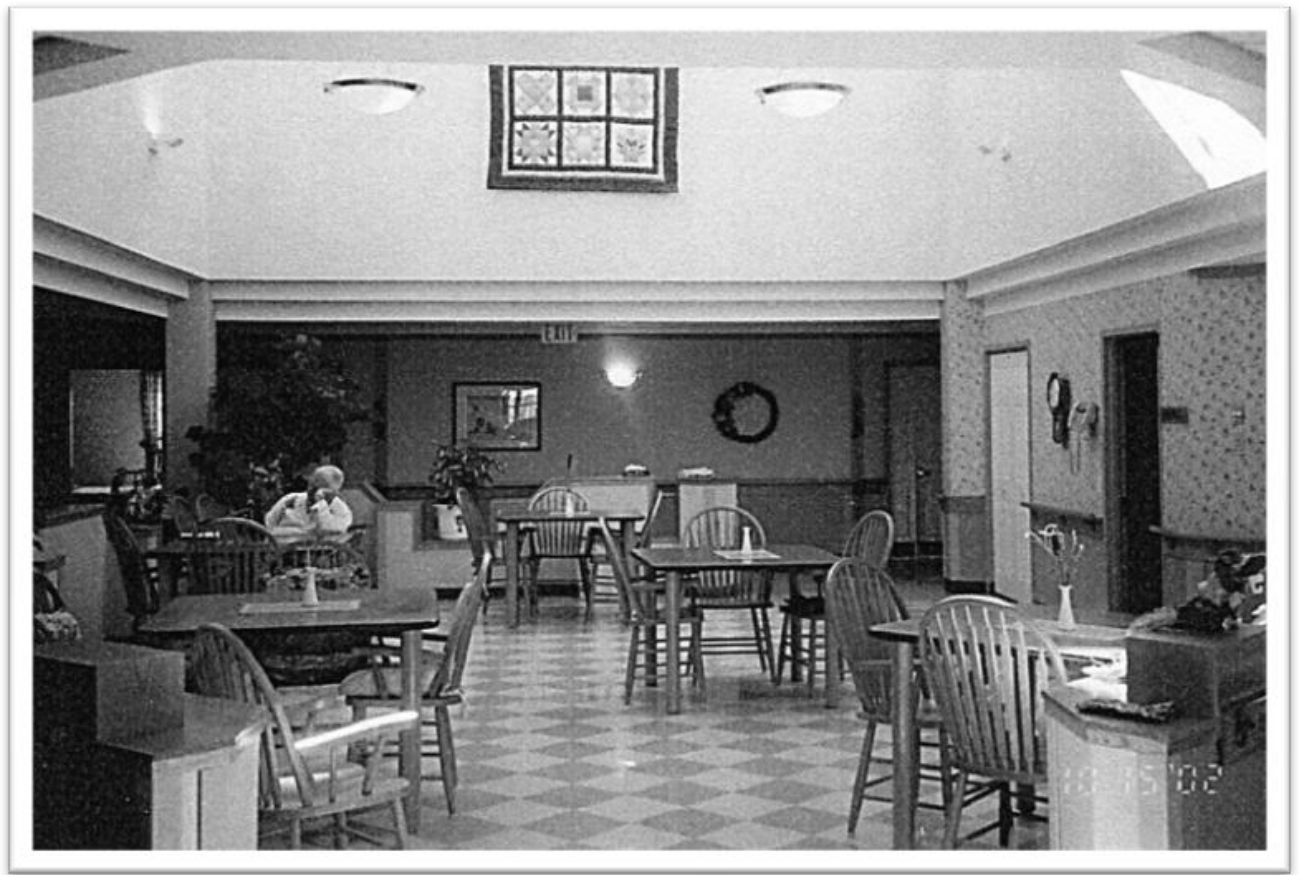

Figure 34.

Ridgmont Renovated Hummingbird Dining Area

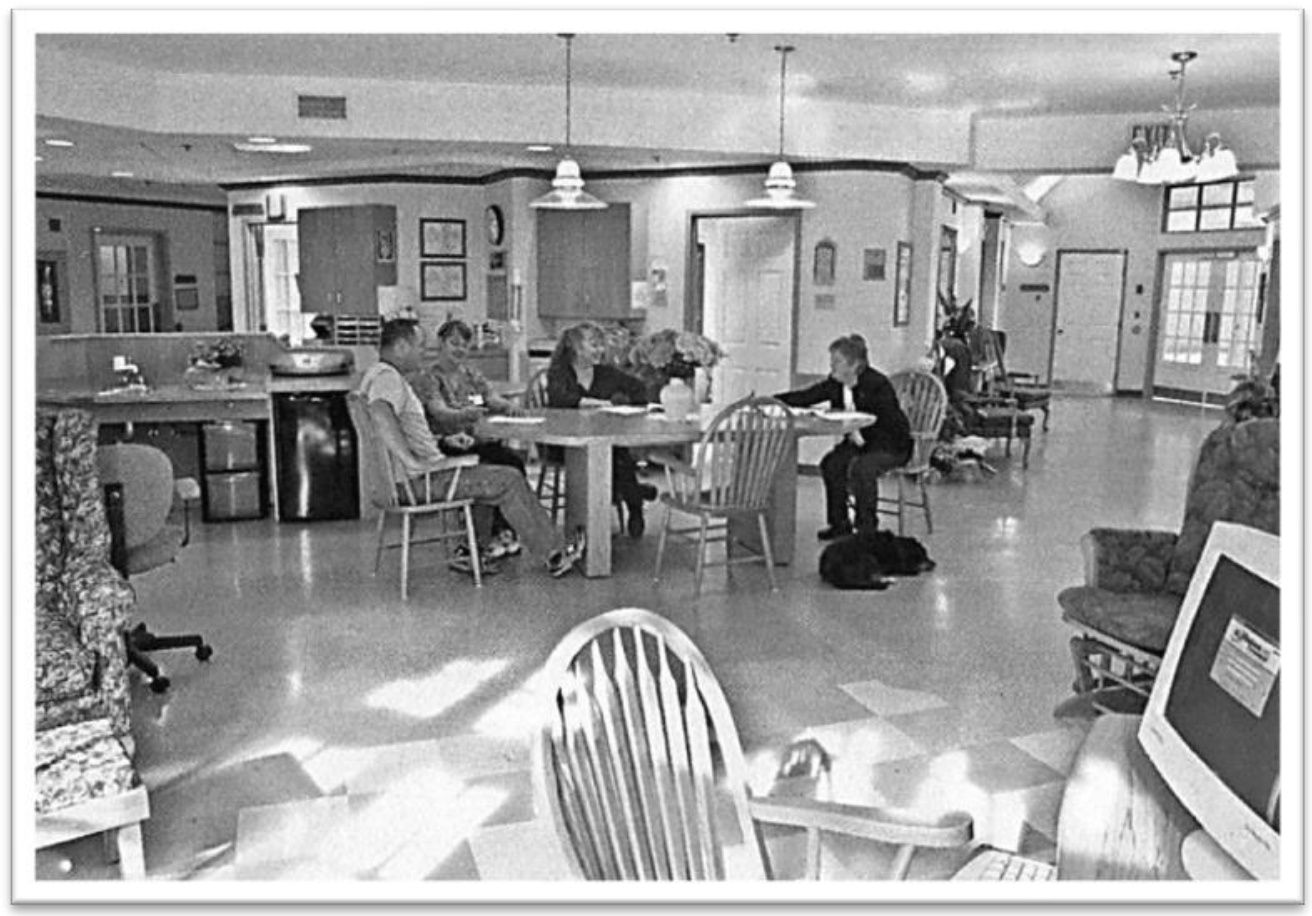

Figure 35.

Ridgemont Renovated Nurse's Area 


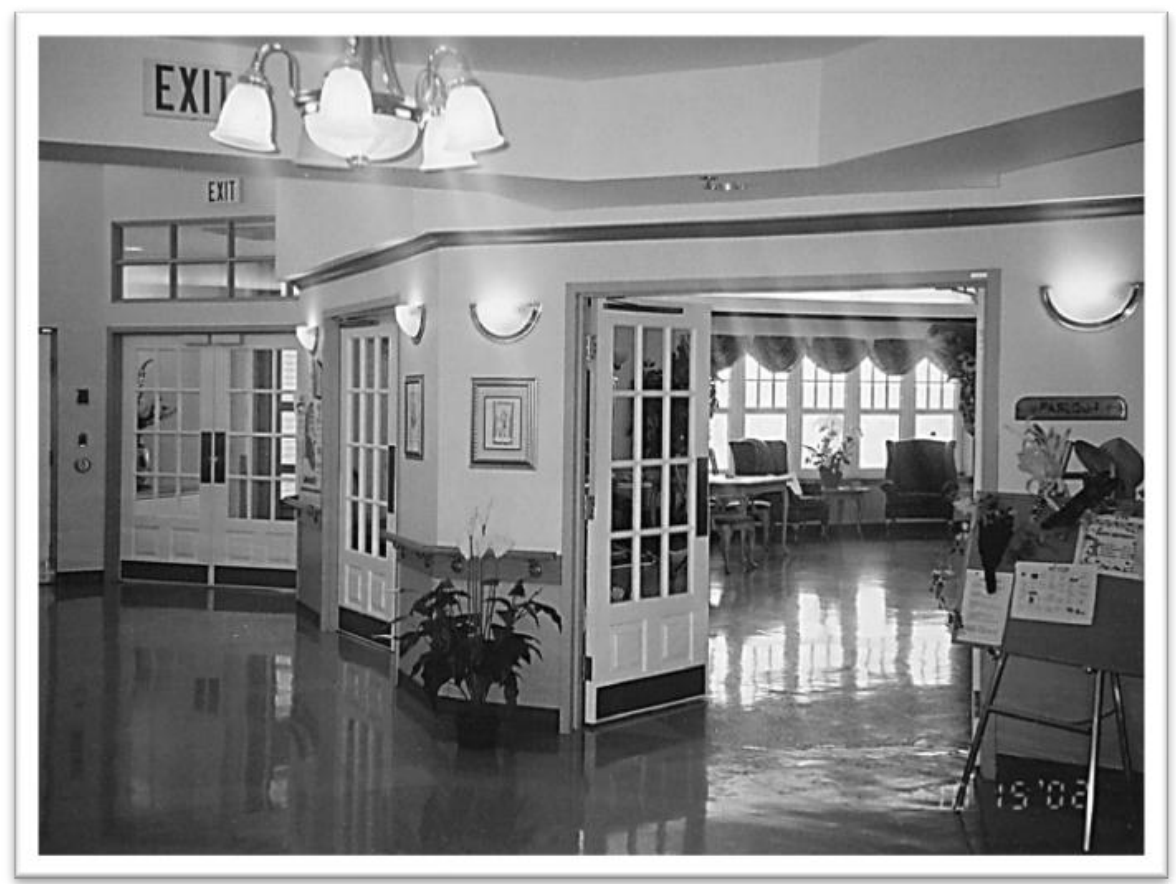

Figure 36.

Ridgemont Renovated Entry and Parlor

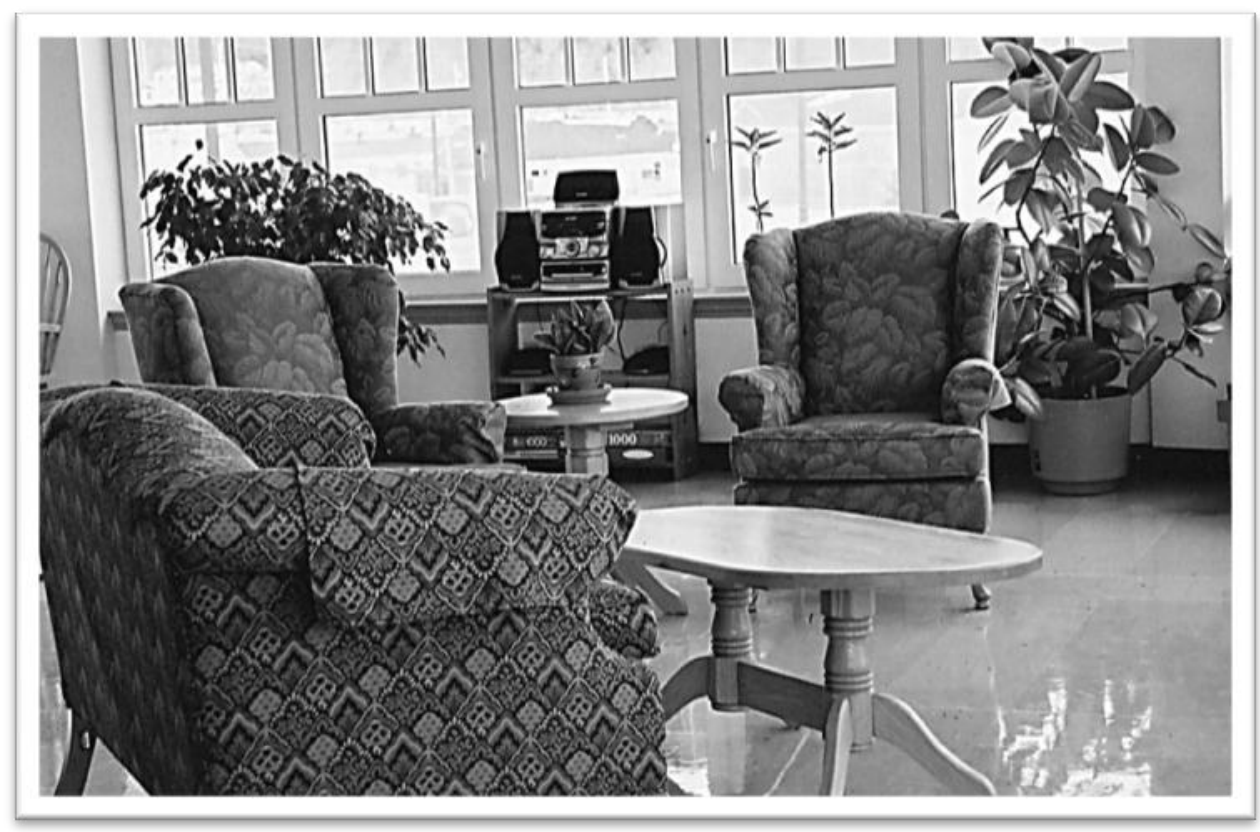

Figure 37.

Ridgemont Renovated Resident Lounge 


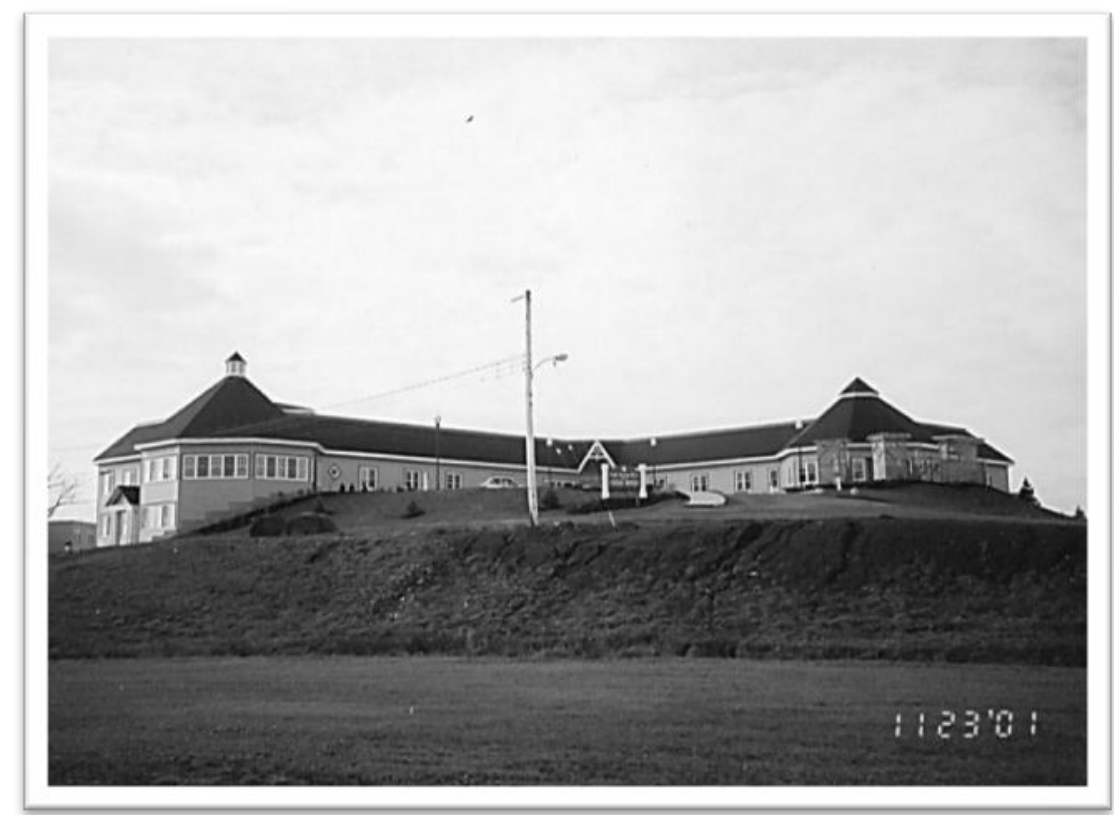

Figure 38.

Ridgemont Completed Renovation

\section{The Mansion on the Hill}

Ridgemont Nursing Home Opens Doors: The facility has long been known for the dedication of its staff and quality of care clients receive, but for about 40 years, the green buildings had cast a dreary shadow over the entrance to the Ridgemont community. (The Woodside Weekly NewsOctober, 1998, pg.1)

The nursing home renovation went smoothly, while one wing was being worked on, residents doubled up in rooms in another wing. Wyatt remembers that, because the workers were all in-house with a Welsh Group construction arm, they were very careful during the renovation not to obstruct daily routines for the residents:

It wasn't disruptive to the residents, they were moving to the new area. One or two complained about the noise or something, but they knew that this was only temporary, and they knew that they would have their own room when it was done. And it was phased. The people who worked here were so considerate, you couldn't ask for a better group to come in here. If we had to come through for any reason, those men got out of our way.

Once the renovations were complete, the staff had reason to be relieved; their jobs became easier and the nursing home building had a completely new interior and exterior (Figures 
34-38). Maureen discusses the changes in the setting which impacted the way in which she was able to give care to the residents:

It was the mansion on the hill after it was done, before it was just drab navy barracks. The primary changes were that everyone has a bathroom, and the dining room was divided up, which makes it just a little bit calmer. Also, in the neighborhoods it's calmer; we could divide the residents into groups of their care needs. Like down here, we still have a lot of people that you have to use the lift on, but they have more on the ball. Down there you have heavier lifting. Down there is the Alzheimer's. The parlor is nicer, much nicer than it used to be. And there are more private places. Like down here, they can use this room if there are just one or two residents, you can read a story, or have some private time. When I think of the differences between then and now, it's unreal.

Another caregiver from the ARC was Joe, who moved up to work in the nursing home after the renovation. He describes what he saw and the impact of the renovation on the work environment:

A lot of the changes were done before I came from the ARC. The kitchen, which is now downstairs, was upstairs. This over here was not there; this was where the stairs were. I find that now, its lot homier and brighter and updated. These are all new windows. Some of the patient rooms became the sunroom. Some of the rooms down there where we have to use a lift, those are still a little cramped for space. I worked at the ARC and we had to. do rounds up here and make sure that it was all secure. So it's really changed since then, but all for the better. It really needed the upgrading.

Because of the dual provincial funding of the Ridgemont services at the time, once the nursing home renovations funded by the DoH were complete, the owners looked to the Community Services division for funding in order to work through the physical and organizational issues for the renovation of the ARC buildings. 


\section{The Demise of the ARC}

The Adult Residential Community at Ridgemont was the only private, for-profit ARC in

Nova Scotia. In the late 1960s, when the City Home in Halifax closed, a large number of the residents were transferred to Ridgemont, and in 1976, under the Homes for Special Care Act, the ARC was created. Wyatt remembers the political climate in early 2000 when the ARC clients' ages averaged from 30 to 86 , with approximately 120 staff members working as managers, registered nurses, licensed practical nurses, residential counselors, housekeeping, dietary, laundry, and administrative staff:

There were ten ARC facilities around the province, we were the only private one, the rest were all municipally owned. That's even a double whammy, because in the community service world, it's all very non-profit oriented, private is bad. The $\mathrm{ARC}$, that was under a whole different department from the nursing home, a whole different mentality. It was more of a welfare model as opposed to a health model. We had bought the property in the 60s and we have reports back to 1972 that the ARC should be closed. This was a population that nobody cared about, we had all of the people that no one wanted, we were always sort of a dumping ground. If you had a family member who was a strong family advocate, you wouldn't be at the ARC at Ridgemont. At one time we had 88 in one unit aged 19 up to 100 , from the queen mother to the pyromaniacs, pedophiles, and street people. So this was a population with a lot of mental illness, and family members that didn't want to have anything to do with them, they had burned their bridges and didn't want to admit they were ever like that. Nothing's easy the first smash or everyone would be doing it, right?

The Welsh Group knew that changes had to be made in the ARC, the population mix was

unhealthy. Maureen remembers the crowding and mismatching of residents with mentally and

physically handicapped residents housed together:

When we had the big community, you had the mentally ill, the mentally handicapped, and the seniors all mixed together. Ah, that was awful, I thought that was awful. The mentally ill people would abuse the mentally handicapped; they shouldn't have been put together in the first place. At meals we'd have 48-50 people, they all ate together, some of the fights we'd have in here were unreal, there were so many personalities. 
But Maureen also remembers the bonds that were created between the residents and the staff due to the length of time that many of the residents had lived at the ARC. Often residents had no family ties or visitors, and the staff and other residents had, in essence, become their family:

This was their home, definitely. This was their way of living, the only way they knew. For some of those people, this was the only love and attention they ever got, because a lot of the residents felt that the staff here gave them more love then they ever saw out there.

Due to the success of the nursing home renovation, and the need for an updated building for the ARC residents, the Welsh Group had moved forward with finalizing a plan to renovate and reduce the number of beds in the ARC to the neediest of the population. When the plans were submitted, however, the Community Services division made the decision that instead of renovating the ARC buildings, they would have them demolished and move the residents into other living situations. Wyatt remembers that the decision appeared to have more to do with politics at the time than the actual needs of the residents:

Originally, we were going to maybe take it down from 165 beds to maybe 60 or 80 , maybe downsize and specialize in the population that really needed to be institutionalized. In the end, what happened was Community Services didn't support the facility, it was all about deinstitutionalization. They just said, "Why are we going to put money into an institution when that's not the direction we're going?"

In the January 2001 Ridgemont newsletter, the closure announcement was made to the Ridgemont community that the Department of Community services had made the decision to close the ARC rather than update the building:

The Department of Community Services and Ridgemont Adult Residential Center (ARC) have agreed to close the Adult Residential Centre over the next two years. The decision is consistent with the North American trend of locating adults with physical and mental disabilities in smaller settings. As well, the ARC has been 
operating since the late 1960's and the building would need major renovations to maintain current standards. The needs of each resident living at the $\mathrm{ARC}$ will be the primary consideration in their relocation. Residents are from across the province and they will be relocated, whenever possible, close to their home communities. These decisions will be made with the best interests of the resident in mind. "Our priority is the ongoing care, supervision and safety of resident during this transition period," said the Minister of Community Services. "We are confident that the relocation will result in improved living arrangements for these residents." (ARC Newsletter, 2001).

The closure soon became national news, and with the notoriety came polarization between the provincial leaders, and union leaders and the issue was debated openly in the press.

\section{The Closedown}

Halifax: A center near Halifax that treats adults who have physical and mental disabilities in Nova Scotia is closing. The Community Services Minister said yesterday, the building, erected in the 1960s, would require extensive renovations. He said the center, which cares for people from all across the province, will close over the next two years. 138 patients will be moved to smaller facilities. (The National Post, Jan 10, 2001)

The Community Services' decision to close the ARC was unexpected for the staff and residents at Ridgemont, especially after the successes with the nursing home renovation.

Maureen remembers the national attention and the pain for both the staff and the residents at the time of the announcement:

In the transition, a lot of the residents didn't know why they were moving "Don't you love me anymore?" they'd ask, that made the staff cry even more. This was the thing that happened, we couldn't do anything about it, it was out of our hands. Staff tried as hard as they could, and a lot of days they cried together down there. These were the people who were left behind, the people that nobody else wanted.

While the plight of the residents was at the center of a political storm, the voice of the nurses' union and job security began to emerge as reoccurring themes in the newspaper articles. The January $10^{\text {th }}$ issue of the Mail-Star ran this article about the pending closure: 
The province pays $\$ 106.37$ per day for residents at the center. Nursing homes won't be any cheaper, but small-option homes charge less, about $\$ 60$ day. The minister said, "This approach hasn't anything to do with cost-cutting." But the New Democrat said the province is merely finding ways to save money; since large institutions are expensive, many of the workers are unionized, and the land the buildings are sitting on is often valuable. "There's all kinds of little dollar signs in the eyes of bureaucrats." Mr. Deveauz said Tuesday. He said small options homes are just smaller versions of institutions, but without any regulation. Liberal MLA Jim Smith said when his party was in power, it worked on moving resident to smaller facilities. But he warned the change will be expensive. "The Hamm government can't do it on the cheap," he said. (The Mail-Star January, 2001)

An article written from the nurse's union perspective ran a few days later in the same

Halifax newspaper, expressing the concern that the union leaders had about the fate of the ARC

residents who were going to be relocated:

Many of the mentally and physically handicapped residents at Ridgemont will have no place to go once the facility is closed, nurses fear. They contend the plan to shut down the ARC is ill-conceived and will affect the health and well-being of residents. The Nova Scotian Nurses Unions' president said yesterday that there aren't enough facilities to accommodate residents, some of whom have lived at the center for more than 20 years. "It's their home," she said. "They have no idea where they will be living when the ARC is closed." Union leaders want to see a new wing built at Ridgemont, and said that there are only about ten residents able to cope on their own. The fear is residents who need specialized care will be shoehorned into limited numbers or small options homes or simply left to themselves. (The Daily News, January 2001)

And finally, the finger was pointed back at the government, charging that the closure was a result of poor provincial planning and cost cutting on the backs of one of the most vulnerable populations in the province :

"This is about saving money, not trying to ensure the best services available to those who need them," charged a community services' critic. Liberal critic Jim Smith accused the government of again targeting society's most vulnerable, while neglecting to put the proper supports in place. "This is just another example of government planning on the fly," Smith said. But the local Tory MLA defended the government and accused opposition politicians and the nurses' union of fearmongering. He said the government is committed to providing the best care 
possible. "We all agree that the status quo is not good enough. (The Daily News, January 2001)

\section{Transitions}

In the end, many of the ARC residents were moved where department administrators could find a place for them in private homes in the community, and $60 \%$ of the residents were moved to another large institution in Welford. The closure would not only mean transitions for all of the ARC residents, but the job loss for the majority of the staff at the ARC as well. Some senior staff were able to move up to continue working at the nursing home, while others transitioned into other jobs or retirement. A nurse remembers the staff transitions:

The staff that were here the longest were allowed to stay and the others went elsewhere. At that time, our union was in, so the ones with seniority kept their jobs; staff in the ARC who had been here longer stayed on at the nursing home, because they had seniority. Some people left, some retired early because they were getting up there in age. The drastic change was hard on the staff that stayed on; they would cry when the residents left, they had worked here with these people from the time that they came. We also heard that a lot of the residents died shortly after the move.

When Wyatt looks back on the impact of the closure on the staff at Ridgmeont, he recalls that some staff who lost their jobs actually took residents home to live with them, rather than have them moved into living situations where they would not know anyone:

I don't know anywhere else where staff would have done that. The staff up there were grieving. I can relate to that, I would never be the same again, it was devastating. These are caring people; they are not left-brain people. Some of those residents had been there for 40 years, had the same roommate for 40 years.

Due to the fact that the Ridgemont nursing home was run with funding by the DoH, throughout the months up to and after the closure of the $\mathrm{ARC}$, the nursing home continued to operate as usual. 


\section{Scar Tissue}

We can only do so much with the resources we have, if you want better results, you need to do more and have more to fund it. (Joe- Ridgemont RN)

\section{Ridgemont Today}

By 2002, the ARC closure and demolition of the buildings had taken place. Over 150 staff members, all junior union people, had been laid off. The staff who stayed on to work at the Ridgemont nursing home were the oldest union members, and the support people who were left had to know everyone's job, learning to work with less support. The differences in running a smaller community became apparent quickly, and it was difficult to find management who could handle the organizational changes that needed to take place. Wyatt explains:

It's actually harder to run a small place because the office person, all of a sudden she has to do sick calls, she has to do payroll, all these new functions. And the director of care, all of a sudden, she did everything from education to fire drills to everything. So the staff over there had seen a lot of loss and the management has turned over a lot. I was over there for a while, another was there for a few years, he had mental health issues and then a guy came in for three years before me, he just didn't have management skills, he just couldn't handle it. It was a very difficult place to run; you almost have to just let the staff run it. It's been on auto pilot for several years, that can only go for so long.

The nursing home administration was in constant flux because the job of dealing with the losses and the restructuring of the community was overwhelming. Joe describes a string of administrators and directors of care who worked at Ridgemont, each who tried to leave their personal stamp on the organization:

Every time someone new came in, they are going to put their own stamp on how things should be done. Just as soon as you get used to one, that person's gone. Then you've got to re-trace, start over, and do it differently. It's not just administrators; we've had quite a few directors of care over the years. 
The present day administrator at Ridgemont is Anna. She felt the push back from staff the day she took over and she describes her understanding of the impact of the ARC closure on the current remaining staff:

They've been traumatized, there's scar tissue there, it's so obvious. I remember the first day I walked in, they said, "Oh, here's another one." You can just feel it, so to gain their trust, it's going to take a while. We're being supportive, we have started a social committee and a wellness committee. They deserve that, the rewards have to start for them. They want a gym in house, and I'm doing all that I can. They are thrilled, they deserve it. They've worked hard.

She also feels that the remaining staff have been through transitions that have made them stronger caregivers, but she understands that the pain from those closures has not dissipated a decade later and goes on to describe the current staff at Ridgemont:

The staff here are amazing. They take ownership, for the most part, they are from this community, they've been here a long time. We are looking at some third generation staff, which just blows me away. These folks, they've been on auto pilot for some time and there is a fair bit of resentment, there have been multiple management changes. So I really have to be careful.

The majority of the core staff at Ridgemont are made up of RN, CCA's, and support staff that have either worked there for multiple years, or are in some way related to someone who has been there since the beginning. The culture of care there is palpable; there is a real camaraderie between the staff and between the staff and residents. Daily activity is centered in the nurses' area, and in the afternoons when shift changes take place, caregivers preparing to leave for the day will greet the incoming staff with hugs, bags of unfinished snacks, and cautionary stories of what has taken place that day. Robin, the Director of Education for the Welsh Group, spent many years working in management at Ridgemont. Her impressions about 
the current staff at Ridgemont are similar to Anna's; she feels that the dedication of the caregivers is unique:

They have that commitment and dedication up there, I'll tell you, there is no such thing as a storm day out there. Those staff will bring their sleeping bags and guitars and have a pizza party. That doesn't happen anywhere else, they are a very unique group that way.

\section{Care Goals}

Anna had worked in acute care nursing for two decades before transitioning into LTC administration. Her goals in caring for the frail elderly revolve around the individual and the life they have led, and she describes her personal understanding of what person centered care is about:

Even when a resident gets to the point when they don't have language, they don't recognize any of the family, that's still a human, that's still someone with a body and a soul that needs to be nurtured and taken care of. So when I look at the elders, I just have an instant respect for them anyway. I think of years and what they have done in those years. Part of that came from my mom when she passed away at 75 , when we packed up her little apartment, 75 years of someone's life actually ended up in a couple of boxes. I'm thinking, "Oh my god, once these boxes are gone and we're not there to tell the story, did she really exist?" But it's the impact that she had her children and the people who knew her who will carry on her story.

The principle goal for Ruth, the Director of Nursing, is to keep the equilibrium in check in the community. She knows that the scar tissue exists for the nursing home care staff and makes a consorted effort to keep the environment calm in the nursing home. Ruth considers herself to be one of the newer staff at Ridgemont, even though she has been working there for ten years. When asked about her day to day activities, she describes her role of as that of a peacekeeper: 
It's the day to day running of the units, from the nursing perspective. Helping residents' families navigate through the health care appointments, I answer questions, physician's questions. I'm just somebody that's here every day, so you have someone who knows what's going on, especially with the resident's appointments, how they are, stuff like that. A lot of putting out fires, that's a big one, keeping everyone calm. You have to be calm, you have to radiate that. If I'm flipping out, they're going to flip out. So I don't run, I talk quietly, it calms them. You know if you work under somebody who's hyper, you kind of pick up on that. There's not that sense of urgency, you know what I mean? And everybody plays a role; we've been together for a longtime. Joe has been here for 30 odd years. If he doesn't know what he's doing by now...you know, this place pretty much runs itself. We don't have a great big support system, there's not a lot of support, but we manage to do quite well.

Joe's has been working at Ridgemont as a caregiver for over three decades, both in the ARC and in the nursing home, and is a central figure in the lives of the other staff and the residents. He describes the impact that the residents' stories have on him:

The residents fascinate you because they've gone through what we're going to go through, so you can learn from some of the stories they tell you, of what it was like back then. Some people in today's society, the younger group, they don't understand, they think, "Oh, you're just old," but they're not, they have so much to tell you, if you take the time and listen. I get along with everyone, this is their home. It's not my home, this is where I work. It's a privilege for me to come in here to work with these people in their home. In some situations, you don't ever see a family member. So we become their family, that's the way I look at it. Most of the staff have been here 30 years plus, I like to call us seasoned, it sounds better. We come in here, we do our work and then we leave, but this is their home.

While Joe has a clear understanding of the importance of his role in the lives of the residents, he is often frustrated by the restrictions put on him and his co-workers due to provincial funding issues. He describes multiple issues and restrictions in the current LTC system in Nova Scotia, primarily due to funding issues:

We have what we call adult protection. And we have people who have, through no fault of their own, ended up here; we provide a place for them to go to. At least we have it, I think that's aces, but these people come in here and they are upset. They have been taken from their homes for safety reasons. I think the whole concept is that we need to give the people what they want, not what we want. It 
starts with government, in my opinion, then the owners. Most of the facilities are privately owned, but government subsidized. When you have to deal with the mighty dollar, they have a budget that they have to operate under, so their hands are tied. People outside need to be educated, not just everyday people, you've got to educate the people who control the purse strings. They need to see what we do, see the frustration levels when you can't get things because the money's not there. I understand it's business, but if they would just put themselves in this situation, would you still be penny pinching, you know what I mean? This home for the residents, we come in here, we leave, and we go back to our lives. This is their life.

While never calling the model of care by name, Joe discusses his perception of personcentered care and the need to listen to the voices of the residents when making decisions. But Joe is pragmatic, understanding that this will take an entire organizational and funding shift; staff just don't have the time or resources to implement the changes for residents that they are asking

for. In the meantime, he describes how he makes it a personal goal to practice person centered care on a daily basis with the residents.

Sometimes when we have our evaluations with the Director of Care, I say "What am I doing wrong? "Well you're too slow." If the day ever comes when I'm judged by how fast I go, then I won't be here. This isn't like working at an auto shop where the more cars are fixed, the better, in an assembly line. There are small things to do; they don't have to be major, start small. What you have to do, which a lot of us forget to do, is listen. "What do you want, what would make you happy?" I talk to residents here, and they'll tell you, "They don't listen. They don't care what we think." I don't buy that, I've been here a long time and we do, we listen to them, but there's not a whole lot we can do. We don't make the decisions. Whoever is controlling the purse strings calls the shots, that's where the frustration sets in. I can't compare this to any other facility because I've only been here. We are told, Anna tells us all the time that from what she hears from other directors, that this place has top notch care. But care is only part of it; we take care of the physical and try to take care of the emotional as well as we can. I try to listen, I'm not just here to wash them, I'm here to listen too. Sometimes, I really don't take the time because I don't have the time. I should just sit down and talk with them.

The Nurses' Union

Unfortunately, Joe's desire to spend more time with each resident comes up 
against an implicit roadblock with the staffing philosophy of the nurses' union. The nurses' union is as dominant at Ridgemont as it is in most hospitals and care centers around the province. The union represents over 6,500 nurses in Nova Scotia, and Wyatt describes how the nurses' union has moved in and out of the equation at Ridgemont over the years that he had worked there:

The staff unionized in 1979 and decertified in 1991, that means they kicked the union out. It was written up in the legal book how that happened, because it's not easy to kick a union out. The staff did it, but what it did was kind of create a civil war between staff, because some wanted it, some didn't, so they voted and kicked it out. Ten years later, the wounds were still pretty evident. Coincidently, the ones who organized the decertification in 1991 were the ones brought it in the next time.

The staff at Ridgemont work within tight regulatory and staffing hierarchies. The newer staff are aware that the senior staff kept their jobs during the closure of the ARC, so they understand the importance of this hierarchy. Each staff member has his or her specific task: There are housekeeping staff, kitchen staff, CCA's, LPN's, and RN's. Ruth believes strongly in the structure of the union and the staffing hierarchy, and she sees it necessary for junior staff to follow certain protocol when asking for help for the more senior staff:

I'm a unionized member, I'm a nurse. Then there are the Licensed Practical Nurses, then the CCAs. The LPNs take a leadership role with the CCAs in their respective units. It's good if the CCAs learn to go to them first, so they can learn how to trouble shoot, and what they can't handle, they will come to me. That doesn't mean the CCAs can't come to me, I would just prefer that they follow some sort of hierarchy, otherwise it would be a flood in here. There has to be some sense of structure or there would be chaos.

Joe is currently the executive of the nurse's union at Ridgemont, but he explains that he has his conflicted feelings about its relevance: 
We didn't bring the union back in until 1993. There were situations when we thought well, we can use the union, so we brought them in. I still believe there's a good and a bad in all things. I'm the executive now; I think to myself, have things really changed? I don't know. Before you always had that worry that you could be laid off, there were no safety nets, but then I've got to remember that it was just the senior members who kept their jobs though ARC closure. That was the province though; we had no control.

The union influence is strong at Ridgemont due to the staff's need for job preservation, and in many ways speaks directly to the institutional philosophy of care that is well known in both Canada and the United States. When the Community Services' division closed the ARC, it not only resulted in the displacement of the residents, many from the only home they had known, but the closure also required remaining nursing home staff to double down on the support from the unions for job security. In the case of Ridgemont, the strength of the union mentality has a direct relationship to the provincial funding structures.

\section{Chapter Summary}

Because one of the principle goals of this research was to understand how funding by the Province impacts staff and resident outcomes, it became important to go into the Ridgemont history in depth, because in so many ways the story reflects the philosophy of care that we find in the United States. While other communities may not have the specific elements of the Ridgemont history, there are reasons why an institutional, highly regimented model of care has been in place for decades based on staffing quotas and funding issues. As we will see in the following chapters, that philosophy of care can often be difficult to shake, even for the Welsh Group as they looked toward different care models. The Ridgemont story also describes some of the positive outcomes of these experiences for the staff and management. Through these transitions, the Welsh Group has become a stronger organization, cohesive in their determination to improve the lives of the residents in their communities, whether in a traditional renovated 
LTC community or, as we will see in the following chapters, a new building designed through a process which has transformed both the philosophy and model of LTC in the province. 


\section{CHAPTER SIX: THE CONTINUING CARE STRATEGY}

While the Province of Nova Scotia continues on its quest for a better society, for better health care, and for better outcomes for their citizens, as politicians move through office, the continuity in social thought may be lost and goals can change. Often by the time there is a shift in power, everything that was brought into play by the previous group is suspect. We have seen this in the history of the provincial focus of funding and organizational structures at Ridgemont, particularly in the news articles and finger pointing that took place at the time of the ARC closing. As we will see in the coming text, the provincial goals in the LTC system will change again multiple times. In scientific research of any kind, Kendig (2003) writes that the bridges between theory, research, and practice are exceptionally important, and these gaps in continuity and shifts in power are an organic part of the cycle of change, relating in many ways to paradigm shifts in the scientific process which Thomas Kuhn wrote about in the 1960s and 70s.

\section{Paradigm Shifts}

In The Structure of Scientific Revolutions (1962), Kuhn saw the most characteristic feature of the scientific enterprise as its conservatism, which is seen as the consequence of the prolonged paradigm indoctrination that scientists receive during their training. Kuhn felt that it is the paradigm itself which represents the structured whole of given science, guiding research activities rather than a true search for truth (Fuller, 2004). As Kuhn (1970) has informed us, we cannot hope to observe facts neutrally, knowledge may be guided by action, but is primarily a product of interest and activities .

Larvor (2003) writes that the patterns displayed in Structure of Scientific Revolutions have been taken up and brought to bear on problems far outside the history and philosophy of 
science. Numerous researchers from widely different backgrounds including education (Harasim, 2000), organizational systems (Imershein, 1977) as well as mental health research (Barker, 2003) have considered the usefulness of extending Kuhn's notions of paradigms and paradigm shifts for analysis. This shift in world view and practice occurs at a point when a new paradigm is perceived not only to handle most of the already manageable research problems, but also to handle recalcitrant problems which have predicated a crisis and remain unresolved despite the efforts of practitioners using old paradigms. Moreover, the perception of these unresolved anomalies typically sets the stage for paradigm revolution (Imershein, 1977).

Christa Hojlo (2010), the director of the VA community living centers in Washington D.C. discusses the correlations between paradigm shifts in science and the current LTC system in in the United States:

Anomalies are questions and issues that can no longer be adequately addressed by the current system. When the tension around these increases enough, new ways of thinking begin to emerge and the crisis begins. New ideas are proposed. People take sides. The dialogue, the argument commences and something new evolves. The change itself, the transformation is personal initially. The individual acknowledges the anomaly. Then, as more individuals acknowledge and begin to dialogue, they form communities of persons willing to take risk to address the anomaly and find alternative solutions that might be dramatically different. Solutions this different often require almost unheard of approaches - approaches that transform. As more individual come on board, the transformation spreads through the system.

The analogy of paradigm shifts appears to relate well to the inherent structure of a medical model of care which has permeated the system of LTC both in the United States and Canada for decades. Environment communicates what we expect out of people, and in the medical model, staff in the past have been trained to deal with illness rather than patterns of daily life. Sawyer \& Rusk (2004) describe the pushback for philosophical change in LTC: 
The problems that the Eden Alternative philosophy address are not new, nor are the ideas that form the basis of the philosophy. The paradigm it offers, however, is new. The most prevalent reason why we cannot change and improve is that the foundation of our system is flawed and our leadership continues to seek improvement within that flawed foundation. The foundation is what needs to change.

In the mid 2000's, a consortium of individuals came together to change the way that nursing care was to be delivered in Nova Scotia. Each of them, at first, had individual acknowledgement of the anomalies in the LTC system in Nova Scotia, and had come together as a group in order to take risks with previously untested approaches to transform the system there. Participants in that consortium and in the ensuing transformation included the current management of the Welsh Group, as well as some of their future staff. It is important to note that the root of the changes of the models of care in Nova Scotia were based on outcomes at Evergreen Community in Oshkosh, Wisconsin where renovations had been done with the household model in 1992. That community was one of the key precedents for Sherbrooke Village in Saskatoon, built in 1999, which in turn became a precedent for many of the providers responding to the $2006 \mathrm{CCS}$. It is at this point that we will pick up the story of the provincial LTC system transition in Nova Scotia.

\section{The Continuing Care Strategic Framework Project}

In 2005, around the time that the Cost of Care Initiative was launched by DoH, a Provincial Steering Committee and the Province of Nova Scotia began a project with the aim of identifying possible ways to improve their continuing care system. The burden on the acute care hospital system was at a peak, resulting in extended wait times and more people trying to get into the LTC system. Over a 14-month period, the Continuing Care Provincial Steering Committee heard from 1,400 people from around the province. With their help, challenges were identified in order 
to develop a clear vision for the future of continuing care in the province. The project was based largely on consultation with the public, professionals and stakeholders, and the information and advice gathered was used to inform the Provincial Steering Committees' recommendations, which in turn were used for the 2006 Continuing Care Strategy (CCS, 2006). The ensuing goals defined by the Provincial Steering Committee called for a continuing care system that should:

- Be innovative and creative and seek new ways of looking at old problems

- Use the best available evidence when making decisions

- Be provided in a manner that is sustainable

- Be accountable and transparent and maintain open communications

\section{Provincial Design Standards}

The completed 2006 CCS document noted a key feature to the success of the new approach to long term care:

...the smaller numbers of residents living in one 'home area' or 'neighborhood'. Smaller numbers of individuals encourage relationship building between and among residents, families, and staff. The more familiar staff are with the residents, the better they can understand the person and the individual's unique needs.

The first exploratory communities to be designed with provincial money were built based on precedents in the United States and other provinces in Canada. The administrator describes in detail the need within the system and the history of the changes in the provincial goals for LTC, which culminated in the CCS and ensuing RFP's:

We were looking at building new homes because the government felt it was important to build more facilities and there was a lot of push from acute care because they were backing up. The answer to alleviating that back up seemed to be to build more long term care beds. In doing that, we really needed to know program standards, but design standards too. We did cross regional research, and ended up focusing on what was done by David Green at Oshkosh, and also in Sherbrooke Village in Saskatoon. We had been involved with the Eden philosophy for some time, so we really wanted to go to the small household 
environment. We built a facility up in Cape Breton, that was one of the early ones, before we went through the RFP. That was built with all single rooms, with the caveat that in each wing, there had to be at least two rooms that were connected for couples. That was after 2005. It was the first time we had that many private rooms, it wasn't in the small house model yet, so there were 30 rooms on a wing, you had to walk a distance if you were at the end of the hall. This did have its own kitchenette and its own living room; it was really a self-contained wing, though they did end up sharing a kitchen between two wings. We found the distance all the way to the kitchen was too much. But we did find that the noise levels had gone down and there were a lot less negative interactions, but people were staying in their rooms more. They were cozy; it was like their own apartment, but the interaction, the whole social thing changed.

After analysis of these first communities, the DoH began to look at the sizes of the models, determining that there needed to be smaller households in order to cut down on walking distances for the residents and to increase socialization. Because the model was new to Nova Scotia, the province hired a full research team to study communities in other provinces and in the United States, which had been successful in the model. The DoH administrator continues with an explanation of the issues involved in reassessing the requirements for the new LTC communities:

So how do you keep that socialization going? When we started with the next small group of RFPs, we wanted the kitchen and the dining room closer, in the middle, so we came up with the guideline that there couldn't be any room further than 75 feet from the living area. We were trying not to do a cookie cutter program, but at the same time we were trying to set a precedent, it worked better. But there still were issues and we learned from those things. We went on and had David Green and some other people come up from the States to help develop our standards. We hired somebody to do some cross country jurisdictional research on sizes and structural issues.

In addition to the need for completely new communities, some existing long term care facilities in Nova Scotia needed renovation, while others needed to be replaced. These renovated communities' guidelines were not as structured as the new communities, but there was a similar resident and family focus. The standards for all of the construction required that the organizational environment must: 
- Help residents maintain choice and self-determination even as their need for support increases.

- Encourage residents and families to be partners in care.

- Support a holistic approach to resident centered care-addressing physical, social, mental, and spiritual well-being.

- Enable flexible scheduling of activities of daily living.

- Provide opportunities for meaningful relationships, interactions and companionship with residents, family, staff, and the community.

- Maximize resident's abilities through improved design.

- Provide a clean, accessible, comfortable, homelike, and secure environment for residents and family.

Another key component of the new approach to care was staff organization. Staff

organization was to be decentralized, with empowered, working teams in order to better meet the needs of residents. Based on research demonstrating the significant relationships between this aspect of care facilities and resident quality of life and satisfaction, the guidelines required that the physical environment must

- Support the occupational and organization health, well-being, and safety of staff.

- Support innovative and alternative models of care delivery for the provision of resident focused care.

- Provide a workplace for staff that is pleasant, safe, and efficient.

The process of putting together the space and design standards took about two years.

Some of the DoH employees were working on the standards full time. The DoH went on to develop the final guidelines for 11 new nursing facilities, and the Nova Scotia's Procurement Request for Proposals (RFP) process was used to award contracts to build over 800 new long term care beds in Nova Scotia's CCS. The RFP was released in three phases:

Phase 1: Included the contracting process, the location of beds, details of the selection process, vendor evaluation criteria, and response requirements.

Phase 2: $\quad$ Included the design, space, and program requirements, as well as information on the required financial proposal in draft. 
Phase 3: $\quad$ Included the design, space, and program requirements, as well as information on the required financial proposal in final format.

\section{The RFP Process}

Nothing was put in writing more than the RFPs. (Robin-The Welsh Group)

Phase 1 of the RFP was released on April 5, 2007, and follow-up documentation was released in June and July, which included the Master Program describing each service/department to be provided in the new communities. A functional program followed, providing room data sheets for each unique room in each department. Room data sheets identified the number of people expected in each space, any special design issues, architectural items (built-in), major equipment, furnishings, and unique electrical/mechanical requirements. The DOH administrator commented on the provincial accomplishments and lessons learned in the set of standards for the RFPs:

It really blows me away that we were able to move away from 35 bed wards to 12 bed households. And the staffing ratios, already the staffing ratios in the province are some of the highest in Canada, not extreme, but when you go to the others it's higher. They are all still saying it's not enough... but that's the way it is. So really, over less than two years we put together the standards. There are lessons learned of course, next time we will be much more restrictive on the size of the unit, we did say we wanted them to be 12 beds. We needed to have the living area central, we didn't want people to have to go around a corner, or have to get lost in their home. We wanted it to be quiet, and to have it be client focused. So that's basically how we got to where we got. There was a point in all this, that we had something like 52 projects going at one time. For a small province, that's big.

The following are partial guidelines released by the DoH, as a portion of Phase 2 of the

RFP that speak to the specificity and level of detail in the requirements for submission:

The new LTC facility will have 50 beds organized into four resident houses. Each resident household will be a self-contained unit, and will have a front door from the main street connecting all resident households to the shared public areas. In addition to the resident houses, the new facility will include resident ancillary 
spaces such as a multipurpose room, beauty parlor, main entrance foyer, and overnight family spaces, space for rehabilitation services and support services such as plant/maintenance, materials, management, administration, and staff facilities. Each Resident Household will include:

- Single resident bedrooms with private washrooms

- Resident assisted bath and shower room

- Living room, kitchen, and dining room

- Staff work spaces and support service areas such as personal laundry, housekeeping room

- Each resident bedroom will be 190 sq. ft., which includes space for a resident clothes closet, bed, dresser, and chair

- Each resident dining and living room will be sized based on no less than 36 sq. ft. per resident

- All resident bedrooms will be single rooms and all nursing home bedrooms will be equipped with ceiling mounted tracks

- All resident households will be designed with appropriate walking areas and way finding design

- A small staff/medication work space will be provided within each resident house dining room

- Every household will share support space. Staff will have easy access between each household to provide backup coverage. The central dietary, materials management, laundry, and plant maintenance will be separated from the LTC resident households to reduce the impact of noise from support spaces (RFP, 2007).

By August 2007, the RFP responses were received and an evaluation committee, made up of representatives from the $\mathrm{DoH}$, reviewed the submissions. Submissions were evaluated according to criteria outlined in the RFP, and included: (1) the ability of the vendor to deliver the proposed facilities and services; (2) the specifics of the proposed facilities and services; and (3) the proposed net costs to the province (CCS, 2006).

\section{Making the Pitch Based on Ridgemont}

The Welsh Group's bid for the RFP was overseen by Wyatt, whose role was project manager because of his intimate working knowledge of user group requirements from being a 
long time nursing home provider. In addition, he understood what was involved in the design/build sector due to his involvement with the Welsh Group's parent construction company and the nursing home renovation at Ridgemont. This knowledge of both the nursing home and construction industries reduced the need for cross-education and had the capability to streamline communication requirements. The other group of individuals on the team each had their reasons for becoming involved in the RFP process for the new community. Robin had been the Director of Care at Ridgemont for years. Francis, the current Director of Care at Stonebridge, had originally come to work with Wyatt at Ridgemont because she had heard about his work on the nursing home renovation there in the 1990s:

I heard about what Ridgemont was about, I had heard about it from a long time ago. I remember when I was working at another facility and they had residents called "bad residents" because of their behaviors, they would send them out there. That was the final stop, or a place in Dartmouth. Those other facilities weren't looking at what's causing this behavior; they were just considered bad residents. When I heard about all they had done at Ridgemont, I gave Wyatt my resume, long before they had a position open; I'd heard such good things about the care there. So I got a call finally, a couple years later, they were looking for a Director of Care. Peggy was off at maternity leave, I didn't know her at the time, but I got to know Robin. I sat in on some of the meetings between Robin and Wyatt and listened and got to know where they wanted to go in the future and thought, "Yes, I want to be a part of this." I said, "This is where my heart is, this is what I want to do."

The formative discussions about how the Welsh Group was going to tackle the RFP took place in the renovated Ridgemont conference room. The positive and negative experiences over the years there had prepared Wyatt and his team for the road ahead. Wyatt explains:

You can imagine the staff, how good they were to cope with that environment. How amazing they were, those were old buildings that weren't designed for this use at all, they were dormitories for the military. If you look at Ridgemont, I have to think that we are a lot less institutionalized now, because of our history with the mental health population. If you picture back when we had 155 folks in the ARC, more than half of them had schizophrenia and bipolar issues. If you tried to treat 
them the way that people treat seniors, you would get clocked. If you tried to get them all up for breakfast at 8 o'clock because that's when the food cart comes, you would get the crap beat out of you. We had no uniforms; it was a much more social model than any other homes in town. What you are getting at Ridgemont even now is less institutional than most nursing homes. We are kind of halfway between those two.

Robin agrees that the strength of the care giving staff at Ridgemont was really the backbone of the company at the time of the RFP, and describes how the staff and management experiences there formulated the Welsh Group culture of care:

The things that I would find to be heartbreaking, the staff didn't. Every one of the staff who had been there for 20 or 30 years, they loved it. To me it would have been chaotic and scary, just hearing some of the stories. But they'd say, "We loved it." "Why, what was it that made you love your job?" Even Wyatt has said himself, "Yeah it was crazy, but I loved it." The thing is too, when you look at what they are doing, they love their residents out there; they take so much pride in their work.

The Welsh Group submitted their proposal and was shortlisted for the work. Wyatt

remembers the scramble to put together the paperwork and a presentation for the $\mathrm{DoH}$ in order to better describe who they were as an organization. One of the primary focuses for the presentation would be the previous work done in the nursing home renovation at Ridgemont and the strength of the caregiving staff there:

Based on our RFP submission, we were shortlisted, so we had to make a big power point presentation. Part of the reason that we won it is that we did it all ourselves, in-house. A lot of the other people who submitted proposals hired consultants to do it; no consultant is going to understand the business like we do. And between Peggy, who really has a good grasp of the vision, and I, who has the vision and the building side, we nailed it. We had gone out to Ridgemont and taken pictures for the presentation and talked a lot about quality of life there, like the guy who liked to plant in the vegetable garden, the activities and what we did in the nursing home renovation, which was really quite leading edge at the time. We kind of took all of that in the presentation and said, "This is what we hope to do." So the long short of it, we pulled this thing together really quickly, we did a knock-out presentation and that's what got us the job. 
Because the parent company to the Welsh Group is a design-build organization, the entire bidding process was in-house, and the firm did not need to tender anything out which cut down on time and cost. As Wyatt remembers, "In our case, we just did it all ourselves, I was probably a one man project management firm. We did everything in-house." Wyatt's leadership continued to guide the group throughout design-build process, reducing the overhead and confusion which results from having to hire an outside project management team.

\section{Getting "it" in Saskatoon}

Prior to their bid for the RFP, Wyatt and Peggy had been to see the SH model of care at work at Sherbrooke Village, a 270 bed community in Saskatoon. After winning the bid, Wyatt made the decision to send Robin and Francis to gain more insight into the model of care in order to help prepare for the design and implementation of the model. He explains:

Saskatoon is sort of the Eden center for all of Canada. The people at Sherbrooke Village offered these half day tours, and a lot of people from Nova Scotia went out for those, but we knew that you would never get it, you need to live it. Robin and Francis spent a week there and lived it. They worked with the personal care workers and saw how it worked and had their questions answered. They came back more enthusiastic and more determined than Peggy and I did. They got to ask their questions; that was the best thing we did along the way. It was a bit of a gamble, but it clicked. It clicked better then Peggy and I would ever have dreamed.

Robin and Francis travelled together to Sherbrooke Village and both were deeply moved by the experience. Both had been nurses in traditional LTC settings throughout their years of professional experience, and Robin recalls her initial reaction when she visited the Sherbrooke community:

I'm telling you, when I got it, in Saskatoon, I had this epiphany. Everything got easier for me, this is not rocket science, this is just day to day living. Honestly, just by virtue of wearing a uniform, you are saying "I have control over you." I 
know I'd be tarred and feathered for saying that, because there are caregivers who are very excellent caregivers, but they don't understand that a uniform sends a message, even a pretty uniform sends a message. A lot of people are really proud of their uniform because it says something, a visual speaks louder than words sometimes. We all said, "How are we going to implement this? It all sounds good, but how are we going to do all this stuff? Like how are we going to deliver meds without a med cart?" "I don't know, but it sounds nice."

Francis had a very similar personal reaction to the visit, and she describes her realization at the time that she wasn't as far along in her understanding of the model as she had originally thought:

Robin and I were sent off to Sherbrook Village; it was an amazing eye opener, because even though I wanted to do it, I knew that there were still going to be all kinds of blockades. It wasn't as simple as the things that were going through our heads, I didn't realize how institutionalized I had become. I didn't think that I was, I thought, I'm one step above that in my thinking. We learned a lot, we learned a lot about ourselves, about our visions, where we were. Like I said, we thought we were further ahead than where we were. We began to realize some of the challenges that we were going to face.

After the visit, Robin then took the Eden training to further her understanding of the model of care that she had been introduced to at Sherbrooke Village, and she began to feel that the model of care that she and others had been working under for decades was, in essence, a form of emotional abuse. She describes her need for a complete change in her thinking about the provision of care in LTC:

I began to feel that the way we were treating residents is a kind of abuse, right? I don't mean restraints; I mean not letting them do things on their own time. I remember when I was taking the training, I kept trying to put the Eden alternative in perspective with the old model. I was like, "OK, no medical carts in the hall, where do we put them, we need a closet that's big enough to hold the cart (she laughs)." They kept reminding me not to think in those terms, the old way is the old way and this is something else. Now I can't imagine going back. 


\section{Design as a Group Discussion}

The room sizes and building square footages had been pre-programmed in the RFPs;

therefore, when the building design process began, there wasn't a lot of flexibility with materials, layout, or cost per square foot. Wyatt was doing all of the paperwork associated with the RFP requirements, while the Welsh Group architect began the design process for the building. The architect describes his impressions of the process of designing a building within the well-defined provincial guidelines:

The program was so well defined, in terms of the required spaces, the size of the spaces and the finish within the spaces, so there were a lot of decisions you didn't have to make. You knew what the flooring was, and you knew what the wall finishes were, and you knew the size of the rooms, and basically the size of the facility, no more, no less. You could build it more, but you're not going to get paid for it. So, from a costing point of view, you knew there's a fixed budget that the government allows for these facilities, so that was strictly controlled. You had limitations as to what you could do in your design, what materials you could use, and those kinds of things. But you absolutely could not build one square foot less than what they set out. That put everybody on the same basic page when they responded to the RFPs for these various facilities.

Because of deadlines and time constraints, the architect was focused completely on the

design, while Wyatt did most of the communicating with DoH. The architect felt like he was

having a crash course on LTC design, though he was not able to do much research and depended

on Wyatt for a lot of the general concepts for the design. He explains his role in the design:

I'd heard Wyatt talking about the design he had worked on up at Ridgemont. He had spent a lot of time over the years researching the various models and certainly what we've done we didn't invent; we were just trying to improve upon that cottage model in some way. It was a good learning experience, but it was difficult. It was part of a group discussion, and it was explained to me why things weren't going to work the other way. I dedicated two years of my life to designing Stonebridge and the other one that opened later, that's all I did. That doesn't sound like a lot; architects do that all the time. But normally, I'm used to working on half a dozen projects a year in some capacity as a designer. 
The architect explains that because the Welsh Group is a design-build firm, the design process went a little differently than it might have in some other offices, in some ways creating more flexibility in the design process, while at the same time resulting in a loss of the ability to share ideas with other designers:

We do architecture, we do design-build, which is a little different than a typical architect's office where there would be, I don't know how many architects and designers working on a project of this size. In another office, a facility of that size, it would be a large project, with a lot of support staff. That just wasn't the case here; it's not the way we do things. I did have people here that I could rely on, like the production side of things, and also certainly they are good at costing things out and sourcing materials and all of that, so I had all of that help here. There are times though, that you would like to be able to bounce certain things off of other designers, and you just don't have that advantage here. But it was an easy transition from the architect to the builder, we were all working together.

\section{The Physical Design}

The availability and purchase of a suitable parcel for the new building presented a challenge, but the Welsh Group worked with the Halifax Regional Planners to identify potential parcels within the community boundaries. A site was located in an area with a mixture of residential and commercial uses, and was chosen with the hope that it would offer a residential feel, with close proximity to commercial enterprises. The site was 5.67 acres and relatively narrow, therefore, the site dimensions dictated the actual building layout (Figures 39-40). While the notion of a central administrative core with surrounding neighborhoods or cottages initially made sense, the team decided to make the community two stories in order to fit the site and reduce the size of the building footprint. The architect describes the thought behind the general placement of the building on the site:

We had originally looked at a central administrative core with the pods coming off of it, conceptually, that's what you want, but we looked at it with a cost point 
of view and the piece of land that it was going on and we said, "Really, that's an expensive thing to build. How and where can we save money doing it?" That's where we came up with the two story idea. It was sort of a no-brainer, though you are still into an elevator which is expensive. There were other firms whose buildings weren't constrained by the land and they were just building these sprawling things. So we had to show DoH that we could get access from the second floor and the green space outside and the bridges and things like that.

There were also issues of interior circulation. One of Wyatt's primary goals was to create a main street with places for residents to safely go if they wanted to leave their cottages, like shopping and seating areas (Figures 41-42). The architect describes some of the other central concepts incorporated into the final design:

The concept of the interior street, all of the common area, that was important. We looked at that many times over. Wyatt had said he really wanted the residents to really feel like they are going somewhere. Also in the cottages, it was important to make sure these places were easily monitored, that there weren't any sort of hidden dead end areas where people could get lost or confused. And I wanted create activity areas within the common dining room. That was a focus. And the other thing was to get some sort of daylight in there, and some connection to the outside.

Financing for the new community was through a guarantee from the Housing Development Corporation. Wyatt explains, "The HDC gave us $100 \%$ of the money to build the homes, because they can borrow the money cheaper than we can, so we didn't have to come up with any equity. In 25 years, the building is ours." 


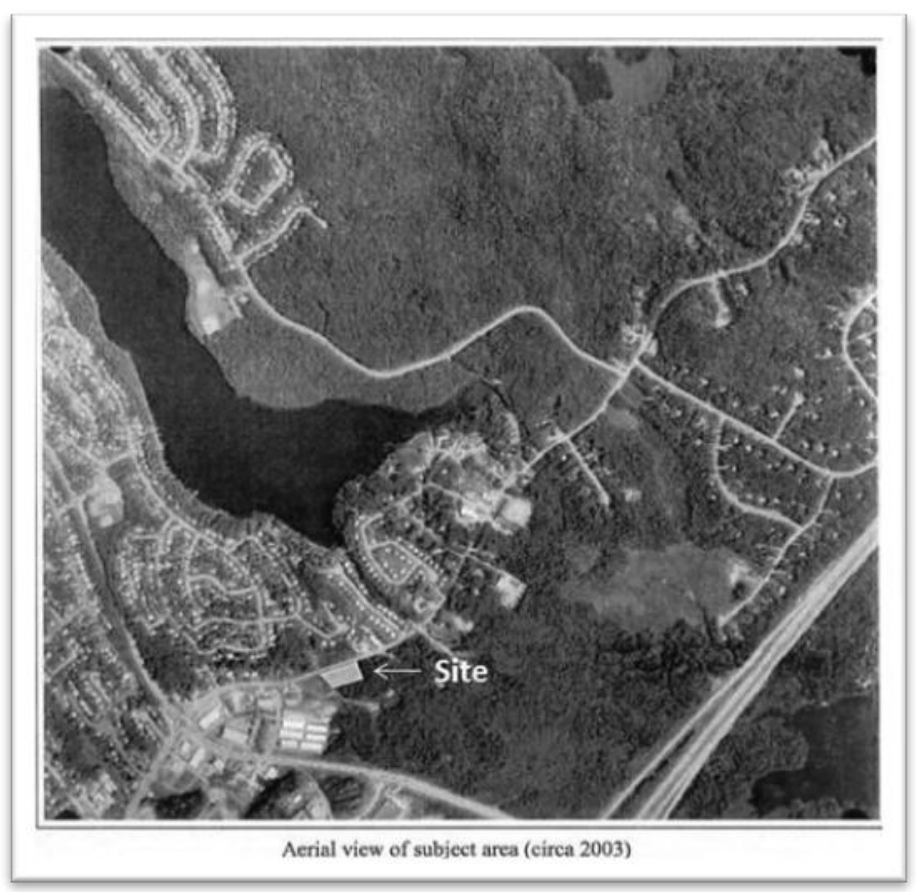

Figure 39. Stonebridge Building Site and Millville Aerial View

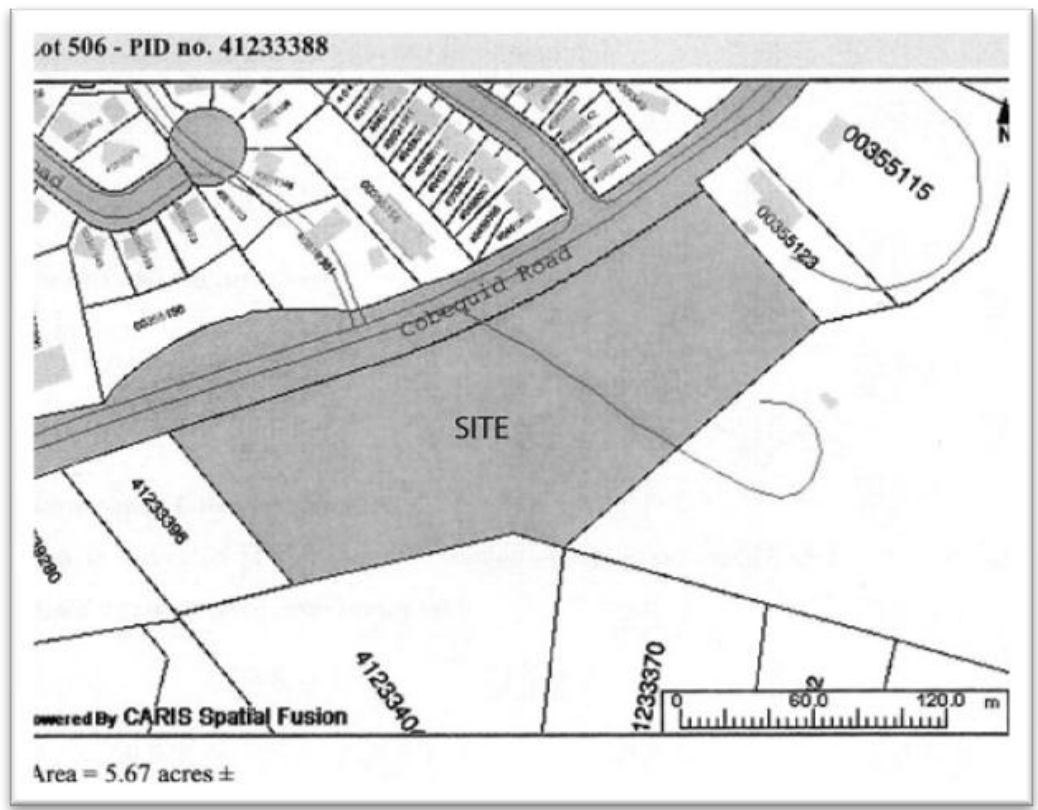

Figure 40 .

Stonebridge Plat Map 


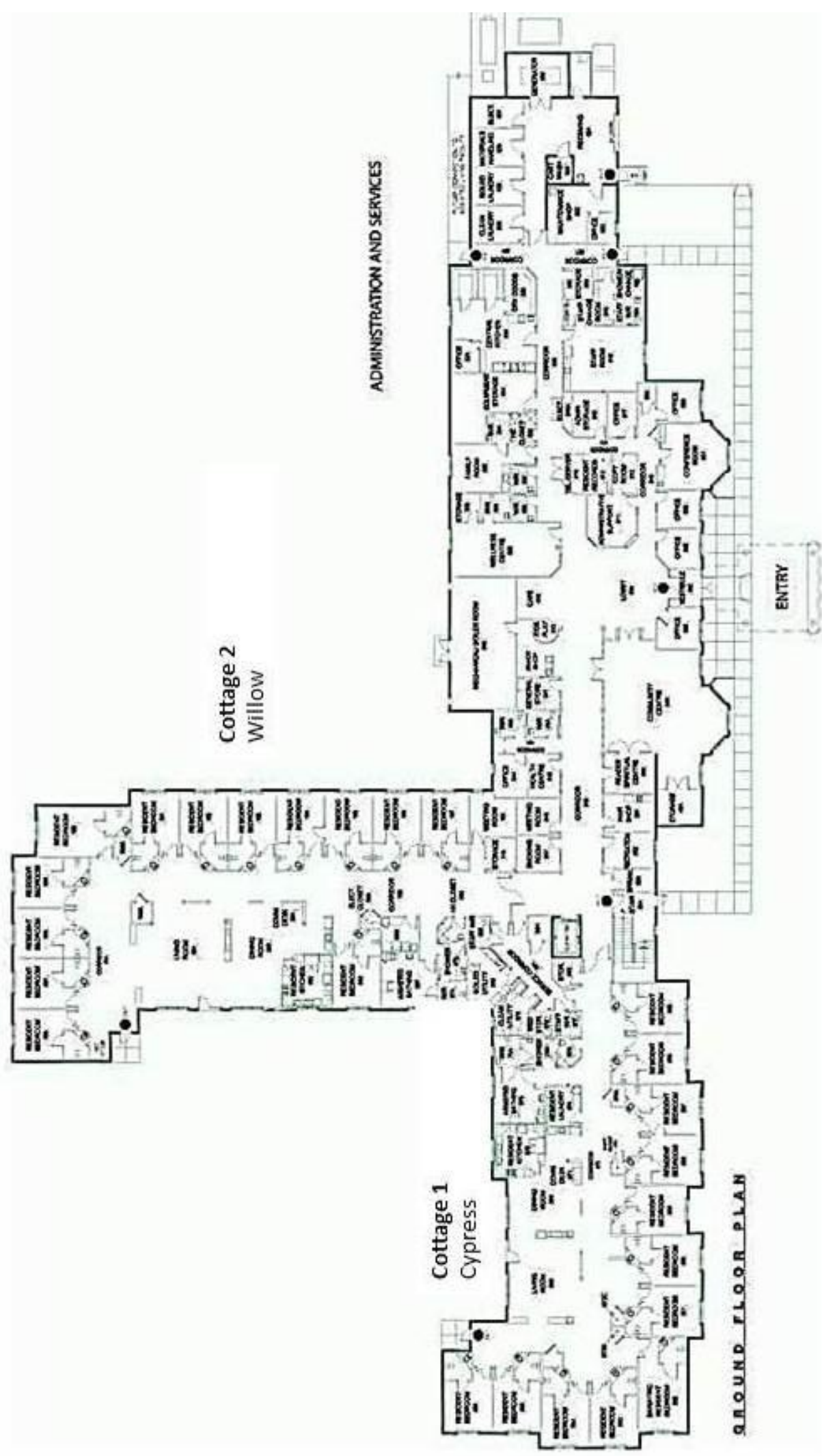

Figure 41.

. Stonebridge Level One Floor Plan 


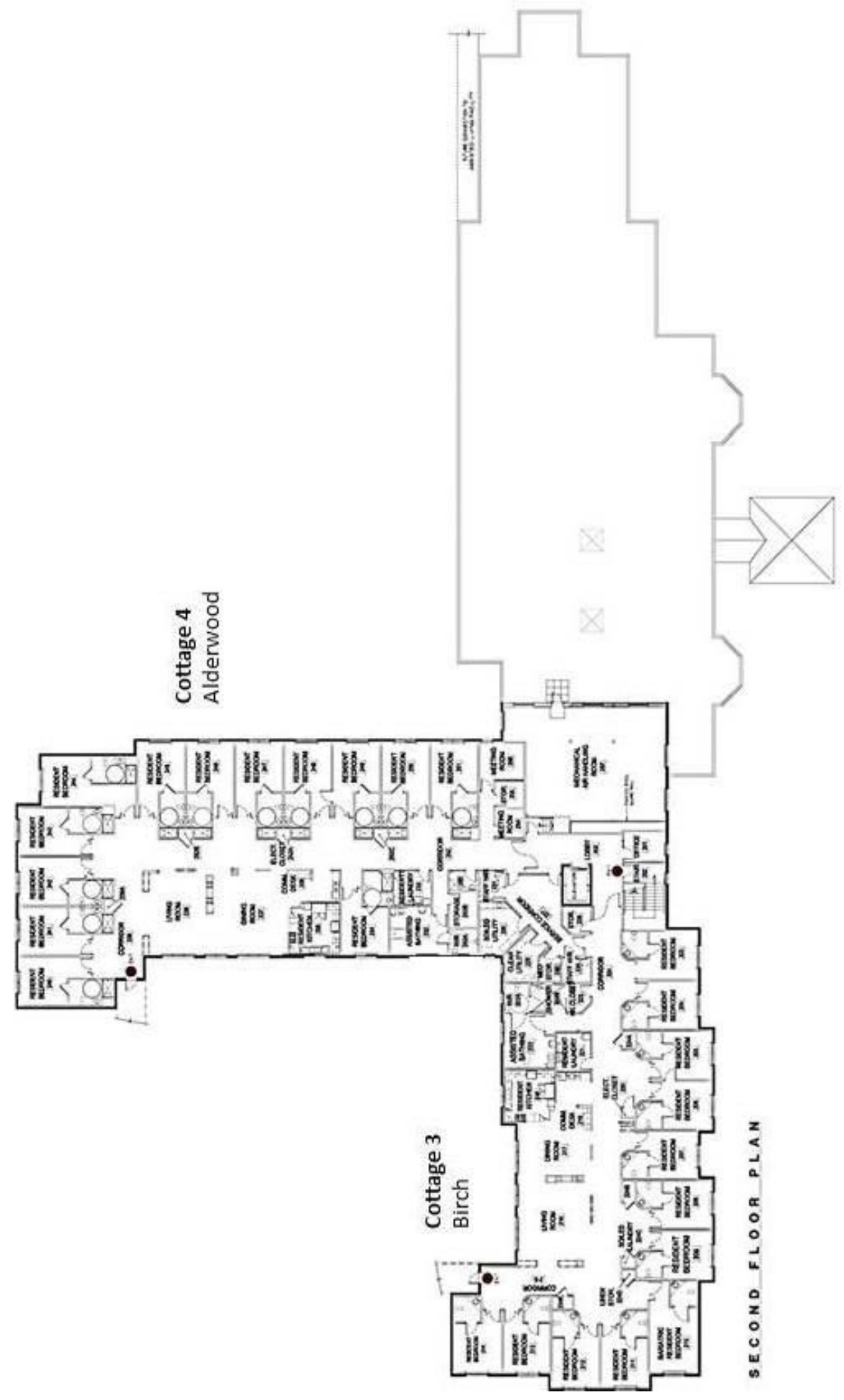

Figure 42.

Stonebridge Level Two Floor Plan 


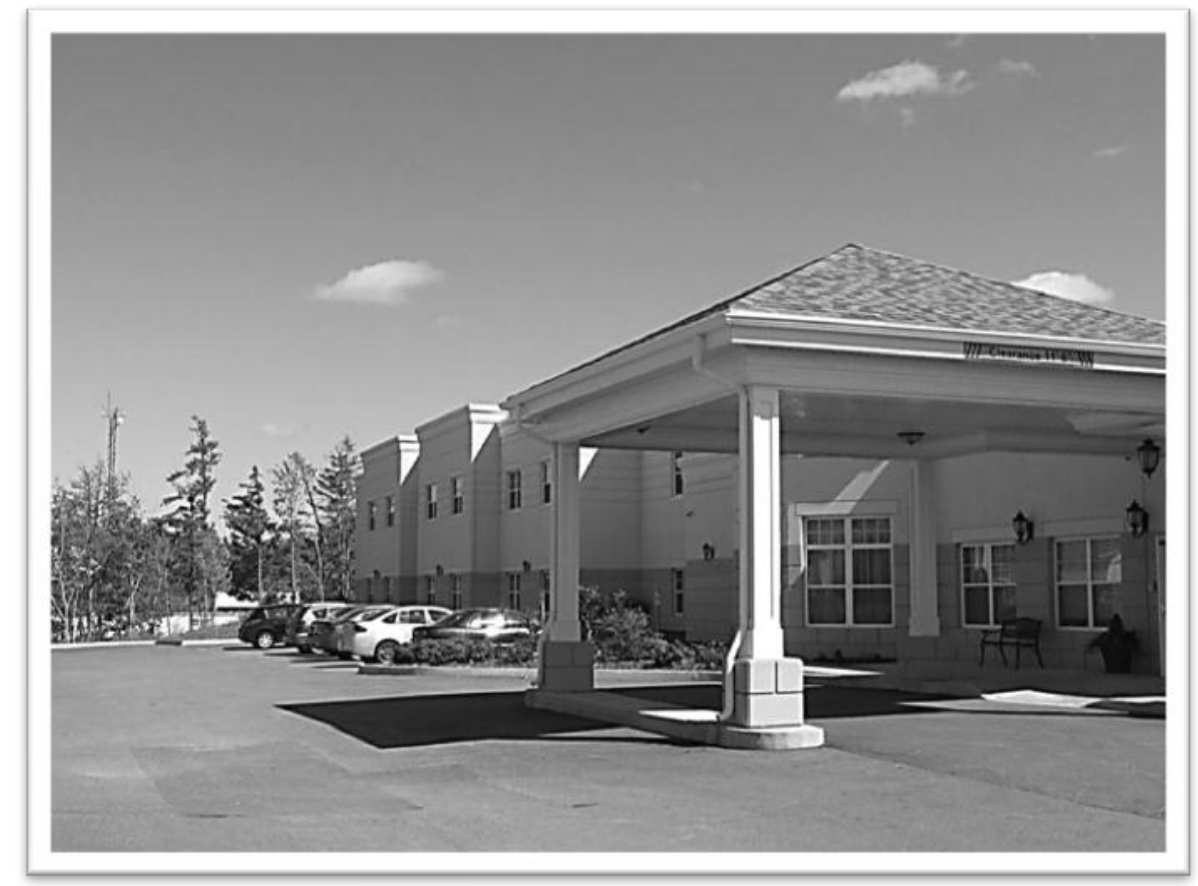

Figure 43.

Stonebridge Entry Looking East

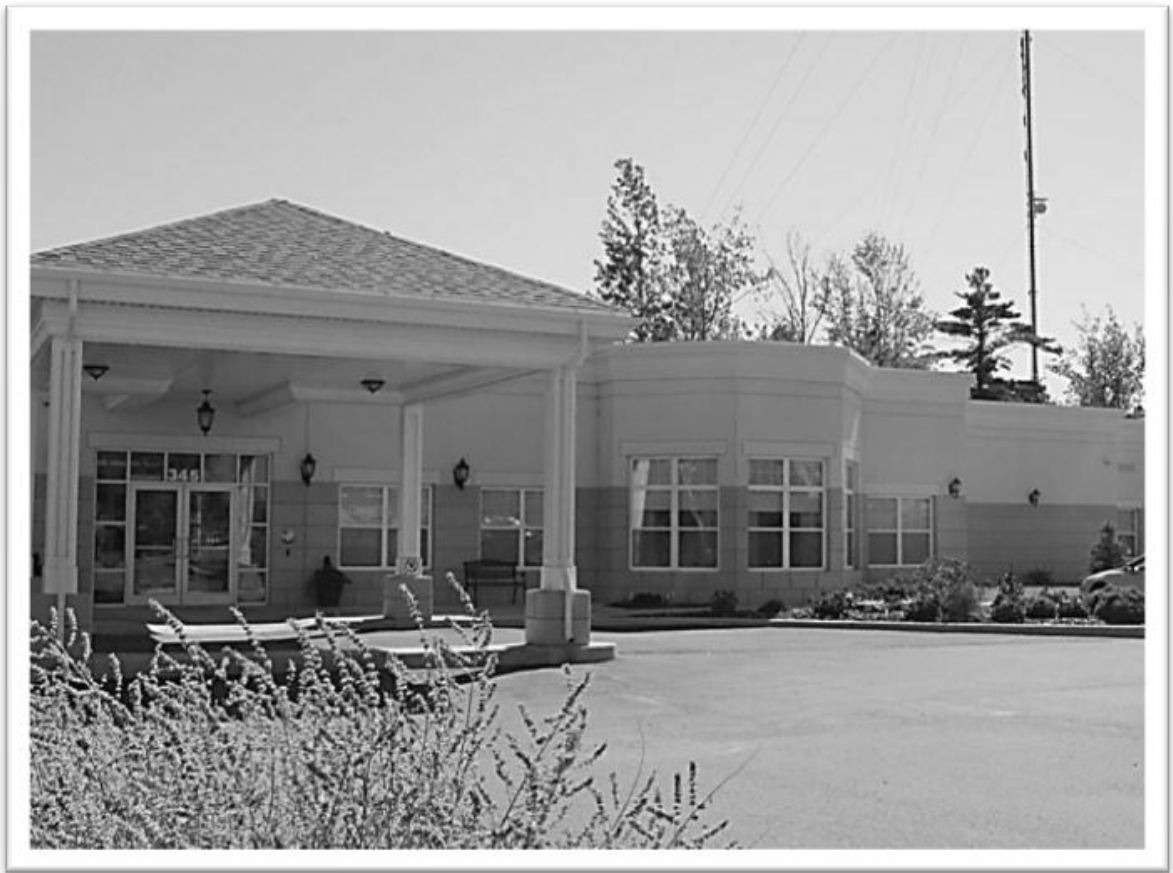

Figure 44 .

Stonebridge Entry Looking West 


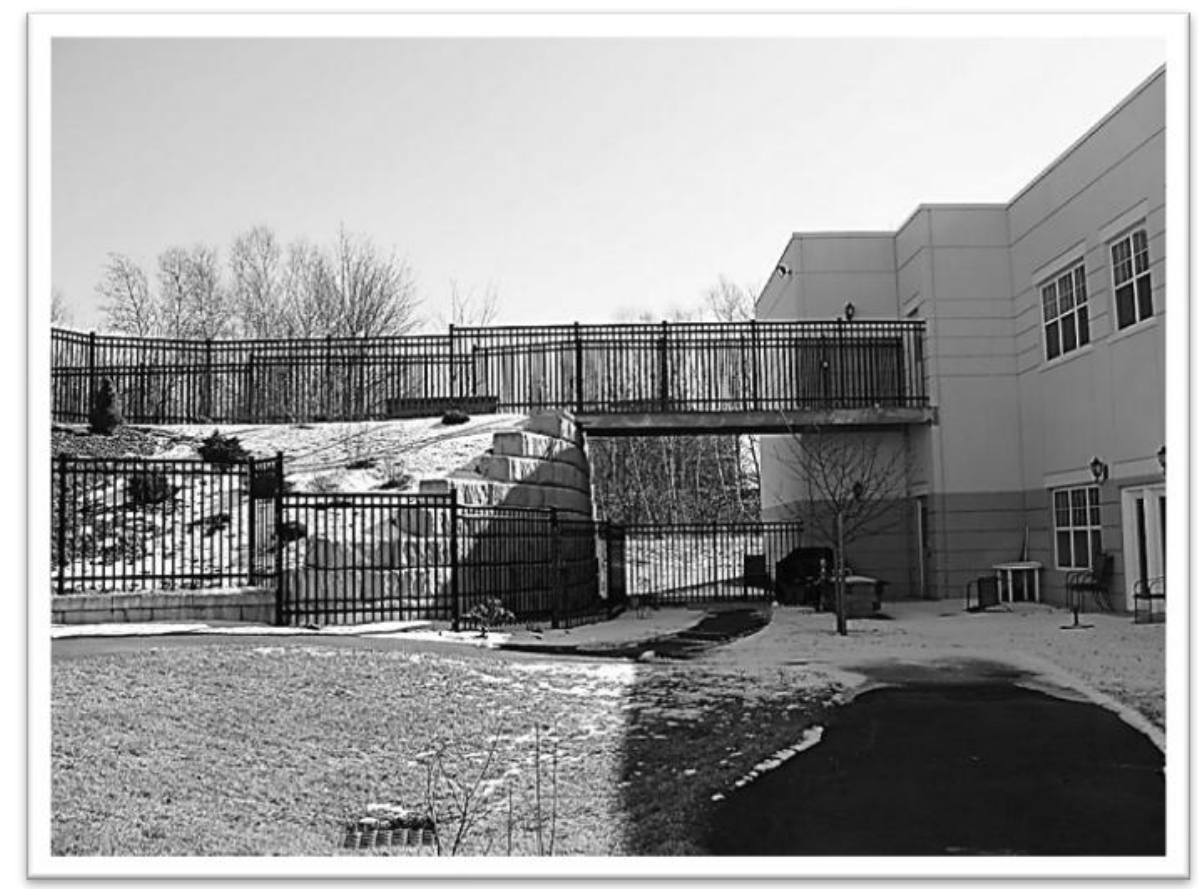

Figure 45. Stonebridge Level Two Link for Exterior Egress

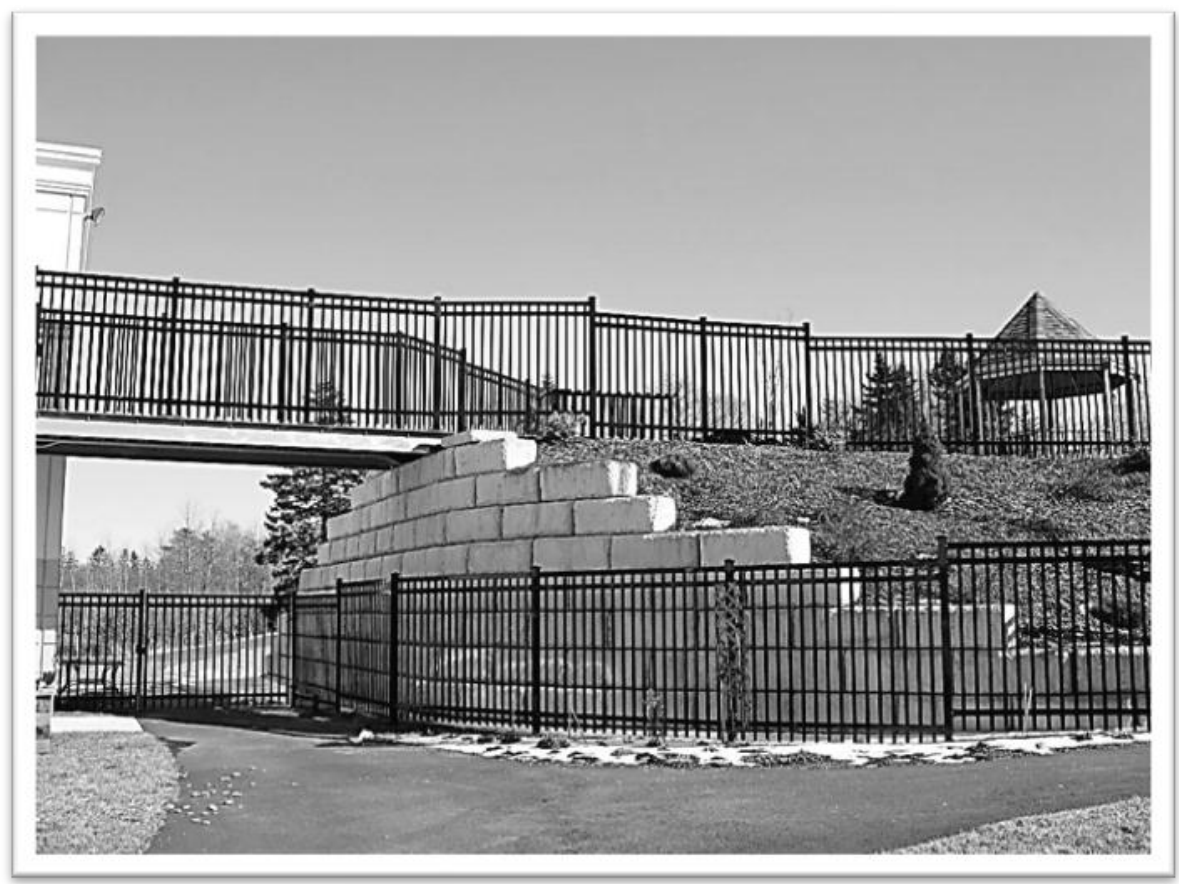

Figure 46.

Stonebridge Level Two Link and Gazebo 


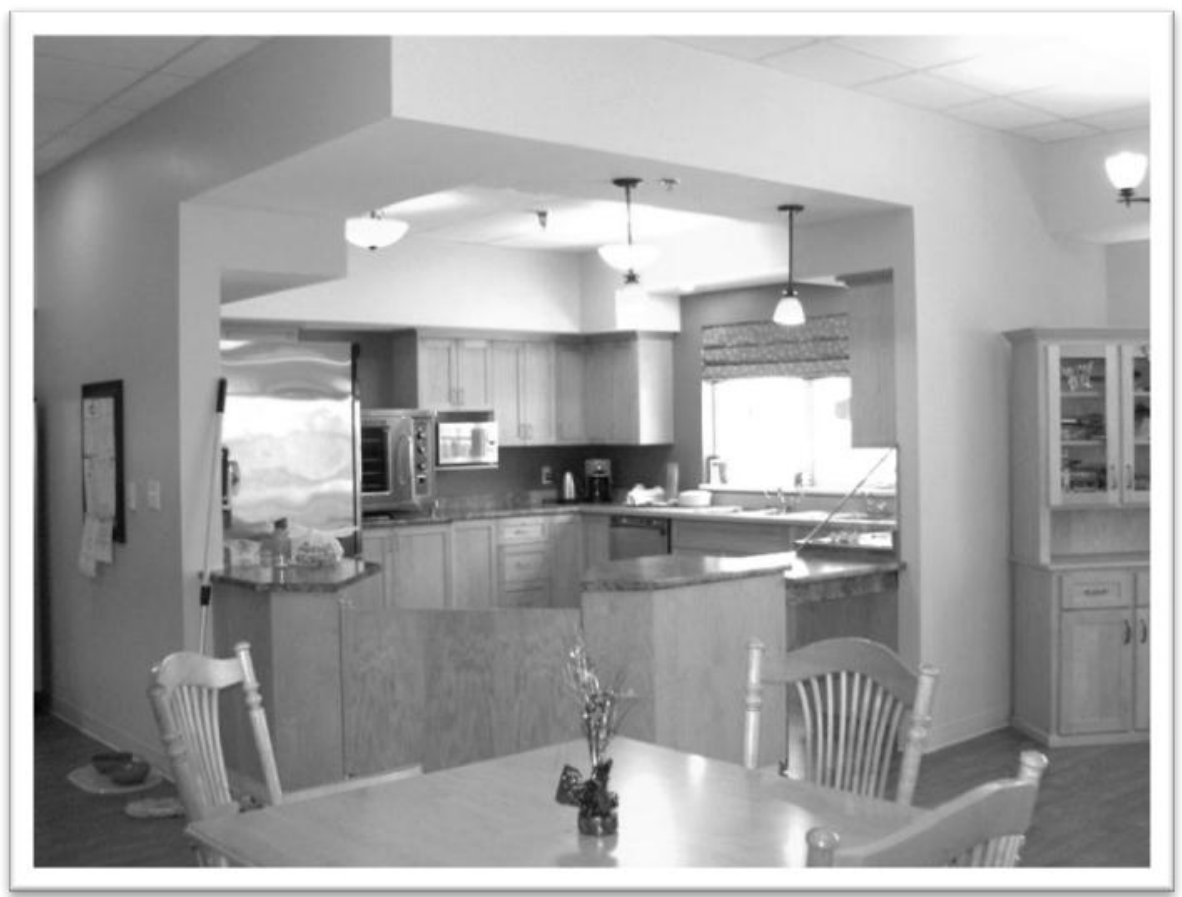

Figure 47.

Stonebridge Open Kitchen-Alderwood Cottage

The Fight for the Open Kitchen

While approval for your plans may be granted, brace yourself for the first fire inspector "walk through" after the building is complete. It can be as if plan approvals never took place and the price tag can be startling. Annual inspections may bring up new issues with long-standing situations never before identified as problems. Fire Marshal inspections are one of the regulatory system's most expensive for providers. ( Norton \& Shields in Bowman, 2008, pg. 65)

One of the major design goals for the management at Stonebridge was to have an open kitchen in each of the cottages. Most people are familiar with the notion of the kitchen as the "hearth" or hub of activity for the family; this can also be true for the dining room and kitchen in LTC (Cohen \& Weisman,1991).With a move away from a central spot for activities, small eat-in kitchens work well for more conversation and encourage resident to eat when, where, and what they want (Brawley, 2006), and intimate, non-institutional dining in which residents dine family style at small dining 
tables has been linked to increased social interaction and communication during meals and to improved eating behavior among residents (Day et al., 2000).

If Robin and Francis brought back one thing from their visit to Sherbrook

Village, it was the determination that the Stonebridge cottages would have open kitchens

(Figure 47). While other facilities from the same RFP did not incorporate the open

kitchen concept, Robin remembers how hard the Welsh Group would have to fight for it:

When we were ready to go to construction, we had the DoH saying, "Wait a minute now, we thought you were doing the same thing as those other facilities." And we're saying, "No, no, this was in the plans that were already approved." Then they were talking about putting all kinds of restrictions on that and walls up and a full door in a closed kitchen and we were saying, "We can't." Had we not gone to Sherbrooke, we would not have gotten it. If Peggy had not sent Francis and I, we would not have fought as hard as we did. We said, "We will do whatever you need us to do. Don't tell us it can't work, tell us what we need to do to make it work, because we are at that point now, we need to know." They were like, "Well just put a couple of walls"... and we said, "No, no, no, that's not an option."

Wyatt was adamant that the open kitchen was not up for debate as well and worked hard

with the $\mathrm{DoH}$ and the fire marshal to ensure that there would be no change to the kitchen layout:

I remember the health inspector at the time, I'd known him for years and he was listening to Robin explain her goal for an open kitchen. Then I said to him, "This is going to happen, and we will work together to make it happen." He came up to me months later and said, "You know, you were really serious about this." Working directly with DoH helped us a lot. Normally everything heat generating is required to go behind a door, that's why the kitchenettes at Ridgemont are all behind doors. For the new kitchens, I said "We're not doing that, we have to keep them open, this is going to happen." So the DoH, they ended up hiring a fire consultant, they took all our designs and did a study on it, on how the smoke would disperse; they took a year doing the study. In the end, we were allowed to do it with certain conditions like the bulkheads. I tell you, we just dug in, we fought that, so that's how we got the open kitchen. 
In the interim, Wyatt had gotten word that many of the people from DoH who had created the original 2006 CCS documents had either left or resigned. He was concerned that more issues like the debate over the open kitchen might pop up if the new provincial leaders did not understand the philosophy behind what the Welsh Group was doing at Stonebridge. In order to avoid any other last minute surprises, Wyatt pulled together the management and design team for a meeting with the DoH:

We were going along, the home was being built and we were about two months from opening. We were getting drift that the people in the DoH had changed and the new people that we were dealing with had all left or were reassigned or something and that was really worrisome. So I said, "We need to have a little meeting with some of these people to make sure we are all on the same page, because when we open, we don't want any trouble." So we decided; Peggy, Robin, Francis, and myself, we called this meeting. We told people in government and health to pull people together as they saw fit, because we were going to come in and present. We went in thinking we'd be presenting to about six or eight people, we walked in to a room of, I'd say, about 40 people, everyone that you can ever think of in government. The plans examiner, the fire marshals, a whole slew from infection control that I didn't even know. We were just there to present and they had the executive director who is under the Deputy Minister of Health. It was a mixed bag, you had people like the driver of the CCS who really understood long term care, but then you had all of these other people in the $\mathrm{DoH}$ who didn't necessarily get it. Basically Robin and Francis did the presentation; Peggy and I were just secondary because the care aspect was the main topic. They did an awesome job with their enthusiasm. There were some people from DoH there who understood what we were doing, some were not really part of the background, but they just loved hearing about what we were going to do. One lady had tears in her eyes, it was very emotional; it was a turning point in the whole process. What I found was that it was so well received, that they didn't want to rock the boat, there was this really fuzzy feeling.

\section{Hiring Goals}

A general staffing goal in the SH model of care is to have staff shifts and work locations arranged such that direct-care workers always work with the same group of residents (Rahman and Schnelle, 2008), with the same group of caregivers consistently working together, creating strong reciprocal relationships with the residents (Angelelli, 2006). It would be expected that this 
group of workers would function well as a team, and in fact, teamwork has been touted as an important component of culture change (Stone et al., 2002) By training and facilitating staff with behaviors that will benefit residents like communication, patience, and tolerance, an attitude of kindness and flexibility can ensue, allowing for an environment of compassionate care (Rader, 1995). A major challenge for the Welsh Group in opening Stonebridge was to find a cohort of caregivers that had a clear understanding of the philosophy behind this model of care.

The Welsh Group was well aware of the existing caregiver training due to their experiences at Ridgemont, so what came to make the most sense for the organization was to start with a completely new cohort of caregivers, trained specifically for the philosophy and model of care. The Welsh Group connected with the local community college system to set up classes for the new CCA positions, using two of their RNs who had previously been instructors to teach the classes. Wyatt describes the hiring process for Stonebridge:

When we were recruiting, we didn't really want that many people from the business, and of course we couldn't hire people from Ridgemont, because that would have left that place short, so I think we only took about one or two people from there. That's why we really wanted to train these staff ourselves. The students were all committed, Robin had heard most of them didn't really want to work in the traditional model; they were all excited to come work for us. That was our goal; we wanted to be the place of choice to work. That was one of our goals at the beginning.

A presentation area was set up at the Welsh Group offices and potential staff were invited there to hear about the care philosophy and new community. The reactions to the presentation by potential candidates were gauged and Wyatt explains that that information session was kind of like a prelude to a first interview:

All the recruits were put through what our model of care was all about, and at that time it was all new to us, too. We gauged from their reaction to the discussion if it was going to be a fit. Of course, the biggest problems were people from the RN 
group. If an RN is sitting there saying, "This is never going to work," then that showed us that it probably wasn't going to be a good fit with that person. If they got through the information session and were positive, then they would have a first interview.

\section{Keeping the Unions Out}

The management team felt strongly about keeping the unions out during the start-up of the new community, if not indefinitely. The strength of the union at Ridgemont was one of the reasons why the team had not held their hiring information sessions there. The union focus was on staff hierarchy and strict scheduling, and Robin had strong feelings about why the union philosophy was antithetical to the Eden philosophy and the new model of care at Stonebridge:

Well, one of the main things that is important with the new model is spontaneity, and in the union mentality, you are geared toward keeping the scheduling tight, when people work, what they wear, and most importantly, seniority lists. The union mentality really goes completely against the philosophy of this model. Pretty much every nursing home in Nova Scotia has a union to work with seniority, vacation, and pay; unions exist solely to get more for their members. They say they are trying to do more for the residents, but union dues are paid so that there is quality of life for the staff, for their members. There is an old school union mentality which is still loud and clear.... "Fight, fight, fight." We're saying that's not the way it works.

In essence, the union influence is about job security and staff hierarchy for participating caregivers, rather than the needs of the residents. The importance of the relationships between the residents and staff are at the center of the philosophy of care at Stonebridge, therefore, the union focus would detract from that relationship. Robin describes the tensions with the union based on her previous nursing and management years spent at Ridgemont:

Truly the center of this philosophy is the resident and the staff. It's about developing that relationship between the staff and the elders, and you have to treat your staff as well as the residents. Why does it have to be at odds, if you don't have the relationship, then what do you have? If it's good for one, then it's good for the other, because a healthy living environment is a healthy work environment. I get that having a healthy salary is important, but we are restricted in this funding whether we are unionized or not. The union can't see the bigger 
picture, unfortunately. If they did see the bigger picture, we wouldn't need a union; think about it...

The provincial buy-in and understanding of the Welsh Group goals resulted in the team being able to move forward with the final interior work on the building without any more major hurdles. By pulling together a cross-jurisdictional group, the team ensured that there was not only a cohesive understanding, but a shared sense of direction in their goals between the management and care staff. Robin comments on her perception of the strength of the Welsh Group team from the time of the initial application for the RFP through the remainder of the design and building process:

We are all on the same page, that's why it worked so well. We were all in agreement with each other; it started from the main points of the philosophy, down to the color of chairs. That was an experience, and I think I'll probably never be able to develop something like that with such a cohesive group again.

\section{Chapter Summary}

The cohesiveness and leadership within the Welsh Group resulted in Stonebridge opening within their budget and on schedule in July of 2009. The group's dedication was a key factor in driving the project, and the last minute information seminar that the management presented to the provincial legislators makes evident that the tide of change could have moved in another direction had they not pushed so hard. Even though the provincial development of the CCS and RFPs took place over less than a five year period, the original legislators who began the process had either moved out of their roles or lost their focus by 2009. The following chapters in Part II will address the themes surrounding the implementation of the new model of care at Stonebridge with respect to the management, staff, and the province, and will be followed by a chapter which will explore family and resident perspectives in the two study communities. 
PART II.

FRAMING HOME 


\section{CHAPTER SEVEN: STONEBRIDGE CONTINUING CARE CENTER}

An organizations' culture is defined as a set of values or beliefs held in common by an organizations' employees (Schein, 1985), and the positive and negative experiences that the Welsh Group have gone through at Ridgemont have made them a stronger and more cohesive organization. This cohesive leadership from Wyatt, Robin, Peggy, and Francis resulted in the opening of Stonebridge Continuing Care Center on time and on budget. Yet the next steps required to run a completely new community within a completely new model of care were to became a whole new set of challenges for the group, some expected and some unexpected.

The Stonebridge community opened with accolades from the $\mathrm{DoH}$ for its innovative and open design. The main street creates a clear connection between the private and the public spaces, with the building entrance, community center, administrative and health offices, and the

operational areas at one end of the connector and the private cottages at the other. In addition to the community center, there are two small seating areas at the building entrance and a small children play area. The main street includes a general store, beauty salon, the activity director's office, and a smoking room.

The community center is at the front of the building and is a multi-purpose room, with storage closets for tables and chairs so that the room can be set up for multiple need levels (i.e. church services, parties, dinner club, Bingo, etc.) Between activities, a grand piano, a couch with two chairs, and a bookcase are the only permanent fixtures in the room. The room is basically a large square with a bay window which faces the parking lot and main street.

The floor plans for all four cottages are similar, although the two cottages on each floor are mirror image plans. The open kitchen is in one corner of the cottage and looks out onto the 
dining/living spaces which are divided by a central fireplace wall. The goal of the architect was to keep the cottages clear of any areas where residents could get lost, and other than the seating alcoves that are set up by low storage cabinets, the space is open to the corridor which connects the residents' rooms in an L-shape. Each cottage has its own color schemes and décor loosely based on the cottage name, and there is some personalization through resident photos, crocheted blankets, and houseplants in the common areas. Two of the cottages have a resident cat, and two have resident birds. All residents' rooms have a small window box at their doorway for personal mementos and pictures.

The cottages share utility spaces on each floor and there is a spa room in each cottage for resident showers and baths. The resident bedrooms each have a built-in wall unit which includes a closet, dresser drawers, and shelves, and there is enough room for a few pieces of personal furniture like a desk or recliners. The resident doors were primarily left open during the day, so there do not appear to be issues with noise levels or theft.

Because the opening of the community was in July of 2009, and this study commenced about $2 \frac{1}{2}$ years later in January of 2012, many of the operational kinks in the new community were just being addressed and the impact of the model on staff retention ratios and the fiscal outcomes were not completely clear to the organization. While this study is the first in any of the new communities built from the 2006 CCS funding, there is a currently a comprehensive, government funded, province-wide study getting underway which will focus on the physical and operational outcomes in all of the new communities built with the CCS funding.

The focus of this chapter will be on the staff and management perceptions of day to day life at Stonebridge. While both communities are run by the same management, there are stark 


\begin{tabular}{|c|l|l|}
\hline Care Staff & $\begin{array}{l}\text { Discussion relating to the individual } \\
\text { caregiver in the SH setting }\end{array}$ & \\
\hline Teamwork & $\begin{array}{l}\text { Discussion relating to the role of } \\
\text { teamwork in staff work scheduling } \\
\text { and job rotation }\end{array}$ & $\begin{array}{l}\text {-You can have as much flexibility as you need, } \\
\text { but if people aren't willing to help be a team, it } \\
\text { doesn't work. }\end{array}$ \\
\hline $\begin{array}{c}\text { Choice, Risk and } \\
\text { Autonomy }\end{array}$ & $\begin{array}{l}\text { Discussion relating to the conflicts } \\
\text { and ambiguities of balancing } \\
\text { autonomy and risk in LTC }\end{array}$ & $\begin{array}{l}\text {-How are you supposed to deal with that, still go } \\
\text { by the Eden Philosophy and at the same time } \\
\text { have your nursing coincide? }\end{array}$ \\
\hline $\begin{array}{c}\text { Physical and } \\
\text { Environment }\end{array}$ & $\begin{array}{l}\text { Discussion relating to the impact of } \\
\text { the physical and organizational } \\
\text { environment on the care staff's ability } \\
\text { to do their job efficiently }\end{array}$ & $\begin{array}{l}\text {-Being in the same cottage and knowing the } \\
\text { residents and co-workers as well as I do, having } \\
\text { the consistency, I really like it. }\end{array}$ \\
\hline $\begin{array}{c}\text { Empowerment } \\
\text {-The relaxed environment is the best and the } \\
\text { worst thing here, the management don't } \\
\text { micromanage you, but then sometimes } \\
\text { communication becomes an issue. }\end{array}$
\end{tabular}

Table 5 .

Stonebridge Care Staff Themes

differences in the physical environment and the organizational structure of each, and studying them at the same time made it easier to understand their similarities and differences. Based on observations and care staff interviews, the themes that emerged regarding daily life at Stonebridge became: (1) teamwork (2) choice, risk and, autonomy ; (3) the impact of the physical and organizational environment; and (4) staff empowerment.

\section{Teamwork}

Stonebridge opened in July of 2009, fully staffed. The four cottages are divided with two on the main level and two on the upper level. Willow, the Alzheimer's cottage, and Cypress are on the lower level; and Alderwood, the RCF, and Birch are on the upper level. The care giving goal in the model is for the resident needs to be the central focus, and hands-on care providers are trained and given responsibility for the multiple roles in the daily care of both the physical 
and emotional needs of the residents. This may be accomplished with the reduction of middle management in the existing staff hierarchy and an empowerment of CNAs with responsibility (Carradice, 2002 ), which can run antithetical to the prevailing organizational culture.

Care staff teams in the model carry out cooking, cleaning, and resident care within the cottage and teamwork among direct-care workers is often promoted as an important aspect of culture change. However, studies have found that among facilities attempting culture change, teamwork was the least commonly implemented culture change component. This suggests that facilities may be having difficulty implementing certain elements of teamwork and also raises questions about the link between teamwork and facility organizational culture (Tyler \& Parker, 2011).

\section{That's Why I'm here}

The CCA coursework includes subject matter for all CCAs in the nursing field, including homecare, and several of the Stonebridge CCAs had worked in homecare prior to their current job. Annette sees definite differences between the CCAs that would prefer home healthcare to working at Stonebridge. She describes the benefit of working in SH community rather than moving from house to house in homecare:

I like this better than home care, I like being in the same spot every day. I like routine, that's why homecare wouldn't work for me, because I would have anxiety about where am I going tomorrow, who am I going to see, what's that person going to be like. I would have too much anxiety, with my personality, it wouldn't work for me. Being here, being in the same cottage and knowing the residents as well as I do and my co-workers as well as I do, having the consistency, I really like it. I know some people that it doesn't work for them, they like the change, they couldn't stand being in the same spot, it's a personality thing. 
With the notion of teamwork, there is a move away from institutional models of care, in an attempt to both improve quality of life for those receiving care and improving the work of those providing care. Another Cypress CCA had made the decision to work at Stonebridge rather than doing home care because of the camaraderie with co-workers. She explains her decision:

I thought about it, but after I heard about this job and the model of care and everything, I liked the idea of coming here instead of going into a bunch of different people's homes. I like the idea of being able to work with the other staff members too, and not being by myself. I like being able to count on someone else at any time.

Teamwork cannot simply be mandated by facility managers and carried out by the directcare workers, it must be supported and sustained by manager's attitudes and behaviors. Francis, the Stonebridge Director of Care, understands the importance of setting the example:

We have an excellent team, we're all on the same train, we all know where we are headed and what we have to do to get there. There have been a lot of little pit stops along the way, we overcome those, we get back on the train and keep going.

While the majority of the current staff at Stonebridge are young, each has a story behind their choice to be a caregiver. Many had interned at older nursing homes, but for others, working at Stonebridge is their introduction into LTC. The CCAs in the Alderwood cottage describe the multiple paths which have brought them to their current job:

AW1: I used to work in a nursing home in Halifax when I was younger, that was my first job, and I worked in dietary, so I just did things with food. There was a lot of free time there, when I didn't have much to do, so I would go to the resident's rooms. It was more of a clinical setting, so they would kind of sit in their rooms all day. So I would just go around to their rooms and talk to them, just ask them about their lives and what they did when they were younger and stuff like that. Then I just knew I liked working with these residents, seniors; I eventually just went to school to be a CCA.

AW2: Actually, I started this because of my grandmother. She was really old and I took care of her every day for the last two months of her life. She told me that 
this was I was meant to do. I had never really thought about it, that it could be my job.

AW3: I actually just jumped right into it. I didn't know what I wanted to do until grade 12. I knew I wanted to do something with healthcare, so I kind of just jumped into it. I did my clinical at a setting that was very hospital like, so I've seen the difference.

For many of the CCAs, this was their first full time job, but they were drawn to work at Stonebridge for different reasons. Each of the caregivers in the Willow cottage described their reason for working there:

W1: I always had a thing to help people, either children or the elderly; I love helping and just doing things for people. I knew I wanted to get in to some type of thing. My friend actually told me about the new community, and I looked into it.

W2: My teacher actually works here and she told me about it. It's really close to my house and it's convenient. I like the way they do their whole philosophy. There are a lot of factors that drew me here.

W3: What drew me to this place was the fact that it's more like a homey feel for the people, it just seems like people would able to be a lot happier being in a place like this, it's a lot easier to work around people who are in better moods and are not down and everything. That's what really drew me to work here.

Trish is one of the more experienced caregivers in the Willow cottage; she had worked at Ridgemont for several years, as well as at one of the larger communities in town. She is a little more ambivalent about the new model than some of the caregivers who are new to the business.

Yeah, I started at Ridgemont a long time ago, and when I went back in 2001, they had demolished the ARC. I was staff from upstairs, so I became just casual again. I came here because it was a full time job, not really because of the philosophy. I felt like there (Ridgemont), it was like home. I think what they have there is unique; I can't say the same thing about the other facility where I was for five years. I know some places are regimented, but I didn't see that at Ridgemont. I know we still had routines, but there was flexibility. For myself, I'd be iffy choosing between the two models. 


\section{We Called Them by their Room Number}

Multiple studies (Agich, 2003, Calkins \& Marsden, 2000, Cohen \& Eisendorfer , 2001), Eckert, et al 2009, Golant, 1998, Gubrium, 1975, Kendig, 2003, Lawton \& Nahemow, 1973, Schwarz, 1992) have focused on the institutional culture of nursing homes. It has become evident that the physical environment and daily routines in the traditional nursing home are designed to serve the needs of the staff and often "the bottom line": Large dining rooms make it easier for staff to serve meals to all residents at regimented times; wheeling the medication cart to the dining room three times a day is perceived as less labor intensive than walking to each resident's room and administering their medications; offering only one meal choice for all residents is easier, regardless of personal preferences and so forth (Bowman, 2010). Many of the CCAs interviewed who had worked at other communities had stories about their previous routines. The Birch CCAs describe their work schedules when they worked at other traditional communities:

B1: Yeah, you would just come in and it was the same thing every day, there were people from every department, dietary would come up and dish out breakfast, you'd put everyone down in the afternoon, it's the same thing over and over. You do see differences here. The previous place I left because I just wasn 't happy there, I was stressed out and overworked.

B2: At those places, you're kind of forced to do everything by yourself, you're afraid to ask people for help, it's just too institutionalized. People are just sent back to their rooms after the meals, and they just lay down in the afternoon. Sometimes it's just a CCA thing, where you just don't have time. It was too hospitalized, I didn 't get to know any of my residents, cause it was just kind of like an assembly line.

B3: It's much better here, I'm so happy to come to work, I never feel like I don't want to come in. At Halifax Nursing Home, it was one of the hardest things that I've done, I hated it every day. It was the people, the amount of work, it was a lot. They have that set amount eight or nine people and I had to get them up. It was just go, go, go. You didn't get to spend any time with the residents at all, you 
hardly know them. We called them by their room number, not even their names, because you had this eight people today, but then the next day you had eight other people, you never got to know anyone. They just sat in their room watching TV and then I wanted to go talk to them and the nurses said, "So do this now, come help me do this." I couldn't get to know anyone at all.

One of the hardest things for the CCAs in their previous work settings was caring for residents in a way that they knew in their heart was wrong. One of the Birch CCAs, Annette, describes these internal tensions in her previous education and work environment:

Here, you get so close with the residents, you can't help it, here we've learned that it's OK to get close to them. What we were taught in school is "No, no, no, don't be like that." In school, it's was like, "Do your work and go home" kind of thing, that's what I was taught, that I wasn't allowed to care." If you care, then you care too much," that's what I was told. I was like "Then why am I a CCA then? Because I care!"

And finally, Trish sums up her feelings about the current connection she has with the residents in her cottage, "I like having that connection with them. It's a good connection."

\section{Staff Self Scheduling}

Each cottage has had to formulate bonds of trust between the CCAs, and with those bonds, comes a sense of ownership of the team and the work setting. Trish feels the Willow cottage has the best sense of teamwork in the community:

We have a good team here, not just to say that. This cottage is the best for helping each other; management will tell you that, it's true. More people will come in and help each other out than any of the other cottages. We know what the other's strengths and weaknesses are, so we know, say if I'm not so good at doing that, then someone else will come in and do it and I'll go do something else.

Her co-worker Dana agrees, "Yeah, it`s great. We all get along together as a team, we all get along together, it's not stressful at all." When asked about their typical day in their cottage, 
the Willow CCAs all laugh. This is because the Willow cottage is the Alzheimer's cottage, and it is harder to create a schedule that residents stick to, it's really a moment to moment experience. Trish explains:

There are no typical days in this cottage; this cottage is a little bit harder to have a routine because it's Alzheimer's and dementia. But, pretty much we spend from 7-11 am getting everyone up. You have some who are early risers and you know that when you come in, that they will need to eat right away. And then there are those who don't crawl out of bed until about $10 \mathrm{am}$. So the morning is about getting everyone up, doing whatever showers are for the day, doing their personal care. Also, we have a lot of people with behaviors we need to deal with. And then we get them their meals, and then we have cleaning, and we also do cooking of the meals.

Caregivers trade off on meal preparation duties, although each cottage is different and scheduling is customized to the resident and staff needs. The staff in Alderwood cottage appreciate the fact that they can work out their vacation days without having to go to management. Reina, a newer CCA explains:

We don't need to worry about something like seniority when it comes to vacation, we don't have to need a request a day off from downstairs. If we want a day off, I just look up at the schedule "Oh, you're off this day, so you mind working this shift?" So for a day off, we kind of depend on each other to help each other out. If we can get someone to assist us and switch, it works, the only stipulation is that you can't work seven days in a row.

The Willow staff agree that it makes more sense to talk with each other to work out daily and even hourly scheduling, rather than going through management. They explain that selfscheduling leads to a smoother flow in their days, as they cover for each other as needed:

W1: I like that we can set our hours around the residents and their needs, it's nice we can know that everything is covered. We change our schedules around to meet theirs. We get to make up the schedule that we want, we get to talk to the co-staff here, and if I want a couple more 7-3 shifts, if I can find someone to switch with 
me, then we can do it that way. We can make up our own scheduling as long as our co-staff agree.

W2: Right, I could say to Trish, "You're 7 to 7, I'm 8 to 4, can I do kitchen tomorrow?" Just switch hours, or I can go into the kitchen and work as needed. As long as all of the shifts are covered, they don't care. It's a lot easier to talk to a staff member here than have to go all the way down there (management offices).

W3: I love that part of this. I worked casual at another place. There was a person there, high seniority, 20 some odd years, and I asked for a float day. One day, and it took eight times for me to request it before I could finally get it approved. For one day, that's ridiculous.

But the care staff also have to understand that it is a team effort and need to be flexible with their time. Trish points out that everyone on the team must be on the same page in order for the cottage to run efficiently:

I just think we've got a good bunch of workers here, that's what makes it the best, that's my opinion. You can have as much flexibility as you need, but if people aren't willing to switch and people aren't willing to help be a team, it doesn't work.

\section{Staff Workloads}

A key aspect of the philosophy of care at Stonebridge is that the CCAs are not only there to care for the resident's physical needs, they are there to cook the meals and keep the cottage clean. Unlike Ridgemont, where each staff member has an appointed job throughout their tenure, the goal of the SH model is to create an environment similar to a residence, where all staff and residents are well acquainted with each other. Trish recounts the differences in her experiences at Ridgemont and Stonebridge. At Ridgemont, because staff had their specific jobs, when they finished them, she feels they had more time than at Stonebridge to spend just interacting with the residents. In her current position, Trish always feels like there is something else that needs to be done, whether it's cleaning or cooking, and she doesn't feel that she has quality time with the residents. But when another CCA points out that there is extra one on one time, because the 
CCAs are serving the residents directly from the kitchen at mealtimes, Trish agrees. She appears to be torn; she likes Stonebridge, yet she just feels a little overworked. Her co-worker Allison agrees:

We have to be cross trained on everything and do everything. Sometimes when you have to cook, then you clean and that can take about two hours. Plus, you need to have time to spend with the residents. I think it might help to have someone come in for the different jobs, at least for cleaning.

While most of the staff understand that the workload is related to the philosophy of consistent staffing, Dana points out that some staff don't last because there is a need to be dedicated to the philosophy of care:

We do have some people who come here that can't handle that we do everything; we do care, dietary and cleaning. Some people say, "That's too much for me." So there has been a lot of that too, there have been ups and downs. But I don't mind it all, it's just the care philosophy, it's just the way it is. We don't want someone that the residents don't know coming in to do the cooking or the cleaning, it's supposed to feel like a home. It doesn't bother me, but the new people who come in are kind of shocked. It as a shock to me when I first came in, it's like "Wow, am I really going to do all this?" It's a lot to do, but it's worth it.

\section{Night-time Staff Shortages}

The staffing ratios for all of the new LTC communities are set by the province, and in the evenings there is one RN and one LPN on duty for the entire community, and one CCA in each cottage. Many of the CCAs agree that there are staff shortages at night, particularly if there is an emergency like a resident falls or passes away. Even on a normal night, the demands of looking after that many residents can be too much for one person. Dana describes the problem as she sees it:

There's only one RN at night time, one person on this cottage, one person on the other three. It's difficult when something happens, like when a resident has passed at night. So if the RN is now occupied with that resident, the other three cottages 
don't have a nurse. If there's a fall, which I've had on mine, a resident fell and broke her hip; they had to call the paramedics to come take her. And some nights, like my last night shift, at 1 o' clock in the morning, I had six residents wide awake wondering around, you need help. So that's the one major thing I would say, we need an extra RN here at nights. Basically what happens is if we are short, the CCA will sit in the middle by the elevator so they can watch both cottages. Yeah, it can be quite hectic.

Annette explains that another reason that there are nighttime staff shortages is that many of the residents in her cottage have chosen to have their showers at night. This ties up the night staff, leaving the other cottage residents more vulnerable. She describes the ways that the cottages cope with the nighttime shortages:

I do think that it would be nicer to have another person on with you for the 1-9 shift, I think it would be better to have another person at least from 6-9. We used to have showers in the day more, but the residents like to take their showers and get their PJs on in the evening, instead of doing it in the day and putting their clothes back on. That's why most of them are more geared toward the evenings. The evenings you are by yourself. But there are things we can do to help, we can transfer call bells to the unit next door, we can let the CCA next door know that we are doing showers. We can always call the LPN and let her know that we need her for a little bit to cover. One nice thing is the phone system can be switched over and someone over there can answer the phones.

\section{Staff and Management Communication}

When participants' roles in places are not well defined, this may lead their participants to assume quite different logics in dealing with each other (Gubrium, 1975). Because there are fewer rules and guidelines for staff to follow, and because every cottage is run independently, there is an issue with communication between the cottages as well as between staff and management. There is no central nurses' station at Stonebridge, which often leads to a breakdown in communication between the RNs, CCAs, and the management. The Activity Director, Noreen, describes the duality of the issues involved in staff communication in the new model: 
The relaxed environment is both the best and the worst thing here. The management doesn't micro manage you, nobody is breathing down your neck, that's great. But that also is the worst thing about it, because communication is sometimes an issue. Staff sometimes feel like the management don't care because they're never here, and sometimes it feels like they don't know what's going on.

A CCA from Alderwood has a similar perspective about the communication issues between staff and management, and shares the fact that communication is probably the number one problem in her job at Stonebridge:

The worst thing about this (job) from my own experience would probably be communication, but I don't know. The management is not here all of the time and they do travel from place to place, so it's hard to get answers some times.

But as a manager, Francis' perspective on communication issues is a little different from the caregiving staff:

There is a lot of communication, we try to keep a lot of communication open between staff and management so problems don't arise, but if they do, we try to take care of them right away, if anything develops we take care of it right away.

Francis also thinks that the CCAs sometimes don't understand that they have been given the tools needed to make decisions on their own, “I don't know if they know how empowered they are, that they can take the initiative and do things on their own. Simple tasks, people just don't know what to do with them; they just don't realize the power that they have."

\section{Choice, Risk, and Autonomy-The Triple Edged Sword}

Caring is an activity fraught with conflicts and ambiguities (Gubrium, 1975), and for a caregiver, resident habits and routine movements are managed on the basis of ensuring their safety and protection. The traditional concept of autonomy as rational, free agency implies that free actions are the result of a deliberative process that yields a decision defensible on rational 
grounds. Yet in LTC, some resident actions and choices reflect habit, therefore the picture of actual autonomy is more like a complex collage than a schematic or line drawing. It is a picture rich with detail that is experientially established and grounded (Agich, 2003). Choice is always contextual, for each individual, there are consequences associated with any choice. Ideally, the choice that enhances autonomy is a choice that is meaningful for individuals and allows them to express and develop their own individuality. This suggests that caregivers and managers must be attuned more thoroughly to the question of the meaningfulness of choices actually afforded residents under their care (Agich, 2003).

\section{Don't Have to Go in and Wake them Up}

For the CCAs, allowing resident a choice in their day to day activities is a primary benefit to the new model of care, and many saw the restrictiveness in the policies in previous care locations. A Cypress cottage CCA explains the importance of choices for residents:

I think because they have choice, they have their autonomy, it's very open. There are rules and guidelines in place, but still at the end of the day, it's their choice. They are still an individual, they don't lose that.

Another Cypress CCA agrees and feels that enabling residents to do as they wish is a large part of her job description:

Letting them be who they are is so important, this is their home. Just because they are 89 years old doesn't mean they don't know that they want anymore. They are more of a person than I am; they have so much more experience. They are entitled to do whatever they want.

In the old model of care, one of the hardest parts of the caregivers' job was waking residents up in the morning. Many of the more experienced caregivers expressed the sense of the 
guilt they felt in their previous community experiences having to wake someone up to fit the staff schedule. Dana describes the rules and her experiences doing her clinical internship at Ridgemont:

I did my clinical at Ridgemont. Even though I liked it there, I didn't like the rules. I didn't like the fact that everyone had to be up at 7 am and had to eat their breakfast at this time, and lunch at this time and if they missed breakfast they had to wait for lunch. There were residents who didn't normally get up until 8 or 9 am, but we had to get them up. They were asleep and you're still forcing them to get dressed and get out of bed. They wouldn't eat 'cause they were really still sleeping through their breakfast, I didn't like that.

One of Dana's cottage-mates had had similar experiences at another community.

She too understands the importance of even the smallest choices for residents, like when to get up in the morning:

I just couldn't do it, there were some residents, if they didn't want to get up, I didn't have the heart to make them. I figured, they worked their whole life, this is for them, what's the rush? If they want to sleep in, let them sleep in. When you take something as minor as that, when you take that choice away from them, whatever time they want to wake up, it makes a big difference to them.

Breakfast in the cottages is served to residents as they wake up, though CCAs may go in and remind residents that breakfast is being served. The CCAs do not consider a reminder the same as requiring that all residents get up at the same time. The Birch CCAs discuss at what point they will go in to wake someone up:

B1: There is a certain point where we will get a resident up because we don't want them to be in bed all day, but it's their choice if they want to sleep till 9 or $10 \mathrm{am}$, if they want to miss an activity. Some of them are just so tired sometimes, that they just don't want to go to activities. We encourage them, but at the end of the day it's their choice if they want to go or not.

B2: I like that people can sleep in. There are times when we do kind of have to go in and say "You know its $10 \mathrm{am}$, time to get up." But certainly, we're not getting everyone up by 8 am. 
As the Director of Care, Francis agrees. Her experiences for many years in traditional communities has led her to the conclusion that at Stonebridge, "It's OK if somebody doesn't want to have breakfast and they skip a meal, it's OK if they don't want to get out of bed, and they say, 'I'm staying in my pajamas all day.' It's just fine that we don't have to go pick out the blue outfit for them today." While there is consensus among the management and CCAs about the importance of choice for residents, the RNs at Ridgemont have a much more conflicted nature to their roles.

\section{Regulating Risk- The RN Perspective}

In any LTC setting, regulating risk, freedom of action, and autonomy in decision making is sometimes the subject of tensions and constant negotiation (Gilmour, Gibson, \& Campbell, 2003). Parker (2005) writes that caregiving and control practices are connected in such a way that it is difficult to extricate one from the other. The regulation of boundaries is two-fold: the resident is intent on retaining control and in order for that to happen, there is an important step where the caregiver needs to step back from the role of deploying discipline over the resident and their body (Parker, 2005).

Risk is related to concepts of danger, yet simultaneously to the opportunity to gain benefits precisely in those situations in which harm is also possible (Tirado, Callen, \& Cassian, 2009). The central question regarding resident choice and autonomy, as described by Radar (1995), discusses the behavior and lifestyle choices that may have been contributed to the need for this level of care. What are the safety needs of the resident and how can they best be met efficiently while honoring the rights of the individual? Jill, the RN on duty, sees the issues of choice and autonomy a little differently than the CCAs. She explains: 
It's the whole thing about looking at it from the nursing perspective. It's one thing to look at the individual; this is their home, this is what they want to do. But when I look at it from a nursing perspective, what the people are doing is not necessarily best for their health. To sleep in till 1 in the afternoon or skip meals when you are a diabetic, if you look at it from the nursing perspective, it's not the best thing to do. But then you have to look at the Eden philosophy, if that's what they want to do, that's what they want to do.

The Activity Director Noreen agrees that there is a fine line between telling someone what they have to do versus suggesting what might be best for their overall health. She describes a recent incident at Stonebridge when a resident had almost died as a result of eating a holiday dinner with his wife:

George has been in the hospital, he has severe pooling in his lungs, and he's been on a feeding tube for years. His only goal in life is to eat, so we've had care conferences with his family and made these decisions. He would have a snack twice a day that was the consistency of pudding and then he would eat once a month with us at supper club. The whole thing with aspiration and pneumonia comes into play, that's what happened just a couple months ago, he ate Christmas dinner with his wife for the first time in three years, that was so exciting because she loves him so much, but he almost died in the days following. The things that he wants to do are contributing to his illness. That's the thing here, we can't tell you what to do, but we can help you with your decisions.

Other residents make it a little more difficult. The conflict between resident/caregiver roles becomes very apparent when an individual vocalizes their desire for autonomy in a situation. Jill describes tension when residents overtly override her suggestions in order to express their desire to live by their personal preferences, rather than what is best for their health:

We even have some residents who we'll give them suggestions, right? And they'll look at us straight in the face and say, "I'm not going to do that, it's the Eden philosophy, if I were at home I wouldn't do that." So, it kind of makes nursing, where we are trying to look out for their health, a little difficult.

Jill did her clinical internship at a hospital in Halifax, within a strictly regimented model of care. She has strong feelings about the push and pull between the caregiver goals and the resident goals within the context of the care needed at Stonebridge: 
We're here to give out pills and assess things and we're supposed to go on how the resident wants it. Whereas in the hospital, we know at this time, this is what's happening. There is a completely different structure here from what I've experienced. It's hard, I am here in a nursing role and I will go in and wake some people up if they have certain pills that they have to have. For some, I can't let them sleep in till 12 o' clock because it would jeopardize their health. If they were home they would still be sleeping in, but hopefully have someone going in to look after them. That's the biggest thing that I had to get used to, it's very flexible here in that way, but very different from how I've been trained for the last four years with specific times to get things done.

Finally, Jill asks the central question with respect to risk and autonomy in the new model, "How are you supposed to deal with that, still go by the Eden Philosophy, and at the same time have your nursing coincide? So yeah...that (resident choices) might have been part of their health issues, which might be why they are here to begin with."

\section{Resident Participation and the Social Environment}

In any setting, the physical environment is meaningful because, within it, we directly experience environmental connections, meaningful events, meaningful places, and social actions (Heft, 2001). In the case of the LTC environment, the setting becomes home and community, and the relationships and social interactions which take place on a daily basis are critical to individual coping capabilities (Chaudhury, 2003).

\section{Interpersonal Social Connections}

While autonomy in LTC is critical, there also is the need to subscribe to the relational view of human beings as belonging to a network of social relationships within which they are deeply connected and interdependent. Social connection as a psychological construct might be

understood as relatedness, an important factor in identity development and mental health (Townsend \& McWhirter, 2005). Lee, Draper, and Lee (2001) defined social connectedness as the subjective awareness of being in a close relationship with the social world, suggesting that 
social connections include a sense of closeness to others that is critical to one's sense of belonging. Thus, a challenge for communities of all sizes is to provide frail residents the appropriate opportunities for social and leisure pursuits to meet their needs, as well as environment and services that encourage proactive responses to changes in competences (Scheidt \& Norris Baker, 2003).

It's Good for the Soul

The activity director, Noreen, and her assistant, Beth, develop their activities a month ahead of time. Every month, an activity calendar is posted in all of the residents' rooms and the common areas. Community activities include Bingo, Jeopardy, jewelry making, an occasional art class, and the Wednesday night jam session, which is the highlight of the week for many residents. Once a month, there is a supper club down in the community center, where residents from all of the cottages can eat together, and there are weekly church services. The Alderwood CCAs discuss resident activity patterns:

A1: Oh, yes, they all know the schedule by heart, they know what ones they like and what ones they don't. The Wednesday night jam is their favorite. They also love playing Bingo. Some of the residents even wanted to donate some of the things they had in their rooms so they could play Bingo in the cottage.

A2: They have a calendar, so they know what's going on. Some people are in a wheelchair and need assistance traveling the distance downstairs. So there might be a volunteer that comes up to take them downstairs. We have a resident here who also like to assist with getting people down in the wheelchairs. She's somebody who's from this field, she was a nurse's aide, that help really makes a difference.

The CCAs in the Willow cottage have a little different socialization issue for their residents. While all activities in the community room are open to all four cottages, it is normal to have a Willow resident attend an activity, but forget shortly afterwards that they have been there. 
The CCAs agree that despite this, the act of getting out and socializing is good for the residents of the Willow cottage:

W1: Sometimes I'm not sure how much they get out of the activities, it's almost like it's delayed. Like Bill, he'll be complaining in the cottage, and then he leaves, does an activity down in the community room and is absolutely fine. When he comes back, he'll start complaining again, but I do think it's a break for him.

W2: Right, Laura has been taken to the Legion Hall to a dance where they have near beer, where it tastes like beer. She's come back from those and ten minutes after her being back I'll ask "Oh, how was your time out, did you dance?" She'll say, "I was out? I was at a dance? I was there?" She had just gotten back, I just don't know. I still think it's good for the soul though, even if they don't remember. They had a good time, for that moment.

\section{Cottage Proximity to the Community Room}

Because of the two story layout at Stonebridge, residents on the second level have a trek to get down to the community room, located at the building entrance (Figure 50-53). As one of the CCAs pointed out, "Those residents who live upstairs in one of the rooms at the back of the cottage have a long way to go just to get out of the front door of the cottage, much less down to the community room." Due to staffing issues, the CCAs depend heavily on the activity director and her assistant to get residents down to scheduled activities on time. While they will remind residents of what's going on that day during breakfast, the CCAs have too much work to do around the cottage to bring residents to and from the activities.

Residents do have a number of options for the day in the Community Center. The Alderwood cottage is on the second level of the building and it is the RCF, so the residents are a little more independent than others in the building. The Alderwood CCAs discuss the protocol for getting residents to the activities: 
A1: Most people up here are pretty mobile, a lot of them smoke too, so they are used to going down to the smoking room.

A2: Downstairs is another world for them, it's like their city, with the little shops and stuff. They do think that it's a whole different place, like they're going somewhere else. Some people do feel like they are getting out when they go to things.

A3: There are a couple people who will go down by themselves, but when the recreation girl comes up, they' 11 normally all go down with her. Sometimes we'll help out and go down with them.

For the Willow cottage in particular, there is often a disconnect between the needs of the residents who want to leave to go to an activity and the staff who need to be in the cottage for the others. Trish and Dana discuss the disconnect:

$\mathrm{T}$ : The recreation person usually comes in, because in this cottage, nobody can leave without someone with them because they can get lost. So if the recreation person can't come, then one of us has to go. That doesn't always happen though, because that just leaves one person on the floor. Sometimes it's just too hectic.

D: Like yesterday with the supper club, with the weather and stuff, some of the volunteers and family members weren't able to make it in. Jack, because he's one that when he eats, he gets up and walks away and wanders, his wife was going to come in for supper, but she wasn't able to make it. So I had to go down and stay with him. If I hadn't come, then unfortunately Jack wouldn't have been able to go.

\section{Resident Interaction in the Cottages}

Due to the cottage layout, the residents spend the majority of their day either in their rooms or in the living room or kitchen. Residents can sit at the kitchen table and have coffee during the day, or spend time in the living room watching TV (Figure 54). There is not a lot of group activity in the cottage, but when it does occur, the cottage works well for multiple group interaction. Annette discusses one of these afternoons:

One afternoon Beth brought her Wii in for our residents, Wheel of Fortune or something. So we had six or seven residents sitting in the living room doing the 


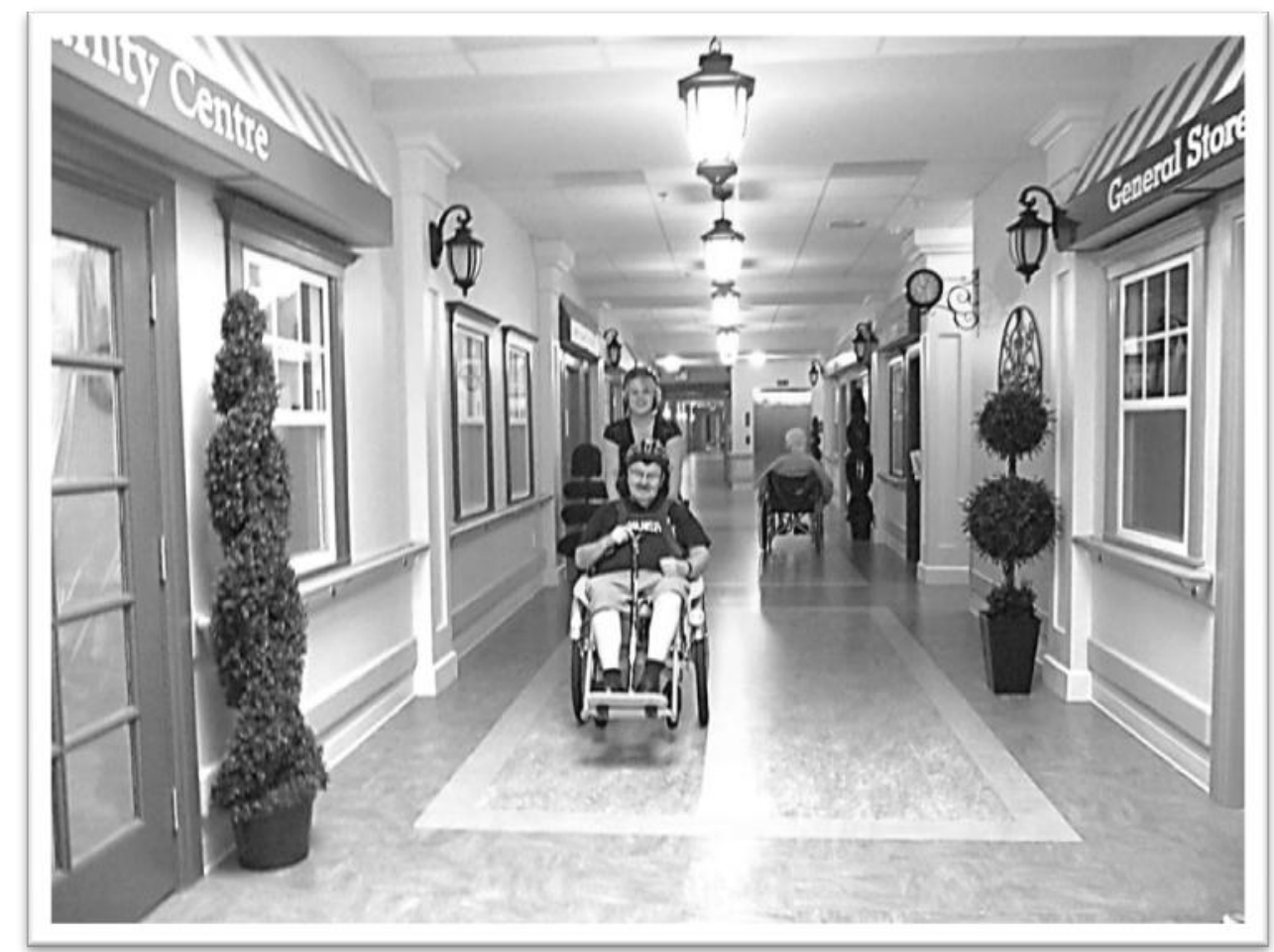

Figure 48.

Stonebridge Main Street Looking East

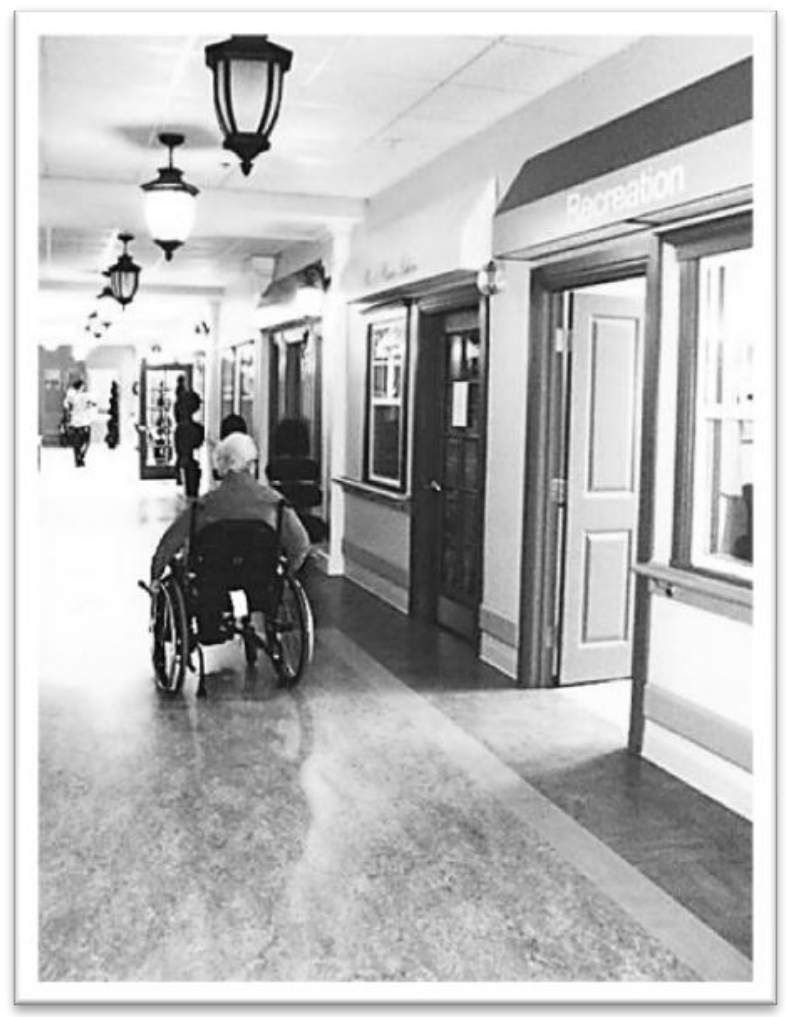

Figure 49. Stonebridge Main Street Looking West 


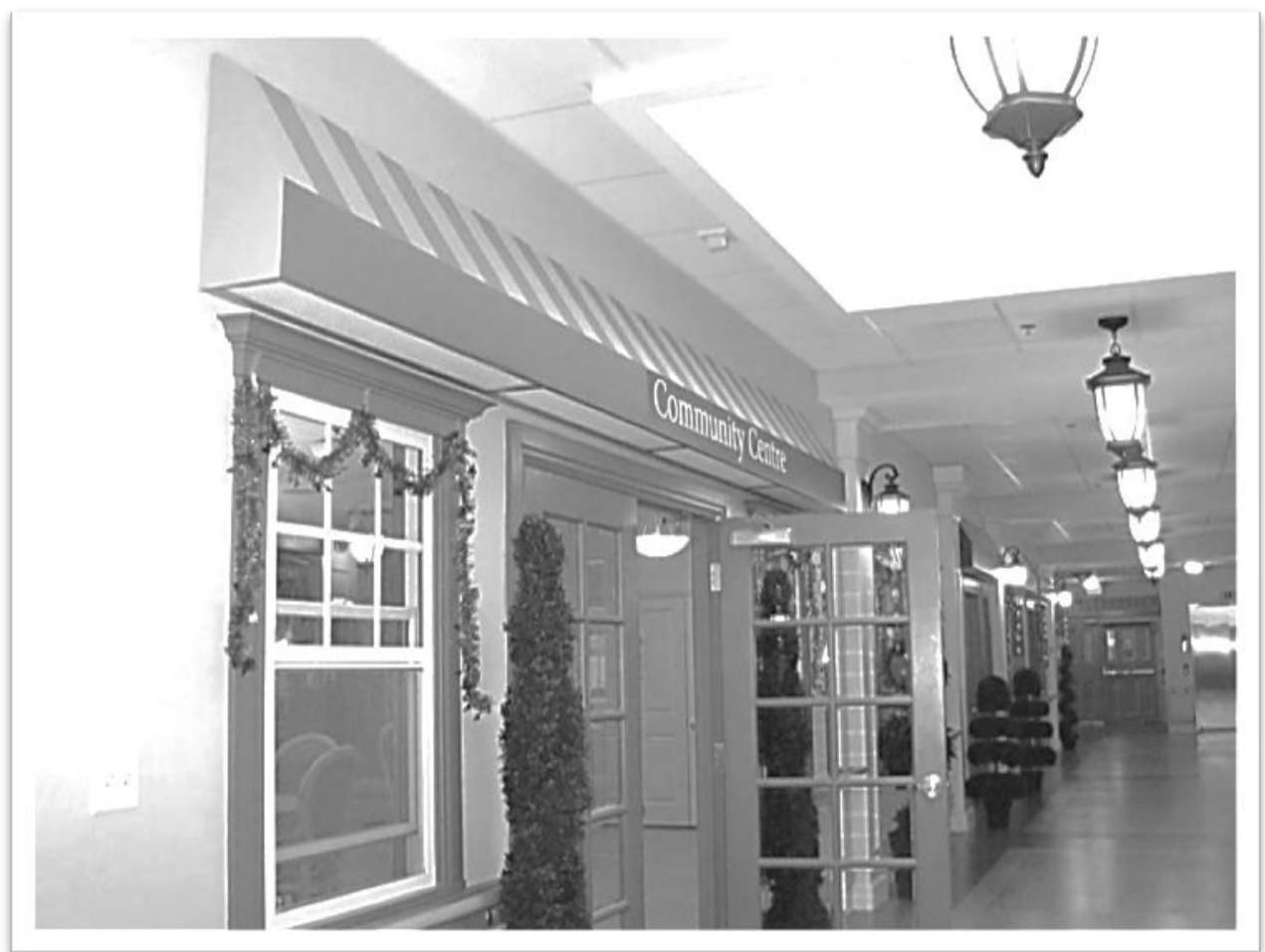

Figure 50.

Stonebridge Community Center-Exterior

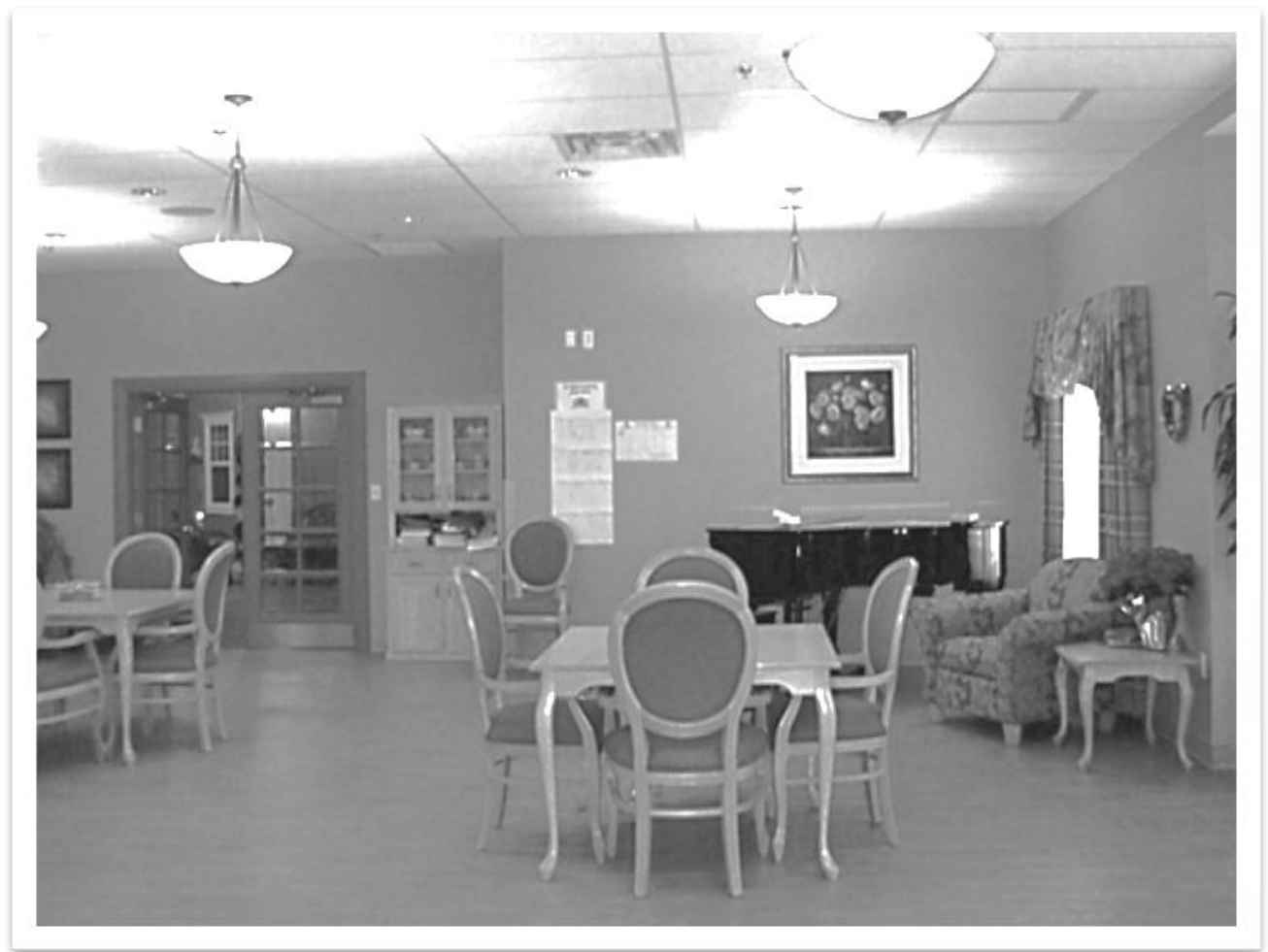

Figure 51.

Stonebridge Community Center-Interior 


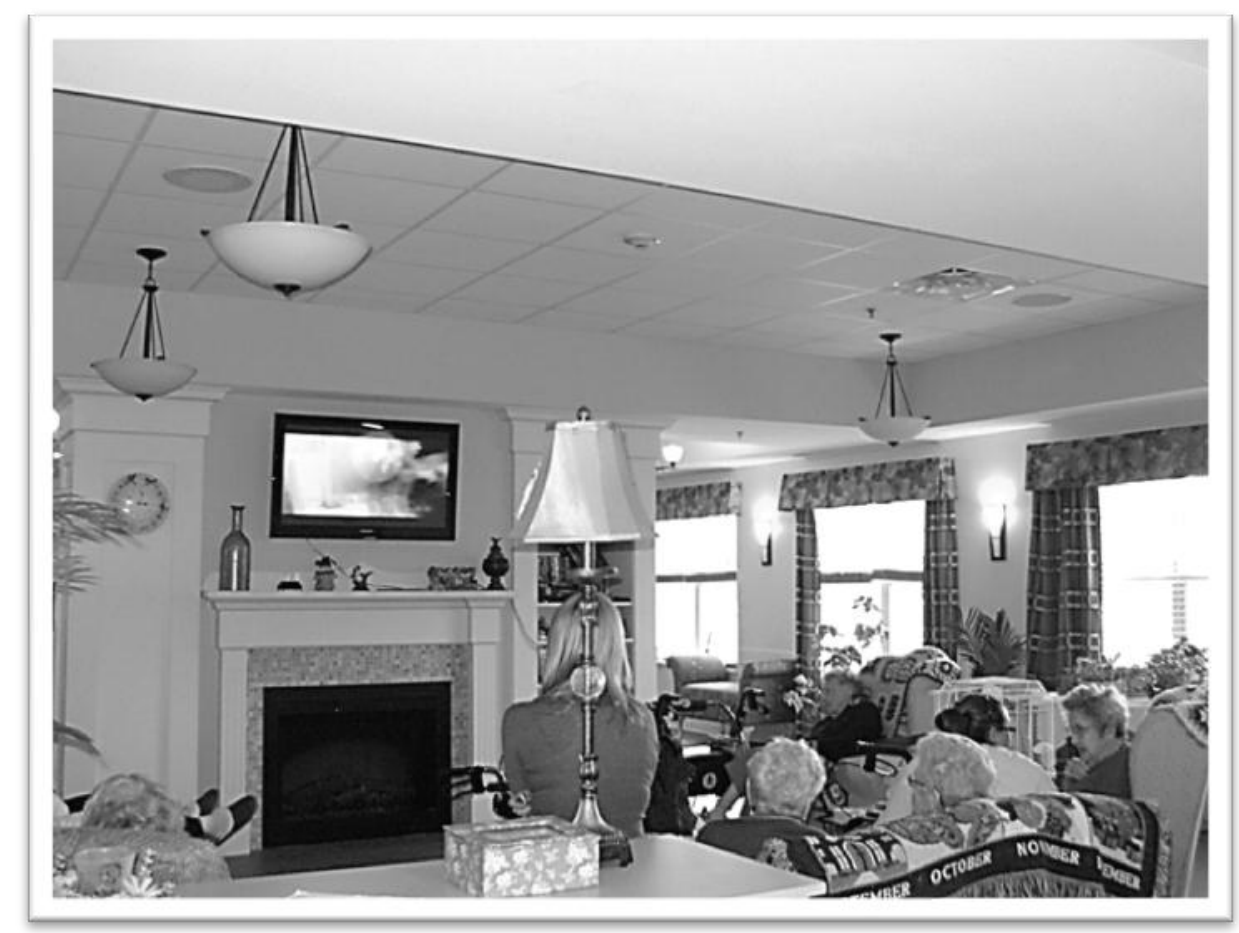

Figure 52.

Stonebridge Cottage Iinterior

Wii, and then in the kitchen one of our staff, who had been on maternity leave, brought in her new baby. She had this little group of ladies talking to her. We were able to have two things going on, we could see each other and hear each other, but we could also do what we were doing and not be distracted. It worked fine, and at a very comfortable scale. It was intimate, but the fact that I could lean back to check out what was going on in the other room was nice.

Annette makes it clear that although some residents prefer to spend time in their

rooms, it doesn't mean they are unfriendly. She sees this clearly in one of the residents in her cottage:

A few get out, a few are really early people and they get up early and they like to go to bed early. So, when it comes to doing things in the evening, there are only four or five of them that will do anything, most of them will stay in their room in the evening, but they are very friendly people. They might be in their room, but that doesn't mean they don't want to talk in there or do something in there. Like Gertie, she loves being in her room, she keeps busy! She's super friendly, she just doesn't like being around a huge group of people. So it totally depends on the personality. They are just a little more private in the Birch cottage, but they are still very friendly. That's really OK. 
Other cottages have residents who are closer knit, spending more time as a group in the cottage. The Alderwood and Cypress CCAs discuss the activity participation in their cottage:

AW1: It can get pretty loud in here. They each have their own little groups. There are four ladies here who always sit together; there are four different groups here at each table. They all have their conversations; it's quite loud here at mealtimes here.

C1: Oh, yes, especially the table with Art, Edward, and Penny. They always come out for coffee when it's not supper or lunch or anything, just to talk.

C2: Yes, but not as much as I kind of thought it might be. I don't know if you've found the same thing, people are still a little quieter here; people tend to be in their spaces.

\section{What Did She do at Home?}

While socialization is a key element of the LTC setting, personal preference plays a large role in how individuals balance how they spend their time there. Francis talks pragmatically about how we live at home and how we live when we are in LTC, and feels that the SH setting becomes home and community:

This is both, just like when you are living in your own home, when you're not living in LTC. You get to know people in your community, you get involved in your community, and it's the same thing. There are definitely people in LTC who like to stay in their rooms, that's the kind of person they've been throughout their lifetime, or that's just who they are right now. For the people what want to stay home, you have to respect that. There are those that like to stay in the cottage and that's why we really encourage the staff. OK, instead of mopping that floor, if you want to sit down and play cards with that person, or listen to them or watch a movie, just sit with someone if they like company. You don't have to talk, just sitting and holding a hand speaks volumes. That's what we encourage. That's where a lot of the older staff really struggle, because they still think of the tasks.

While of the same residents show up to the scheduled events, there are also many who do not attend activities in the cottage or the Community Center at all. Trish thinks it's just because there haven't been any new activities added. 
Yeah, I think the things get repetitive for them too. Like when I first got here, the entire floor would have gone down for music on Wednesday night, except for one resident that doesn't do any activities. But eventually, it just becomes like the same old thing. Sometimes, the activities, they have to tweak them a little, but some of it is personality too.

Noreen's activity assistant, Beth, did her internship at another traditional LTC community. Her motto is, "Get a resident to come to the activity and they will enjoy it." She feels that in the traditional model, residents are more inclined to spend time in the community areas:

I would want to get out of my room too, especially if I'm sharing it with somebody else. It was so much easier to have spontaneous activities in the traditional model, because everyone is just out and about anyway. I could walk out from my office and see pretty much every resident that lives there, at least the majority of them, in the same spot. Somebody might say, "Oh, why haven't we done this?" And I'll say, "Let's do it!" I already had a group of people together and they loved it. They were there because there are other people and new faces, more stimulation; I think that's so important.

Beth sees major differences in resident participation between Stonebridge and the

traditional community where she previously worked. These differences relate to the

layout of the buildings as well as the organizational structure of the activity programs.

Yeah, that's the thing, here people just come down, do their activity and then they're gone. I understand, OK, it's the sense of going down to the community center to play Bingo. OK, that's a good idea, you feel like you're getting out of the house and you're coming down to the community center to bowl or play bingo, I get that. But other times I feel like they come down here (for activities) and then it's over and then it's kind of like, "Well, now what, where do I go from here, I'm not in my home, what am I doing?" It's hard because we don't have a lot of traffic in the community room other than with scheduled activities.

It's difficult for me to do recreation here really, I find it so hard going door to door, saying, "Do you want to come down for this?" Sometimes you can try that until you're blue in the face, but if they don't want to come down, they don't want to come, it's so hard though. Whereas where I worked before, when they were already there, they're joining in, even if they don't necessarily want to, by the end they are participating. 
The physical therapist, Judy, works at both Ridgemont and Stonebridge. She sees very

distinct differences between the two settings with respect to resident socialization.

I guess it just depends on how lively you like things. I tend to be a pretty interactive person, and that's why I think I really like Ridgemont, it has this atmosphere about it. Those residents who can't interact very well with other residents, they sit there and they know the staff are there all the time, so they kind of have that feeling that people are around. It's just kind of the layout of Ridgemont, even if it's an older structure, I think it's better.

Environmental conditions require adaptation, and some of the characteristics like privacy and social interaction are in opposition to one another (Regnier, 2002). The Activity Director, Noreen, has a perspective on resident participation that is very different from her co-workers. She feels that the social patterns in LTC relate directly to the impact of environmental choices and the personalities of each individual. While past goals in LTC are to have high resident participation in activities, that norm is based on the expectations in the traditional model of care where there are very few options for how residents spend their time. In the SH model, due to the environmental changes, there are more choices for residents in where they will spend their time, either in their private rooms or in the cottage living area or in the community rooms. Priorities have changed, leaving the question for the staff and management less about what the individual is doing in the new community and more about how that individual may have spent their time at home. Noreen argues that it is really no longer up to the staff to make this judgment, because within the new philosophy, it is up to individuals to make personal decisions about their preferences:

Where I worked before, we had three or four people in one room. Those people wanted to get out of there; they didn't want to be stuck in a room with people they didn't know. So maybe they are now comfortable enough here that they just are fine in their room or reading the paper, who am I to make that judgment? At some point, you have to make a decision, oh, maybe they're depressed or maybe they 
are just tired, or is this what they had always done? Right now, we have a lot of little ladies who went to church and were very family oriented, it doesn't mean they are not social. In Alderwood, there are about five ladies that will watch movies together, they'll do their nails together, but at home they didn't go to dances, they didn't really leave their houses, so it's really more normal that they don't come down here on their own. If doing puzzles and reading is what they did all day, then that's fine. I have people who say "Mom doesn't do anything here." I ask them, "Well, what did she do at home?"

Even in a community setting, true autonomy and choice are completely personal, and cannot be realized in anything but a singular way. For the Stonebridge staff and management, it will take a major shift in the entire organizations understanding and expectations in their philosophy of care to fully comprehend the implications and meaning behind this theme.

\section{The Physical Environment}

\section{The Secure Environment-Peace of Mind}

With respect to the physical environment, the primary purpose of any LTC setting is to ensure that within the environment, each resident will sustain no harm, injury, or undue risk. Appropriate use of interior materials and an upkeep of technology systems to ensure reliability and quality should be a primary focus of staff and caregivers. In addition, wandering and getting lost are primary safety/security issues in all LTC facilities, with residents with cognitive frailty having added issues (Regnier, 2002). The building layout should allow and encourage wandering 


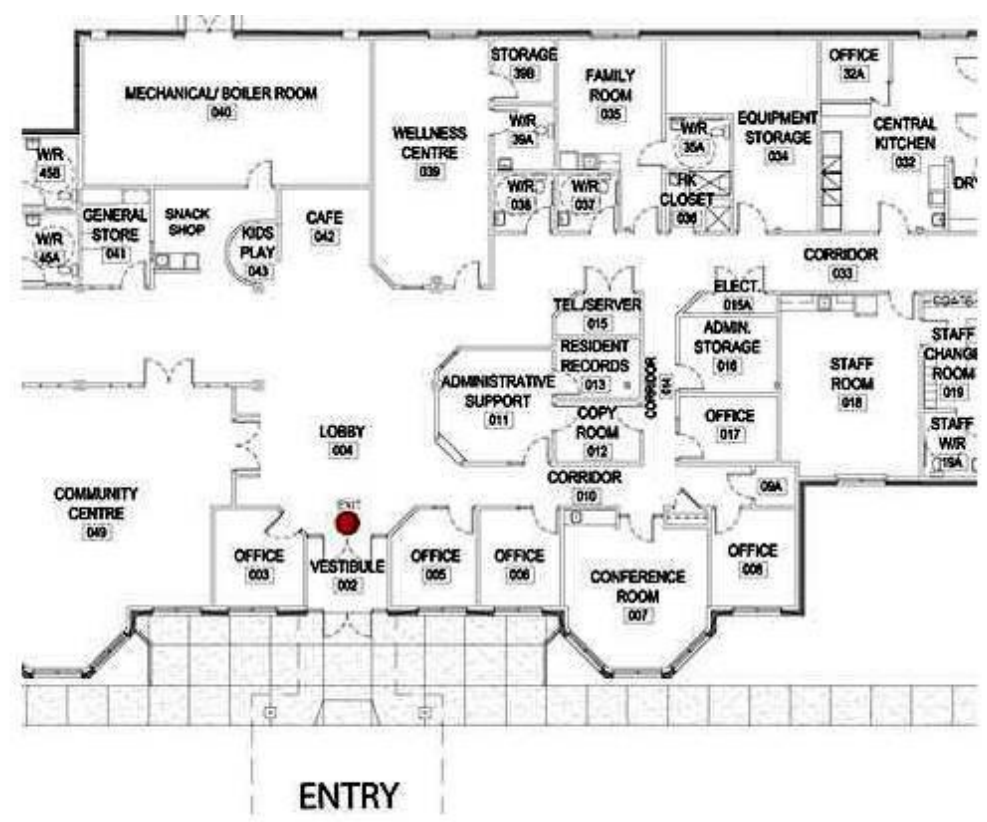

Figure 53. Stonebridge Enlarged Lobby/Administration Plan

through routes that include community activity areas and there should be plenty of secure outside areas for the residents to wander. Security issues for dementia residents may include a need for alarmed doors. If this is the case, there should be some unalarmed doors that allow residents access to multiple areas and any alarmed doors can be situated as side doors which are not in the direct lines of sight for egress. The front entrance to Stonebridge is not locked during the day and Willow is the only locked cottage. Trish compares the security in place at Ridgemont and Stonebridge (Figures 53-55):

We do have our exit seekers; there are wanderers, so the front door of our cottage is locked. It doesn't happen very often, but every once in a while, one of our residents has gotten down to the foyer and walked out the front door of the building because it's not locked. At Ridgemont, you have a code that you have to punch in to open the front doors, but here it's not like that. I wish it was like that here though, I really do. It would give us more peace of mind, because at least you know that if one of our residents gets out into the lobby, they're not going to get out the front door. 


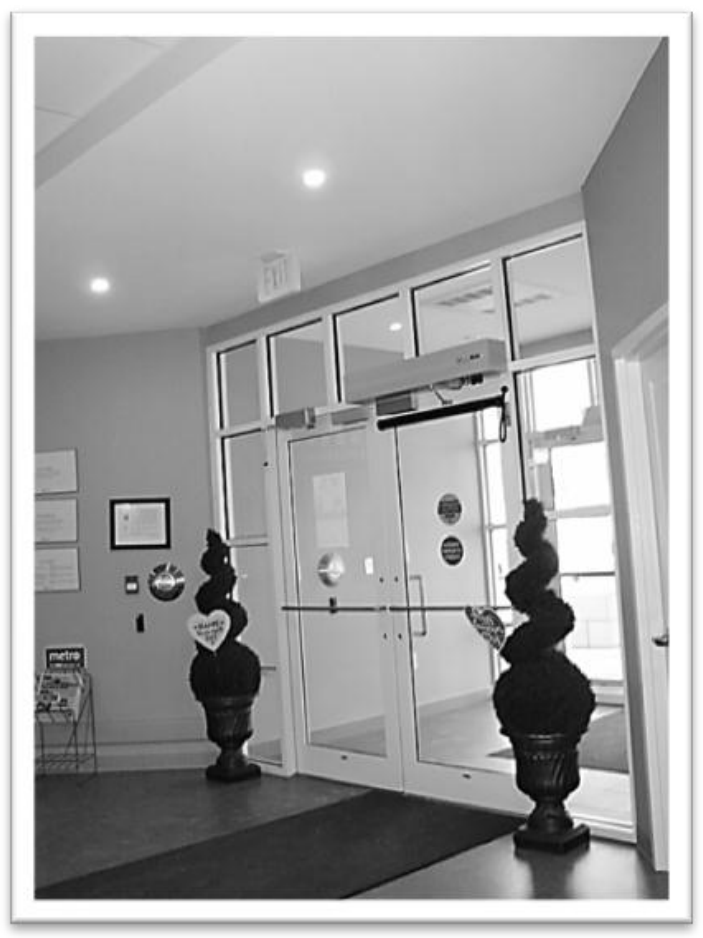

Figure 54. Stonebridge Front Entrance

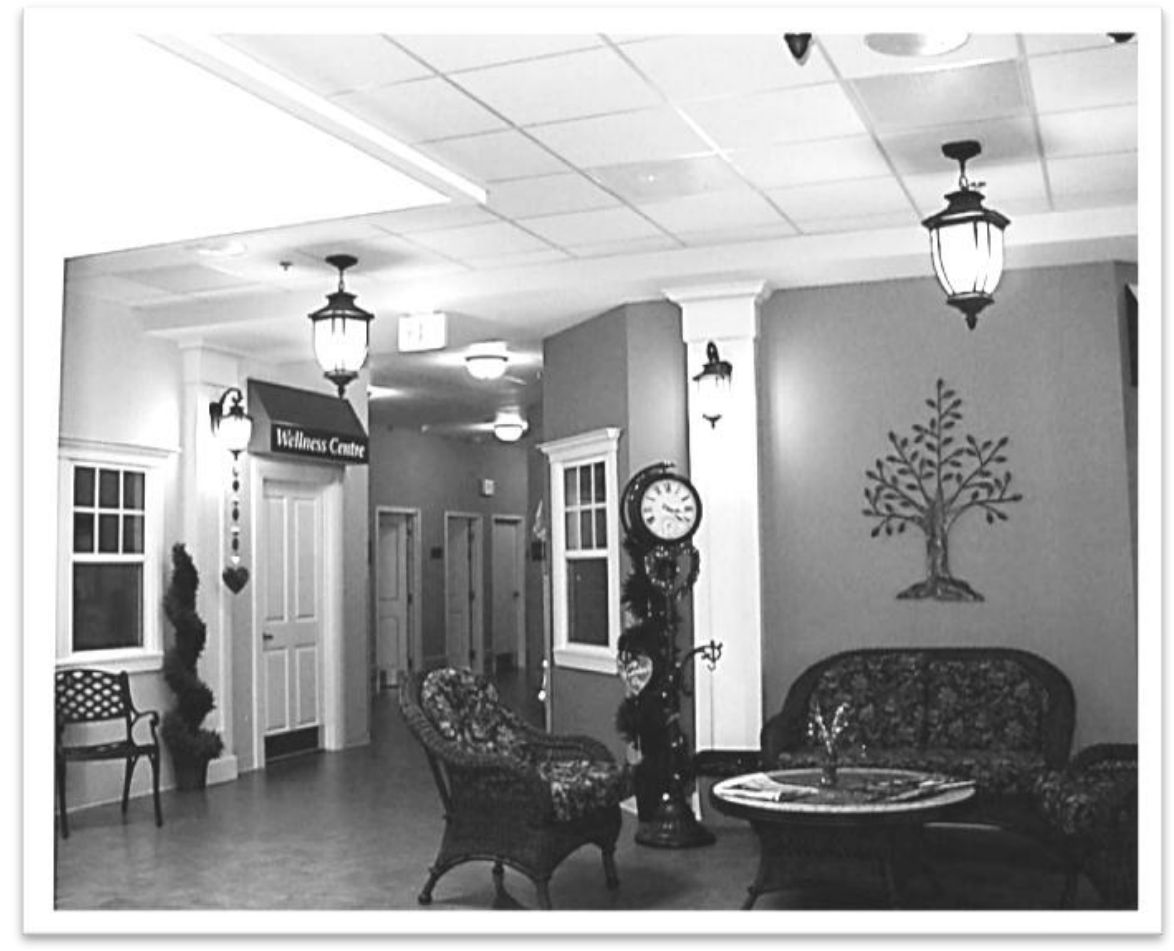

Figure 55.

Stonebridge Front Entrance Seating Area 


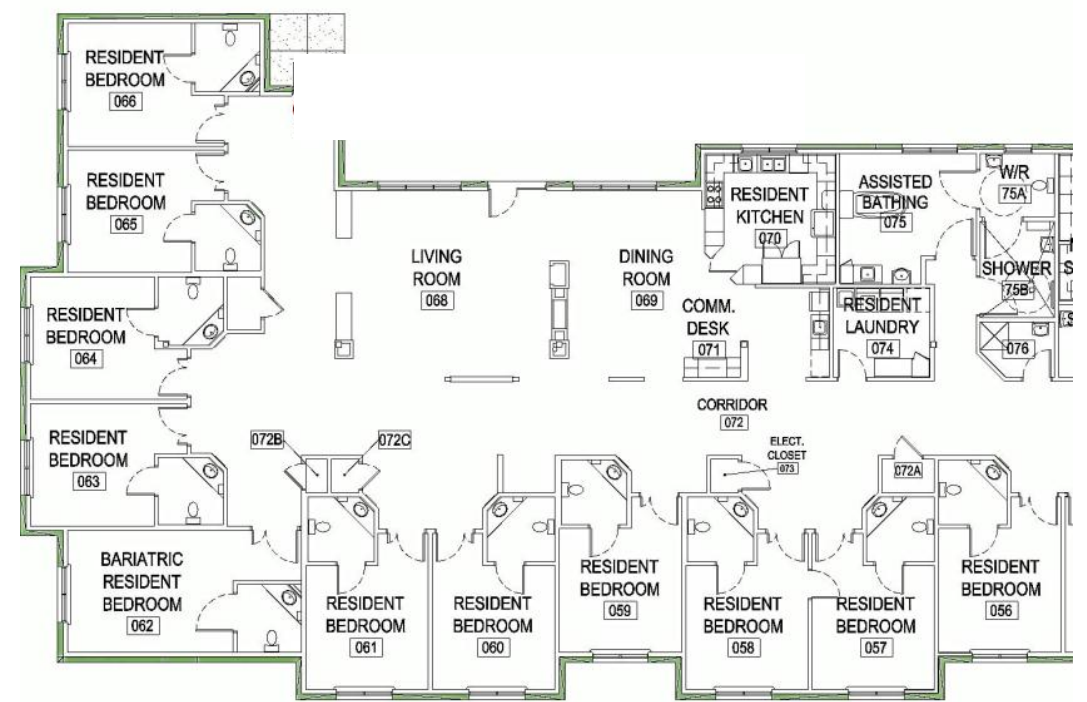

Figure 56. Stonebridge Enlarged Cypress Cottage Plan

\section{Working in the Open Kitchen}

We didn't want there to be anywhere where someone would go and just be working and not be engaged with the house. There was a real conscious effort to get those stations out in the open, make it so someone can do their work. (The Stonebridge Architect)

The CCAs are content with the open kitchen and they like the fact that where they do their charting is integrated into the dining area, but there are issues with the need for privacy when they are on the computer or having a conversation. Residents are very dependent on the CCAs; they tend to stay close, especially in the Willow cottage, so if a CCA is sitting, charting, or on the computer, a resident or family member may be standing or sitting right beside them or behind them (Figures 56-58). Trish describes the challenge:

It can get challenging, because right now they are napping, it's down time. But normally, if you are charting or talking on the phone or discussing something, we don't have any privacy. So residents are coming over, Laura's singing or Bill's out hollering, or family members come and sit down here. We put that round table in the living room by the window hoping that they would go in there, so we would have more space to discuss things. 


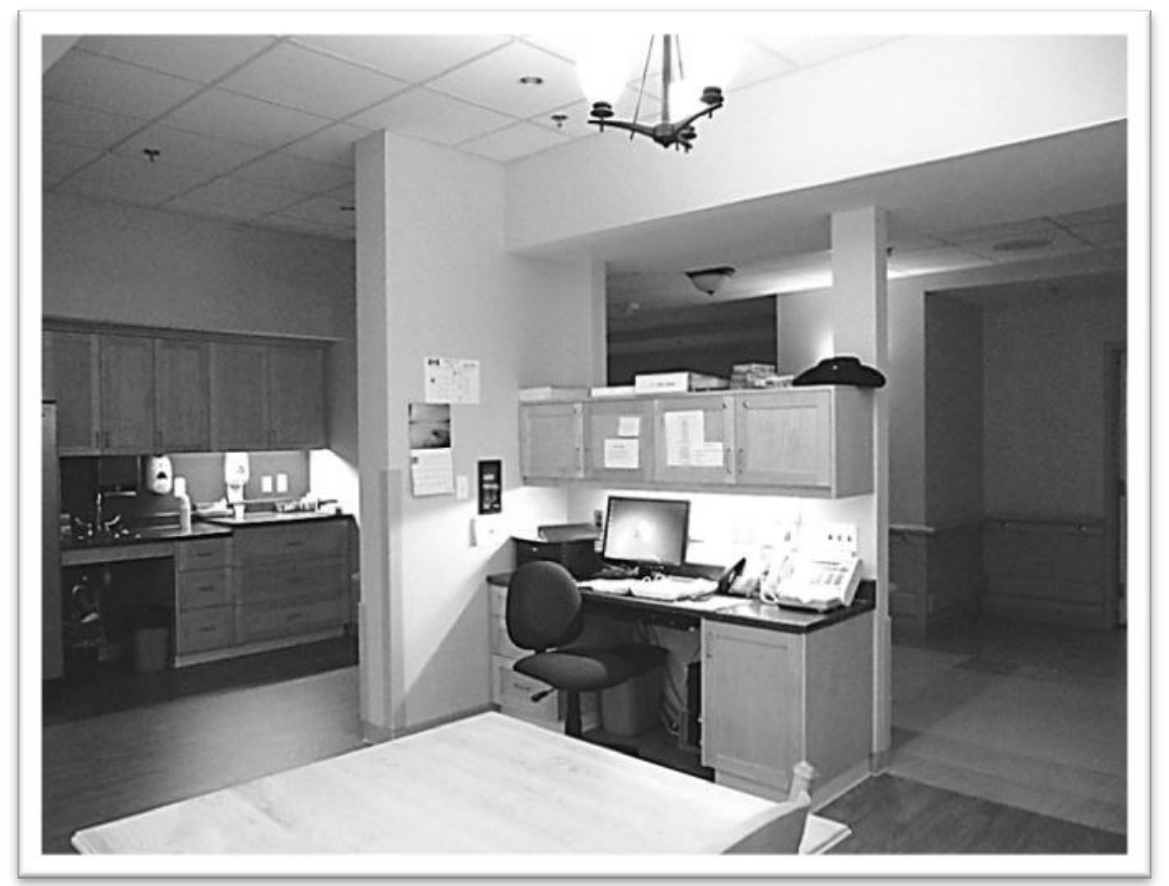

Figure 57. Stonebridge Charting Area in Cypress Cottage Kitchen

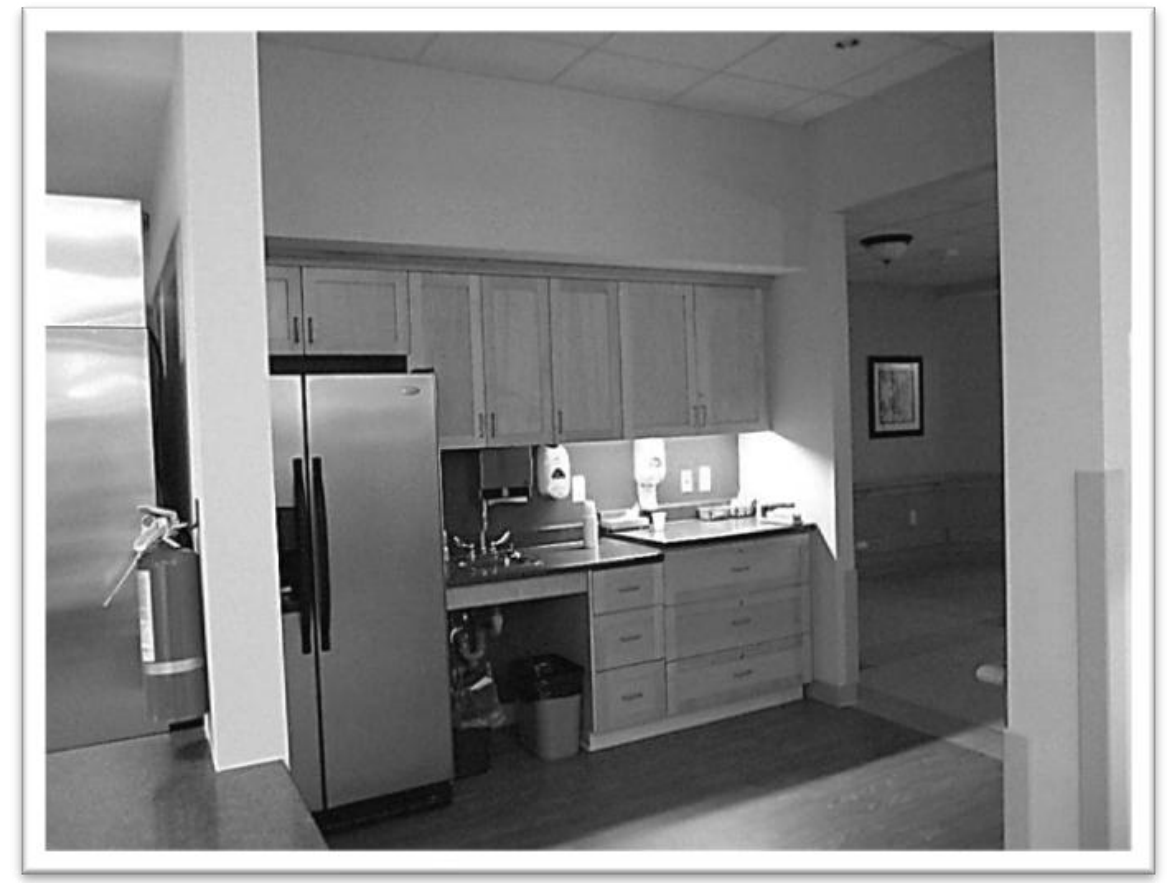

Figure 58. Stonebridge Medication Cabinets in Cypress Cottage 
However, at the Birch cottage, Annette appreciates the convenience of having the charting right in the kitchen area:

I don't see a problem, we can always go down the hall and sit in the meeting room if you need more privacy, you're still on the floor, but you can step away. It's actually nice having it here, because if the doctor calls, then you have the charts right there, it's convenient. This is where we spend most of our time anyway.

While the layout and functionality of the kitchen appears to have been worked through, family members are complaining that they do not have access to the kitchen. The assistant Director of Care also notes that she is getting complaints from the CCAs about the family members in the kitchen:

Well, people are just coming into the kitchen, "I'm just going to grab the coffee pot," when our CCAs are taking something hot off the stove, there's definitely a safety concern. We have that area right there, there is a little fridge right there and at one point we were hoping there would be coffee for residents and family in the building foyer, but that's not happening right now, because we can't leave a pot out there unattended.

In addition to the safety issues, with respect to staff and family in the kitchen, the DoH

mandates that only those who have the CCA certification can be in the kitchen. This has caused a small rift between the family members and management. The Assistant Director of Care continues:

Family members are ticked off because they can't walk into the kitchen to make a coffee; they feel like it is their right. But we have to protect the health of everyone, if they have some bacteria on their hands and they wipe their hands on a towel....you know, you need to be able to step back. If you want to make coffee with your mom, that's fine, trying to work toward the greater good of everyone, that's hard. I think we need to put in a little coffee bar outside of the kitchen, or maybe something a little more formal so that family member won't say, "Well, we thought that this was our kitchen, too." 


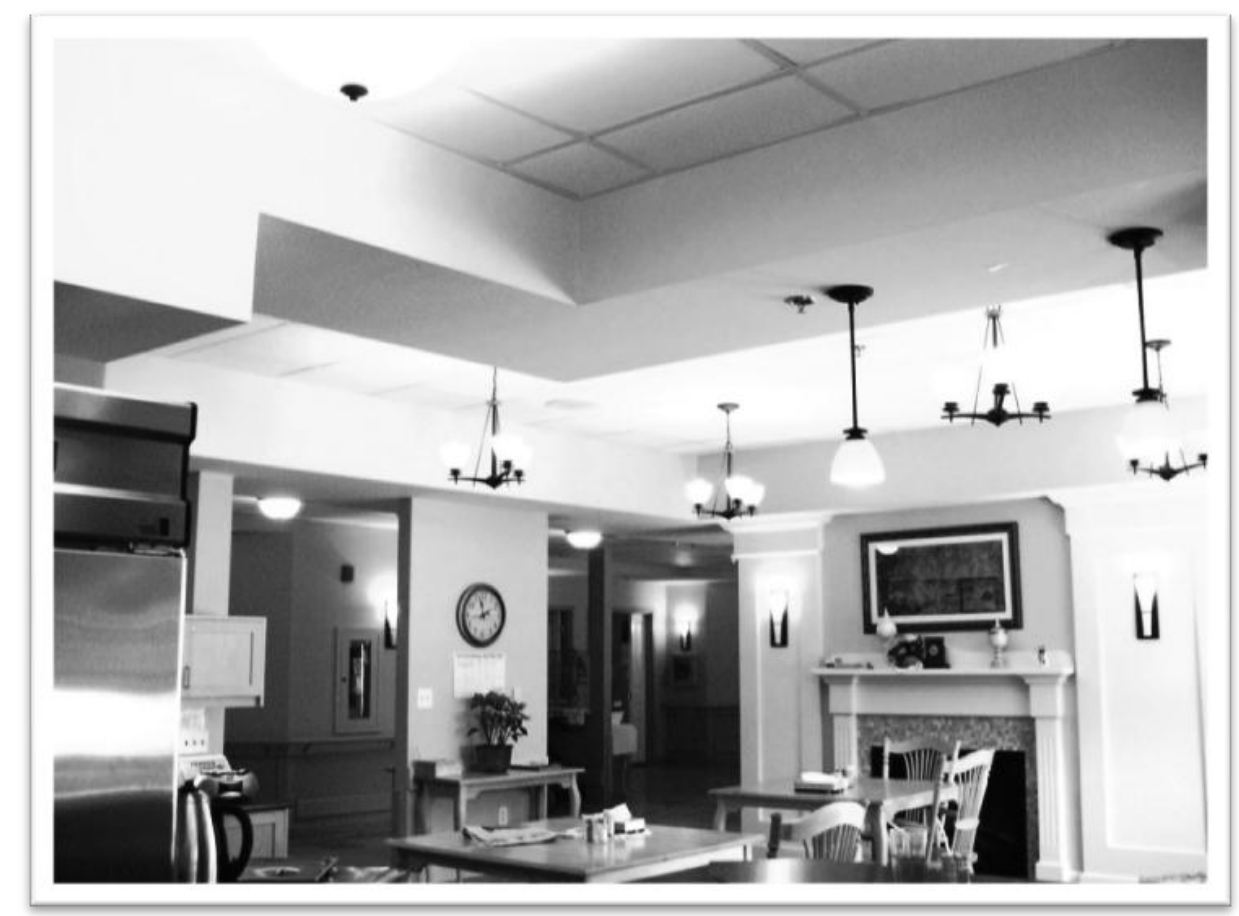

Figure 59.

Stonebridge View from Kitchen in Birch Cottage

\section{A Setting for Care}

The residents in the four cottages at Stonebridge have different levels of need. Upstairs, the Alderwood cottage is the RCF, and residents have higher levels of acuity and are able to do more independently. The Birch cottage upstairs and Cypress cottage downstairs are for residents with higher need levels with ADLs, and Willow is the Alzheimer's/dementia cottage.

\section{Assessing Care Needs}

The goal at Stonebridge is to have residents move through the cottages as their care needs change or progress. Yet, due to the fact that the DoH assessment system begins when the resident is either in the hospital or still at home, often a resident will wait to get into Stonebridge, and their care level may have changed by the time they get there. This can often leave the care staff short-handed because of higher car needs. Noreen speaks about this breakdown in the assessment system: 


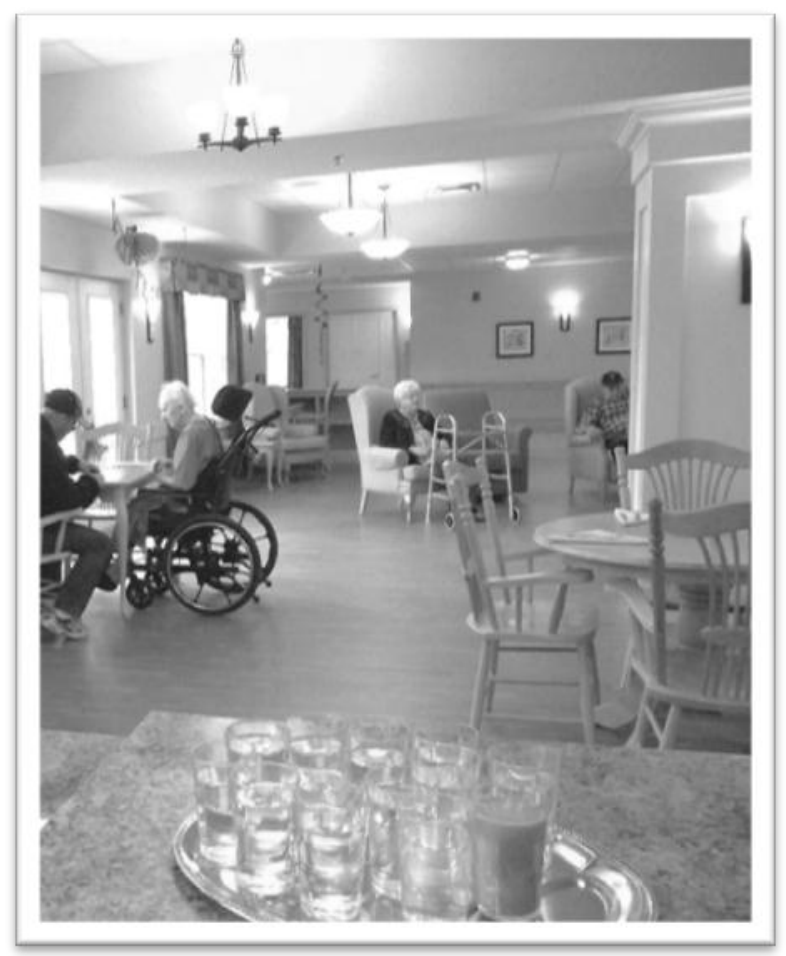

Figure 60. Stonebridge View from Kitchen in Alderwood Cottage

We have this really great model, and everything is awesome, but people want to get in here and they have to wait so long that for a bed to become available, they come in here sicker, needing more care. It depends on if you are in the home or the hospital, you may wait at home, in transitional care or in another community. Just say you waited at Oakdale for six months, you could have deteriorated quite a bit. They don't get reassessed until they are in the new place and often times they are sicker. When we first opened, we had people who were going to the RCF, and within a week we had to move them down to Willow, which is the locked cottage.

Reina sees the problem too, as she works in Alderwood, the RCF. Often, she spends

much more time on an individual's physical needs than is normally required in that cottage.

Staffing levels are lower there, which leads to less time spent with other residents:

A lot of times, we'll be able to see within a few days that someone really needs more care, but then we have to wait for a new bed to open, and for that person to get reassessed. It takes a long time for the $\mathrm{DoH}$ person to come to reassess, and it's hard on staff that way, because we spend more time with one person every single morning and the other residents even talk about it. I feel like I'm more busy because here, some of the residents seem like they need more care. I feel that maybe they should be in one of the LTC cottages. 
Reina goes on to say that she feels that if the assessment procedure really worked like it had been designed to, there would not be these issues, "If they were more independent, and did their own things, and we were only here for a few things, then we would have enough staff."

\section{The Learning Curve in Memory Care}

Despite the different care needs in the cottages, the RN, Jill, sees a high number of residents with some form of dementia throughout the community. While the Willow cottage is considered the Alzheimer cottage, residents there are free to participate in all activities which take place in the community center. She explains:

Well, we have what we call the Willow cottage, which is a locked unit, so you see a lot of Alzheimer's and dementia there. There are different degrees there, and there are also those in the community that I like to say are just pleasantly confused, they will have these periods of lucidness when they know you and what is going on. Then there are other people who, I don't know the best way to describe it, but they are just not there. I would say that as a resident population, at least half of the residents in Stonebridge have some form of dementia.

The CCA course has one class in care for Alzheimer's, but other than that, there is no special training for the staff in the Willow cottage. While there is an older, more experienced team, it has been a trial and error learning process for them in trying to keep a calm and consistent environment for their residents. Trish and her co-workers speak to the challenges of caring for the individuals in their cottage:

It was a learning curve for us, and we made a lot of mistakes when we began, us CCAs. I can remember we used to set the tables in the morning; we used to do that because that's what we're supposed to do. We'd have people just taking the forks into their rooms, flushing things down the toilet. Thinking back to when I first started here, it took us a while to get the idea that we just can't do things like presetting the table in this cottage. The CCAs in the other cottages were setting the table in the morning, putting the nice table clothes out and everything, we just can't do that. So now we're locking things up, we used to have cabinets open and 
full of things. Even clothes, like clothes hampers in some of the resident's rooms, they would take their clean clothes off, put them in the hamper and take dirty clothes out and put them on. We've learned that all residents can't have garbage cans in their rooms because they take the dirty things out or pee in them. We had one Alzheimer's course in our CCA training, the rest of it was kind of learned, it took time for us to get it and when others came in, we passed it on to them.

Teamwork is critical to the Willow staff, and Dana agrees that working in the Willow cottage is a shared, ongoing learning process:

Any new resident that comes in, you kind of have to learn their behaviors, adjust and teach each other what you have learned, like, "This person does this and did you know the other day this person ate toilet paper?" It takes time, like, I really wouldn't have known all of this. The book that we had in the course, I'd just say, throw it that out the window, you've got to work here to get it.

\section{Comfort Care}

The management of Stonebridge have an agreement with the local EMT that, for minor emergencies, residents can be treated onsite instead of being transported to the hospital. The RN, Jill, describes the importance of the partnership for both staff and residents.

What we have now is the EMT have hooked up a non-emergency paramedic, so they are actually able to come in here and do things that are typically done in the emergency room. So for instance, someone came in and did stitches on a lady's leg the other day, and that prevented her from having to go sit in the ER for six hours. If people get sent out to the hospital and they get sent back saying they need this, this, and this therapy, we can't do IV therapy here, but the paramedic can come in and do the IV therapy there, so they can stay here and still have what they need without having to leave.

Another important benefit of the model is that residents may choose to stay in their cottage if they are on put on palliative care. If the family and resident decide they want comfort care, the doctor will sign the orders and they can continue get the care they need at Stonebridge 


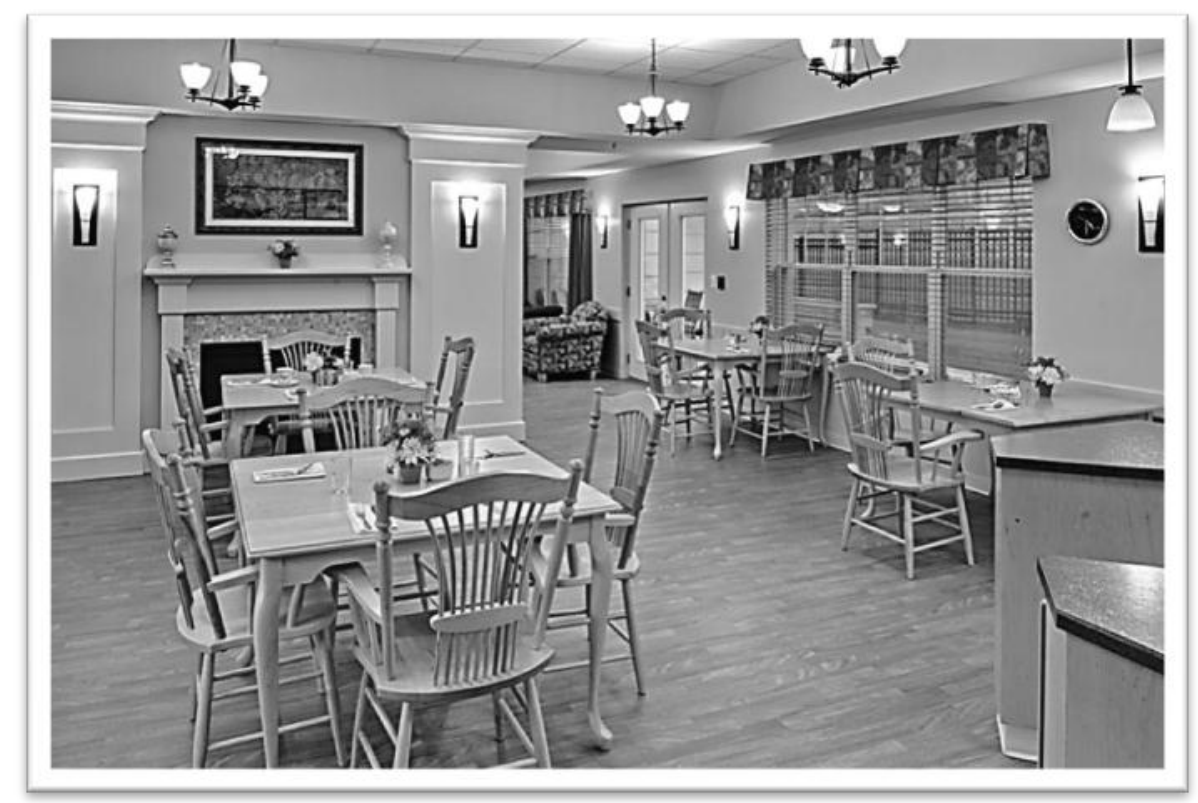

Figure 61.

Stonebridge Cypress Cottage

until they die. Some residents do choose to go to the hospital though to seek treatment, but as Jill describes, many will come back to Stonebridge for their final days:

There is also comfort care, when they no longer want to seek active treatment. We had a gentleman who is on comfort care, and he got ill, and he decided that he wanted to seek treatment, so he was sent out to the hospital, where he stayed for almost a month and then he was sent back to us. He was in renal failure, so he will probably die within the next three months, but he is not acutely ill. He is technically palliative now, but he is not in the active dying process. So the concept of aging in place, they can do that here, they can live here until they die, we can look after them comfortably here. A lot of people, since I have been here, I think I've had seven or eight deaths, the majority of the people want to die here, cause it's their home now, right? We had a couple of people who were sent out to the hospital, they received their diagnosis of no treatment and decided they wanted to come back here to die. One or two of them were people we didn't even think liked it here, like Lucy, we never really thought she liked it here, she was kind of cranky sometimes. We all loved her, but we didn't think we had that much impact on her after her husband passed away and she was ill. She had a massive stroke, couldn't do anything, woke up one night and told her son she wanted to go home, never spoke another word. Came back here and died a few hours later. She held on until she got back here and everyone came in to say goodbye. 


\section{Framing Home}

\section{The Power of the Model}

While the staff have perspective about the power of the new care model at Stonebridge, they feel that residents are not particularly aware of the changes in the way care is given. Residents may not have a specific understanding of the model of care at Stonebridge, because many of them have come straight from home or the hospital due to an illness; often this is the first place that they have lived since they left home. Noreen has this perspective due to the amount of the time she spent working in other communities:

People who come here from home complain about the food and stuff, but they don't realize that in other facilities that if the hot cart comes at 8:30 am and if you're not up and ready to roll to eat wiggly eggs, you won't eat. Your laundry here isn't getting washed with everyone else's laundry, things like that, things that just seem so normal. When I first got here I was like, "Oh my gosh, this is so amazing," but now it's becoming sort of old hat, it's nothing new; I guess that wears off on them.

A CCA in the Birch cottage agrees with Noreen that the majority of resident don't really express their understanding of the model because they don't know any different:

No, I don't think that they really realize it, they can't see the philosophy. The only residents that would pick up on that are in our RCF and most of them, this is the first place they have lived other than their homes. The other residents haven't really picked up on that due to their level of dementia, or other things.

Yet the caregivers feel that the residents have a connection to the staff and to other residents living in the cottages. They see that residents have concern for each other and, on the whole, the Cypress CCAs are in agreement that residents appear to be comfortable with the setting and the scale at Stonebridge:

C1: This is very much like a home for them, not like the other ones like Oakdale and Ridgemont, where it's more hospital style. Where here, it's like a home, they 
have their dining room, kitchen, the living room. They have their personal bedrooms that they don't have to share with anyone else; they have their bathrooms they don't have to share with anyone else. So, this is what I think a nursing home should be like.

$\mathrm{C} 1$ : Oh, yeah, a lot of them will agree that they like it here; everyone is concerned about the others. If one goes to the hospital, they worry about them. You really see the community at times like holidays; it's nice to see some of the things they do for each other.

\section{Feel Like I'm Coming into My Home}

There is a general consensus amongst the CCAs that it is they, the staff, who truly feel at home when they walk through the door of their cottage to come to work. The CCAs spend so much time in the cottages, taking ownership and responsibility for all aspects of the physical and organizational environment that instead of feeling like they are coming to work in an institution or someone else's home, they have a sense of place attachment to the cottages. The benefits of this outcome of the model are that staff are much more inclined to work in the same place for longer periods of time if they feel empowered in their workplace. The CCAs from the four cottages express their sentiments:

B: Actually, I feel like I'm coming into my home. Like when I worked at that other new facility, I just didn't feel like home there. Even though it was a brand new facility, the building was built a year and a half ago, same feel and look, with 62 residents. It was small, but it still just felt very institutional. Here, I feel like I'm home, I honestly feel that I could live here at any time.

AW: I feel a lot more welcome, it's more home for me, this is like my second home. When I was doing my clinical, I actually didn`t think I was going to like the course, but since I came here, I loved it, it's more homey. And you get to spend a lot more time with the residents, whereas the other place, I didn't at all.

C: It feels like home, definitely. Yeah, in the morning, when somebody's frying bacon and doing scrambled eggs, it's just like at home.

W: I feel like, honestly, this is my home too, because I am here so much. I spend more time here than I do with my own family, because I'm always here. So it feels like home coming in here. 
The perception of home that CCAs feel has in part to do with the bonds that have been created between the caregivers and the residents, an understanding of each other's problems and needs. Annette from the Birch cottage discusses this closeness:

You get pretty close with them when you work with them for so long, and so many hours. And they say, "Oh, I feel like your Grandmother, I want to take care of you." Or if I come in to work one day and I'm not feeling well, they all just want to take care of me. They'll say, "Just sit down." Or one says, "Just go lay on my bed and I'll watch the place for you, don't worry." I'm like, "Well, you can't do that." They are really good like that; it really is just like a big family. They will say, "Just sit down, I'll take care of it, I'll do the supper," I say, "No, I'll do it."

But the CCAs also understand well what the residents have had to give up in moving to

Stonebridge. The Cypress CCAs discuss their perceptions of the reality of moving into LTC:

C1: We taught to better ourselves and do all these great things and then you get sick. You look at Brenda, she had kids and all these things and then they are all taken away from her. She has four walls.

C2: They may live in the same cottage, it's supposed to be their little home, but they didn't chose to live with those people. You're not necessarily going to get along with all of those people. We say, "OK, you're living here now with all of these strangers. Have fun!"

C3: This is how I think about it, you've spent your entire life doing things to better yourself, building your home, your entire life to this point, then you get here and you have to make the decision of what you are going to bring to these four walls, it's all gone.

\section{Chapter Summary}

The staff and management perspectives from Stonebridge articulate the sensibility of change which occurring there. While the culture of care at previous institutional settings was difficult to accept, the staff are now empowered in their new roles and have a clear understanding of the implications and outcomes of their hard work. Gone are the conflicted days when staff called the residents by their room number, or wheeled them into a large dining room 
at 8 am for a plate of wiggly eggs and cold oatmeal. The physical environment and organizational structure of the SH model has resulted in a sense of place attachment in their work environment for the care staff.

In the following chapter, we will hear the resident and family member perspectives at both Ridgemont and Stonebridge. These interviews will describe a very different perspective from that of the staff and management in the two communities, because these participants are looking at life in LTC through a lens of the need for, rather than the provision, of care. 


\section{CHAPTER EIGHT: VOICES FROM DOWN HOME}

Within any study in a community setting, there are multiple voices to be heard in order to understand firsthand what is happening in each setting. The management and staff at both Ridgemont and Stonebridge are focused on working through obstacles of staffing and communication issues in their communities, while providing the best care possible for the residents. However, all of the planning, concern and conversation about the development of LTC communities needs also to be reflective of the people who move there because of their care needs. and the family members who have to come to terms with those needs. A necessary, but often overlooked elements in any study of the LTC environment are the voices of the residents and family members.

In this study it was important to hear the family and resident interviews from each of the communities in the same chapter, because the voices are strikingly similar. There is little mention by family or residents in either community about room layouts, staffing levels, or management communication. What family members do want to talk about, however, is how their relative has gotten to the point where they have needed to move into LTC and the oftentimes confusing and frustrating road to that move. For residents, their concerns run much deeper; these are stories of memories and regrets, about coming to terms with not only where they are, but more importantly, where they aren't, both physically and emotionally. This chapter will include four family and six resident interviews from each community. The majority of the interviews were pre-arranged, and all occurred in public settings like the lounge or dining area at Ridgemont or the living room or kitchen at Stonebridge. 


\begin{tabular}{|c|c|c|c|}
\hline $\begin{array}{l}\text { Resident/Family } \\
\text { Member }\end{array}$ & $\begin{array}{l}\text { Resident } \\
\text { Age }\end{array}$ & $\begin{array}{c}\text { LTC } \\
\text { Community }\end{array}$ & $\begin{array}{l}\text { Family Member Theme/ } \\
\text { Resident Transition to Care }\end{array}$ \\
\hline Tom/Wife & 87 & Ridgemont & $\begin{array}{l}\text { He calls me 10-12 times a day. } \\
\circ \text { Moved from hospital after broken hip and } \\
\text { pneumonia. }\end{array}$ \\
\hline Rose/ Husband & 82 & Ridgemont & $\begin{array}{l}\text { I'm not moving her again. } \\
\circ \text { Moved from another nursing home due to } \\
\text { progressive dementia }\end{array}$ \\
\hline George/ Son & 82 & Ridgemont & $\begin{array}{l}\text { He doesn't really know we're here. } \\
\text { O Moved from son's home due to progressive } \\
\text { dementia }\end{array}$ \\
\hline Frank/ Daughter & 82 & Ridgemont & $\begin{array}{l}\text { Caring for two parents. } \\
\circ \text { Moved from hospital after pneumonia due to } \\
\text { rummaging and danger to himself due to } \\
\text { progressive dementia. }\end{array}$ \\
\hline Richard/ Daughter & 80 & Stonebridge & $\begin{array}{l}\text { They sent him to the wrong nursing home } \\
\circ \quad \text { Moved from hospital after car accident }\end{array}$ \\
\hline Terry/ Husband & 67 & Stonebridge & $\begin{array}{l}\text { She's well cared for. } \\
\circ \text { Moved from Ridgemont, need for } 24 \text { hour physical } \\
\text { assistance }\end{array}$ \\
\hline Vincent/ Wife \& Son & 89 & Stonebridge & $\begin{array}{l}\text { There's a limit to what you can do. } \\
\circ \text { Removed from home by adult protection because } \\
\text { of concerns about night wandering and progressive } \\
\text { dementia. }\end{array}$ \\
\hline Carol/Son & 83 & Stonebridge & $\begin{array}{l}\text { This location works } \\
\circ \text { Moved from apartment after loss of husband, } \\
\text { unable to care for self due to progressive dementia }\end{array}$ \\
\hline
\end{tabular}

Table 6 .

Family Member Interview Information

\section{Family Voices-Anger and Guilt: The One-Two Punch}

People say, oh there are some really challenging families. We don't have challenging families, we have families that want the very best for their loved ones, just like we would. I would want even more, I would be even more demanding. (Francis-Director of Nursing at Stonebridge) 
Family members who are experiencing what has been called the 'unexpected career of caregiver' may experience a multi-faceted, complex, and stressful life situation that can have important consequences (Raina, et al., 2004). This stress can be related to the unknowns that arise as the parent or spouse's health declines. The degree of strain that is caused by these changes is measured and referred to as caregiver burden. When assessing caregiver burden, it is important to consider what is happening psychologically, physically, financially, and socially in the life of the person who is giving care, as well as what is changing for the individual receiving the care. The burden of care is also affected by different factors which include the illness severity and level of disability of the patient, the behavioral problems and dependency of patients, and the strengths and coping mechanisms of the caregiver which is impacted by the social support and community resources available to the family.

Making the decision to relinquish the care giving role to health care providers is a very difficult and stressful event (Caron, 2006). When a family caregiver does decide that a permanent move to a care facility is necessary, their reasons are often multifactorial, and understanding these reasons is an important step in understanding the institutionalization process (Buhr, 2006). Within the scope of the continuing care system in Nova Scotia, there is an added element of the assessment and wait times to get into a community. Extra time in the hospital can create more stress, as the resident and the family member wait in limbo for a bed to open in a nursing community.

The eight interviews with family members follow (Table 6) and descriptions of the emergent themes will be discussed in Chapter 9 . 


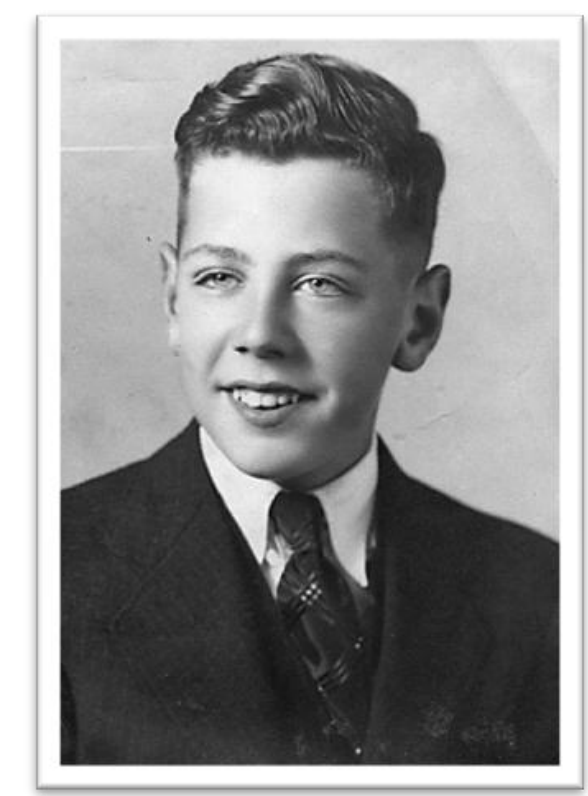

Figure 62. Tom as a College Freshman

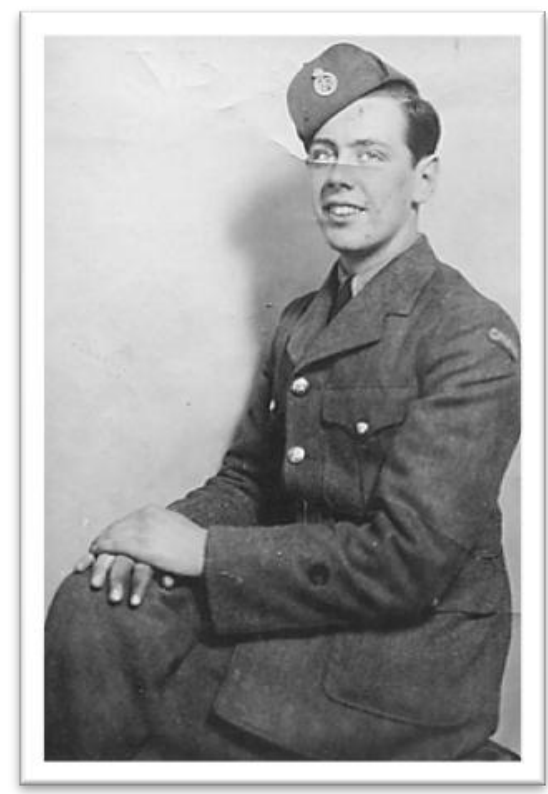

Figure 63. Tom in Military Uniform

\section{Ridgemont Family Interviews}

\section{He calls me 10 to 12 times a day}

Tom is 87 and is new to the Ridgmont community. When we first met, there was a lot of family activity in his neighborhood. His grown daughters and their children were coming to visit; and his wife Joan was in and out several times a day. The family had conferences in various seating areas around the community, but it was clear no one was comfortable in the new setting, especially Tom. It was evident by the look on Joan's face that things were not going well, and when we sat down to talk, she appeared to be relieved to discuss the long road to moving her husband into LTC:

$\mathrm{J}$ : When this all came up, we started with a home care assessment but it took them four months to come and assess Tom. Then it took another six months until they called me and said they could give me an hour and a half of home health care in the morning. I said, "Well, you're a little late, he fell and broke his hip." $\mathrm{He}$ broke his hip seven months ago, but he had dementia before that. We were aware of it several years ago. The doctor would give him the standard test in the office, "Do you know what day it is" and stuff like that, and he would memorize it. We 


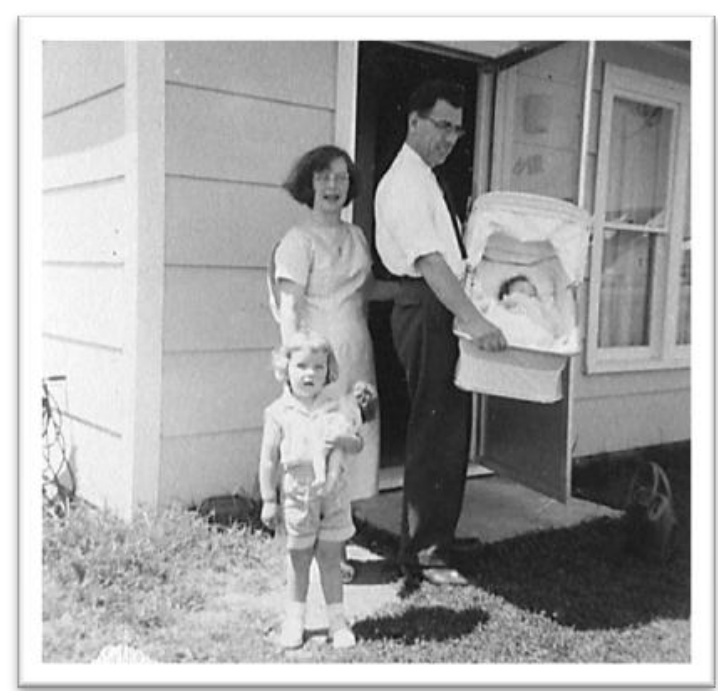

Figure 64. Tom and his Family

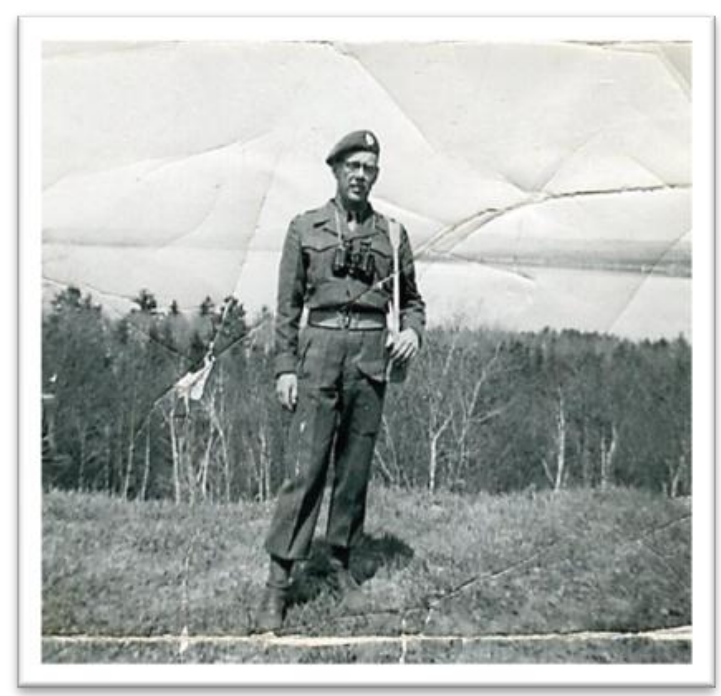

Figure $65 . \quad$ Tom in the Army

knew a while back when he used to go into rages that weren't typical of him, we knew there was something wrong. But he wasn't diagnosed until a year ago January, when he almost died from severe pneumonia. When he was in the hospital then, they diagnosed him with the onset of dementia.

I: Then did he wait for an opening in transitional care?

$\mathrm{J}$ : No, they told me that he would never get to transitional care at the VG (Victoria General). There used to be 34 beds in transitional care; there are now 17 because they closed down one of the wards, and at the time when he was in the hospital, there were 100 people there waiting to go to transitional care. They just kept him at the hospital, so they started charging him then what the nursing home would charge. The whole thing was a nightmare and I'm not the only one that goes through it. It's the system, but it shouldn't be that way. I don't know why it is, there is enough money for what they need to do, but it's more of the money going toward administration. As soon as the government gives money for healthcare, the nurses go on strike. Or they give money to the university; the professors go on strike right before you are supposed to write for final exams for the year. What the money should be for is not where it's going; it's going toward administrative salaries.

I: Well, you know in the States, we don't have any safety net. So there's aggravation at both ends.

J: Right, we wait here but we have a safety net, you (United States) don't have the services period, without the money for insurance. It's confusing though, just this year there will be changes on our taxes, because we married but now we are separated by care. So when we used to file individual tax returns, we were taxed on our combined incomes, but now we are going to be taxed separately.

I: What did Tom do for a living? 
$\mathrm{J}$ : Tom was a refrigeration and heating mechanic. We moved a lot. Tom's life has been defined by coming from a broken home. His father was very controlling; he hated his father and he felt guilty about it. He's been depressed all of his life. He has had these problems since he's been young, his parent divorced when he was 11. Nobody wanted him, so they shipped him off to a college. No one ever went to visit him; he had the pain of "Where am I going to go?" So he's had a difficult time, I wonder if that has to do with his dementia or not? And he drank, he was an alcoholic, he'd try and stop. He just...there were the girls and I, and Tom was always over here in left field. He had a lot of acquaintances, but never a true friend. He did love the army, he loved being in the Loonies.

I: So when you married him...?

J: I wanted him to know that he had a place that was going to be there all the time. Although I did tell him that if he didn't stop drinking, he was gone. He said, "You can't kick me out." And I said, "Yes, I can, I'll get a lawyer." So he tried, he struggled for years. Eventually he got there, maybe 10, 12 years ago. It's been difficult. He doesn't talk much about it, he keeps pretty much everything to himself and he'll tell you, he says, "I've built a brick wall around my feelings and nobody is ever going to take it down." He built the wall so he can't get at those feelings and they can't get at him. You have to accept that sometimes.

I: So had you put Ridgemont as the top choice?

J: No, I had put Stonebridge, because it's right up the street from us. I don't know, I haven't been to Stonebridge to see what it's like in the cottages. I did go one day and they showed me the main floor, but this is where the bed was.

I: Is there any burden off of you now that he is here?

J: Oh, he wants to be home, always wants to be home. I hear Garney's wife, she can't say anything else, but "I want to go home, I want to go home," she's had dementia for years. They all want to go home. Tom will put a guilt trip on me, but not on the girls. He'll be fine when the girls come in, oh yes, everything is fine. Then I'll get a phone call, which bothered me a lot at first, but now I just listen, and let him rant. I am still angry that this is happening and the lack of control. I feel guilty sometimes that I have done something wrong, especially when he calls me 10-12 times a day and says, "Well, you haven't been here to see me." And I say, "Well, I was there yesterday Tom." He doesn't remember, time doesn't mean anything to him. Then when I haven't been here for two or three days, he thinks I was there yesterday. And I'm trying to cut it down to two days a week here, but it's not working. I'm coming three, sometimes four, days a week; my girls help out when they can, but they have their own lives. 


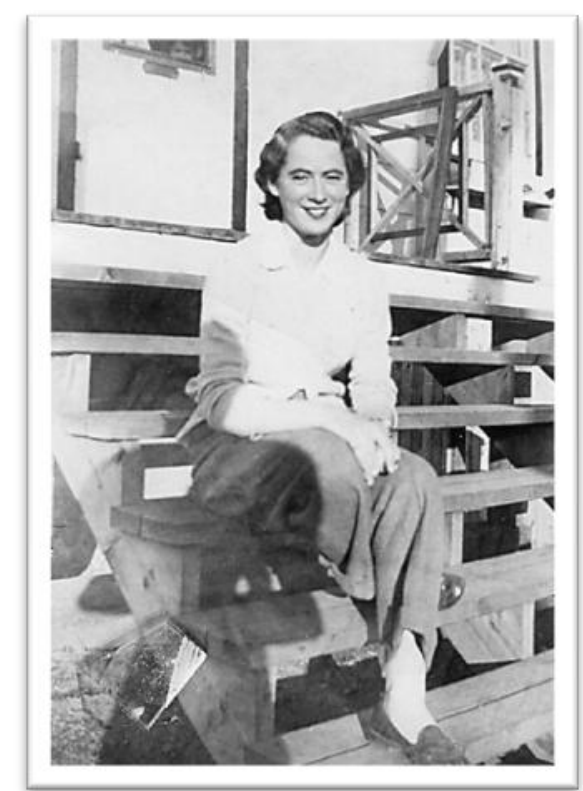

Figure 66. Rose on her Mother's Steps

When I was walking out with Joan past the Bluebird neighborhood, the door was locked. Joan had just gone to find a nurse to open the coded door when we heard someone shoving and pushing at the door. Joan said, "Uh, that's got to be Tom, he's using his walker to try to open that door again." When the caregiver opened up the door, there was Tom, standing there smiling, waiting to walk through. As she was leaving, Joan turned around and said to me quietly, "When those doors are locked, he feels like he's in prison."

\section{I'm not Moving her Again}

Garney visits his wife Rose every day. Not a short visit; he comes in around 9 am and leaves around $4 \mathrm{pm}$, "Unless, of course, there's a snow storm or I'm sick." He is kind of a fixture at Ridgemont, he knows all of the residents and staff by first name, and helps in the parlor, setting up chairs or breaking down tables, whatever needs to be done. He knows the activity director Sara's routine so well that, "I can get things done before she even gets there, because I know what she's going to be doing." Most days, Garney sits next to Rose's wheelchair, just 


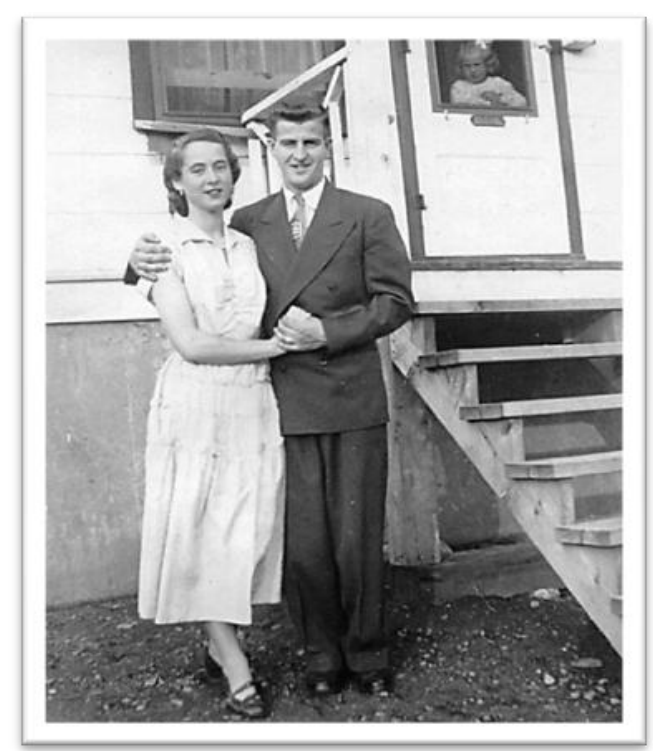

Figure 67. Rose and Garney

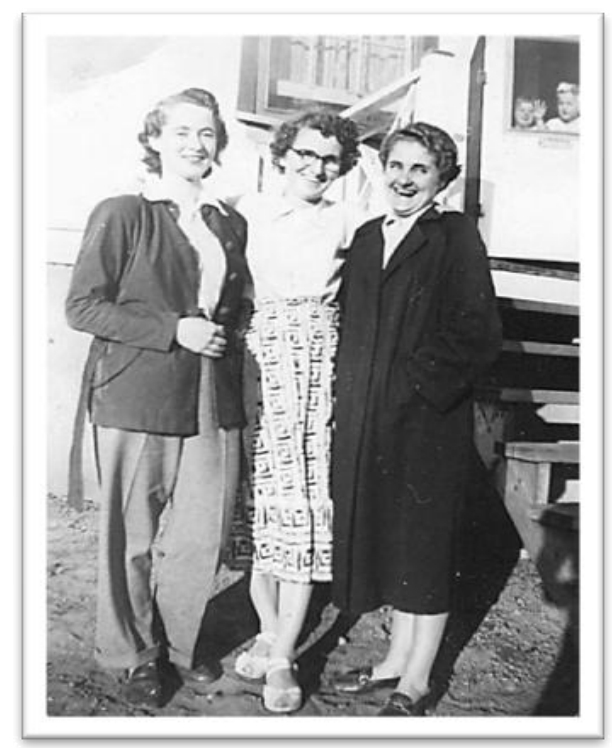

Figure 68. Rose, her Mother, and Aunt

holding her hand. Rose is 82 , has Alzheimer's, and while she will repeat words to herself, she does not speak to others. I asked Garney if she still knows him:

G: Probably not, she knows I'm someone who cares about her though.

I: How long has she been here?

G: Rose has been here for three years, and before that she was at Harbor Side, it's really nice over there, the staff are great, but she was not happy. She was there for 14 months, I was in the hospital and we needed to find a place close by so that's where they put her. My first choice (waiting list) was here. At Harbor Side, it was just too many people, so she wasn't relaxed like she is here. It was beautiful down there, but it was too crowded and she wasn't getting the attention that she needs. She was agitated and not calm there. Here, she laughs and lives it up and smiles and there she was stone faced and tense. When we got the call to have her come over here, I told the nurse that I would have her ready, but would they be ready for her? We had my son and his wife with us; they helped pack her stuff up in half a day and we were here in time for lunch. They invited Rose to move down to Stonebridge when they opened, I just couldn't move her again, she is so happy here (Rose is asleep in the chair next to Garney, he is holding her hand).

\section{I: How did you and Rose meet?}

G: She came to one of my softball games, and afterwards I invited her to go ice skating with me. She borrowed my jacket and forgot to give it back, so it gave me an excuse to call her. 


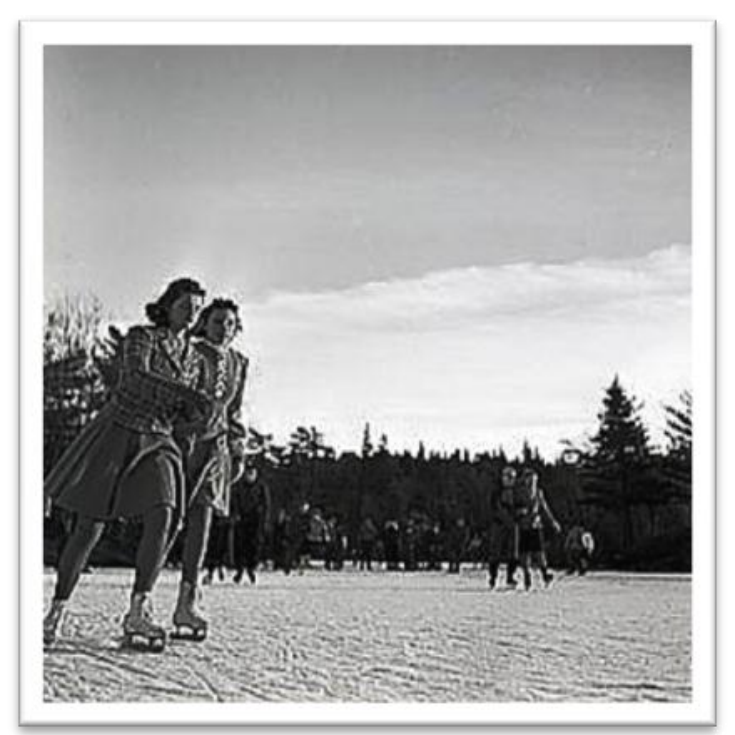

Figure 69. Ice Skating in Halifax

I: So you are here every day?

G: Just about. Our kids say I should just move here, but I like the house where we live. It looks over the Bedford basin, at night you can see the lights all the way out to the island. I need to look after the house, it's still our home.

I: When did you know that Rose had Alzheimer's?

G: There were seven other people in her family that had Alzheimer's, her mother, aunts, and so on, so I knew what was going on. I invited a family friend who is a doctor over several years ago to the house. The doctor talked to Rose and asked her a lot of questions and when he was leaving he said he could see what was happening, that things were going to get worse. Another time we were at a party, and we were talking and joking with a couple that we had known for a really long time, we used to ice skate with them every weekend. When they left, Rose asked me who they were. She could cover up for a long time.

Garney has a lot to say about the staff at Ridgemont, he is very impressed about how well they work together. He can see that they really enjoy working together, they know each other so well, they socialize outside of work together, probably because many live further north than Ridgemont. The staff appreciate Garney too and keep an eye on him as he has had some health issues of his own. Maureen doesn't know would happen to Rose if anything happened to Garney. 
"He is her world; I don't think she responds to anyone like she does him. It would be very sad if she were left alone."

\section{He Really Doesn't Know We're Here}

John comes in when he can to visit his father George. George is 82, and when George's wife died, he had come to live with John and his family. That period of time was very difficult for John, and while it is hard to visit his father at Ridgemont, it was much harder caring for him at home.

$\mathrm{J}$ : Dad was living at Oak Manor before this and he was with us before that. When an opening came up here, he was moved from Oak Manor because we are just 5 minutes down the road. Dad's problems all started when my mother died in 2000. He just went downhill from there. She did everything, he was in the Navy, so when he was away a lot, she ran the house. When she passed away, he had no idea what to do. He had a bank card, but had never used it. He had never done any banking, just didn't know how to do it.

I: So did he spend time overseas during the war?

$\mathrm{J}$ : No, it was through the 50s. There was no wartime stuff, but the first year he was married, he was home for 10 days. There were a lot of 3 month, or 6 month time frames when he was gone. So our Mom had to learn how to do everything, so when Dad came home, he didn't even bother doing things, that's where he got the dependency on her.

When he was living with us, we would find things in his trash can that shouldn't be there, we'd find his socks in his water container. One day, he told us that someone had stolen his glasses, and we told them that he was wearing them and he said, "Yeah, well I stole them back." He had a really hard time with the drugs for the Parkinson's, he would have hallucinations at night time, night terrors. He had all of that stuff, it was to a point where he was just saying, "Why don't you just go ahead and shoot me?" And again, you're up all night, you have to work all day, and then you're up all night again, it's too much after a while.

I: You come up once a week to visit?

J: We used to come up every Sunday, but lately I don't think he even knows that we are here, he barely knows how to eat and drink. Last time we were up here, I asked him, "Do you know who we are?" He said "Yes," but then he started 
playing with the quilt, it was like he felt awkward or something. Yeah, I'm sure we're a familiar face, but that's about it.

I: So you used to be able to come and have conversations?

$\mathrm{J}$ : Yeah, oh yeah, he was perfectly normal. It's in the past year that he has really gone down a lot. It was June when he started having his mini-strokes frequently. This past year we've seen a big change.

I: In terms of the setting here, since he was at another facility, is there anything here that you particularly think works well or doesn't work well.

$\mathrm{J}$ : The central area is pretty noisy, because when he does try to talk, his voice is just a whisper, so you really can't hear him. It doesn't really matter though, because if you are in his room, the TV is usually on and it's the same thing. I'd rather have him out with people, rather than stuck in his room, at least this way, there are people moving around, there is some stimulation. It's not clinical, it's not like you're in a hospital and the nurse is looking after you, it's more like they treat him like they care.

I: Have you heard about any of the new nursing homes that went up recently?

J: I just saw the one in Millville from the outside, but I haven't really heard anything about it. We're happy with him being here, we're not really looking for him to go anywhere else.

\section{Caring for Two Parents}

I met Tina the day that I was visiting with one of the residents in the Bluebird dining area. Tina and her dad Frank were sitting next to me, having a one-sided conversation. A caregiver came to give Frank his medicine in a small dish of pudding. He took one bite and kind of spit it out. Tina is an architecture professor in Ontario, she had been driving to Nova Scotia a few times a month since Frank had originally been admitted into the hospital for pneumonia. Frank is 87 and has lived at Ridgemont for four months. 


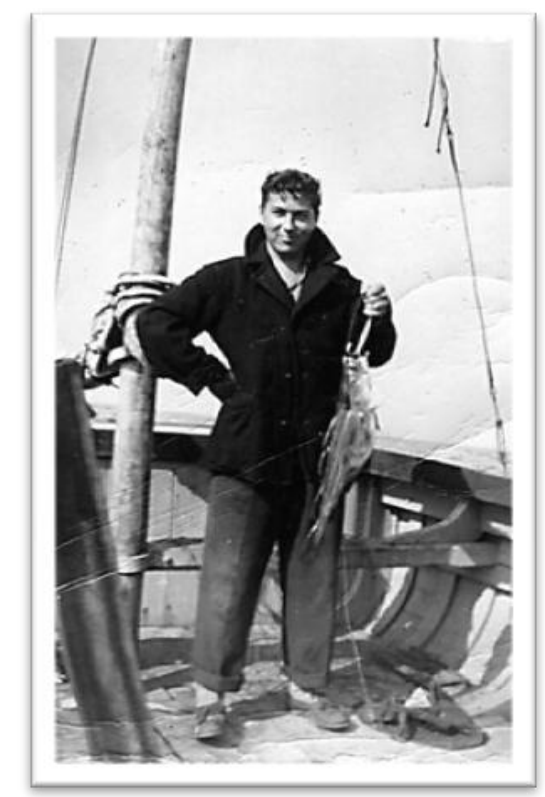

Figure 70. Frank Fishing

T: Well basically, I'm based in Ontario, so I am down every weekend. My brother had been doing the caretaking for a long time, so Dad was living with my mother and my brother. I had tried to convince him to get a home care helper and he did after Mom was in the hospital. Dad was extremely unable to deal with a stranger in the house, and would not recognize them or he would recognize them favorably for a half an hour and then would become extremely troubled and aggressive like, "Why is this person in my house?" It just wasn't working. Then he kind of got a bit like that with us too. We had to call adult family services and they told us that he was about half way through the process of dementia. They had a file from his family doctor that was shared with us, we knew he was taking Aricept, but we didn't know that it was fairly advanced.

I: So you really didn't know where the problems were coming from before that?

T: He was pretty autonomous until he was stopped in July by a policeman because he was too far out in to an intersection or something. The officer decided to escort him home and took away his driver's license; that was a blow. In August, we started unplugging the stove and putting things up. At the house, we have a big property, in the summer he'd say, "I'm going to go out in the backyard." He is a real guy's guy; in his workbench he has every kind of knife, every kind of machine that could hurt you. He had a BB gun that looked like a pistol and he would go out in the front yard and shoot at the crows, it looked exactly like a gun. It's like he had an inexhaustible supply of things that he could hurt himself or other people with. We started locking things up, number one being the car. One day my brother came home and Dad had built a fire in the middle of the living room because he said he was cold. Pretty soon after that he had to go to the hospital with pneumonia, that's when we sort of realized that he was not really 


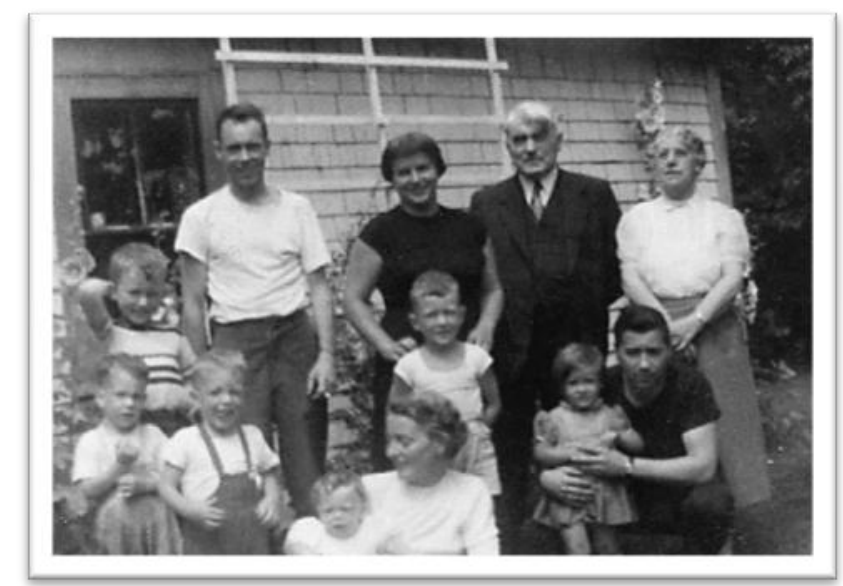

Figure 71. Frank at Front Right and Alison in Black

able to handle the transition. He was already sort of rummaging, not really wandering but rummaging.

I: Did he have to wait in the hospital?

$\mathrm{T}$ : The hospital admission processor told us that we could make him an urgent case. In that case, they would give us the first opening, so that's how we got here. My brother did the forms and he basically asked for a couple of places that are closer to downtown. We said we would take anything, because at the time, my mom was in the hospital and my brother was basically just visiting her at mealtimes to make sure that she was eating properly because she is diabetic. Mom has a bit more of her personality left, but she has always had heart problems and diabetes, so there are more physical things wrong with her.

I: What did your parents do for a living?

T: Dad was an engineer, Mom was a nurse; they were from that generation where that happened a lot, kind of bohemian. Mom ended up not doing nursing, she taught French to elementary school kids.

I: Could you have your parents live together at the same community?

T: We have kind of wondered if they would get any benefit from being together. Even at the place where Mom is now, she's at a transitional place at the VG, the social stuff is more up her alley; Dad does the outdoor stuff. Mom's in a ward with three other people and I would say of the three, she is the most lively, even if she doesn't know exactly what's going on. She may ask a question over and over, but she still really enjoys stimulus. At this point, I think she enjoys being where she is more than being at home with my dad. In the VG, she really enjoys the crafts thing; she really enjoys the Bingo thing.

After our interview, Tina said she was going to the VG (Victoria General sectionof the

QE II hospital in Halifax to visit her mother Alison and invited me to join her. 
This is part of a larger hospital complex near Dalhousie University and is the oldest hospital in Atlantic Canada. I met Tina later that afternoon at the VG and the experience was an eye opener as it illuminated a lot about the need in the system and the waits that the DoH administrator had talked about. Alison is in the transitional unit where many frail elderly who have been in the hospital but who no longer sick enough to be in acute care are held until there is an open long term care bed. The VG appears to be like a purgatory, an in-between place where many of the patients decompensate, both physically and cognitively, because of the lack of stimulation, and an undefined length of stay. There is a single narrow corridor painted light green with about a dozen rooms off of it, with residents four to a room. At the end of the corridor is a small dining/community room with crafts, folded up wheelchairs, leftover plates pushed to the side, and a few sickly plants next to the window. Quite frankly, it was a surprise that Tina was so calm that her mother was still there after two months.

After the visit, I invited Tina to come to Stonebridge the next day to see the cottages. It made sense that she would be interested in the layout as she is an architect. Tina was surprisingly underwhelmed when she visited Stonebridge, asking very few questions about the structure or the organization. Perhaps she had put up a wall to block what she could see and not see with respect to these communities. Perhaps she had to tell herself that her parents were in the right place in order to be able to leave them in their respective communities until her next visit. I think about Tina a lot, how torn she must be to have two parents living apart and needing so much attention. The last time I saw Frank, he was sitting alone in the Bluebird nurses' station, situated so that he was looking at the side of the desk. When I walked back by about an hour later to visit another resident, Cora, he was still there, not asleep, but not awake. 
Stonebridge Family Interviews

They Sent Him to the Wrong Nursing Home

Carmen's father Richard is 80 years old and has been at Stonebridge since it opened.

Carmen had been a frequent visitor, coming at least once a week until a few months ago when she had her own health problems and could not make a visit for three months. This is her first visit with Richard since that time. She spends about an hour with him, the conversation is one sided, as she is trying to explain to him why she has decided to move from her current house.

After their talk, we sit down in the living room in the Willow cottage because no one is watching TV at the time.

I: When did your dad move here?

C: My dad came directly from the hospital. He had an automobile accident, our family had seen signs of dementia, and people would say that they would see him driving down the wrong side of the road. It took a long time to get his license removed, because he would pass the test, so they would not remove the license. When he lived with my brother, he would usually go down to the local gas station and talk to everyone there; they had a stool there that is his. He was raised in the community, he knew everyone and they knew him, so he would go every day. This day he was going for his regular cup of coffee, then three minutes later a guy comes to my brother's door and said, "Bill, you've got to come; your dad's been in an accident." Bill said, "But Dad just left", and he said, "Bill, you have got to come now, your dad's not going to make it, it's bad." He had hit a culvert at about 80 miles an hour. He broke his back, his neck, and he had a large gash above his skull. They got him into an ambulance and he spent five months in the hospital. This was about two years ago. Then he waited another three months for a nursing home, he was supposed to come here, but they sent him to Oakdale which is another 50 minutes away, so they sent him to the wrong nursing home, the hospital did. Finally, they realized that they had sent the wrong person. Where you live determines where you are going to go to your original residence, so finally he got to come here. Even though Dad didn't need to be in a nursing home, they told us that he would need 24/7 nursing care. When he got here, he'd complain, they'd say, "Oh, here comes Cranky," or whatever. But when he's here, they do things with him, there is lot's to do in the community, he just needs to be reminded. 
I: So when he got here he wasn't really ready to be here?

C: Right, he thought the nursing home wasn't for him. He was 76 or 77 , he wasn't old, he didn't think he needed to be here. But now he likes it, he likes it here. It feels just like home, they have a cat that visits everyone. Recently Dad had a setback, he caught a cold and ended up in the hospital, Dad spent a little over a week there. He's had pneumonia. Over the years, he used to be a heavy smoker, over five packs a day because he was a truck driver, cement trucks, long haul, tractor trailers. He always worked hard outdoors. My mom passed away at age 38 and there were five children and we were just kind of shuffled around to relatives. My sisters were two and three, and the others were 14, 15 and 18. The music that they have here on Wednesday night reminds me of our house when I was growing up. Ours was the house where everyone dropped in with their instruments. My uncle brought the stew pot where you'd boil potatoes, but he would turn it upside-down and it was like a drum with his knuckles. Our house was the center for our community; my dad played a lot of instruments: the harmonica, the mandolin, and guitar. He loves to dance. Our house was the main drop in; even the teenagers would drop in. There were always extra people in our home.

\section{She's Well Cared For}

Gill visits his wife Terry every day. Terry is 67 years old and is physically immobilized by a degenerative nerve disease. Gill pushes Terry's wheelchair daily through the downstairs corridors, around the administrative office and then back to the Cypress cottage. Gill does not stop to talk with other residents or staff; he comes in, spends time with Terry, and leaves. He was surprisingly open about discussing his wife and her transition into the need for LTC. We met in the activity director's office and he began the conversation on his own.

G: My wife lived at Ridgemont for $3 \frac{1}{2}$ years, and then she's been here for $1 \frac{1}{2}$ years. I had her home for $3 \frac{1}{2}$ years before that.

I: Were you caring for her alone?

G: Lifting her up and down, yeah.

I: Did she end up in the hospital or did you make the decision to have her move from home?

G: We made the decision together, we put in for it two years before they started this place, from what they were telling us, it takes about two years to get in. It actually only took about six months to get in to Ridgemont. Then they told us that 
we weren't on the list for here, because there wasn't such a thing as a list. Well I said, "How come you've got 50 people in there then?" "Well they were on the list." "Well, you just told me there wasn't a list."

I: Was that Department of Health?

G: Whoever brings people in here.

I: Can you tell me a little about the two places?

G: Up there at Ridgemont, they have more experience, they are older people. Like Joe has been there over 30 years, he's almost up for retirement, and his wife is there. It's different up there too, because they have different people who bring the meals out, there are different people who clean the rooms. Here, they do everything. They work in the kitchen and clean the rooms. Up there they have about 20 people to look after; I'd say about a dozen here, that makes quite a difference too. I just can't figure out the staffing here, though. One day, you have two people there, the next day you have four. There are supposed to be three, it doesn't make sense. I don't know if it's a problem with the person making the shifts or what. For a while on the weekends, there were only two people on.

I: Do you think your wife is taken care of better at either place?

G: Terry was used to the people up there; she's just getting started getting used to the people here. She's so much different, like she sits in a dark room all the time now. She can't get out of the chair by herself; she has to be put on the toilet and everything else. She doesn't even want to go down and listen to the music; it's just noise to her now. I don't know if she's happy or not. She can't talk, she has to spell everything out on a board. She used to be the best speller in the world, now it's just guess work.

I: But you know her well enough that you can have an intuition of what's she's needing, right?

\section{G: Right.}

I: Was the decision to come down here from Ridgemont because it is closer to where you live?

G: Right, it's only two kilometers to here. It was 20 kilometers to out there. And in the winter, it's bad. That's a snow belt out there; it's not a pleasant drive in the winter. Nice in the summertime though. It's nice here, nice and open and bright. When she comes out of her room, she wears sunglasses because the light hurts her eyes. We have to lift her for everything.

I: Do you think the staff are competent to care for her?

G: Yeah, oh yeah, if they have a full complement. Sometimes they have two people in there instead of three. In order to get in to help Terry, it takes two 
people, a two person lift. If someone is busy, they need to wait until one more is free until they can get to her.

I: So you come every day?

G: Yes, I come in at about 10:30 am and stay until around 1:00 pm and put her back in her chair and get her all set up for the afternoon.

I: And she expects you?

G: Oh, yeah, even though she has a rare disease, it's when the spinal cord comes into the brain, it comes into a pocket and there are lymph nodes all around those pockets. The disease eats away at that. First thing to go is balance. In 2000, I had to hold on to her hand or she would look like she was drunk. Then in 2003, they finally diagnosed it. They said, "We've got good news and bad news. The good news is that we know what it is. The bad news is there isn't a darn thing that we can do." Then we wrote away to the rare disorder place down in the States.

When I first put her in here, I didn't think she would last until Christmas. She has the will to live though, her mind will never let go. Everything else will go. She sits there all day in a dark room and thinks, that's all she can do. Before she came in, she said, "Why can't I just die?" When she gets depressed, that's the way she is. Just to sit there and do nothing all day, it would drive me nuts.

I: She's lucky she has you.

G: Oh, yeah. If I'm late, she lets me know it too. The other day I came in and she starts giving me hell and I didn't know what it was for, something that happened about 30 years ago. She just sits there all day and thinks of stuff, she has nothing else to do.

\section{There's a Limit to What you Can Do}

Vincent is 89 years old and moved to the Willow cottage at the end of December through adult protection. His son, Grant, and wife, Elizabeth, have been spending their afternoons and weekends with him, as he begins to adjust to life at Stonebridge. Elizabeth still lives in their home in a small town which is about an hour drive from Millville. She is drinking a cup a coffee from the local fast food restaurant as her son does most of the talking in our discussion at the kitchen table.

I: Are you here a lot over the weekends? 
E: No, we're here a lot during the week. I travel here from Sheet Harbor; it's about 120 kilometers from here. I stay in for about two or three days and then I go home. I stay home for a week or so and then I come back in.

G: And I live right around the corner; you're lucky that you caught me. I'm usually here for about an hour and a half; it just depends on how Dad is doing. But usually in the evenings after supper, I come and visit him. I normally work in Alberta, in a few weeks I will be gone again until next December.

I: What do you usually do when you come by?

E: We sit and talk and if he's sleeping or cat napping, we just let him sleep.

G: Sometimes when we want to eat together, we'll bring something in or have coffee or something. Other times we'll just walk around and chit chat, he and I have great conversations, but there's limited to what you can do. This is a wonderful facility; this is new to the province, right? These buildings are only about $21 / 2$ years old. This is an all new type set up for this province. The older style long-term care places in this province don't hold a candle to this, not even close. Here, there are only about a dozen people, where in the older style, everyone went to one big cafeteria setting where you had 100 or 150 people in the same setting. There were people with dementia and then people with other illnesses or people who are just old and can't take care of themselves and there's no concentration on one type of illness. Whereas here, everyone in this one place is suffering from the same thing, they have Alzheimer's or dementia. The concentration is on dealing with people with that condition and that's it, it's perfect. We've been offered to have Dad transferred, because when you deal with adult protective services, they do a six month re-evaluation. When they revaluate in six months, if they think that now is the time where they can just step away and leave it up to us, then they will step away and we have the opportunity to put in for a transfer to get him closer to his actual home, but we've declined. We feel much better having him here rather than a facility where everyone is mingled and there's no concentration on the illness that he has. All the people here are so wonderful, they understand what they are dealing with and they treat everyone here with compassion and care, they care for the people here. You can't ask for more.

I: When the decision was made that he needed more care than at home, did you have a series of places that you chose and then he ended up here?

G: No, Dad was actually placed on a waiting list in September; I was away when he was actually placed on a list and there was nothing available at the time. They say the person will be placed within 100 kilometers of their choice; he could have been just about anywhere. Since July, he has been up and down and home and in the hospital a lot. He got out of their house in Sheet Harbor December $12^{\text {th }}$ in the middle of the night. Somebody found him at 5:30 in the morning at the side of the road; he had frost bite on his feet. They took him to the hospital and adult protection stepped in, and two days later he was here. For the betterment of 
everybody, he is here. We had already decided that it was getting close to time, because in six months he had gone from completely self-sufficient to this.

E: He had a stroke and many TRAs. He has bowel cancer.

G: He found out about the cancer and dementia on the very same day, so it was two blows in one day.

E: From September when I brought him home from the hospital down home, from September to December, it was $24 / 7$ care. I was just so exhausted.

G: Outside of a facility like this, the system of the health in this province is really not geared towards people like Dad with an illness like his. The hospitals aren't set up to deal with it. At times, they are just not willing to deal with it, like their hometown hospital wanted nothing at all to do with him. There was a time when he was in the hospital when I was away, he was in an area with five rooms, he was the only one in there. There were three nurses and nurses' assistants working on that ward, and Mom and one of my sisters had to sit with him 24 hours a day, because the nurses said it wasn't their job. I like the set up here, I like the concentration of people with the same illness being in one cottage, all the employees are treating people with the same issues. It lessens the confusion a lot; they know that they are dealing with on a regular basis.

I: So is this a comfortable setting to come visit?

G: Yeah, the staff are extremely caring, they do what they can with what they have. They would probably do more if they could. I have seen them stay here late past their shift, to make sure everyone is taken care of. I don't think they are staying because of the money, you can tell when someone is staying for the money. These people care, they care for the residents. It shows, it shows in their approach to their jobs. They could change how the scheduling overlaps though. Unfortunately, today, in this sort of work environment, there's a lot of paper work, and there are times that there are only one or two staff on. One person is over there, and one person is catching up on paperwork and someone else has an emergency, then you have a gap there.

I: But your dad is well cared for?

G: Absolutely. He has his private bedroom and bathroom. There is a cost associated with this, also. I suppose compared to the overall cost of having this type of facility, as a family, the cost is relative. I don't know what the overall cost of running this facility is, the cost per patient, or how much is being billed to Capital Health. Because this is private enterprise, this isn't run by Capital Health. But as far as we know right now, based on Mom's income, his share is about $\$ 1100$ per month. He gets the care that he needs; the cost is minimal compared to what you'd face trying to do this on your own at home. 
I bumped into Elizabeth, her daughter, and grandchildren by the community center the last week that I was at Stonebridge. Elizabeth looked rested, and her daughter told me that this was the first time that her children were able to come visit their grandfather there. There is relief on all of their faces; it appears that the shock of Vincent's move may have worn off, and now there is an acceptance that this is where he lives. Before they leave, Elizabeth's daughter expresses how glad she is that she lives near her mother. "I am close to her and she needs me. I'm so glad that my family and I can be there for her, she's in that house all alone now, you know, I still have this one to look after."

\section{This Location Works}

Andrew and five of his siblings visit his mother, Carol, frequently at Stonebridge. Carol has 10 children and is widowed. At 83 years old, she has some cognitive issues related to early stage dementia, but she is generally in good health and spirits. She joins us at the kitchen table with her cup of tea as Andrew and I discuss her move.

I: How often do you come in to visit your mom?

G: Twice a week.

I: How long has she been here?

G: 15 or 16 months.

I: Did she move from home or from another community?

G: We sold her home and her and Dad moved into a senior apartment living. After Dad passed away, she lived for about five years in the apartment. It was a nice spot. What we have done in our family, we are a big a family, there are 10 of us. There are six of us who take turns coming in, there's a schedule in her room. We want to make sure... they are good here, but she needs a little bit more. We come in and then we have a girl that we hire on top of that. She comes five days a week, 20 hours a week. We take turns, every other weekend we do a day. But you have to do it.

I: So when the decision was made to move from independent living, was this the top choice? Did you know about the model? 
G: We wanted to stay in the area; we went around and looked at a few that were similar. We wanted her to stay in this community because the house that we owned is very close. Also, it's a newer facility and it's what we wanted. A few years ago, they were not like this, they were not very nice. What this is is assisted living; it's not really a nursing home. This is for a person that can come to the table and do their own thing. Downstairs, that's more of a nursing home, they help them with everything. But I think that if the family helps a little bit, it makes it better, much better. You also get to know the staff, you get to know them on a first name basis. If you get to know them on a first name basis because you are here all the time, it makes a difference. My sister comes and takes four or five residents out for a drive, not everyone can do that, there are some here who don't have anyone. I do think that this is a good model, I really do. I don't know how you would improve it too much more.

I: So do you think your mom feels at home here?

G: Yes, she's comfortable, she likes it. The biggest problems are later in the evening with sundowners. But other than that, she likes it here, this location works. What she likes about it is she's got her independence. Even though they are here to help, she's got her own little place, her own room, she can stay there if she wants to, or she can go talk to others. I think that's really important at their age, that's one thing that we noticed. My sister and our other siblings wanted to make sure of that.

In theory, families represent the bridge between the time and place that have been left behind and the present day (Chaudhury, 2002). The family interviews in this study were windows into the experiences for residents which have brought them to LTC and were helpful in distinguishing the personal emotions for family members who relinquish their role as care giver due to trauma, long standing illness or the direction of adult services. Further discussion into the role of family members will take place in the following chapter. The concluding section of this chapter provides stories from residents themselves. 


\section{Resident Voices-Daily Life in Long Term Care}

The self is determined by multiple developmental influences that combine to compose a sense of identity. One builds from experience, from one's actual choices and motivations, a sense of self that includes or is amenable to expression in terms of higher level principles. (Agich, 2003, p. 115)

Agich (2003) writes that the significant point about stories is that what people tell about their lives comprise one of the most important modes of access to what is important to them. Stories drawn from life can indicate the things that people value the most; they tell us who the person is and with what they most identify. Within a temporal framework, a long term perspective on the housing situation acknowledges the importance of the accumulation of experiences up to a certain moment to explain the situation at the time, and people's biographical pasts affect their present circumstances, and present circumstances shape future life direction (Dykstra and Van Wissen, 1999).

Interviews were conducted with seven residents in each of the two communities. Six of these interviews from each community were chosen to share with the reader (Table 7). These stories tell us that no matter how big, small, homey, institutional, noisy an environment is for LTC residents, what truly matters to most is not where they are, but where they aren't ...both physically and metaphysically. Emotions form an important part of our lives and our memories, and for residents there was very little discussion of their current living situations. What they did want to talk about was life as it had been for them prior to their move; the good and the bad....falling in love, moving to a new city or country, transition, fear, living at war time, losing a dear spouse, or getting away from an abusive one. These stories tell of the duality of strength and vulnerability in each individual interviewed, but also speak to the similar qualities of the 


\begin{tabular}{|c|c|c|c|}
\hline Resident & $\begin{array}{l}\text { Resident } \\
\text { Age }\end{array}$ & $\begin{array}{c}\text { LTC } \\
\text { Community }\end{array}$ & $\begin{array}{l}\text { Resident Theme and } \\
\text { Transition to Care }\end{array}$ \\
\hline Jean & 75 & Ridgemont & $\begin{array}{l}\text { You can't go anywhere, really. } \\
\text { O Moved from apartment, unable to care for self due } \\
\text { to early stage dementia }\end{array}$ \\
\hline Perry & 83 & Ridgemont & $\begin{array}{l}\text { I have to talk to the head honcho. } \\
\quad \text { Moved from apartment through adult protection } \\
\text { unable to care for self }\end{array}$ \\
\hline Marion & 89 & Ridgemont & $\begin{array}{l}\text { It's not home, but so far, so good. } \\
\quad \text { Moved from hospital after illness, wheelchair } \\
\text { bound }\end{array}$ \\
\hline Margaret & 85 & Ridgemont & $\begin{array}{l}\text { If you don't use it, you lose it. } \\
\circ \quad \text { Moved from home after husband died, heart } \\
\text { condition and eyesight failing }\end{array}$ \\
\hline Pala & 81 & Ridgemont & $\begin{array}{l}\text { Oh, I think it's lovely. } \\
\quad \text { Moved from transitional unit after hospital stay } \\
\quad \text { from fall, wheel-chair bound }\end{array}$ \\
\hline Claire & 84 & Ridgemont & $\begin{array}{l}\text { You've got no other home, so this is your home. } \\
\quad \text { Moved from home after cancer diagnosis, wheel- } \\
\text { chair bound }\end{array}$ \\
\hline Art & 84 & Stonebridge & $\begin{array}{l}\text { I know it's nice, but it's not my cup of tea. } \\
\text { O Removed from home by adult protection, wheel- } \\
\text { chair bound }\end{array}$ \\
\hline Edna & 89 & Stonebridge & $\begin{array}{l}\text { This is where I'm from. } \\
\therefore \quad \text { Moved to Stonebridge from Ridgemont by choice, } \\
\text { close to home, frailty and eyesight failing }\end{array}$ \\
\hline Elsie & 81 & Stonebridge & $\begin{array}{l}\text { It's different having people you can count on. } \\
\quad \text { Moved from home through adult protection due to } \\
\text { abusive husband }\end{array}$ \\
\hline Penny & 73 & Stonebridge & $\begin{array}{l}\text { I don't think he's found me yet. } \\
\circ \quad \text { Moved to Stonebridge from another nursing home, } \\
\text { progressive disease }\end{array}$ \\
\hline Robert & 84 & Stonebridge & $\begin{array}{l}\text { It's a long way from being home. } \\
\quad \bigcirc \quad \text { Moved from hospital after stroke }\end{array}$ \\
\hline Edward & 78 & Stonebridge & $\begin{array}{l}\text { They cleaned out my apartment. } \\
\circ \quad \text { Moved from hospital after surgery }\end{array}$ \\
\hline
\end{tabular}

Table 7.

Resident Interview Information

residents in the two communities because one experience may be illustrative of others in structure, feeling or tone (Rubenstein, 2002). In addition to the individual interviews, the remaining sections of this chapter will incorporate threads and descriptions of everyday life at Ridgemont and Stonebridge in order to portray life from the perspective of the residents in LTC. Discussions of the themes of these interviews will occur in Chapter 9. 


\section{Daily Life at Ridgemont-Resident Interviews}

Caregivers begin to wake residents up at 7 am at Ridgemont. This month, Maureen is in the Bluebird neighborhood, as staff members rotate within the community on a monthly basis. Breakfast is at $8 \mathrm{am}$, and then individuals are free to go back to their rooms to get dressed and prepare for their day. Garney has Rose up and into the parlor by 9:30 for the set-up for the morning activity, which is exercise class. Other morning activities might include news hour, or a once a month visit from a local musician who comes up to play favorite hymns or oldies but goodies on the piano.

Lunchtime at Ridgemont starts at 11:15, at least that's when the set up begins in the three dining areas. Residents may sit in their designated dining areas, waiting for up to an hour, as the dietary staff make their way from neighborhood to neighborhood. With each meal, the food cart is brought up on the elevator from the downstairs kitchen and serving begins in a particular neighborhood, with lunch time normally starting in the Bluebird neighborhood. Dietary staff have a small kitchenette where they keep silverware, napkins, and cups, and there is a refrigerator for milk and juice. Pans of food on the carts are kept warm in a hot box and served by the dietary staff onto plates which are then passed to residents in the dining area.

Cora can hear the cart coming down the corridor and lets the others at her table know. "The lunch truck, it's coming, the lunch truck." The lunch of vegetable soup, crackers and cheese, and apple cake are served to residents in about 15-20 minutes. The servers joke with each other and with residents as they pass out the plates. The dietician serving from the meal cart has been doing this job for over 25 years. She has a hand and say into how and what each resident is served, and comments frequently to the less experienced serving staff, "Now careful with that, you know May can't have those crackers." "Have you made sure that Ron has his nonfat milk?" 
When the last plate is served, the dietary staff move the cart down the corridor to the next neighborhood. Two or three of the CCAs stay to coax residents to finish eating their lunch and offer dessert and tea or coffee. As residents finish, the remaining staff stay to clean the tables and sweep. The dining areas in the Cardinal and Hummingbird neighborhoods clear out after each meal. Residents in the Bluebird neighborhood have their own TV in their dining room, so about half will not leave after the meal, often dozing or watching the country music channel. For the remainder of the afternoon, they are left alone, with staff members checking in occasionally to pass out medications and or to offer assistance with toileting needs.

For the rest of the community residents, afternoon activities in the main parlor begin at 2:00 pm. Thursday is Bingo day, which has the highest attendance of the weekly activities; other afternoon activities may be themed, such as summer in winter day, Elvis day, or a history lesson on a local poet or dignitary. Stella rolls in for Bingo; she is a 93 years old and has lived at Ridgemont for over five years. She speaks in a small voice and normally carries a stuffed animal with her; today it is a well-worn stuffed dog. She is wearing a turquoise blue velour sweat suit and pink jogging shoes.

When the prize cart is pushed by her table, Stella eyes a pink and purple stuffed bunny, the kind given to a child at Easter. The colors are bright and the fur is soft. "If I win, that's the one I want," she reports. As the game progresses, Stella forgets to cover several of the numbers which have been called, but with the help of staff, wins the game. "BINGO!" Stella is dozing in her chair. "You won!" "Really?" "Yes, you get to pick a prize.” Stella is floored, "I won? And this is the prize I wanted, see?" Stella picks up the pink and purple bunny, strokes it with a tear in her eye. She moves into the nurses' area and is lost in the world of her new prize. 


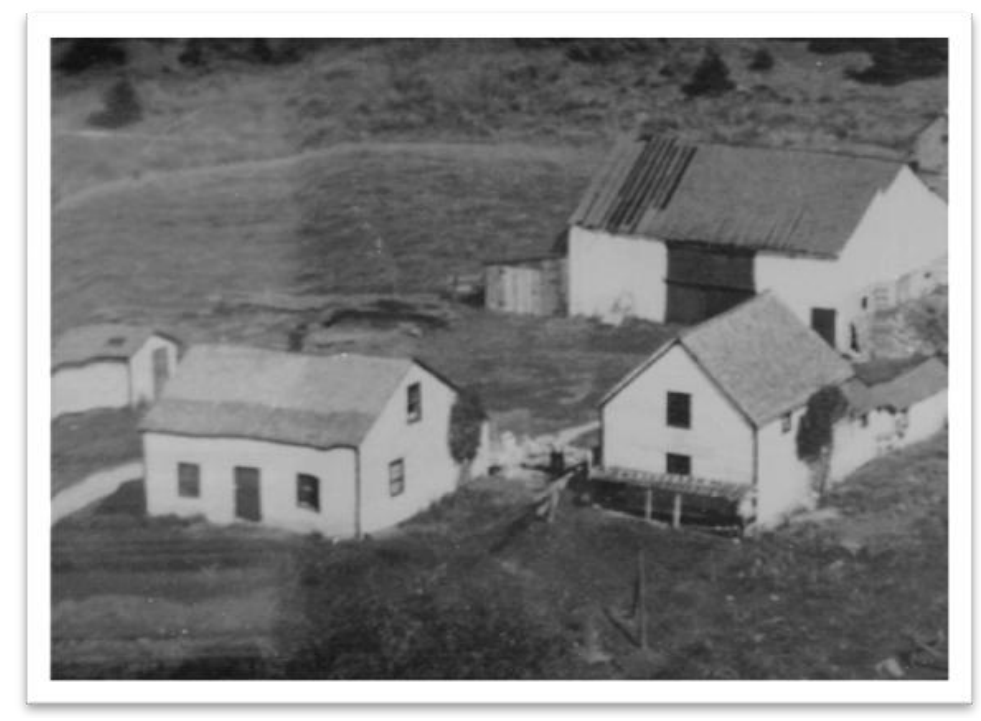

Figure 72.

Jean's Family Farm

\section{You can't go Anywhere Really}

Overnight, ice encased every twig, cone, bud, branch, and trunk for tens of miles in every direction. God alone knows how many million spruce and fir needles wore their own glistening sheaths this morning. Glassy cylinders hugged every wire, fence-post, and clothesline pole. Doorsteps, woodpiles, rocks, pebbles, cars, trucks, tractors, roadside garbage drums, and letter boxes-they all shone under this new, hard, gleaming and transparent skin. Before breakfast, the light of the low sun struck the white hills and turned the whole infinitely intricate maze of ice into an impossible razzle-dazzle of sparkle and flash and golden magic, and beyond it all lay the royal blue of the implacable bat. ( Bruce, 1988, p. 4)

The next time I am at Ridgemont, it is Saturday morning. The activity director, Sara, is off on the weekends, so Saturday mornings are generally quiet. This morning is busy though; the front doorbell is ringing hourly. George's family members are in and out of the building as the doctors have told his family that he has just a few days to live. Maureen says she thought he would be gone last night. The family members that stayed the night are just leaving as another round of bundled-up cousins and small children show up at the front door.

The music in the nurses' station is playing Patsy Cline's You Belong to Me; "Just 


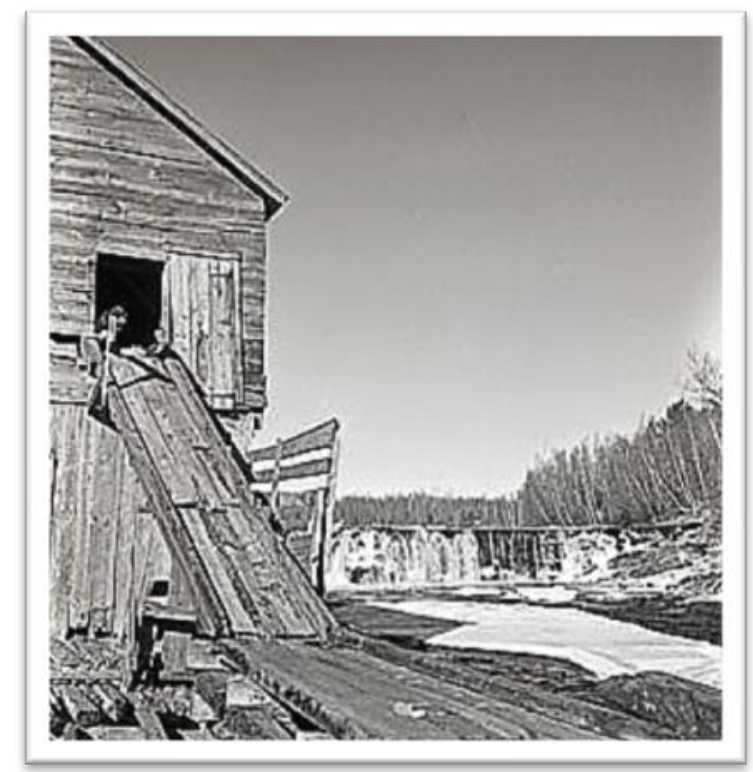

Figure 73. Lumber Mill,-Nova Scotia c. 1945

remember 'til you're home again, you belong to me." Jean is standing by the window in the parlor, watching the visitors making their way to the front door as the morning snow is falling.

At 75, Jean is one of the youngest and most independent residents living at Ridgemont. She was divorced many years ago and her daughter lives in another province. She lives in the Cardinal neighborhood and is cheerful but reserved as we sit down and begin to talk about her home.

J: Well, the thing is, I don't know how to explain it. The home I was born and grew up in is over in Kings County. My parents are both gone, my brother and his wife live in a home where we all grew up. We lived on a farm, he has that to look after, and he's also a carpenter, so he's a busy man. Anyway, I don't see them all that often. I used to have my own car and everything, but I don't know how it came about, but I gave up my car. I wish I had it, you can't go anywhere really. Either someone has to come and pick me up or somebody from here is going somewhere. I don't know, I just feel that I'm here all the time pretty much.

I: So you grew up on that farm in Kings County?

J: That was my father and my uncle's farm. They had a lumber mill, so we would have people in our house for a week at a time staying with us, workers. They actually slept in the barn loft. We had a big garden, so we would put up the vegetables and preserves and we always had enough to eat, even with all those extra people. The farm had wheat and some alfalfa. There was always work to do. 
I: What did you do for a living before you came here?

J: Oh, gosh, I was a typist. I worked for the provincial government behind the Citadel in those white buildings, you know? I worked in there. Supplies and transport was one of the units I was with. Typing and all the charts and whatever. At that time, we used those big typewriters, big enough to do carbon copies.

I: Do you have children?

J: I had a daughter, that's all; she's married and has two children herself. A boy and a girl. They come down maybe once a year. It might not be that either.

I: Have you been able to make friends since you've lived here?

J: Well, there are some who I am friendlier with, I guess, just because I don't know anyone else. You get someone who is friendly and you keep chatting back and forth, that's kind of how things go.

I: So, what are the things that you like best about being here?

J: Well, I'm satisfied with the food I get, I don't mind it. I have my own room. I have the washroom off of my bedroom; the only thing I regret is that I don't have a shower. But there is a shower down the hall, that's where the shower is. But someone is usually in there first thing in the morning, so I usually do my own clean up in my own bathroom, I have a sink and a toilet and my own closet there. I try to keep my bedroom neat and tidy, but I don't wash floors or anything like that. I get up and turn my quilt back when I go to breakfast, then when I go back in and make my bed. Well, I'm satisfied with it; there are more people that I am more familiar with to talk to, that kind of thing, some that I don't hardly know. There are a lot of people that I don't have a clue of what their names are. But you see them so often that you feel like you should.

\section{I'll Have to Talk to the Head Honcho}

After my conversation with Jean, I leave for the weekend. When I return on Monday morning, I am told that George has died. The visitors have all left, and walking down the now quiet corridor, I can see through George's doorway that the bed has been stripped and his photos are no longer on the wall. A few days later, I meet the new resident, Perry, who has moved into George's old room. Perry and his tablemate, Claire, are still in the Hummingbird dining area 


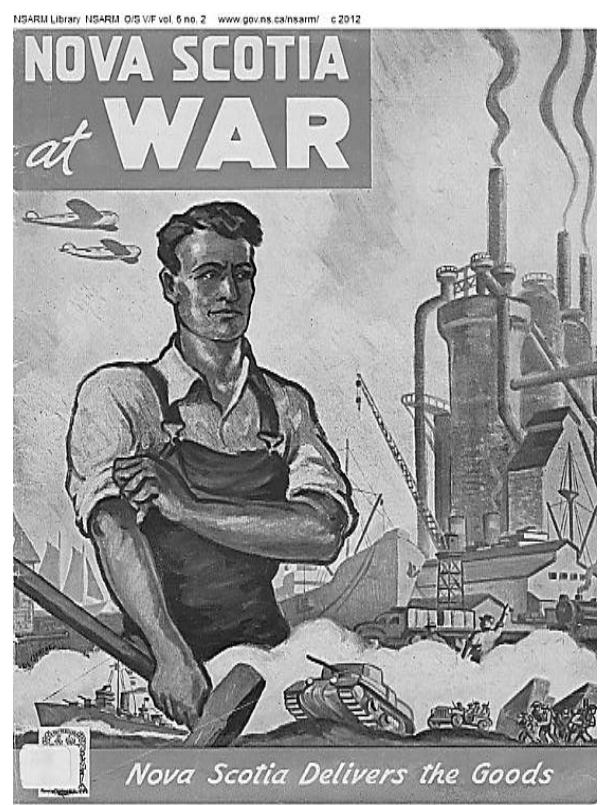

Figure 74. Nova Scotia at War

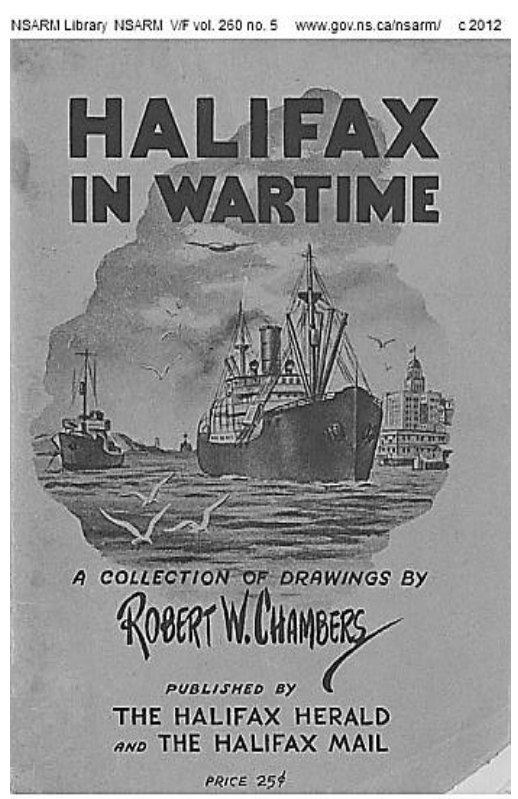

Figure 75. Halifax in Wartime

after lunch and they invite me to join them as they continue their conversation. Perry is discussing life in Dartmouth; this is where he had lived prior to moving to Ridgemont.

I: How long have you been living here?

P: Oh 'bout a week, my daughter had me brought here. I had a very nice apartment in Dartmouth, I've lived in Dartmouth all of my life.

I: How are things going?

P: Oh, alright, I guess. The guy I'm living with is some trouble though.

\section{I: Your roommate?}

P: Yes, he talks a lot, he's upset. He keeps the TV on really loud. I'll have to talk to the head honcho in charge, it's hard for me to sleep when he's like that.

I: So you would like another roommate?

P: Well, I want to have my own room.

I: Anna said you have a lot of memories from WWII.

P: Those were hard times, we didn't have food, everything was rationed. When the convoys were leaving the harbor, they would throw all of the old food overboard. Guys from Dartmouth would be there in rowboats, and would scoop up the food like meat and potatoes and peanut butter that the ships had thrown 


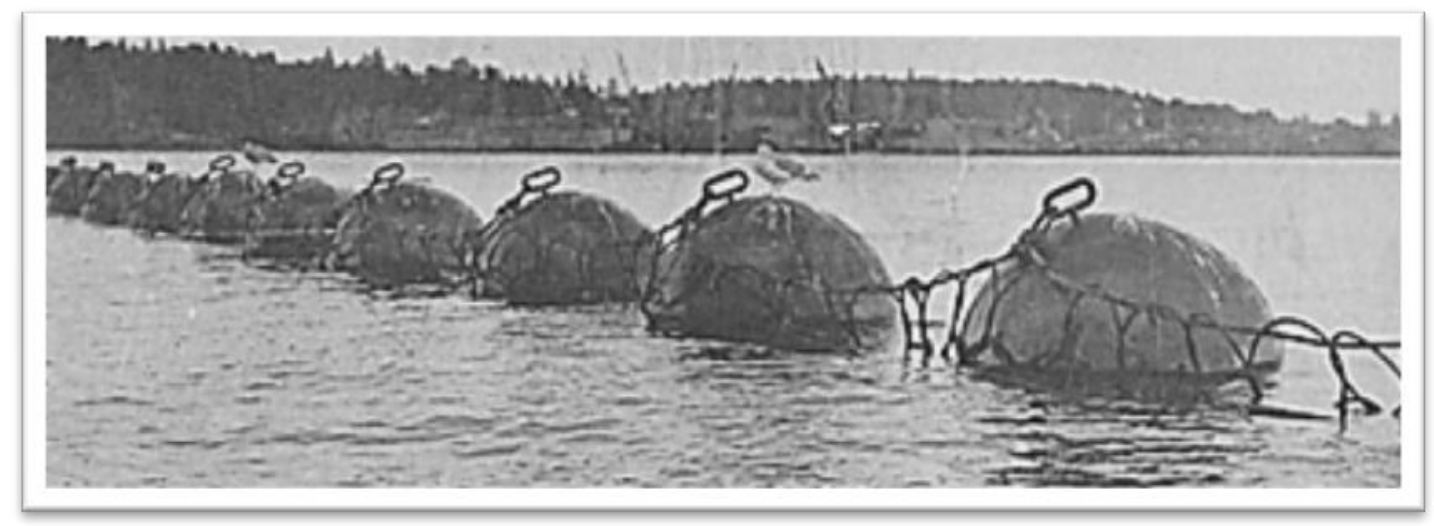

Figure 76.

Steel Gate Across the Entrance to Halifax Harbor

into the harbor. Those guys in the north end of Dartmouth were eating like kings for a while.

I: Really, they ate the food that had been in the harbor?

P: When you're starving, you'll eat just about anything.

I: So who was looking out for the submarines?

P: Oh, they knew that they were out there. I was at St. Joseph's church up on Russell Street and a naval officer came up in full uniform, he said, "Any one for the Mic Mac, report, right now." Then he looked over at the priest and said, "Sorry fella, we're at war." A lot of them were off duty, but they had to report to the ship as they were. They knew enemy subs were out there. It was an anti-sub ship.

I: Did they ever fire from here?

P: Oh, yes. At that time, the only defenses they had against the submarines were the depth charges. They'd just roll right off the back of the ship; the ship would make a circle. Course they'd go down so far, they had to go down a certain depth before they'd explode. Unless they surfaced, they'd put the surface guns on them. At that time they had 4.5 and six inch guns. The six inch had a shell about that long.

I: Was there a sense of fear in Halifax that the submarines would get in to the harbor?

P: They were mostly over here for the convoys that left from here to deliver arms and supply to the troops that were overseas. The Bedford basin was one of the main places to gather the convoys. There was a steel gate that ran across the entrance to the port, the subs couldn't get through, at least most of them didn't, but we knew they were out there. 


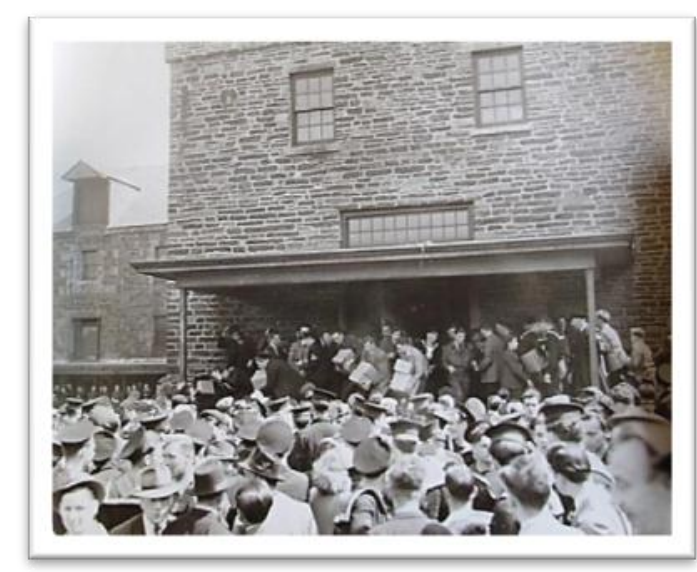

Figure 77. VE Day Riots

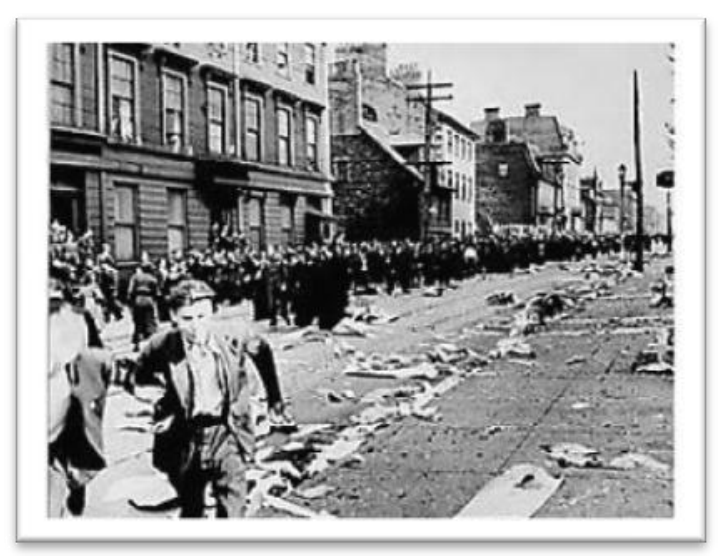

Figure 78. VE Day Looters

P: Did anyone from your family go overseas in WW11?

I: My father did, of course. He spent most of his time over off of the Scotland and England shores. That was deadly over there.

P: How long was he gone?

I: Well, he was late getting in; it was the second year of the war when he got in. But he did about three years, three years into it. But when you went away, you didn't know when you were coming back. There was no connection whatsoever, no phone, not like today. Wouldn't be the first time that my mother would just be sitting there thinking; we didn't know, we didn't know where he was. We didn't even know if he was alive.

\section{P: Did you get word that he was coming home?}

I: That's like that song that Maureen was talking about the other day, The Soldier's Last Letter. He was writing a letter to his mother, he was in a trench. But when she got the letter, it wasn't signed, he'd been killed and somehow his letter got to her, and that happened a lot. Maybe that song was just made up about all this, but that's the way the letters came. Or sometimes, you'd see someone coming down the sidewalk in full military uniform, headed for someone's house, then that's how you knew someone had died, they would send attaches to deliver the message. My dad did come back though, he came back and then he had lung cancer and had died in about nine months after the war.

I: So on VE day, where were you?

P: I was just getting out of the hospital in Halifax, I'd had my appendix out, I was sick, I hurt. I went down to get on the ferry boat and the damned thing was stopped, it wouldn't take anyone from one side to the other. I had to wait till late to get across. I must have been about 17 or 18 . They were throwing rocks from one side of the street to the other. It was a lot of the navy from other places, the ones from here were overseas. They were complaining because there was no way 
to celebrate. So that's what happened. I saw ladies in fur coats and jewelry with boxes of stuff walking down the street. They pushed out windows at the mattress factories and threw mattress and other stuff out on to the street.

Claire interjects that she remembers VE day, she was living in downtown Halifax in a convent with the nuns:

C: They wouldn't let us out; we were prisoners during that riot. Did your parents know where you were?

P: Sure they did, but they had no car to come get me or anything. There were very few cars.

C: Yeah, we had the street cars though, you remember?

P: Oh yeah, they went clanging down the street, God, they were noisy. Those were good times.

C: Well, I had to live with the nuns, so they weren't so great for me. If we were coming in late, they would paddle us as we came through the door. We were working girls, so we were in Halifax without our parents, the nuns looked after us.

\section{It's Not Like Home, but So Far So Good}

When I left the table, Claire and Perry were still deep in discussion, but I had made an appointment to meet with Marian, who lives in the same neighborhood. Marian is 89 years old; she rarely leaves her room, other than for the Wednesday afternoon church service that is held in the parlor. Marian has two leg prosthesis due to double amputation which had resulted from diabetes and feels more comfortable reading in her room than spending her days in the parlor.

I: When did you move here?

M: It must be about two years now, it's been a while. I was here at the rehab getting prosthesis, these, (she points to her legs) and they work so good, hah. I actually think they did a very poor job. Maybe they can't do it because of the knee, I don't know. But this one is from the knee down. I don't know, it seems to me that they could have done a better job because I don't know why they took the knee off. Then it's not good, I can't figure it out. It's comfortable, but the point is you can't walk. I might be able to, but if you only have one to go on and then this 


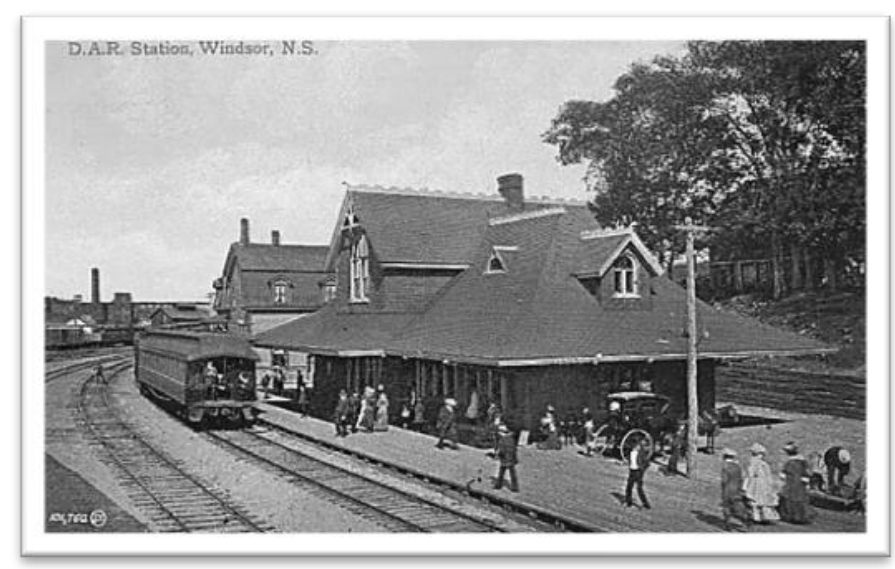

Figure 79. Windsor Train Station, Nova Scotia

one, it's not very good, that's why I'm in the chair here, I'd rather not take a chance. I was born in Meteghan, my parents moved to Windsor, where I got my education, and then I left home when I was 19 and went to Montreal. I worked in the fashion industry there about eight years and then left because the owner of the company had treated me inappropriately, well, to tell you the truth, he was going to rape me. I left and never went back. I went to work for the railway. I stayed there until I retired and when I retired, my parents were still living, so I moved back here. I miss Montreal, because I spent most of my life there.

\section{I: How many brothers and sisters did you have?}

M: Actually there were seven of us, but one died as a baby, and one of the boys was a lot older. So growing up, we had one brother at home; poor soul, he was left with four sisters. I used to be like a tomboy with him. He had bought a truck; in those years, in our time, it was difficult and wages were practically nothing. A lot of the kids today don't know that we had to go through in those days. He was going to work for a lumber company in Yarmouth. He had bought a second hand truck and he took it home, I couldn't have been more than 10 or 11 . He took all the pieces apart of the engine to redo it and try to make it work. I was his helper, when it came time to test the motor, and I can still remember that, although I'm tall today, I had to sit at the edge of the seat and my toes would just barely hit the pedal. Not only that, he had undone the entire engine to get it to work, because he didn't have the money in those days. He would ask me for pieces of the engine to put back, but I didn't know what they were; it was fun though, it was fun to learn, I liked it. Now when I think about it after, he had it all put back together, I just hit the pedal so he could check the engine and everything went fine. Good thing he was a good mechanic, it saved a lot of money. He worked for some milling company just off of Yarmouth. I think they used to load their lumber to the boats in Yarmouth, I don't think it was cut yet. But I had already left and gone to Montreal after being his mechanic.

I: So were you married? 


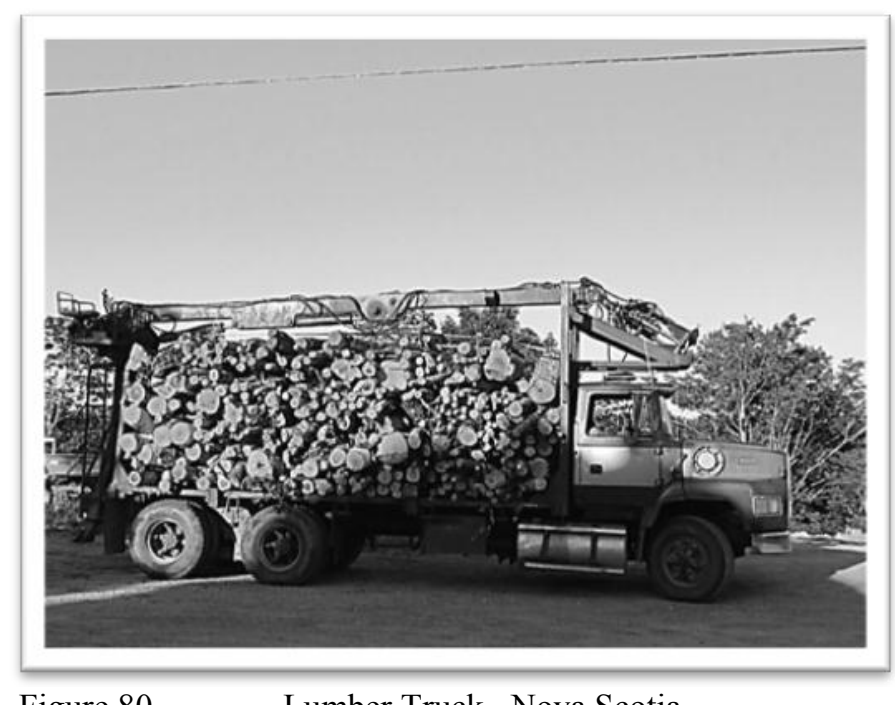

Figure $80 . \quad$ Lumber Truck -Nova Scotia

M: Oh, yeah, but that was when I was in Quebec, I came back when he was gone. We had no children, nothing. The new people who took over, the old Canadian National Railroad, had a lot of hotels and a lot of this and a lot of that, all the way across Canada. The new owners got rid of everything except the railways. That cleared up all of the debt, and now apparently the debts are paid and the girls are getting \$1-2,000 per month, and I imagine they have a pension. We had to retire at 65 , and now I'm 89 , that's a long time ago.

\section{I: How's life for you here?}

M: Yes, like everything else, it's not like home. The owners and most of the people are very nice. I don't know how it's going to turn out, but so far so good. Both of my parents are gone and everyone is married and those who have families all have enough problems as it is. But if worse comes to worse, my niece said that she would take me home.

I: How do you like having a roommate?

M: I haven't minded it so far, we get along pretty good. She sleeps quite a bit, me too, I don't stay up that late. No, we get along very good so far. That's the dining room, that's where we eat, and then down at the end, that's like a solarium, there's a whole lot of windows and there's a TV and jigsaw puzzles and stuff to pass the time. It is a nice place; the people are all nice so far, anyway. They have different things that we can go and look and that. Yeah. It's pretty good considering, you know? It's not like being home, that's for sure. 


\section{If You Don't Use it, You'll Lose It}

Later in the afternoon, a small group of residents pile into the Ridgemont bus and have lunch at the closest Chinese restaurant in Millville. It's the Chinese New Year. I sit between Cora and her neighbor, Margaret, at lunch. The conversation revolves around kids and grandkids, life in Nova Scotia (Margaret is originally from England), and Margaret laments about leaving her house in the hands of her oldest grandchild ("She doesn't quite keep it like I did, but I'm not going to say anything, of course").

Margaret is 85 years old and lives in the Cardinal neighborhood at Ridgemont. Margaret's son, Bill, is married to Claire's daughter, Terry. When Bill and Terry come in on Fridays for their visit, Terry gives Margaret and Claire their weekly baths. The two mother-inlaws do not appear to have much in common, other than their children and their strong personalities. Claire is a devout Roman Catholic and Margaret is Anglican, and they live and eat at opposite ends of the community. Margaret is lively at our Chinese lunch and happy to talk some more when we get back to Ridgemont later that afternoon.

M: My husband passed away. I have three boys, I really must say that I have three very good boys, because they really do take good care of me, and I know that there's a lot of people who won't even talk to their mother. I was put here mostly by the doctors and the hospital. They said that I could not stay alone.

I: So when your husband died, you were told you couldn't live alone?

M: No, at that time I was fine. But I got sick; I do have a severe heart problem, the main artery. I have had a triple by-pass. The main artery now is clogging up, and they cannot operate because I also have a kidney blockage, they said they can do wonders with the heart today, but in my case, the kidney is the problem. If they operate, they are frightened that it will damage the kidney that much more, and they said I would probably end up on dialysis. So, it's a choice I have to make. I do see my cardiologist next month, as a matter a fact. I've felt pretty good lately, 'cause there was a time that I couldn't even walk across the room without getting out of breath. I walk up and down the halls now because I know if you don't use it, you lose it. 
I: So what was involved in the process of getting into this community?

M: It was Department of Health. They just come out and interview you, and then you're on the waiting list. I thought I'd be waiting a year or two, but I didn't, it was about seven months. This was the one that was available at the time. The staff is very good here.

I: So you see no reason to change?

M: No, my daughter-in-law lives just down the road, and she comes every Friday and she gives me a bath, because I was so used to showering every day. Here, you get a shower once a week, so then I get a bath on Friday too. It's different, it's not like home, but you know, you have to adjust. You see some of the people around you, and you thinking, ah, I'm lucky to be like I am. Because there are so many people so much worse off, and I just feel for some of the people here, especially those who have lost their minds, you know? And that's one thing I didn't lose, was my mind. But I did have a lot of problems, heart problems, kidney problems, and very low in blood. I've had a couple of blood transfusions. The hospital just said, "You cannot stay alone." They was frightened I would fall, and they said, "If you fall, you could break your hip and that could be worse." So that's why I landed here, I said I would not stay with my children, it is not fair to them because they've got their lives and it's not my daughter-in-law's responsibility to look after me. But I'd sooner be home. I feel I could look after myself. I can't see very well, that's a problem. They said, "You cannot work the stove." And I said, "I think I can, I know my stove, I know when it's on and I know when it's off, because I could touch the tops."

I: Or possibly have someone come in to help out?

M: Well, I've tried that, but they...well, it's like pulling teeth sometimes to get help. I think I've learned something; it doesn't pay to be too nice. The more you complain...the squeaky wheel gets the grease.

I: When did you move here from England?

M: Well, I was a war bride, my husband brought me back here, we sailed on the Aquitania. Some of the war brides came over by themselves, but my husband sailed with us. The men weren't allowed on our deck though; we could only meet on the main level. Anyway, we moved to his farm in Bridgewater, that's down in Lunenburg County. Well, it was very different there from what you see now. When I first came, it was just one street; that was the town. It's mostly a logging town, they were mostly working in the woods and logging, which I had never heard of in my life in England. It was a big difference, it was a big turnaround for me from what I was used to.

I: Can you give me a couple examples of the differences? 


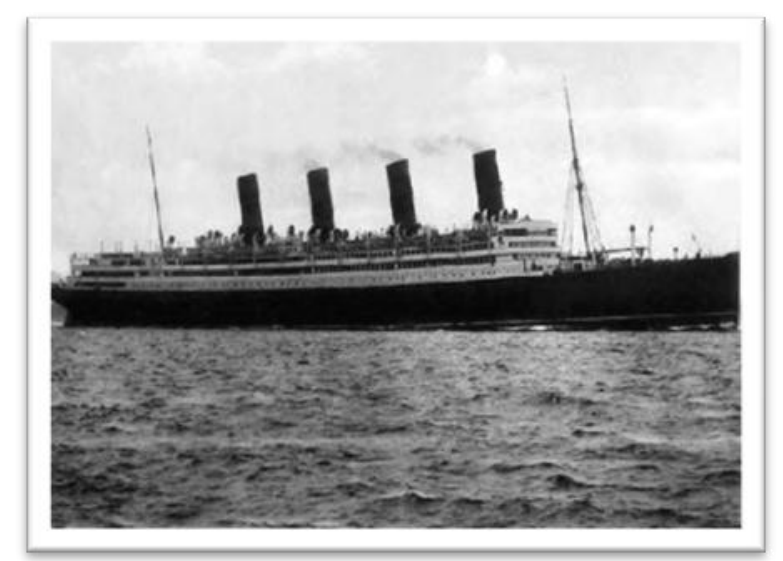

Figure 81. The Aquitania

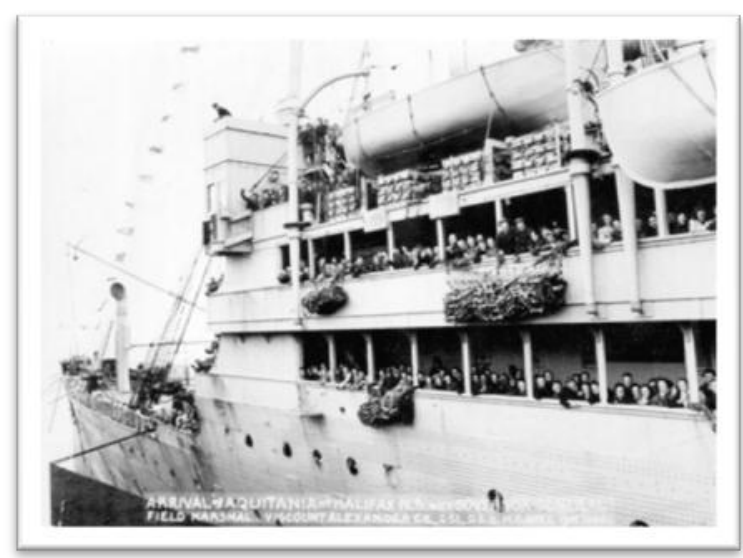

Figure 82. War Brides Arriving in Halifax

M: Well, I came here to a farm, and I was brought up in the city. And when I lived in London, well, I went to all the shows, and then when I went to Bridgewater, I came to nothing. It was quite a surprise for us English girls that came over, because we came from electricity, and gas, and we came to Canada and they had outside toilets, and gas light at night and wooden fires. So it was a complete turnaround from what we were used to.

I: So you left your family behind?

M: Yes, there were seven of us in the family, six girls and one boy. I had twin sisters, and my grandmother was a twin. And then my father's mother, my grandmother, who I never knew, she came from Ireland and she died very young. So my father didn't have a very easy life, he was in Egypt, in World War I. Growing up, my father was a bus driver, he used to drive the double-decker. And my mother, before she married my father, she was a cook; course today, they call them a chef. She worked for a well-to-do family, she was their cook. They didn't have an easy life. Normally, women, when they got married, they stayed home, but when war broke out, everybody got out and worked.

I: What did you do?

M: I put my name down for Knightsbridge, I was going to work at Harrods, I had been accepted to work at Harrods, but as soon as the government got my name, I was called up. I had to go work at a factory where we done parts for tanks and all that kind of stuff. It was all war work, we worked on machinery and stuff like that, and we had a radio when we worked in the factory that was to give us warning when the planes were near. I worked right by the Thames, and at that time, the Germans used to follow the Thames river, because that was all waterfront and I worked right by there. We had a radio and we would get веер... веер....еер....еер...that means the planes were on their way, and when there was beepbeepbeepbeep, that was we were to duck, they were overhead. When we look back, it didn't mean a thing, because if anything had ever 
happened, there was all that machinery over at the top of us, but we never thought of it that way at the time.

I: You mean there was no chance you would have been saved?

M: No...no, we wouldn't have had a chance. But...it was very thick cement place, it was like a fortress. We got used to it, the stress every day, yes, it wasn't easy. I can always remember I was 13 years old when war broke out, and my mother had just made two big pans of bread pudding. My mother says, "Oh, we're going to be rationed for food." And I turned around and said, "Well, we don't need to worry Mum, we got two big pans of bread pudding." That's how much I thought of rationing. I mean at war time, we didn't know what a slice of bacon was, or an egg, you know, we was on a very strict, a very strict diet. Really, but you know, we were healthy. We made do with what we had, and you learned to appreciate things that you didn't have.

I: Is there one thing about living here that works for you?

M: The staff is very good, very good. I love having my own room, I like my privacy, yes.

I: What would you change if you could?

M: The food, it's the not the same as when you cook. The food is made here, but it's the way it's cooked. I understand that a lot if it is steamed. I mean, they make a soup that is just like water. There's not much in the way of spices used, just a little spice adds a lot to a food. When I was home and I used to cook, I'd look at the spices, put a dash of tarragon in, ah, I'll put a little oregano in, and little bit of curry, you know. They would say to me, "Oh, this is good, what did you put in it?" I'd say, "Everything but the kitchen sink."

I: So would consider this your home?

M: If you said to me, where do you live? Well, I live in Canada, I live in Nova Scotia. This is more or less my home; I've lived here the longest. But you never forget your ties, of where you was born. I went back to England and I went back to the place where I was born, and I went to my mum and dad's grave. You know your memories are always there, especially at Christmas time, every time Christmas come around, my mind always goes back to my young days. Whenever I hear that song "I'll be home for Christmas, if only in my dreams," that song always hits me, always hits me.

Oh, I Think it's Lovely

After my conversation with Margaret, I make my way down to the Hummingbird neighborhood to visit with Margaret's in-law, Claire. She has been sick, with deep coughs and an 


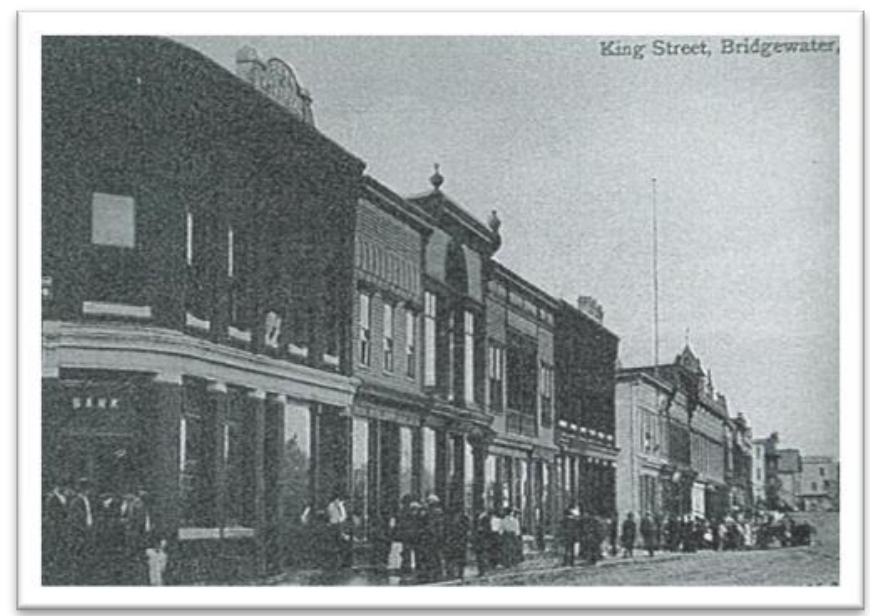

Figure 83. King Street, Bridgewater

inhaler to clear her lungs. When I knock on her door, she is asleep, but her roommate Pala is awake, lying on her bed. "I'm here, I can talk with you if you'd like."

Pala and I move to the vacant lounge in the Hummingbird neighborhood. There is a couch, a fish tank, and a TV, which has the Price is Right on, but no sound. I flip off the TV and ask Pala about her daily life at Ridgemont. Pala is 81 years old, and Joe had told me that she was originally from Iceland. As a young child, she had been a horse whisperer and was paid for her ability to work with skittish horses. "She was good, very good," Joe reported to me. Today, Pala is ashen faced, but ready to talk.

I: So when did you move here?

P: Just over a year ago. My daughter lives near here, I fell where I lived in Bridgewater and was in hospital about six months, they put me up on the 4th floor at the VG. It was similar to an old folk's home and then you wait there until a place comes with an empty bed for you. My daughter has a silver plate in her back, she couldn't lift me. They finally let me know there was a room for me and then they took me up here.

I: So when you lived to Bridgewater, did you have a house?

P: No, we had a flat on King Street. 
I: That was you and your husband?

P: Yeah, and then he was taken into a Lunenburg old people's home, I couldn't manage him no more, because he started hitting me again. I had to dress him, I was scared of him hitting my head, you know, when I was bending down and putting his socks on.

I: So when he was in Lunenburg, did you stay in Bridgewater?

P: Yeah, I stayed there for about five years on my own, and my cats and my German Shepherd.

I: How old were you when you got married?

P: About 21. I was married before. He was in the war; they brought him home in three pieces. I met my new husband because he was a warrant officer in the armed forces, he came up in Iceland. I never went out for a year after my first husband died, and the girls I worked with, they said, "You never go out no more." I said, "Nah". So I went to this dance and I met him. I slapped him down in the snow drift because he touched me where I didn't want him to, so I just bashed him.

I: He loved you from then on?

P: Yeah, you can call it that. He was a brute. My mother told me all about it, I knew it all. But I didn't know enough, I was ignorant, all right. I wrote and told her that he'd smashed every bone in my body, even my ear is busted. I wrote and told her and she said, "You made your bloody bed, you sleep on it," she wrote me back. So that was that. We were married for 64 years; he grew on me like a bad wart.

I: What are the things that you like here?

P: Oh, I think it's lovely. There's a woman that brings horses here, she brought 10 last time. It's all right for a quiet person. I am very quiet, I mostly keep to myself. I don't go to birthday parties and things like that, no, I go to bed.

Maureen comes in with Pala's afternoon medications, and says "Until someone comes along and teases ya."

P: Hahaha. Yeah, she's my best friend. Yeah, yeah, well they're all good, good like, but she's the best. 
On Friday morning I return to Pala and Claire's room. "Claire isn't here," Pala tells me, “She's getting her bath. Yeah, it was good talkin' with you the other day, haven't talked so much since I've been here."

\section{You've Got No Other Home, So This is Your Home}

There's been a stomach bug going around in the Hummingbird neighborhood. The staff are on their feet constantly, answering call bells, and changing linens. Claire comes out from her bath and wants to have her hair curled; the hairdresser isn't there that day. "Come on, sit down there, now." Brenda pulls out her curling iron from the nurses cabinet and plugs it in. "I'll be right back, Claire, just give me a minute" as three call lights come on down the corridor. I wait with Claire and ask how she's been. "Oh, getting better by the day. I feel really good now that I've had my tubbie," she laughs. I tell her that I had checked in on her the past few days. "Well, let's go to the lounge after my hair is done; it's quieter there." Brenda makes it back and finishes Claire's hair just in time to run off to answer another call light.

Claire is one of the most outspoken of the residents at Ridgemont. She is 84 years old and on the resident council. She has something to say about just about everyone and everything.

I: How long have you lived at Ridgemont?

C: A year and four months. I was just asked a few months ago if I wanted to move. I said no, I'm fine where I'm at. I'm not one who cares to move very much anyway, but I told them the truth. I like the staff here, how they treat me good and so on like that. There's no point to leave now.

I: Had you been in another care community.

C: No, I came from the hospital here, I had cancer. Lymphoma, three rounds of chemo, lost all my hair. They tell me I look good now, but I don't know where I'm getting the power to do this. I'm not kidding you. You see, I never had, in my life; 


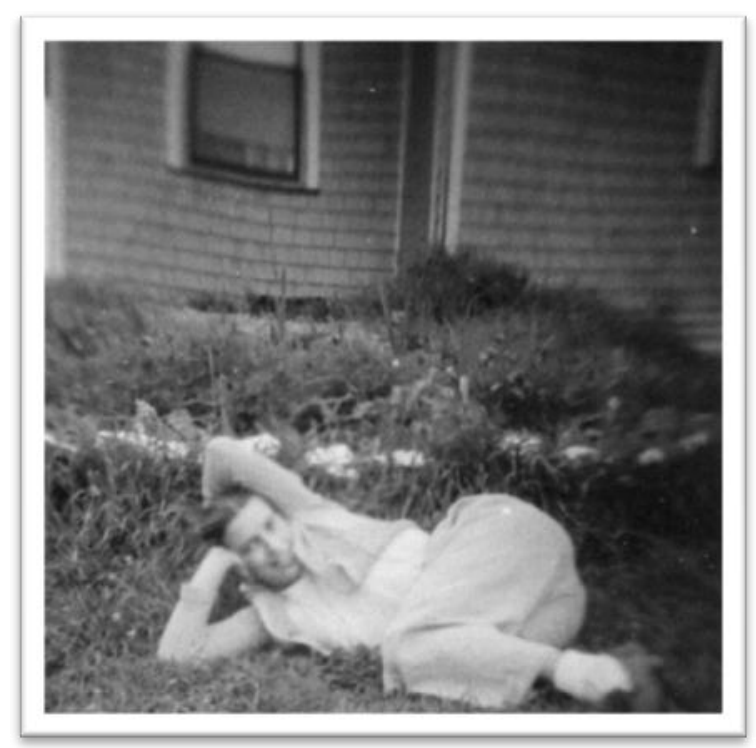

Figure 84. Claire at Home in Cape Breton

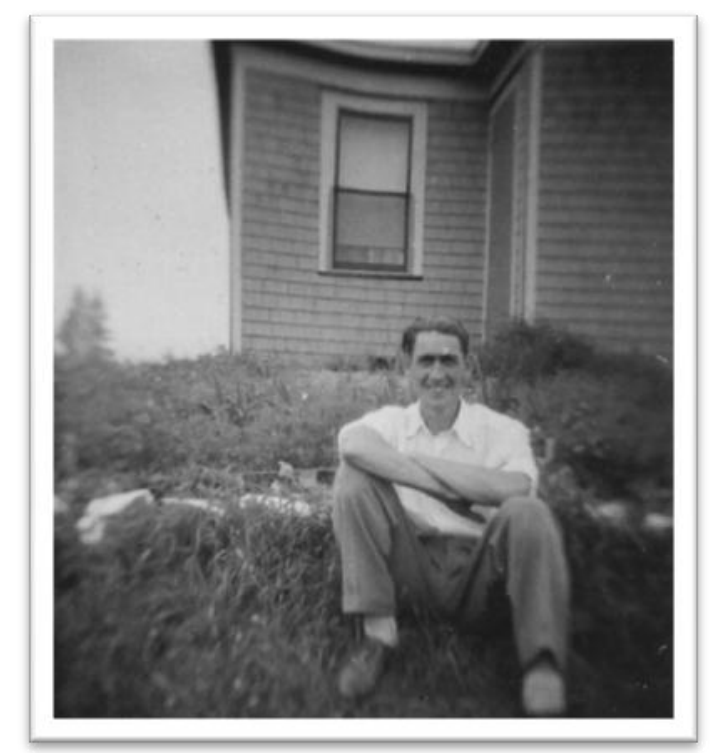

Figure 85. Danny at Claire's Home in Cape Breton

I never had three things, three smacks in the mouth at one time. So, the first one was my husband passing away. Then a month after I was diagnosed with my cancer, and then after my second chemo, they told me I had to move in here.

I: Where did you and your husband meet?

C: I met him at a dance; we were both from down home in Cape Breton. He was the caller, he was there with his friends who were the musicians, I didn't know him at the time. When we were young like that, about 17 or 18 , we would wear scarves over our heads to protect our hairdos, so it wouldn't get messed up. When I walked in the front door at that dance, Danny grabbed my kerchief off of my head and said, "Take that thing off, it makes you look like my grandmother." Of course, that caught my attention, so I was asking around to find out who that guy was. Turns out he was from the Protestant side of town and I was Catholic, so I joked to my friend that, "Well, I guess I won't be bringing him home anytime soon." She said, "Oh, you were already thinking about bringing him home?" Anyhow, I don't remember, I was somehow related to the people who were playing the music, so I was able to find out who this guy was, and we had friends in common. He invited me to come down to see their mutual friends and then after that he came back to visit me. We both really enjoyed dancing, I am some happy that I married somebody who liked to dance, something I really liked to do. We were always doing something with our friends, camping or out in the woods playing music. He worked on the ships, down below, cleaning out asbestos. He died last year of asbestos lung. I miss him so much... (Claire needs to stop, we resume after she wipes her eyes and regains her composure). 


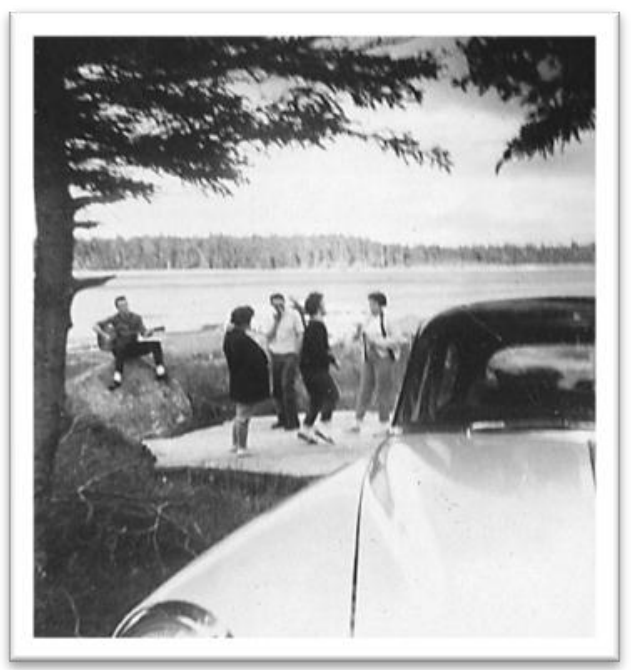

Figure 86.

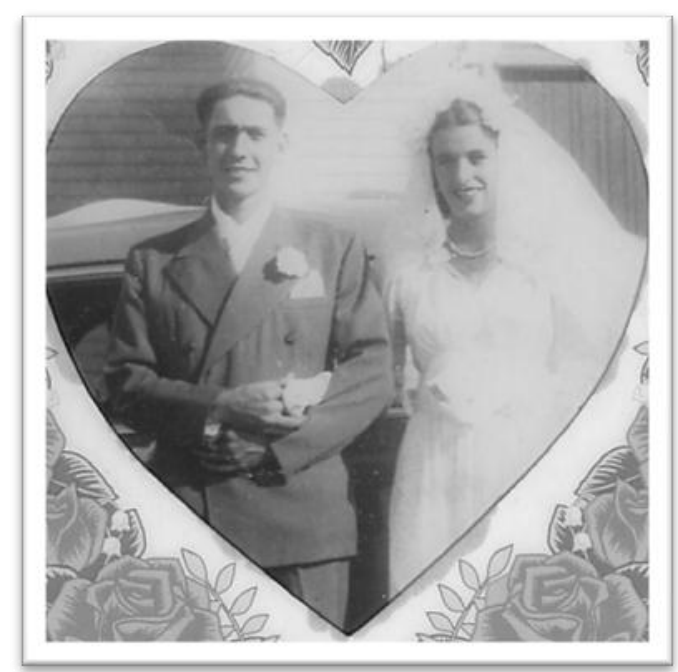

Figure 87. Claire and Danny's Wedding Day

I: Can you just tell me just a little bit about your typical day?

C: The girls help me to get up and then I get my wheel chair, I wash my face and brush my teeth and then come out for my breakfast. I come out and I'm a Roman Catholic, so we have our mass on the TV and I watch that in our lounge. Around 10 o'clock, the girls come in and they'll wash me, you know, sponge bath. And then for the rest of the day, I'm roaming around. I go to a few things that's going on, then I come out for my meals and I like chatting with the others. Me and Pat, we argue back and forth.

\section{I: If you could change something here, what would it be?}

C: Well now, first of all you need to look at the food, because what they've told me is that they have a chef downstairs, well, I'd like to meet that chef. I'm not bragging now, but when I cooked, I went by a recipe, and that recipe, if it looked really good for the picture that was there, then I'm going to try to make it look just as good. Because I worked in a lot of restaurants I know it's the taste and the looks that make it appetizing. Before they bring that plate over, I still hear in my head, "Make sure that that plate is clean, all the way around and nothing hangs." I get my porridge here in the morning and half of it is hanging out like this on the side. Just that could turn me off from the porridge, because that person that gave me that porridge, she cooked that, but she wasn't the best because there's lumps in there. Now we have another one who makes it and it's as smooth as can be.

Now, my father was a fisherman. What I did eat was fresh fish. And my husband, we'd have to have fish at least three times a week at home, because he loved fish.He'd go down to Clearwater in Bedford and get his fish. He never bought any fish in any of these other stores because he'd say, "I don't know how long it's been there." Well, I know how long it's been there when it's comin' up here, I can smell it. I'm not kiddin' you now, it smells strong and if there's a fishy smell, your fish is not fresh. It comes here and then you break it, it's hard and yellow, it's been frozen 
for so long. I had boarders, and if I had given them something that was frozen or had been cooked five days ago and frozen and reheated, they would have been long gone. The nurse comes over and says "Come on, Claire, you eat that, that's really good." I say, "Did you try it?" She says "Now, Claire," and she looks at me with the side of her eye, because I am discouraging the one next to me. But I don't care if I'm discouraging that one, she's paying for that and she should have a good dinner.

Now we have meetings, you know. This Friday is going to be our meeting and I would like you to come. Each time we have different things that we're not satisfied with, I write it down. They put me in charge of the dining room. There are some who don't want to come to the meeting to give their opinion. They say, "Now will you ask them why we get that or why we don't get this?" I have a little book in there and I go in and write it down.

I: Well then, when the baby boomers hit, how would you make people feel like they are in a place that they really should be?

C: You'll never have them feel at home.

\section{I: Never?}

C: I don't think so; you know, I mean, I'll be long gone at that time. But what I'm trying to say, I can see that you are trying to let them feel that they are home. I mean when you're home and about and everything you are able to go and do all kinds of work and, that's great, you know. You can get up from here and go in the kitchen and do your work...now that's long gone, that's a thing of the past, you can't do it. I mean, I'm confined to a wheel chair.

While Claire has a fear of being a burden on her children and a fear of the

unknown, she is making the best of her life at Ridgemont.

C: OK, right, the care is fine, couldn't ask for anything better. When they ask me, is this your home? I say yeah, this is my home, this is the only home I've got. But when my son built his house, he built it for my husband and I. But my husband didn't make it, we didn't go. He's got a ramp and all these doors are made for wheelchairs. He said, "Ma, you can live here." I said, "Who's going to watch out for me?" She's a nurse and he's working for the Mounties now, he's on the road. Then I'm there all alone. I said, "I thank you very much, but you would be worried sick over me."

A Hummingbird neighbor, Pat, wheels herself into the lounge and glances over at us as we wrap up our talk. Claire clearly bristles. 
I: I know people who live with their adult kids in their homes, but they don't really feel at home.

C: Right, they are just using it the same as I'm using this. You can't exactly make it your home. But you've got no other home, so this is your home. This is our family now. We've got to like them. This one (glances to Pat), she's very down on this place, she's down on the poor souls that's coming from the other end. But I'm not too fussy about them, what do I say when they come into my room? I say "Sorry, you've got the wrong room. You have to go out." But I don't curse at them. But that one, she's Irish. She thinks that she's the perfect one and everyone else should be perfect. I say to her, "You are living here, you've got to go a long way to being perfect."

\section{Daily Life at Stonebridge-Resident Interviews}

\section{Know It's Nice, but It's Not my Cup of Tea}

Art is one of the first residents I met at Stonebridge. He lost a leg in a car accident when he was in his 40s; he is 84 now and in a wheel chair. He is happy sitting at the kitchen table with a cup of coffee and discussing world events, bachelor cooking secrets, construction technology, and his favorite alcoholic beverages:

My dad was a home builder. I learned everything I know about preserving old buildings from him. I love to take old homes and bring them back to the way they used to look, only better. There's a good recipe for wood preserver, you know how pine goes brown and black? One part paint/ 12 parts turp, you rub it in to the wood and it brings out the grain and makes it glow and it stays that way.

Art originally told me that he was moved from his home after he had been to the hospital for removal of a large skin cancer on his shoulder. His son had made the arrangements for him to move to Stonebridge, just a few blocks from his old house. Art and I sit at the kitchen table and begin an hour long conversation.

A: I was shanghaied. I know it's nice, I know I am supposed to like it here, but it's really not my cup of tea. I was shanghaied into moving into here.

I: By whom?

A: My son. My son and the doctor. 


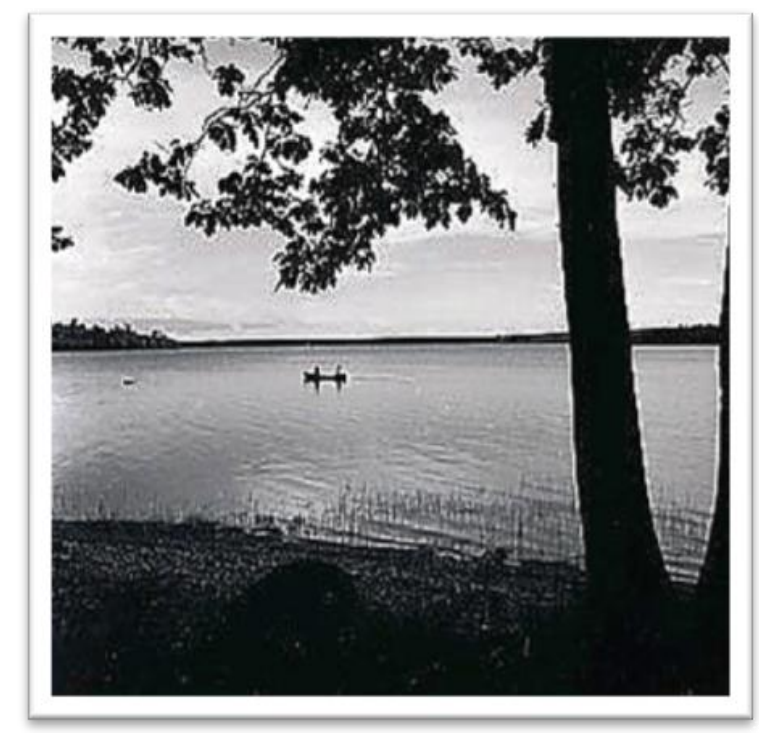

Figure 88. $\quad$ Lake View- Nova Scotia

Art worked as a carpenter for decades to support his family. He talks about

woodworking, joinery, and about his old house down the street that his son now owns and rents

out.

A: It is right by a lake, I used to leave the back door open and the squirrels and birds would come in and out on their own. It was very peaceful. That's where I should be, not here. This place does nothing for me.

The activity director, Noreen, has a little different story; her grandfather had hired Art

over the years to do interior work at his house. Noreen believes that the reason Art doesn't like

Stonebridge is that he isn't allowed to drink.

A: Oh yeah, Art would just love to do his thing. He has a long history actually with my family. He knows my family really well, my family has taken him to rehab several times. He just lived up the road, in a little shack with no utilities and no heat. He was using an office chair for a wheelchair in the house. He was a really good carpenter; he had done all of the cabinets in my grandparent's house. He had actually whittled his own leg and he used it to walk, until they took him out of the house and they took him to rehab. When he got out of the hospital, they took the leg he had made for himself and gave him a prosthetic leg. It hurts; he doesn't like it, so now he doesn't walk. So what's better, which one is better for him? 


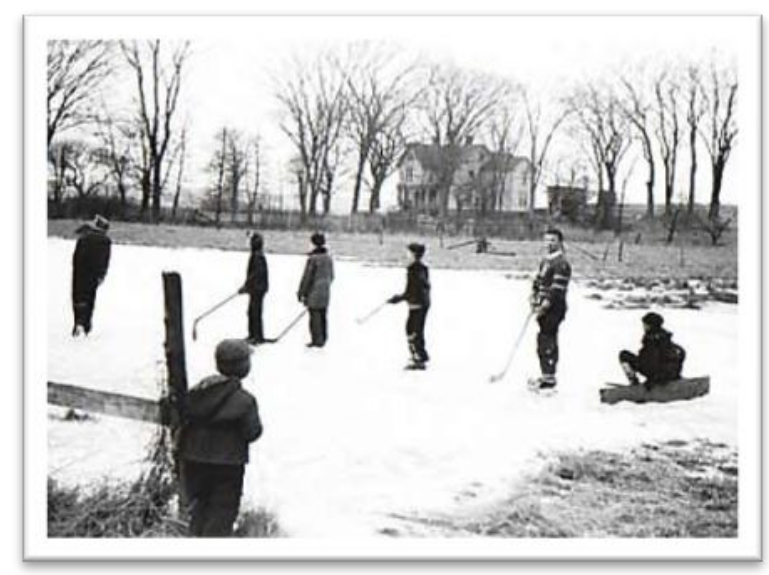

Figure 89. Pond Hocky- Nova Scotia

Art's pet peeve at Stonebridge is residents who do not participate in activities and then complain about having nothing to do. He is a regular at Bingo, Jeopardy, and the Wednesday Night Music in the community center.

A: I don't get it. We have music, we have Bingo, we have all these things to do in the community center and then these people just don't come.

I: Where did you grow up?

A: Down on the South Shore, down by Lunenburg in Liverpool. My dad worked at the paper mill there. Our mom died when I was three, I was the second of eight kids and when we were growing up, our Dad never even looked at another woman, he just worked and raised us kids. When I was a teenager, I spent my time in the winters playing hockey, we just played pond hockey in Liverpool, there was no money there to build a rink. We were good though and ended up beating the rich kids up in Lunenburg that had the rink. I was about 16 or 17 . Boy, that really made those rich kids mad, we were just pond hockey players and we beat 'em bad.

The week before I am to leave Halifax, I arrive in the morning at Stonebridge to find a small group of residents in the front lobby. Art is there, I can tell he is angry as there is a dark cloud over his eyes. He does not acknowledge me today like he normally does. As I continue down the corridor, the general store shopkeeper has come out to talk with Art. She apologizes profusely, “Art, I mean it, I thought they were ordered. This is what came in, but I know you wanted the green kind." Turns out, Art had asked the staff to order green gumdrops over three 
weeks ago and what finally came in were the wrong kind and the wrong color. "I don't ask for much, really. Can't they even get something as small as this right?" Art leaves fuming, but later that afternoon the cloud has lifted and he's back in his element as the winner at Jeopardy.

\section{This is Where I'm From}

Edna is well loved by many of the residents at Stonebridge. She is reserved but friendly, and always gives a little laugh with her responses. Edna had moved from Ridgemont to Stonebridge with her husband, who died a year ago. She is 89 years old and attends most of the planned social activities in the community center. She is not a woman of a lot of words, but she smiles a lot and does her best to compensate for her sight and hearing losses. Edna loves to knit; she goes to knitting class every week, and while she enjoys the once a month jewelry class, she has a slight tremor, so when she is beading or knitting, the work is slow.

Noreen says that Edna's husband, James, was a very overbearing man and hard to live with. Edna does not discuss her husband as she talks about her life at Ridgemont before moving to Stonebridge. She remembers the routines, but not much choice in her daily activities there.

I: Have you ever lived in another community like this?

E: Before this, I was up at Ridgemont, it was nice, I don't know if you know where it is, up in Woodside, so it is farther away. I lived there for two years. I didn't mind being out like that, I got used to it. But we didn't have any exercise or anything like that. We just had music once a week, and then a band came in once a week, so we had music twice a week. The rest of the time we were kind of on our own.

I: What were some of the other differences between Ridgemont and here?

E: I just know we had a set time to get up, we all had to get up at 7 o' clock in the morning, and go for our breakfast at 8 and then we were free, we could do what we wanted to do, which wasn't very much (she laughs). Here, I don't have to get up at the same time every morning; I can get up when I want to get up. 


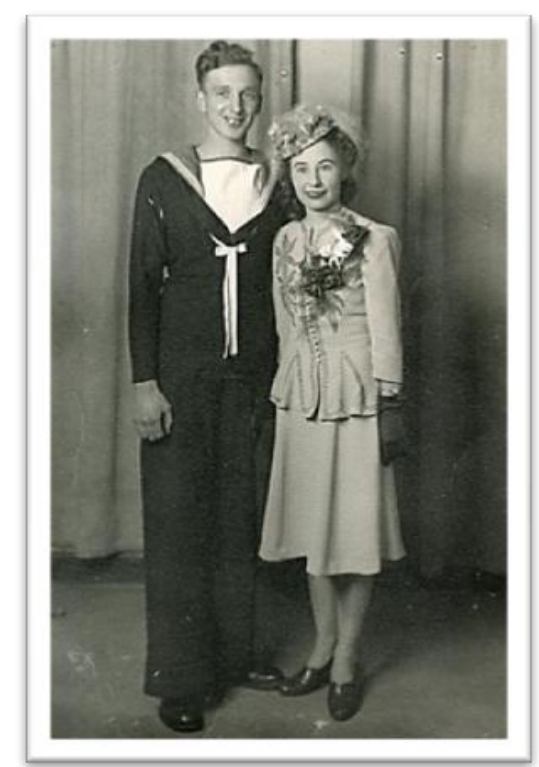

Figure 90. Edna and James’ Wedding Day

I: Does that make a difference?

E: It does, because it makes the time shorter.

I: So it was your choice to move down here then?

E: Yes, oh yes. It was nearer to things because we had lived in Millville. So that's why we came down. It's closer to things down here in Millville.

I: Is there anything here that makes you feel like home? Do you like having your own room?

E: Well, I'm near to the kitchen, it's just out there, there's the kitchen, so I like that. And well, I have friends that come in, which is good. And I go to knitting once a week, which I like. I think things are all right here. If I want to go out, I can go out with friends. But you don't go out alone, especially not this time of year. I've never had a roommate, I've always had my own room, but I think it would be alright if you like the person you're in with. Some people are hard to get along with, I wouldn't like that.

\section{It's Different Having People You Can Depend On}

Often in LTC settings, a sense of time is distorted and the past and future are squeezed into the present and modified by the overriding concerns with one's symptoms, creating a tension between egocentrism and dependence (Agich, 2003). Elsie worked for many years as a 
registered nurse. In a way, she continues her care giving role with her cottage-mates, and the CCAs depend on her to help bring the residents with higher needs to the table or down to the community room. Elsie is 81 and is a battered wife. Her husband is an abusive alcoholic and although she remains married to him, Elsie is happy to not be living with him.

E: My husband lives out in our old home, on Pictou Rd. He still lives out there, but he's drunk all the time. He doesn't do anything for me when he's like that, I don't appreciate it. I'd just as soon be out of his life altogether. Now that I'm living here, he never comes around or anything. I'm just on my own.

I: Do you miss the house?

E: I do miss things at home, but I live here now. And I'm getting so well acquainted with everything, I go to things that go on, it's nice. At first I felt strange, now I don't anymore. I just go to things and we all talk, and we know each other, it's fun. The girls (CCAs) and I always get along well. And they all just come and see me; I just leave my door open most of the time, they all come by. It's great fun to have a lot of friends.

It's a long story to tell about your home, you know? I had four kids and I brought them all up there. Jane was my only girl and she's always there for me. And I have two boys that work in Halifax and one boy that works in Truro. They are all married, making their own lives. The one of them travels around quite a bit and the other one does things on his own a lot, but I don't care. I meet a lot of people, so it's kind of nice to be on my own. I like independence. I don't know, well my husband drinks a lot, so I don't care to be around when he is, it's alright if he does, I don't care, I don't live with him.

I: So you are independent here?

E: This is my room and I have a bathroom of my own. So it's like my own home now, I've lived here for a year.

I: Yes, some of the girls that work here kind of feel like it's home, too.

E: I think it's because the nurses that control this place, they have more care for you. They care about you. I love this place. I had to wait for a room, you know. It's different having people that you can depend on. But anyway, I can get along without a big uproar. I don't mind being by myself and I'm sure he doesn't mind being by himself because he's always...I never see him, I never go visit him. He never gives me five cents. I'm on my own. 


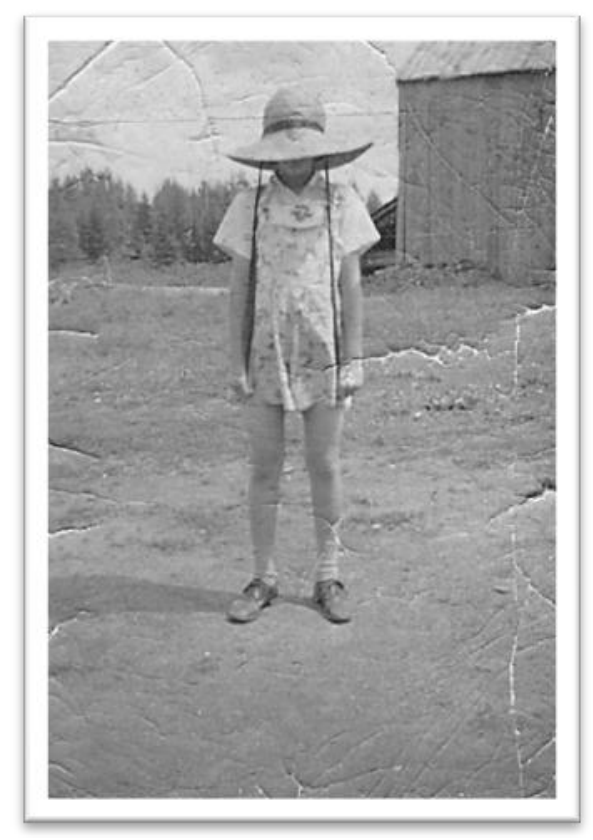

Figure 91. Elsie age 10

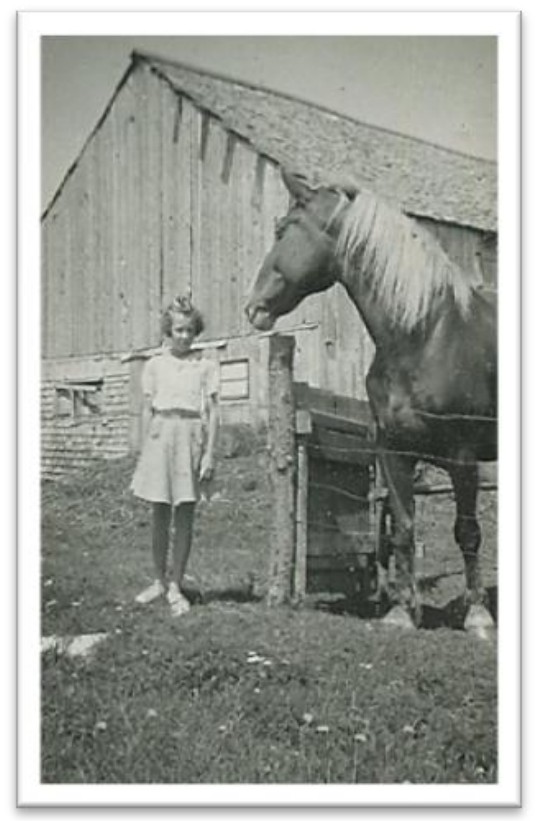

Figure 92. Elsie and her Favorite Horse

I: Then you have independence and you have support?

E: I don't depend on anybody for anything. I have a grandson, David Andrew, and when he was little and growing up, I looked after him. But I don't see him that much anymore because he's on his own. But we're still friends and he still knows I'm Nanny. But David Andrew and I have a lot of friendship; he will come to me and talk to me about something that he's worried about or something. But he never comes to me and asks me for money, you know? It's alright with me.

I'm the youngest of the family and I just found it hard to get along and be the youngest, and they treated me like the youngest and they used to say to me that I shouldn't do this and I should be this and I shouldn't say that, you know? Things are different when I'm on my own, I like being on my own. I don't have a boyfriend or chum around with people; I'm old enough now to know how to take care of myself without having to bother with having someone to look after me. My husband lives out in our home in Pictou Road and he's a drunk. He is a total drunk, so I'm glad I'm away from him, because he was not a good person. I hate to be around people who make an ass of you, if that's what you call it.

\section{Don't Think He's Found Me Yet}

Penny spends most of her days at Cypress cottage resting in her room, although

occasionally she sits in the living room and watches TV or joins in a conversation in the kitchen.

She is 73 and has a hard time speaking clearly as her Huntington's disease has affected her 


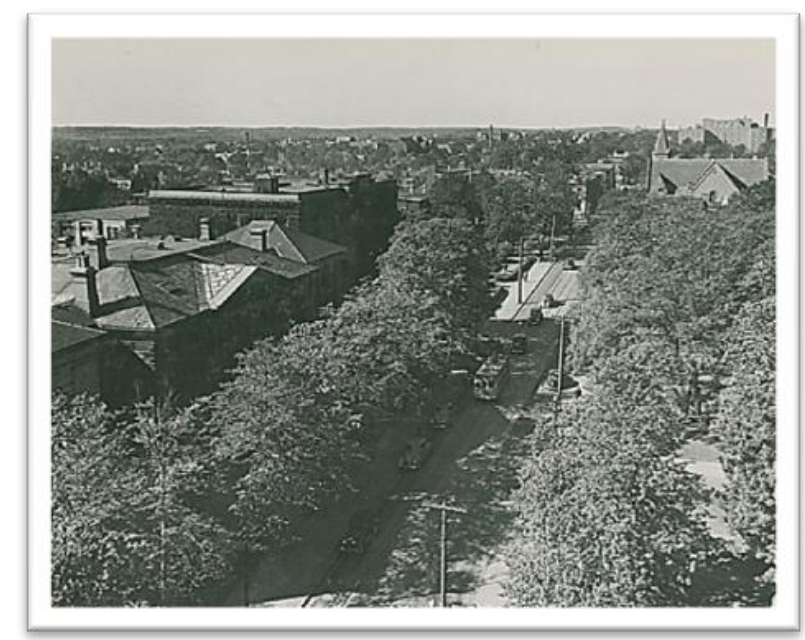

Figure 93. $\quad$ Spring Garden Road-Halifax

speech. She enjoys having one-on-one conversations and is always interested in what is going on with others in the community. She divorced when her two boys were teenagers and holds some guilt about that. Since her divorce, she had a live-in companion who had become adversarial and she has tried to stay out of his life since.

P: I lived in my apartment, all by my lonesome. I was involved with this man, not my husband. I was trying to get rid of him, I didn't want him to find me. I wanted to get away from him and everything that went with it. I moved out to Millville to get away from Halifax and the crowds. In Halifax mainly I lived on South St., down the street from Spring Garden Road. Every time I'd walk down the street, in five minutes I'd run into him, he'd be walking down the street looking for me. So I said, "I'll fix you, one of these days, I'll move somewhere where you can't find me." I told him years ago, "I'll disappear, you won't find me. "He said, "I can find anyone, if I can find my daughter, I can find you." I don't think he's found me yet.

So I moved to Woodhaven Road, I had a beautiful place. Nice apartment, loved it. My youngest son helped me pay for it, he flew down and helped me get the apartment and helped pay the difference, because I had my check, my old age pension. To make up the difference with the rent, he put the money in the account every month. He's a sweetheart, all around good guy, my youngest son, the oldest one is not. My eldest one, he straightened up finally, I gave him tough love, I had to, I turned it on him and he didn't know what hit him. He couldn't believe it.

Then he straightened himself out. Two years ago, I got a Christmas card from him and he said, "You are the best Mom in the world." My daughter has three beautiful girls, they were here on my birthday, they brought me a big bouquet of 
flowers. The youngest said "Grammy look what I have!" They know I like flowers, I'm a sucker for flowers. I'd like to get right out in the dirt; I used to be quite a gardener. My son out west has a friend who said "Where'd you get your green thumb, Brian?" "From my mum!" They have beautiful grounds here. You see, I came in here in September, I've only been here four months, I'm still adjusting.

I: Do you feel that this is as close to being home?

$\mathrm{P}$ : Oh yeah, it has to be. First thing I do in the morning is turn my radio on. Music first, yeah it's homey. I'm 73 years old, I told my granddaughter, Kristal, "Grandma only has a few more years to live, so this will do me fine." It's good place to spend my last years. If I don't want to socialize, I don't, and if I feel like it I do. You know, I get tired, no one understands this disease, no one wants to talk about that, because no one knows that much about it anyway. I would like to have a coffee shop to come down to. I used to live up the hill from a coffee shop, I could go down and have my cup of coffee and talk with the people who were there. That's what I would have here, a coffee shop to come to and just sit and talk with people.

Penny discussed her illness; she said it's not too bad now, but it is degenerative, so she knows that it will get worse. We also discuss her marriage; her husband was a pharmacist and was abusing prescription drugs, that's why she divorced him. She has no guilt about divorcing him even though her children were small at the time. She thinks all men are the same, obsessed about their work and are unable to pay attention to anything else (like kids).

\section{It's a Long Way from Being Home}

The trick was to become a jack of all trades. My grandfather wasn't much of a grocer, but he could build a house, a boat, a rocking chair, a barrel, a muskrat trap. It was usual for a man to be a farmer, fisherman, pulpwood cutter and a bit of a blacksmith. (Bruce, 1988, p. 43)

Robert has the biggest smile in the Cypress cottage, but because of his hearing loss, when you have a conversation with him, you need to talk very loud. Every time I see him, he reminds me that he had been in a mine disaster at Springhill. Robert is 84 years old and is very gentle 


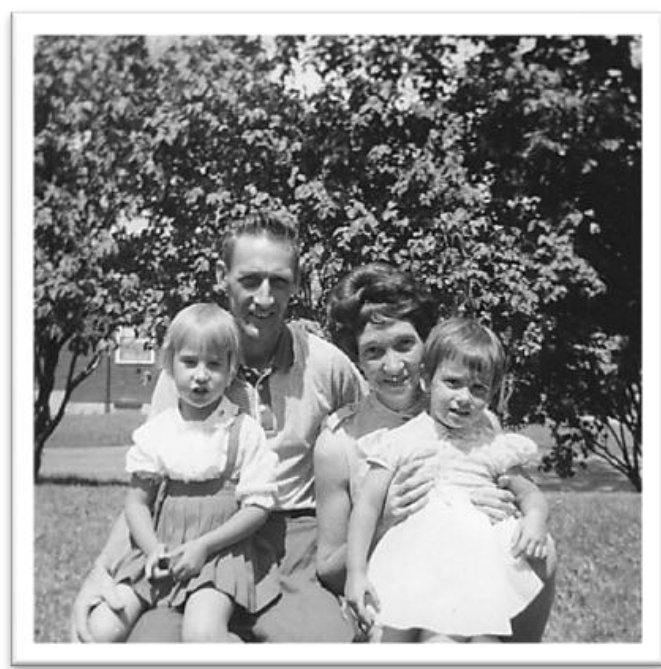

Figure 94. Robert with his Family

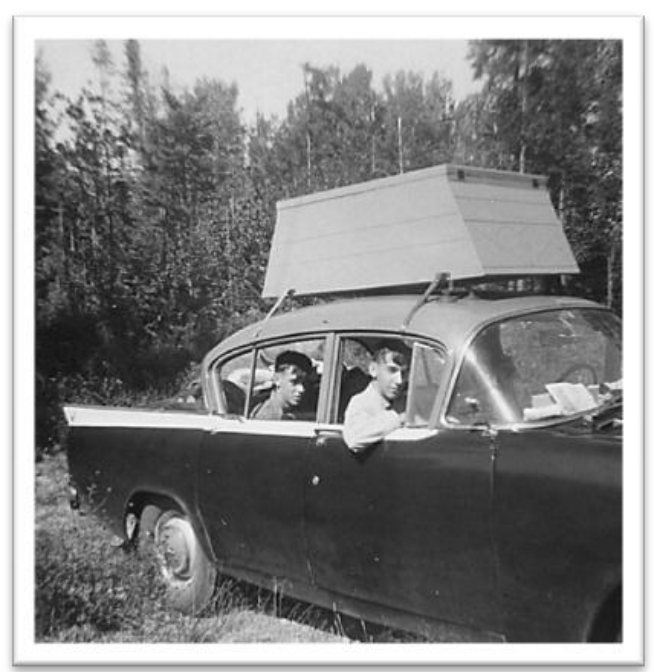

Figure 95. Robert's Camping Car

man. He spends most of his time in the cottage kitchen or the living room with the kitty, who sits on his lap in his wheelchair. His mother died at childbirth; there is a picture of her hanging on his wall, she looks about 20 or 21 . His wife also died very young. After her death, Robert reconnected with a high school sweetheart and they lived together until her death two years ago. I ask him about the 1956 Springhill mine explosion; he was 27 at the time.

R: My dad worked in another mine. They had what they call the explosion door in between the two mines, and when the explosion happened, they opened that up to get to one another.

I: How long were you there?

R: Five and a half days and nights, yeah, the nights were the worst, there isn't any way to describe what it's like to be in the dark for five and a half days.

I: Were you able to sleep?

R: I don't know if I was or not because I was gassed so much in between.

I: So you passed out?

R: Just the same as if you went to sleep. Then if you got somewhere where the air was clean, you are OK, but if you got in a place where the gas was, that was the end of you. I was some happy when they made it to me. Some of my friends were gassed and didn't come out. 


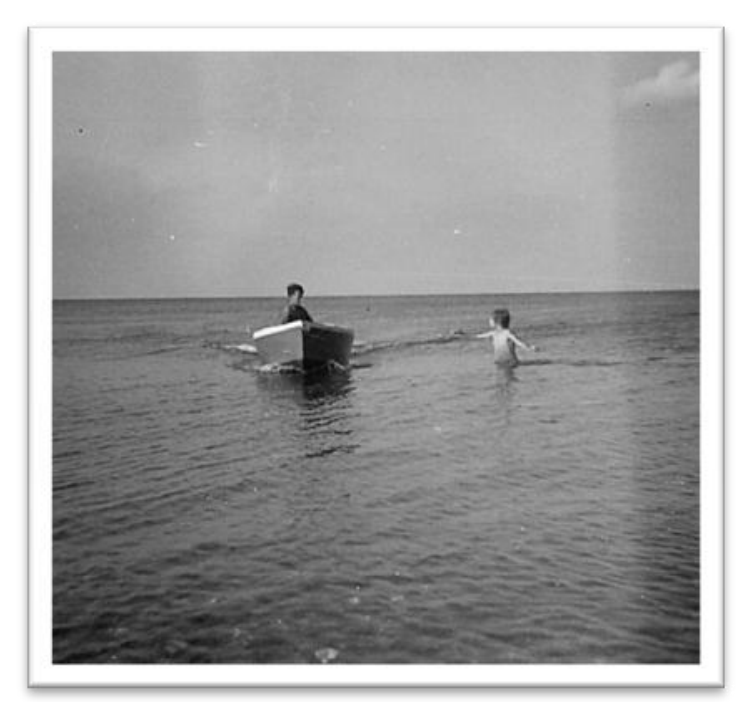

Figure 96. Roberts' Family at Hope Lake

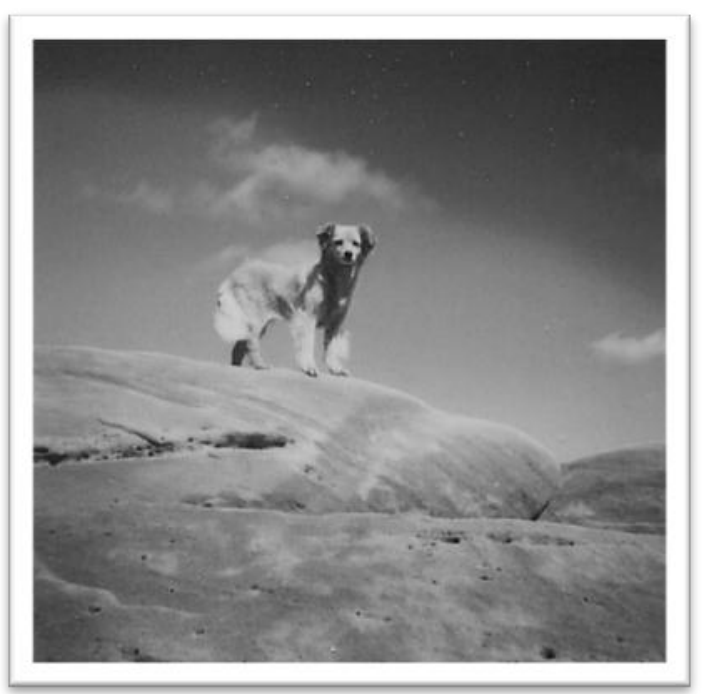

Figure 97. Lady- Robert's Dog

I: After that accident did you go back to the mines?

R: I had to because I had a family and small children and I had to look after them. Then I lost that work, so I did just about anything I could to make a living. I've only got a third grade education, but I took the mechanic's exam and passed it, that's what I did later on in life. Those days were long, I didn't like it.

I: That was in Springhill?

R: Yes.

I: When did you move down to Halifax?

R: Not too long ago, I was in the hospital for a long time. When I got out of the hospital, someone stepped in and sent me to a home.

I: Did you come here first?

R: First I was in a rehab place, supposed to get me back to being better. I'm getting all mixed up, see, I had a stroke and that's when they put me in the rehab. It didn't work out good, I didn't pass it, so they just put me in a home.

I: This home?

R: Yeah, well it's supposed to be. It's a long way from being home.

I: What do you miss the most about home?

R: I had a workshop that had all kinds of tools that I used to make all kinds of furniture. Rocking chairs for kids. I've got picture in that book right there. (We look through his photo album). 


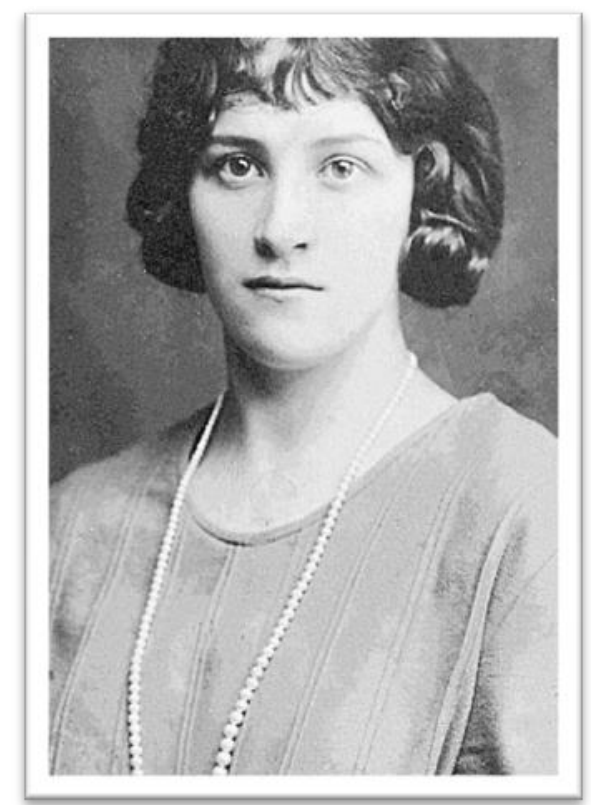

Figure 98. Robert's Mother Alice-Age 20

R: That's my doggy.

I: What's her name?

R: Lady, that dog was the smartest dog I ever seen. In the Spring one year the bank all washed away underneath, it caved in and there were bird nests in there. That dog there carried everyone one of them birds down to where the mother was. I've had a lot of dogs, but that's the smartest one that I've ever had. That's my dad, he was in the band. There are the kids down by the lake, it's about halfway to Springhill. That's my wife, her name was Mary, that's the car we had at the time. That's my half-brother. That's my camp. That's the girl I was going with. There's my young daughter, I haven't seen her since I got the stroke.

I: She hasn't been by?

R: She hasn't been handy. That's my oldest boy and his children. Here are the grandchildren. That's me there with my dog.

I: Do you have a favorite picture?

R: I got no favorite ones, well, that's my mother. Yep, that picture is some old. She was 20 years old in that picture. She was 20 when she got married.

The last time I saw Robert, the CCAs were sitting at the kitchen table with him, using a coloring book and crayons. I left wondering how much closer to home Robert could be if he could just a sit at a work bench with a few hand tools. 


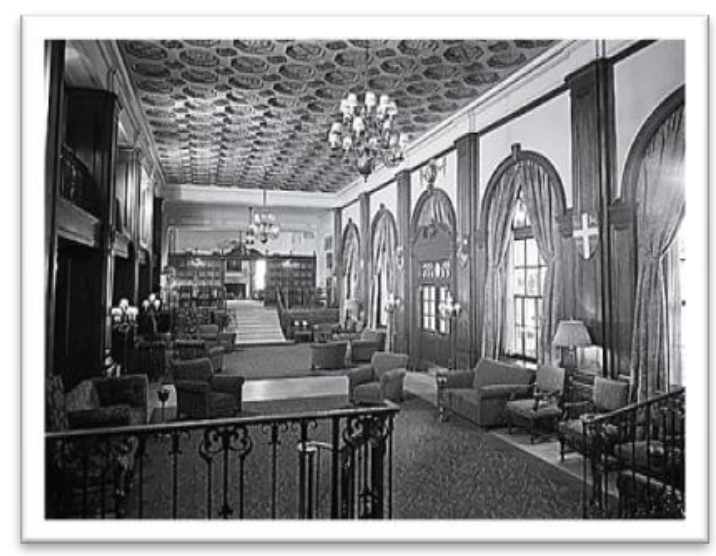

Figure 99. Lord Nelson Hotel-Halifax

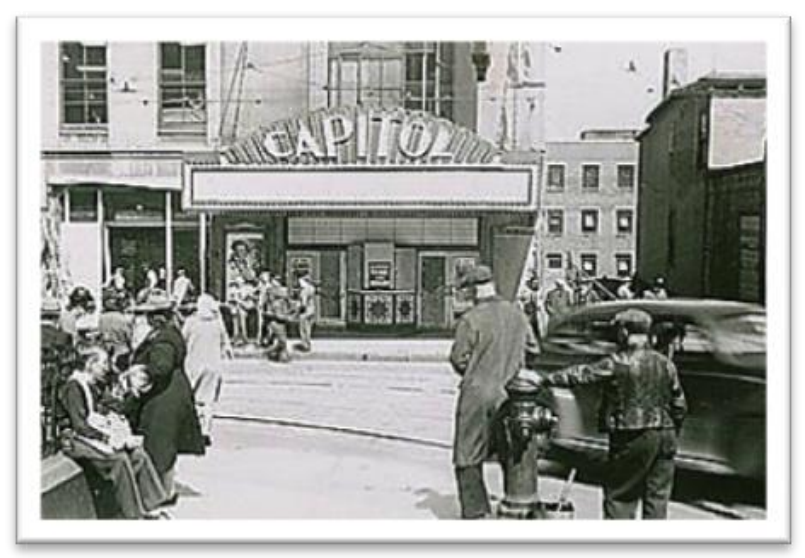

Figure 100. Capitol Theater-Halifax

\section{They Cleaned Out My Apartment}

Edward moved into Stonebridge after being in the hospital for several weeks. He is 78 years old and had lived independently in an apartment since his divorce many years ago. He is estranged from his children, so his brother and sister-in-law are the family who he stays in contact with. Edward was a bartender and a bouncer at several taverns and pubs around Halifax. Now he spends his days in his room and down in the smoking area. He has no problems moving in and out of his cottage, he does not use a cane or walker, but prefers to spend the majority of his time alone. We discuss the move from his apartment to the hospital.

E: I've been here for over six or seven months. My sister-in-law comes in every once in a while. She's been down home for about a month, and I haven't seen her. I got a list of things for her to get for me. I just have her get the things until I get my check and then she cashes my check, pays herself back, and gives me the rest. About \$25, then I wait another three months to get more money.

I: So when you were at the VG, they said you can't go back to your apartment?

E: Yeah, that's what they told Patsy, that's my sister-in-law. They told her, and when I went to the hospital, she went to my apartment and got rid of my furniture and everything that I had, everything that I owned.

I: You didn't get a chance to go through your stuff? 


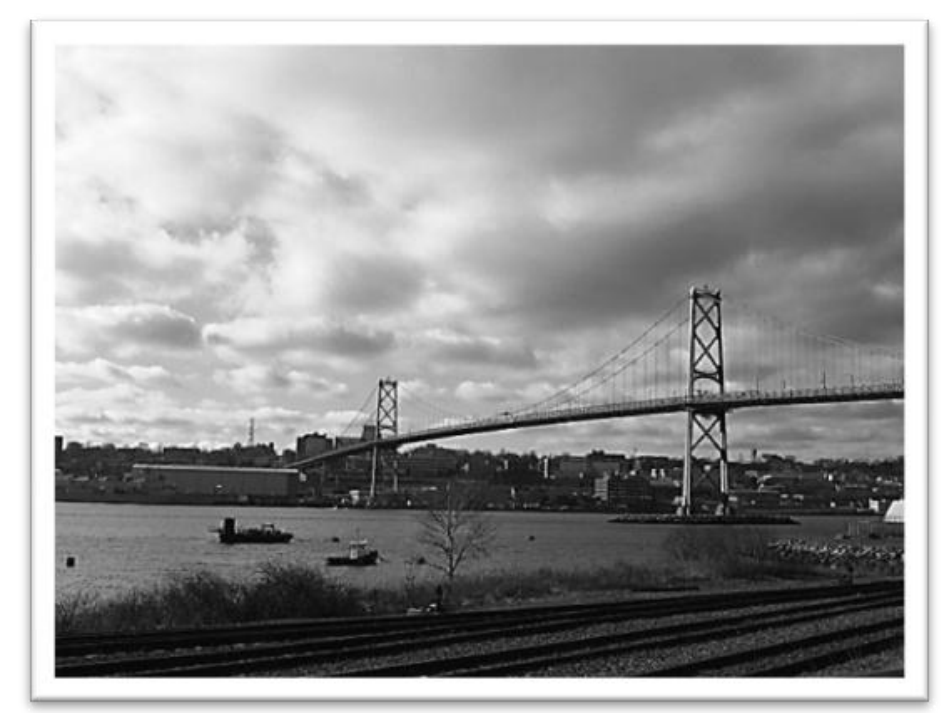

Figure 101. The McKay Bridge and View of Halifax from Dartmouth

E: No, dear, no. What stuff I got, I got my clothing, that's about it. I'm telling you, I still think about it. I lay there at night, trying to get to sleep and I can't, it's impossible, because I think about the apartment that I did have, 5202 Granville Rd., Apartment 6. That place was spotless, I used to keep it spotless, but the last couple weeks I was there, I didn't care for nothing, I could do nothing. Richard and Patsy were up, they said, "Edward, you need to either go to the hospital, or we'll probably have to find a place for you." I couldn't function. So I went to the doctor and the doctor told me that I had to have the operation. I got the operation, got out of the hospital, I was in there for about two months and Patsy told me they had cleaned out the apartment because I couldn't afford to pay for it and not live there. I said "What about all my stuff?" She said, "That needed to go to the Salvation Army, you've got no place to put it." I said, "Mother of God, everything that I ever owned is in that place." That didn't make me feel too good. And I still think about it. Even now, I wish I was back home with my stuff, but I know that it won't happen.

\section{I: Can you tell me about your typical day here?}

E: We come out of our rooms in the morning, we have something to eat, and then go back to our rooms. That's day in and day out, that's not good. I don't see why they can't get a pool table at least for Art and I. The nurses take good care of you though, they keep your room clean. And the food. Oh God, almighty God. Like today we had Shepherd's Pie. Now when I made a Shepherd's Pie, I roasted the crust, it's not hard to roast a crust on potatoes. This just had the white potatoes on top of it. I didn't go for that, I ate a little bit and that was it. Most of the cooks that are here, they don't know how to cook.

I: OK, so the food, food preparation, ingredients, what else? Would you want to have music around? Do you listen to the radio in your room? 
E: Yeah, I've got a ghetto blaster in there. If I turned it up full blast, this whole place would clear out. I listen to country western, that sort of takes me back a little bit, it sort of soothes me a little bit, takes my mind off of the things that aren't here.

\section{I: What was your profession?}

E: Well, my dad was a firefighter. I was a tavern owner, started out as a waiter, then a bartender. I worked as a bartender at the Lord Nelson Hotel. For a while I worked in the tavern downstairs at the Capitol as a bouncer, you couldn't tell it from how I look today. I had a good life, and then this happened to me. I am not able to be where I need to be for work, so I'm here. I went from 195 pounds to 90 pounds. Look at my arms, my arms used to be like that (gestures the size of his arms). Well, I've been through a lot; I had a stroke and a heart attack, and Huntington's disease. I had the heart attack first and then the stroke. After I had the stroke I gave up hard liquor completely, that was 18 years ago. But I love a cold beer, but it's hard to come by. I think I got a $\$ 200$ month raise and that's all going to these people here; that's $\$ 1500$ dollars a month, I don't get one cent out of that. How do they expect someone to live on that? There's one thing about me, I do not have the money to fight the government.

You know what would help me out? If someone would come and get me and take me out for a couple hours, to let me get some air, to see the things that I haven't seen for a long, long time. Like even going over the bridge, you know? And of course, stop into the tavern and have a couple of beers; that would be beautiful. Honest to God, I would appreciate that so much, that's who I am.

\section{Chapter Summary}

Collected biographical information can create a rich and detailed tapestry of a person's

life. Places lived and visited, family life and work, landmarks and transitions in the life course and personal idiosyncrasies are all important discussions (Chaudhury, 2002). Qualitative interviewing is one way to examine meaning through examining experience (Rubenstein, 2002) and Chaudhury (2002) writes that recollection may prove to be a working tool to enrich the quality of social exchange in the present. This appeared to be the case in these interviews. Meaning in these discussion related to home, family, work and places from the past.

Many spoke of the notion of home, or in some cases, homelessness. Schillmeier \& 
Heinlein (2009) describe that for the LTC resident, home relates not so much to a fixed and clearly bounded spatial "being" but can be understood as a "becoming", a moving achievement between feeling at home or not. Many like Claire discussed other homes and places from the past in the context of who they used to be, "When you're home and about and everything you are able to go and do all kinds of work and that's great, you know." Art described his home by the lake, "It was very peaceful. That's where I should be, not here. This place does nothing for me." Bachelard (1964) writes that experiences from one's memory can sometimes be taken with them into a new setting:

An entire past comes to dwell in a new house. Memory and imagination remain associated, each one working for their mutual deepening. In order of values, they both constitute a community of memory and image. Thus, the house is not experienced from day to day only, on the thread of a narrative or in the telling of our own story. Through dreams, the various dwelling-places in our lives co-penetrate and retain the treasure of former days. We comfort ourselves by reliving memories of protection. The chief benefit of the house: the house shelters daydreaming, the house protects the dreamer, the house allows one to dream in peace. The places in which we have experienced daydreaming reconstitute themselves in a new daydream, and it is because our memories of former dwelling places are relived as daydreams that these dwelling places of the past remain in us for all time.

Therefore, the value that each resident brings to the LTC setting is reflected in who they

are and their past experiences. For Art, home is the open back door by the lake where the animals are free to come and go at will. For Edward, home is the tavern and shooting pool. For Jean, home is the loft above the mill on the family farm. For Margaret, home is where her mother and father's graves are. For Robert, home is his camp at the lake. For Penny, home is in the garden. For Elsie, home is her independence. For Perry, home is the city of Dartmouth. For Claire, home is her kitchen. For Marian, home is being able to reach the car gas pedal with her toes. For Pala, home is her bed, where she knows her husband can no longer hurt her. For Edna, home is her room at Stonebridge, sitting in her comfortable chair, with a good light, knitting. 
Despite the diversity of the personal stories presented in this study, they have merged to paint a picture of what is means to leave both the good and bad aspects of life as it was, in order to submit to the unknowns and complexities of life in LTC. Home can then be described as an internal setting depending more on the individual in environment rather than the physical environment itself. Further discussion about the individuality of the LTC experience for each resident's ability to find home will take place in the following chapter, as well as an environmental analysis and summary of the provincial and provider outcomes at Ridgemont and Stonebridge. 
PART III.

FINDING HOME 


\section{CHAPTER NINE: CASE STUDY PERSPECTIVES AND ANALYSIS}

Within an E-G framework related to LTC, there is a need for systematic descriptions and explanations of the relationships between people and the physical built environment (Kloos \& Shah, 2009) because interdependent functional and environmental concepts have an inextricable connection. The two communities in this case study research have divergent organizational and environmental qualities, and the viewpoints from multiple perspectives have formed a complex system of multi-layered outcomes. Case study research benefits from these real life viewpoints and it becomes the role of the researcher to interpret how well bridges between theory, research, and practice connect with real life. With respect to these bridges in the nursing home industry in the United States, Schoeneman (2007) speaks to a need for transformative cross-disciplinary research:
All the changes in the past, whether to culture or to regulation, have come from problems being revealed that were then mandated to be "fixed" with regulations, or from dedicated groups of people gathering together to make the case for change. We need to talk, all of us; regulators, legislators, safety experts, researchers, innovators, designers, and most particularly residents, staff, and families. We need to make some new decisions together, and we then need to work together to make those decisions turn into changes: changes in expectations of what a nursing home is and should be; changes in what is mandated and prohibited; and changes in how we think about people who live in nursing homes and what they want, what they need, and how to keep them safe in the midst of them exercising their rights to a good quality of life in a place that provides excellent care and that can truly be called home.

She goes on the write that, "The answers will not be yes or no, on or off answers, but will be those of how far along on a continuum we can go, how much of resident rights can we provide, and how much safety is enough or too much (2007)."

The following sections of this chapter will discuss the perspectives of the provider, the province, family members and residents, and will include a cross-case analysis of the 
environmental features of the two study settings. This information can help providers, designers, and legislators to understand the possible outcomes of their proposals and is important because the theoretical and practical models that reflect the state of knowledge in a field can serve as a firm foundation in present knowledge for future research and practice, and as a springboard for future paradigm shifts (Zeisel, Hyde, \& Levkoff, 1994).

\section{The Dynamics of System-wide Change in LTC}

With it being resident directed, it is so easy to slip out of that and slip in to what I have to get done today. Our overarching goal is to make sure that the residents are happy, and it can be a chore to keep that present in your mind. That's what we need to remember.

(Noreen-Activity Director at Stonebridge)

\section{The Provider}

LTC quality improvement efforts of all types, including those which fall within the SH model, require that intervention processes and their related outcomes be defined and that factors contributing to the staff's ability to implement the processes be identified (Rahman \& Schnelle, 2008). While the challenges of opening a new LTC community are daunting, the implications of opening a new community with a new model of care can be overwhelming. Robin describes the obstacles the staff and management faced the first few weeks after Stonebridge opened in 2009:

The challenges that we have had, it was like that the day we opened, how do you move 50 people in a day and find out anything about them, find out what pills they take? It took us a year just to get everyone's care plan started, let alone done. We just said, "Come on in, you're starting work today and guess what, all of these people are moving in."

Yet with 25 years in LTC nursing, Robin feels that there are no real crises in LTC; she explains, "If someone dies, it's not a crisis, it might be a crisis for somebody who has never experienced death, that's a crisis, but it's a natural part of what's going to happen." The fact that 


\begin{tabular}{|c|c|c|}
\hline THEME & DEFINITION & EXAMPLE \\
\hline Provider & $\begin{array}{l}\text { Discussion relating to the organization or } \\
\text { company providing LTC system change }\end{array}$ & \\
\hline $\begin{array}{l}\text { The } \\
\text { Interdisciplinary } \\
\text { Team }\end{array}$ & $\begin{array}{l}\text { Discussion relating to the multiple roles that } \\
\text { an organization can play in the design, } \\
\text { construction, and implementation of LTC } \\
\text { programs }\end{array}$ & $\begin{array}{l}\text {-We do design-build, which is a little different } \\
\text { than a typical architect's office. } \\
\text {-No consultant is going to understand the } \\
\text { business the way we do. } \\
\text {-We did it ourselves, we did everything in- } \\
\text { house. }\end{array}$ \\
\hline Focus on Goals & $\begin{array}{l}\text { Discussion relating to the goals to see the } \\
\text { LTC program through }\end{array}$ & $\begin{array}{l}\text {-The old way is the old way, and this is } \\
\text { something else. Now I can't imagine going } \\
\text { back. }\end{array}$ \\
\hline Leadership & $\begin{array}{l}\text { Discussion relating to unwavering shared } \\
\text { values and goals for the organization }\end{array}$ & $\begin{array}{l}\text {-We are all on the same page, that's why it } \\
\text { worked out so well. }\end{array}$ \\
\hline Communication & $\begin{array}{l}\text { Discussion relating to the need for direct } \\
\text { communication between management and } \\
\text { care staff to ensure quick resolution of } \\
\text { problems or issues }\end{array}$ & $\begin{array}{l}\text {-There is a lot of communication, we try to } \\
\text { keep a lot of communication open between staff } \\
\text { and management so problems don't arise. }\end{array}$ \\
\hline Education & $\begin{array}{l}\text { Discussion relating to the role of the provider } \\
\text { in staff and public education about LTC and } \\
\text { the SH model }\end{array}$ & $\begin{array}{l}\text {-You can't teach compassion, they've got that, } \\
\text { uniforms you can change. } \\
\text {-Somebody has to help make the general } \\
\text { population understand what LTC is, before } \\
\text { they're in crisis and have to access it. }\end{array}$ \\
\hline
\end{tabular}

Table 8 .

Provider Study Themes

the group was able to open the doors of Stonebridge on time, on budget, and fully staffed

are accomplishments that Robin is proud of, albeit still a little surprised about:

I can walk down that hall now and it's so calm, that's wonderful. I can't believe it happened, because it shouldn't have happened; we should still be in crisis; we should still be chasing our tails. It took a long time to recover from it. I'm still recovering from it. But we've come so far despite all of our challenges that I think we can go miles and miles and miles.

Five key themes have emerged from the provider's experiences at both

Ridgemont and Stonebridge relating to the implementation of the new model of care 
(Table 8). These themes include: (1) the interdisciplinary team; (2) a focus on goals; (3) leadership; (4) communication; and (5) education.

\section{The Interdisciplinary Team}

As an organization, the Welsh Group is comprised of a family of companies with building materials and construction businesses, as well as a nursing home administrative arm. The management team has diverse backgrounds, including the current C.O.O. and others with professional backgrounds in nursing and nursing home administration. The learning curve was therefore foreshortened for the team as they worked through the design/build process for Stonebridge into the day to day business of running of their LTC communities. Many of the other providers who submitted proposals for the RFPs hired consultants to do the work, and as Wyatt pointed out previously, "No consultant is going to understand the business like we do. Between Peggy, who has a really good grasp of the vision, and I, who has the vision and the building side, we nailed it."

The teams interdisciplinary nature and the past experiences at Ridgemont have led to a flexibility in their perspective, goals, and focus for the future. Robin's earlier comment speaks to the cohesiveness of the group, "We were all in agreement with each other; it started from the main points of the philosophy down to the color of the chairs, I'll probably never be able to develop something like that with such a cohesive group again."

\section{Focus on Goals}

For the Welsh Group, the design of the building and facilitation of the day to day operations at Stonebridge has united them in the focus of their future goals. Robin describes the organization's goals as she sees them: 
We know where we want to be. We have goals set, and the level of quality improvement gets to a higher and higher level. We'll be moving into more ethical discussions that most facilities wouldn't even be moving into. We are the champions for DoH because the few people who are there now who had probably worked with the people who had developed this model or understood it or embraced it or get it, that want it to work and want to see more funding go forward to making it work, are looking to us.

Robin explains that when DoH administrators come to visit, "They sort of do one of these (hand beside the mouth) 'We've got to get so and so in here, that person has got to see this.' They know it's the right thing to do, they see what's happening. The licensing people come in and say, "We hate going to other places, we love coming in here."' But Robin is aware that there are areas for improvement. Based on Sherbrooke Village as a precedent, she believes it will take eight to ten years of operating history for Stonebridge before they can truly look at their accomplishments and operational issues like staff turn-over over rates and fiscal outcomes. But for Robin, the comparison with Sherbrooke Village brings up their differences more than their similarities:

Sherbrooke had different challenges, they had staff who they knew already were good performers and had years of experience behind them, some of them 20 years, and all of them educated in the model before they opened. They had existing residents that already had care plans; staff had already been working there. They just opened the new part of the building and started working there. I'm not saying it wasn't a lot of work, but we started from absolutely not knowing who was coming through the front door. I've never experienced anything like that in my life.

The management team sees that the future road ahead will not be easy, and often has to remind themselves of their goals. But they are optimistic that they can meet their challenges, and are grateful that the organization is on the road to change. Francis describes her focus:

We did face a lot of challenges and we still face them every day, there are always challenges. But I love my job, I love this organization, I love the vision of where we are going. We still have a long way to go, but we are getting there. I have excellent staff, and I have excellent families that work with us. I do still struggle 
sometimes; I have to remind myself to always think about what is best for the resident. I always have to bring myself back to that. I can see how far we've come, but also see how far we have to go.

\section{Leadership}

Because of their history and the diverse make-up of their company, the management team shares an understanding that the accomplishments of their organization are not necessarily transferable to another organization. There are administrators from other communities calling on them to get tips on how to make organizational change work at their own LTC communities, but Francis feels that some of these organizations just don't have the leadership in place to see the change through:

It's funny, the other place that I worked, I learned a lot there and I have a lot of respect for the people who work there, because they work very, very hard. They will call me every once in a while and ask, "What do you think about this, do you think maybe this will work if we tried these little things?" I try to help them as much as I can, but I don't think they will ever get there. I think that leadership is a big part of it and you have to get the right personalities in here. You have to live it and be passionate about it.

Robin, Wyatt, Peggy, and Francis each have had a hand in the successes at Stonebridge, but as Wyatt explains, all also see how fleeting that success can be if the leadership were to change. "What I'm fearful of though, I think it's the sad truth. Unless you have people like Peggy, like myself, like Francis, if we all left here tomorrow and somebody else was leading the charge, guess what, the philosophy would be gone."

\section{Communication}

Other future challenges at Stonebridge include the mix of staff trained in two distinctly different care models. In addition, there are issues around communication in care planning between the CCAs and the RNs because there is not a central nurse's area. Agich (2003) writes that when communicative patterns are deformed or distorted, conflict sometimes results, 
however, with a new computer network for CCAs and RNs in place, Francis is confident that the problems will work themselves out:

We all have something to bring, everybody. It has been hard, because we have that mix of staff, older staff that have been in the traditional care model and some of the younger staff just coming out in the field, and it's a whole new world, bringing them together is a lot of work. I have staff that has been in the field for a long time and they will come to me about the new staff. They say, "They are so young, they don't know the ways that we do things." My immediate reaction to them is, "OK, you know what, you can learn by them because it is brand new. Let's open this up; you put yourself in their shoes." Care planning, we are suffering on that right now too. But once we get that tool in place, it will be easier for CCAs and RNs. The nurses need to be in communication with the staff in the cottages. We don't have that in place, so we are struggling.

\section{Education}

A current goal for the Welsh Group is to transform Ridgemont to an Edenized community in the next five years. The group knows that they have a long way to go, but with their leadership, Ridgemont could be the first existing LTC community in Nova Scotia to change both physically and organizationally to the new model of care.

The care staff at Ridgemont are not enthused about the concept of another transformation in their community. Many had been through the trauma of the transition when the ARC was closed down, and the others have heard about it. Even when prompted to, most of the staff have never visited Stonebridge, often questioning why they should. "They have a brand new building, we have a pot-holed driveway and no landscaping," was the response from Maureen when she was asked about Stonebridge, but the activity director, Sara, had visited residents that moved to Stonebridge when it first opened. She explains her impressions of the new community and the philosophy of care:

S: Yeah, oh yeah, it's beautiful down there. When we lost some of our residents to the place, I'd go visit. But really I don't think that the Eden philosophy could 
work here, like letting people get up when they want, I don't think so. But I do know that people at Ridgemont have choices of what activities they want to come to. When someone is in the parlor for an activity and very sleepy, I usually have a staff member take them back to their room.

The issues around acceptance of a new community versus the reality of an older renovated building within the same organization can create tensions, and the attention that has been directed at the newer community has added another layer of scar tissue at Ridgemont. The care staff there are concerned that the new model is going to have the same impact on community operations that the ARC closing had a decade ago. The current administrator, Anna, relays some the discussions she has been having with the Ridgemont staff since Stonebridge opened:

They say, "We've been forgotten about, they fire a new manager at us every few months. Stonebridge has all of these wonderful decorations and a brand new facility and equipment. We have a bumpy old driveway, the outside of our building needs attention, the work is 10 years old and it looks like crap." All I can say is "It's cosmetic, it's cosmetic." Finally, when everybody settles down, I say, "You know what, they don't have what you have." They are like, "What do we have?" Not seeing the values within the walls. I say, "You have a team here, you've been able to go on auto pilot. The management has trusted you to do these things. You are not going to find that in the new facility because it's so new. The workers haven't established that team and that rapport like you, so they don't function as well as you do." They say "OK, then." So it's the whole cosmetic thing; they were so caught up in that and feeling that they were being left out of the picture.

There will be a learning curve for the Ridgemont staff to accept another structural change in the way they give care. This is particularly true because of the strength of the union, the care staff have worked their way through the system based on their performance and the staff hierarchy. For the Welsh Group management to come in and tell them that the way they have given care all these years needs to change means that all these years they have been doing it 'wrong'. Robin sees that success will depend on the education of care staff about the model: 
I have many conversations with staff here at Stonebridge; many of them were trained at Ridgemont. I tell them, "Even though it's not the same philosophy, they (staff at Ridgemont) have the caring and human connection part. You can't teach compassion, they've got that; uniforms you can change." That's why I think we can have success out there; I think we can build on what's there. We have people who are knocking at our doors at Stonebridge, saying, "What are you doing over here?" But then, they are struggling with, "I can't make that work back at my place." That's where I think Ridgemont can come in, we know they aren't there yet, but then you think about how far behind they are to us here, still they are so much further ahead than the last facility that I was at for 23 years. The divide boggles the mind, doesn't it? This is really a new language, clearly articulated vision, and some new tools. Some of us are just beginning to understand the mission and vision for the first time.

The Welsh Group management also sees public education regarding LTC policy as an important step in ensuring that there is general understanding of the implications of a move prior to a LTC crisis. Education can help ease the anxiety and expectations for residents and their families when they are preparing to make a move. Robin wants the Welsh Group to have a hand in that education, based on their experiences at both Ridgemont and Stonebridge:

Somebody has to help make the general population understand what LTC is before they're in crisis and have to access it, and it needs to be us, we need to get it out there. It's a lot better dealing with an informed person when they move in. As an industry, we know better, we do, we all know better. I can't say that people who hit the ground running know better because we haven't necessarily educated them. But as an industry, we know better.

\section{Provincial Themes}

In the $2006 \mathrm{CCS}$, there had originally been a promise to build a new group of communities by 2012 and 2016, but there are now questions as to if this is the right direction. The Province is currently doing a formal assessment of what's working and what's not in the new communities. Table 9 outlines four themes related to system-wide change in the 


\begin{tabular}{|c|c|c|}
\hline THEME & DEFINITION & EXAMPLE \\
\hline Province & $\begin{array}{l}\text { Discussion relating to LTC program } \\
\text { legislation and funding through a } \\
\text { government entity }\end{array}$ & \\
\hline Vision & $\begin{array}{l}\text { Discussion relating to the core } \\
\text { program goals }\end{array}$ & $\begin{array}{l}\text {-To have every Nova Scotian live well in a place they can } \\
\text { call home. }\end{array}$ \\
\hline $\begin{array}{l}\text { Disparity in } \\
\text { Interpretation }\end{array}$ & $\begin{array}{l}\text { Discussion relating to the provider's } \\
\text { interpretation of the program } \\
\text { requirements }\end{array}$ & $\begin{array}{l}\text {-Nothing was put in writing more than the RFPs. } \\
\text {-The difficulty is that the owners were sure they could do it } \\
\text { and we cautioned them and they said, "Oh no, we're } \\
\text { confident, we have talked to our staff." }\end{array}$ \\
\hline $\begin{array}{l}\text { Regulatory } \\
\text { Consistency }\end{array}$ & $\begin{array}{l}\text { Discussion relating to consistency in } \\
\text { regulation of the program }\end{array}$ & $\begin{array}{l}\text {-But some people as they built, figured out a way that they } \\
\text { could build with } 15 \text {, sometimes } 16 \text { rooms, it's cheaper to } \\
\text { build. }\end{array}$ \\
\hline Commitment & $\begin{array}{l}\text { Discussion relating to the political } \\
\text { climate that enables program goals to } \\
\text { be met }\end{array}$ & $\begin{array}{l}\text {-This is just another example of government planning on } \\
\text { the fly. } \\
\text {-We were getting drift that the people in the DoH had } \\
\text { changed and the new people that we were dealing with had } \\
\text { all left or were reassigned and that was really worrisome. }\end{array}$ \\
\hline
\end{tabular}

Table 9.

Provincial Study Themes

Province which will be discussed in this section, and include : (1) vision; (2) disparity in interpretation; (3) regulatory consistency; and (4) commitment.

\section{Vision}

Through the work of the Provincial Steering Committee and DoH, the 2006 CCS was developed as a strategy aimed at creating a system that would support Nova Scotians in their desire to "live well in a place they can call home (CCS, 2006)." The 10-year plan was designed to enhance and expand Nova Scotia's continuing care system and to alleviate the back-ups in the acute care system. Through cross-regional analysis of other communities both in Canada and the United States, the DoH determined that small groups of residents in large facilities have a positive impact on resident care and family involvement (CCS, 2006). Documents which included the Long Term Care Program Requirements and Space and the Design Requirements 
were developed to provide direction in the new LTC facilities from the perspectives of care and service, as well as the physical environment (CCS, 2006).

\section{Disparity in Interpretation}

Despite the large volumes of descriptive materials with room sizes and space requirements associated with the CCS, there has been a disparity between the way that the Welsh Group and some of the other operators have interpreted the RFPs. Many of the new community administrators are not happy with the outcomes in the new model. Apparently, this is due to the fact that the other communities did not really follow many of the specific guidelines in the RFP, and the definition of care was interpreted very differently by the multiple providers. While there were very specific items in the document about the physical layout and organization for the new communities, there was also a lot of room for interpretation. The reason why some of the other communities don't see the model to be working is because, as Robin states, "It's not really the model."

The interpretation of the RFP was the key to the Stonebridge success; the Welsh Group had been adamant about all of the factors involved in the model philosophy from the beginning of the process based on their experiences visiting Sherbrooke Village and the group's understanding of the Eden philosophy. Wyatt describes the differences in some of the other communities:

Rather than negotiate, we led on this one. In our community, one staff member will come in the morning and do breakfast and then go do cleaning. And then another will come in at 11 and do lunch. What the other communities did was hire a CCA to come in and do the kitchen work all day, basically it's just dietary, it's the old way, it's not the philosophy. So they said, "Why are you paying a CCA to do this, it's cheaper to have a food service worker?" They are missing the whole philosophy. So these homes are called full scope, but they have interpreted it much differently and it's much more institutional. What they've done is to have 
two cottages with a shared kitchen with doors, an enclosed kitchen.

The disparity in interpretation is not only in the physical settings, but comes down to the language used for the care as well. Francis describes what she has been hearing from other providers:

Many of the big institutions say that they are resident-centered, but they aren't. Staff don't take ownership and residents are still "clients". They are all pushed into a common area after a meal, they are pulled out, and they are pushed into a dining area. Then when you talk to the management of these facilities, they are like, "Oh, we're resident centered." I can't help but wonder how much of the real part of their facility have they seen? Have they ever come out of their offices?

\section{Regulatory Consistency}

We know we can do this, because no one else is doing it and the ones who are saying they are doing it aren't, or they are partially doing it. (Robin- Director of Education at the Welsh Group)

The DoH administrator agrees that there are inconstancies in the interpretation of the

guidelines. She explains:

Some people, as they built, figured out a way that they could build with 15 and sometimes 16 rooms; it's cheaper to build. They put in the bids, we went in and sat down with them and said, "Here's your staffing ratio. So if you have 12 people or if you have 16, that's how many hours you get. We're not doing it the way we used to, that you need to prorate the staff hours for more residents." I think some of them didn't really get that, that they thought that, "If I had 50 hours for 12 beds, I would have 60 for 16 beds." Now some have 15 beds and only two people on, that's really just stretching, considering they are doing all of the roles. The difficulty is that the owners were sure that they could do it and we cautioned them, and they said, "Oh no, we're confident, we have talked to our staff." We had put in five hours extra per day for housekeeping and five hours extra a day for food prep. The rest of the time is supposed to be for personal care. But if you take out one of those people all day to work in the server, you see the problem.

Some of the issues at the other 10 communities come down to the economy of scale,

because several of them are either smaller or larger than Stonebridge. Four of those communities 
only have 36 beds, there are a few that have 50 beds, and the largest one has 71 beds. Wyatt

explains the concept of economies of scale in LTC:

The numbers just work better in the larger communities. At 36, I don't know if it was an off-the-cuff comment, but the owners have said to me "Do you want it?" Unless they really cut every corner possible, they will probably lose money on the smaller homes because of the economy of scale. So it is everything: staffing, food, ancillary services, and space. You still need the chapel, the hair care shop, the person at the front desk, but you only have 36 people paying into it.

Like Wyatt, the DoH administrator sees that the scale of each building is important and

feels that a 50 bed community has the best return and efficiency:

The one thing that I think we have found that really works well is that 50 beds is really as big as we should go. It's probably not as cost effective as a little bit bigger will be, but your footprint gets so big when you go beyond that. If you've been to the Halifax Nursing Home, that's a monstrosity, there's no reason for them to be that big. When you build a high-rise, it's just not a community anymore. It's not just the building, it's the programming; how does this building operate? I think we will stay with smaller households, absolutely.

\section{Commitment}

The DoH administrator discusses how the Province is in the process of making decisions

on how to move forward in their system of care, possibly putting funds back into homecare

because the LTC beds don't appear to be alleviating the back up in the system.

We need to look at all of those things before we move forward, because there was a promise in 2006 for a new group of beds by 2012 and another group by 2016, we're finding now that that may not necessarily the answer. So now we're focusing on home care so that we can bring you home to wait. People should not have to make the decision to go in to LTC in the hospital, we know exactly what happens, the doc or social worker says, "You need to go to a nursing home," and the family says, "Mom, the doctor says you need to go to a nursing home, you need to go." Everyone is worried.

Wyatt sees that the longer waiting lists are partially due to the "woodwork effect" that the policy makers in the United States were concerned about in 2005. This is when the operators 
were afraid to build well-designed communities under government guidelines, because people will come out of the woodwork to live in them. He also sees the high cost of building the new communities as the reason the Province may not move forward with more building at this time. He explains:

$\mathrm{DoH}$ found that the homes are so nice that the people wanted to go to them, so the wait lists grew and the big homes are so expensive now to build and operate, like $\$ 270$ per day, whatever our rate is. So now they are trying to look at other programs, even if they have to pay a family caregiver $\$ 20,000$ a year or whatever, at least it's better than putting someone in LTC. Now they are saying they want to keep people in their homes longer, but I thought the idea was to support family caregivers more. You need to stick with one vision and keep going with it, because they do one thing and then they switch back to the other.

The management at the Welsh Group is pragmatic about the chances of more provincial funding for new communities. The multiple RFPs and resulting funding structures have led to confusion in the public about what in actuality the new model represents. Robin sums up the issues:

We don't think that they are going to fund the next group of new beds with the new model of care because they see it as not working. They see it as not working, I would argue, because no one else is doing it. The other places you funded to do the new model of care aren't doing the new model of care. They are doing a traditional model of care with funding in a new facility. That's what they're doing, and it's not working for them because they don't have the philosophy.

Other Province-wide issues adding to the confusion are the differences between the new full-scope facilities that the 2007 RFP and other communities built in order to recapture replacement beds. These recaptured beds weren't under the same guidelines as the 2007 RFPs; they have had a whole different set of rules and funding. Robin explains the differences in the replacement facilities:

Then there were facilities that were replacement facilities, so if you had a 120 bed facility, like the Meadows, that building was so decrepit that they had to rebuild. Instead of building one new large facility for 120 people, they rebuilt two 60 bed 
facilities. They needed to meet building code and have private rooms, but it's still the old staffing model: long corridors, one large dining room. They might be calling them neighborhoods or households, but it's not under the same guise as our model at all.

Robin summarizes her view of the provincial outcomes for the Continuing Care Strategy:

Even in the replacement homes, the operators were looking at implementing the full philosophy and model; they were given the choice when they rebuilt to do the new model and somewhere in that process they came up with a hybrid and in the end they all ended up going with the traditional operational model. So now there are older facilities that are existing under a traditional model of care. There are several new facilities with the traditional model of care, but with new buildings, a newer look and the newer building code. And then there are 11 facilities in the province that are funded for the new model of care, but the majority of them seem to be not really be working within the philosophy of care originally planned for by the CCS.

\section{The Dynamics of the Environment in LTC}

The objective of small group living is to break down both the physical and social environments into units where residents may achieve a greater degree of autonomy and control over their day (Willcocks, Peace, \& Kellaher, 1987), and with the SH model of care comes a whole new set of issues and themes into the already complex world of LTC. The model creates a new set of distinctions between public and private domains and the transitions and divisions between these domains. The outcomes in the communities built through the 2007 RFP are an important factor in this case study research, however another key goal in this study has been to present the distinctions between the environments at Ridgemont and Stonebridge, with particular attention paid to the impact of the environment changes on resident social interaction.

When the Ridgemont renovations took place almost a decade before Stonebridge was built, there were already hints of what was to come architecturally because of the consistency 
of Wyatt's vision for Welsh Group and their long term goals in LTC. The community spaces in both settings are open and flexible, and there are high ceilings and plenty of windows for natural light. The interior architecture in both buildings is simple and easy to interpret, there are no maze-like or football length corridors. The décor in both buildings is minimalistic, but comfortable.

The principle differences between Ridgemont and Stonebridge appear to be what area constitutes the building 'center' in each setting and relate directly to degrees of privacy or access which are available to residents. Ridgemont has been designed with three neighborhoods and Stonebridge with four cottages and both have a central activity area. At Ridgemont, the focal point for all of the staff and residents is the nurses' area, which is adjacent to the parlor and the building entrance. At Stonebridge, there is a shared community room, but the center of activity is in each of the cottage kitchens, because this is the gathering place for the individual cottage staff and residents throughout the day.

The following paragraphs will discuss some of the positive and negative correlations in the two study settings which impact behavior and outcomes for the staff, residents, and family members (Table 10). This framework includes themes related to (1) the neighborhood vs. the cottage; (2) the central parlor vs. the community room; (3) integration of the nurses' station; (4) the open kitchen; and (5) private vs. semi-private resident rooms.

\section{The Neighborhood vs. the Cottage}

When the Province funded the nursing home renovation at Ridgemont in 1998, the division of the spaces into neighborhoods with decentralized dining areas was considered cutting edge. Since that time, the neighborhoods have afforded larger residents rooms and decentralized 


\begin{tabular}{|c|c|c|}
\hline THEME & DEFINITION & EXAMPLE \\
\hline $\begin{array}{l}\text { The Physical } \\
\text { Environment }\end{array}$ & $\begin{array}{l}\text { Discussion of the impact of } \\
\text { the physical environment } \\
\text { on outcomes in LTC. }\end{array}$ & \\
\hline $\begin{array}{c}\text { The Neighborhood } \\
\text { vs. the Cottage }\end{array}$ & $\begin{array}{l}\text { Discussion relating to the } \\
\text { location of the central area } \\
\text { for interaction in the LTC } \\
\text { community }\end{array}$ & $\begin{array}{l}\text {-We were looking at a central administrative core with pods } \\
\text { coming off of it, that' what you want. } \\
\text {-I find it so hard going door to door saying "Do you want to come } \\
\text { down for this?" } \\
\text {-I tend to be a pretty interactive person, that's why I think I really } \\
\text { like Ridgemont; it has this atmosphere about it. }\end{array}$ \\
\hline $\begin{array}{l}\text { The Central Parlor } \\
\text { vs. the Community } \\
\text { Room }\end{array}$ & $\begin{array}{l}\text { Discussion relating to the } \\
\text { primary area for activity } \\
\text { and socialization in the } \\
\text { LTC community }\end{array}$ & $\begin{array}{l}\text {-Downstairs is another world for them, it's like their city, with } \\
\text { little shops and stuff. They do think it's a whole different place. } \\
\text {-Those residents who live upstairs in one of the rooms at the back } \\
\text { of the cottage have a long way to go just to get out the front door } \\
\text { of the cottage, much less down to the community room. }\end{array}$ \\
\hline $\begin{array}{l}\text { Integration of the } \\
\text { Nurse's Area }\end{array}$ & $\begin{array}{l}\text { Discussion relating to the } \\
\text { relationship of the central } \\
\text { nurses' area in the LTC } \\
\text { community }\end{array}$ & $\begin{array}{l}\text { - At Ridgemont, we don't want to have dividers, we want to all } \\
\text { work together here. } \\
\text {-In the cottages, it was important to make sure that these places } \\
\text { were easily monitored. }\end{array}$ \\
\hline $\begin{array}{c}\text { The Open Kitchen } \\
\text { Re-visited }\end{array}$ & $\begin{array}{l}\text { Discussion relating to the } \\
\text { physical and social } \\
\text { elements of the dining } \\
\text { experience }\end{array}$ & $\begin{array}{l}\text {-We have to keep the new kitchens open, this is going to happen. } \\
\text {-What they've done is have two cottages with a shared kitchen } \\
\text { with doors, an enclosed kitchen. They are missing the whole } \\
\text { philosophy. }\end{array}$ \\
\hline $\begin{array}{l}\text { Private vs. Semi- } \\
\text { private Resident } \\
\text { Rooms }\end{array}$ & $\begin{array}{l}\text { Discussion relating to the } \\
\text { provision of private vs. } \\
\text { semi-private resident } \\
\text { rooms }\end{array}$ & $\begin{array}{l}\text {-My roommate...he talks a lot, he's upset. He keeps the TV on } \\
\text { really loud...it's hard for me to sleep when he's like that. } \\
\text {-I've always had my own room, but I think it would be alright if } \\
\text { you like the person you're in with. Some people are hard to get } \\
\text { along with, I wouldn't like that. }\end{array}$ \\
\hline
\end{tabular}

Table 10.

Physical Environment Study Themes

dining areas, but there are still corridors linking the resident rooms, the community spaces, and dining areas, and the only neighborhood with a front door is the locked Hummingbird door. The first thing that most residents see when they walk out of their room in the morning is a public corridor, not a kitchen or a living room, as is the case for Stonebridge residents.

Within the Ridgemont neighborhood design, most residents have a choice of either spending time in their private or semi-private room, or in the public parlor (Figure 102). There 
are separate smaller neighborhood lounges which are located at the end of each neighborhood corridor, but because of their locations, apart from a gentleman who occasionally watches game shows in the Hummingbird lounge, or Cora, who comes down to watch the fish in the fish tank, the spaces are relatively unused. Outside of their bedrooms, semi-private environmental opportunities for residents at Ridgemont are not available. A large part of this distinction is the absence of a "front door" to the neighborhoods which acts as a buffer to public activity and noise.

At Stonebridge, the cottages are truly self-contained residences, each with its own front door, and within the cottages, there are multiple levels of privacy or interaction available (Figure 103). Residents can move from the privacy of their own bedroom to the semi-private settings in the living and dining areas that are shared with cottage mates. They also have access to public areas in the main street and the Community Room at the entrance to the facility. However, this flexibility of privacy or interaction within the model has its costs. Staff shortages may be amplified by the multiple cottages, and residents may be less inclined to take part in community wide activities because they have the opportunity for activities on a smaller, more intimate scale in their cottage.

Another spatial consideration is that prior to the nursing home renovation at Ridgemont, there were resident rooms on both the lower and upper levels of the building. As a result of the renovation, all resident rooms are on one level, reducing anxiety and travel distances to group activities. Stonebridge has resident rooms on two levels, and a question remains as to the impact this has on resident attendance and participation in activities in the community room. While the 


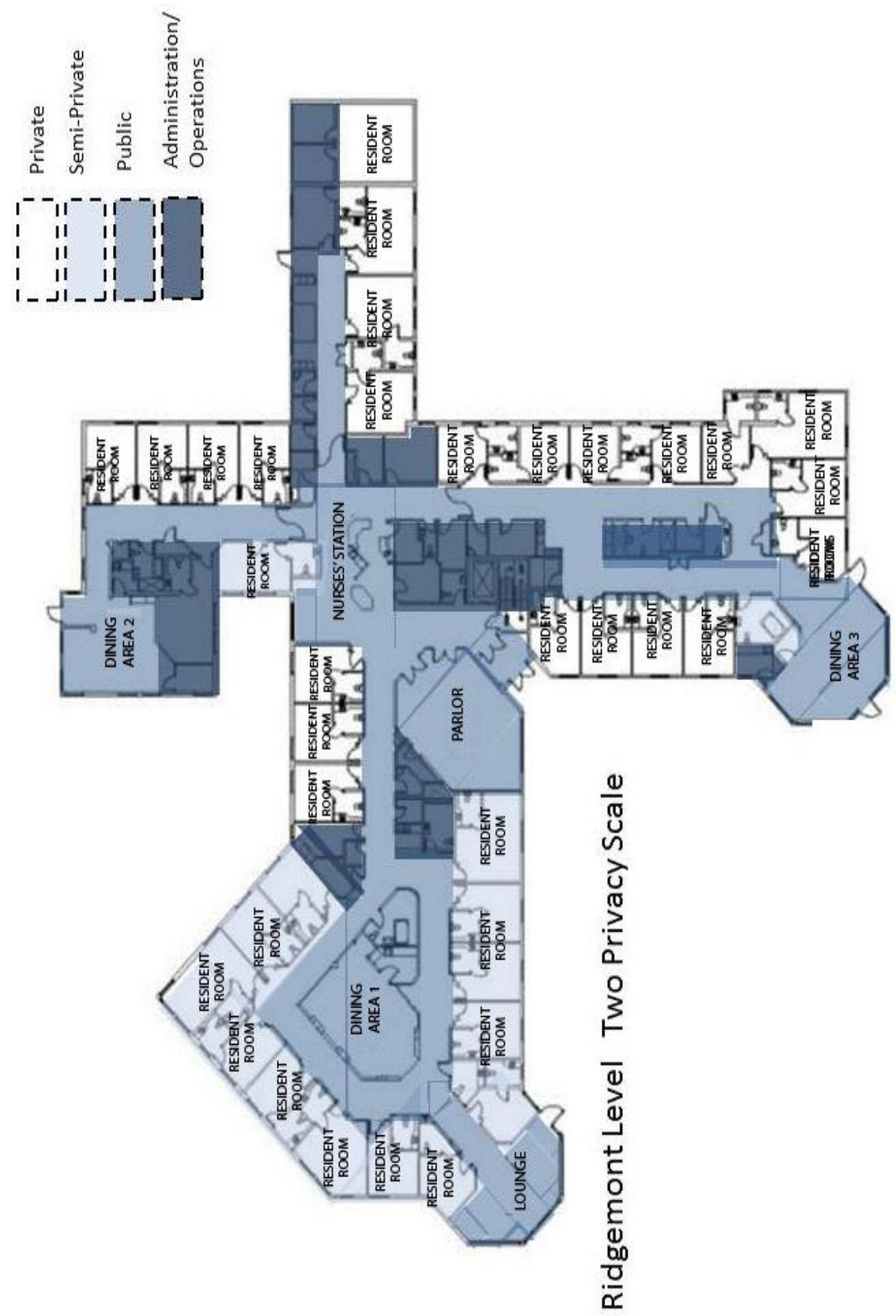

Figure 102.

Ridgemont Privacy Scale 


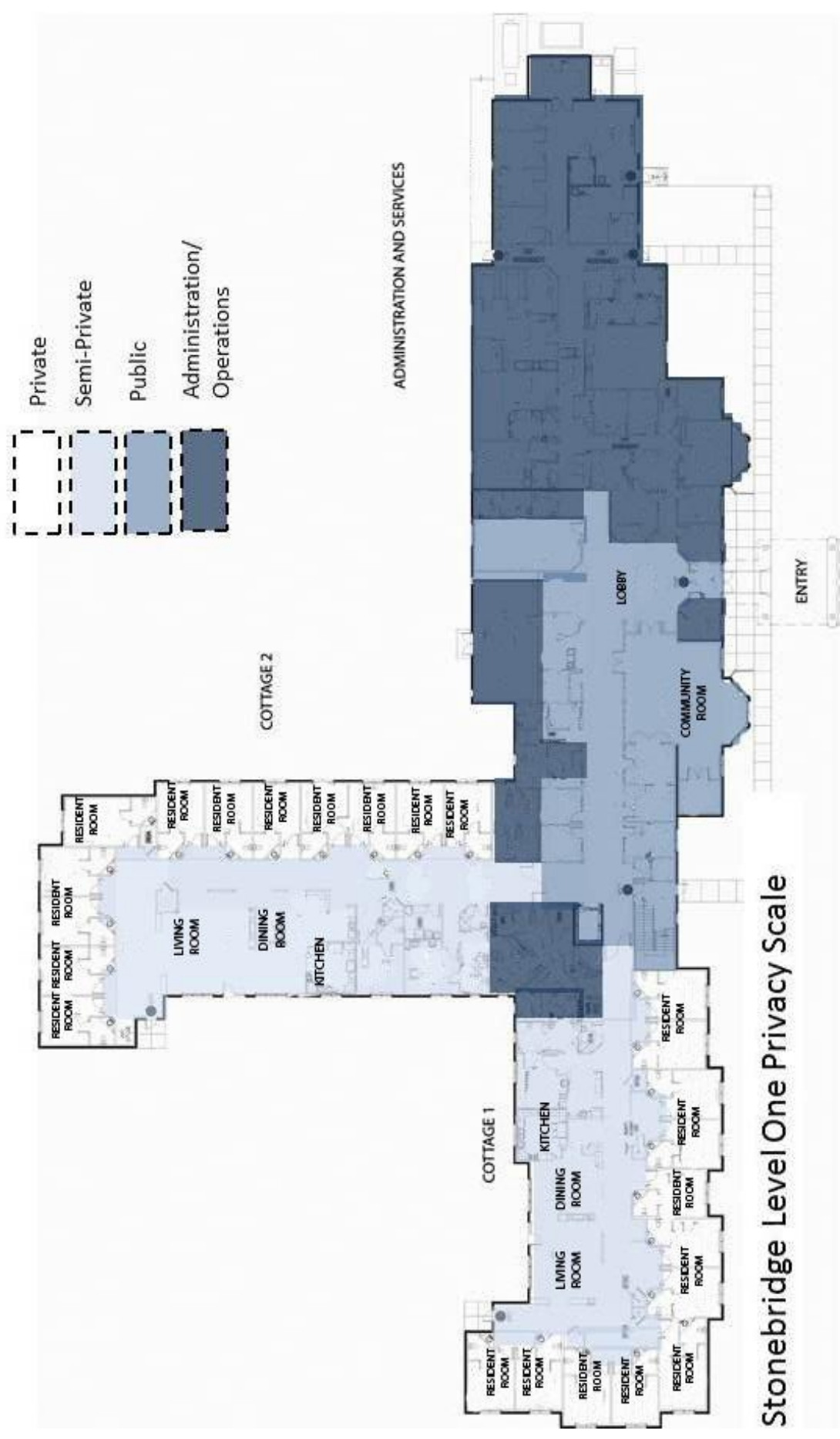

Figure 103.

Stonebridge Privacy Scale 
architect's goal in the design of a two-story building was to reduce the size of the building footprint, there may have been ways to situate the community room so that there are a series of transitional spaces for rest and seating along the way. The only seating in the main street is directly across from the doorway into the community room.

An additional element of the Stonebridge built environment is that while the four cottages are almost identical, each has a distinct sense of place due to the consistency of the interactions and personalities of those who live and work there. The care staff are empowered to take full ownership of their individual cottages as their workplace because their focus is on the entire daytime or nighttime experience for a small group of residents. While the issue of staff workloads has been noted previously, the CCAs genuinely see the household chores as a part of their caregiving role and feel that they are participating in the creation of a positive living environment for the residents.

The Ridgemont neighborhoods do not share in that sense of place, primarily because the staff cycle through each neighborhood on a monthly basis, leaving no sense of ownership by staff members. Instead, the focus is on specific jobs or tasks, and this speaks to the differentiation between goals in the two settings: in the SH model, family-like relationships within the care setting are the goal, and in the traditional model of care, the actual outcomes for each job description become the daily goal (i.e., This person is bathed now, I have done my job, or That person has had their meal, I have done my job).

\section{The Central Parlor vs. the Community Room}

Both of the study settings have similarly sized community rooms close to the building entrances, each with a baby grand piano. But again, the similarities end there because of the 


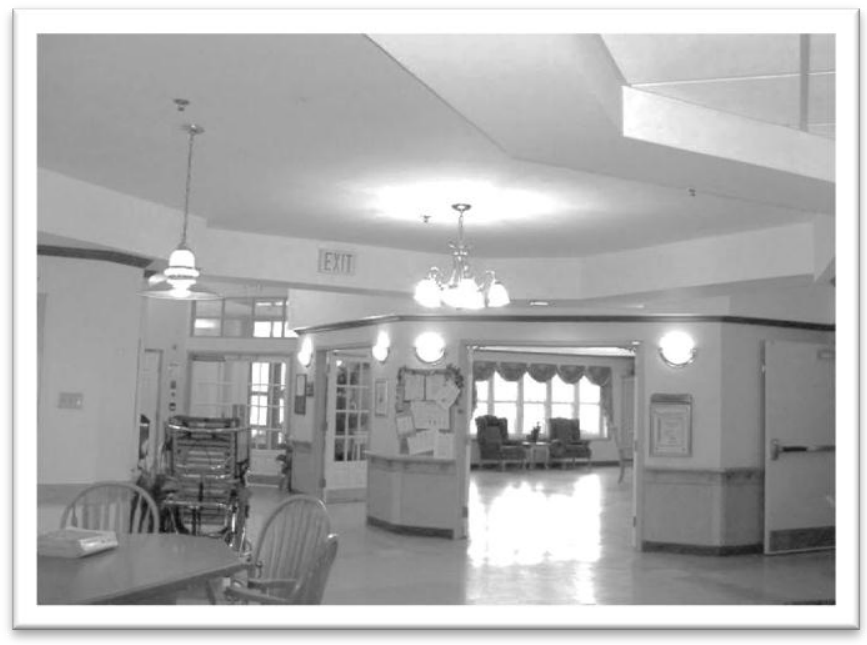

Figure 104. View from Nurses' Area to Parlor

contrast between the way that the spaces are used by the staff and residents. At Ridgemont, residents are brought to the parlor for daily activities by the activity director, and once Bingo or a sing-along are over, residents remain there, maybe moving into the nurses' area where they discuss the activity they just participated in with the care staff who are doing their charting. The flow between the parlor and the nurses' area works well and there is often background music and multiple conversations going on between staff, residents, and family members (Figure 104).

At Stonebridge, as Beth previously pointed out, when an activity in the community room is over, residents do not linger. This is because other than the piano and a bookcase in the far corner, there is nothing to do. Once the table and chairs from an event are taken down, the only comfortable seating is one couch and a two chairs at the back of the room. There are no phones ringing, music, or conversations between the caregiver, because the caregivers are working in the cottages. Residents have no reason to stay.

Integration of the Nurses' Area

At the time of the Ridgmont renovation, the design goal for the nurses' area was for there 
to be no physical division between the nursing staff and the residents. This goal appears to have been achieved; this area is the social and work center of the community, and residents often are seated around the periphery of the room where they can watch the care staff as they work or see what's going on in the entire front of the building without having to participate. However, while the nurses' area is a center for socialization, because of the central location, there are constant distractions and the noise levels are very high, making it hard for care staff, residents or family members to have a private conversation. There are two administrative offices and a small conference room on an adjacent corridor, but they are too small to accommodate a family meeting or someone in a wheel chair.

In contrast, at Stonebridge there is no central nurses' area. Each cottage has a charting area and drug storage cabinetry integrated in the open kitchen/dining room. This absence of a central nurses' station apparently has caused a breakdown in communication between the RNs, CCAs, and management, and, as discussed previously, there are issues with privacy for the care staff when they are doing paperwork or having conferences in the kitchen area. There is a general consensus though, that the cottage feels less institutional without medical carts or a centrally located nurses' area and that computer connectivity will alleviate many of the communication problems.

\section{The Open Kitchen (Re-visited)}

When addressing mealtime activities in LTC, the overreaching goal has been described as the preservation of independence, social interaction, and dignity in order to give meaning to meals and to ensure adequate intake for quality of life (Amella, Grant \& Mulloy, 2008). Intimate, non-institutional dining in which residents dine in small settings has been shown to increase 


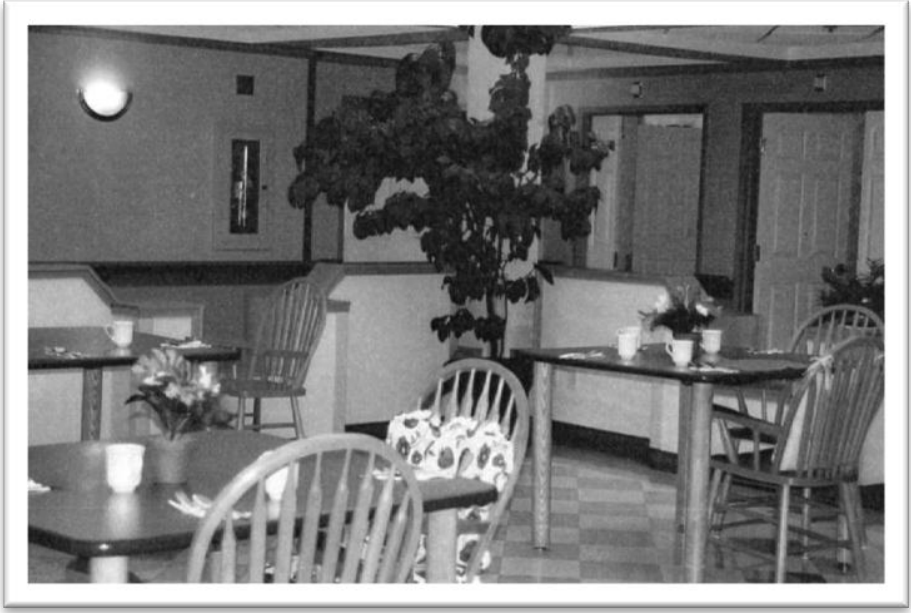

Figure 105. Hummingbird -Dining Area \#1
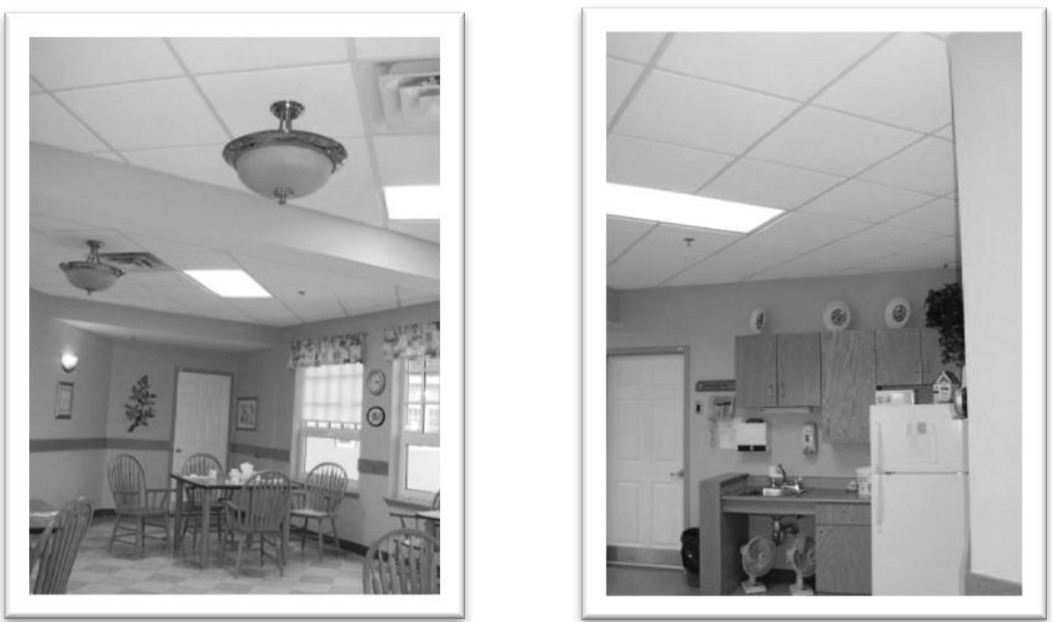

Figure 106. Cardinal-Dining Area \#2

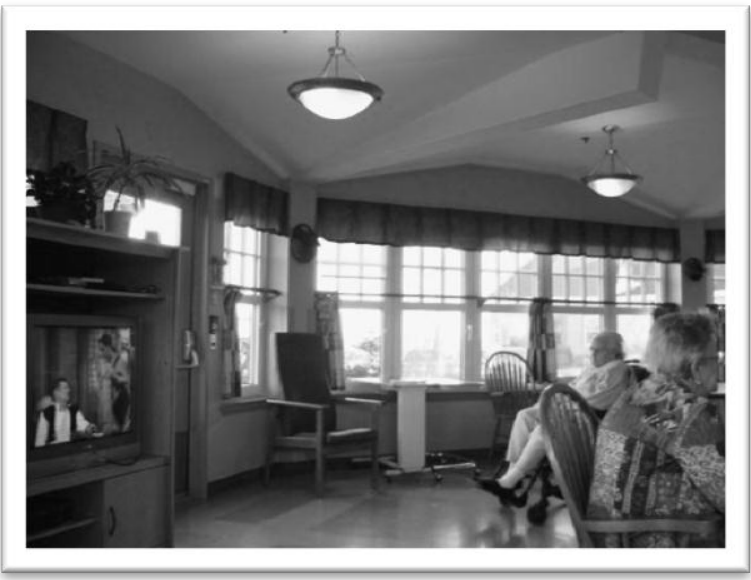

Figure 107. Bluebird-Dining Area \#3 


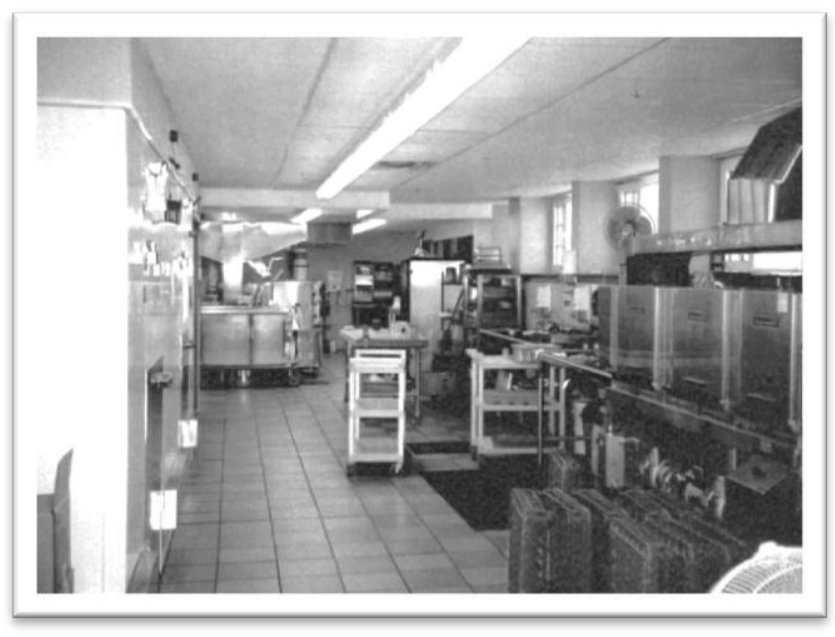

Figure 108. Ridgemont Lower Level Kitchen

intake and improve communication at meals, especially among residents with dementia. There are three small dining areas at Ridgemont as a result of the 1998 renovation (Figures 105-107). Mealtimes however, are still very regimented and revolve around the timing of the specified meal cart stops at each of these areas, And there is a disconnect in the mealtime experience for residents because of the locations and configurations.

The Hummingbird dining area is the largest in the community, and while it is central to the residents' rooms in that neighborhood, it is completely open to the corridors with no barriers for intimate conversations or noise control. There are no windows and there is a very loud air handling system directly above the space which comes on frequently, often running when residents are having their meals. The Bluebird and Cardinal dining areas are located at the end of the neighborhood corridors, which give them a more noise control, but there is very little connection with the community. There is absolutely no connection to the community kitchen in any of the dining areas; food is prepared in the lower level of the building, brought up on the food cart, and served from trays (Figure 108).

Due to the location and configuration of the dining areas, residents lose the benefit of the 


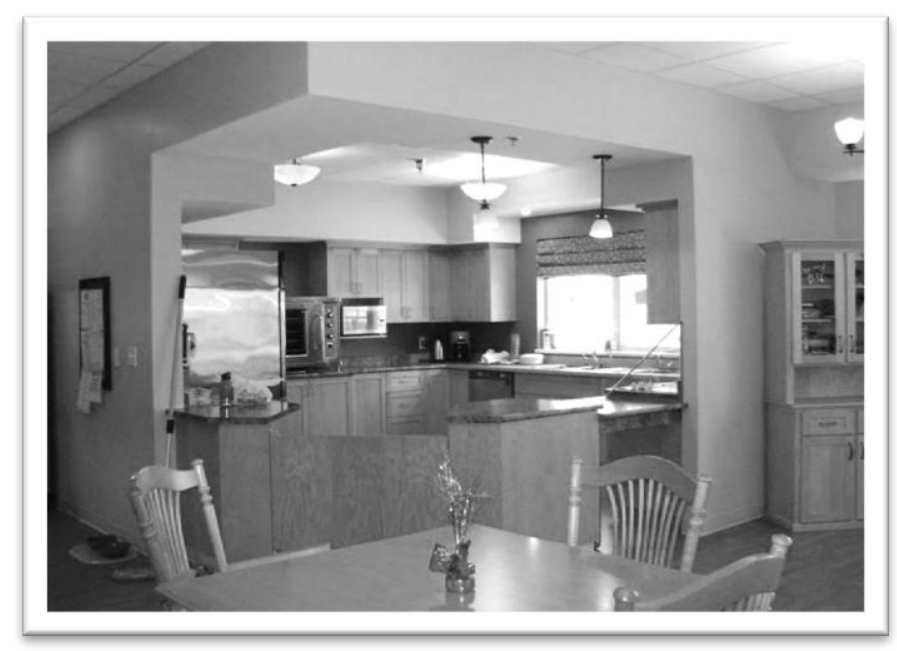

Figure 109. Stonebridge Cottage Kitchen

sights and smells of the meal preparation, as well as the spontaneity of a meal or snack cooked to order. At mealtimes, they wait quietly to be served, and conversation is minimal. Once residents have eaten, they leave, the staff clean up, and the dining area is empty again until the next scheduled meal. In the Bluebird neighborhood dining area, some of the less mobile residents will stay and watch TV there through the afternoon, but in the two other neighborhoods, other than a few lingering conversations after a meal, no one was observed spending time in the dining areas between meals.

In contrast, for the residents in the Stonebridge cottages, the kitchen is the first room that they see when they come out of their rooms in the morning, and there are smells and sounds of food preparation throughout the day (Figure 109). The open kitchen is a gathering place, whether for staff conversations, resident/family member conferences, or joke-telling over coffee. The specific meals themselves can last for over an hour, especially at breakfast. As stated in the care staff interviews, this is the way that CCAs think it should be, they would much rather let the individuals have choice in when and what to eat than have mealtimes be regimented. This does 
create more kitchen work, but the Stonebridge CCAs feel that the choice is the individual resident's right and prerogative.

Another important operational element to the cottage kitchen is the flexibility in the menus, residents choose between two or three menu items for each meal, and there is always the option of a sandwich or left-overs from another meal. When Penny didn't want the apple cake that had been made for dessert one afternoon, she was able instead to have a piece of gingerbread that was from dinner the night before. This kind of flexibility in the menu would be impossible at Ridgemont because there is no relationship between the main kitchen and the dining areas, and once the meal has been served, the serving staff have moved on to another neighborhood.

Finally, in the cottage layout at Stonebridge, the living room is directly connected to the kitchen, making an easy transition to and from the couch and the TV before and after meals. This allows staff, residents, and family members to gather for meals as they would in a residence; this element of the setting is completely missing from Ridgemont because the lounges and parlor are separated from the dining areas by corridors.

Private vs. Semi-private Resident Rooms

Willcocks, Peace \& Kellaher (1987) write that the provision of personal territory offers the possibility of preserving an individual and private life style. One measure of privacy in LTC can be gauged by the amount of space that is designed specifically for the residents' belongings and where they would have primary control allowing for noise reduction, privacy, and less crowding (Kaup, 2007). The discussion of privacy is made more complex by varying needs of participants for help to compensate for physical or intellectual impairment, and some elements of privacy go beyond attributes of the physical setting and depend more on how staff members 
behave in respecting individual's privacy (Kane \& Cutler, 2009). Defense responses may

sometimes occur when territorial boundaries are violated and when an individual is frail or ill, physical defenses are already stretched to capacity.

While observations in this study took place only in semi-private and public areas, many residents did share strong feelings about the privacy afforded in private vs. semi-private rooms. Roommate relationships may be associated with friendship and watchfulness for the well-being of the other resident (Molony, 2011), yet at Ridgemont about a third of the resident rooms are shared, and residents were clear that they prefer having their own rooms. This is a non-issue at Stonebridge because all residents have the privacy of their own room, leaving one less issue to add to an individual's daily stress. However, due to their freedom of environmental choices, Stonebridge residents are spending more time in their rooms, and the socialization patterns in the community have changed, leaving some to wonder if this is a positive or negative outcome of the model.

As a result of the multiple differences in philosophy and organizational structure of Ridgemont and Stonebridge, there would be an expectation that the themes of the resident and family member interviews in the two communities would differ substantially. However, as we have read in the Chapter 8 interviews, the issues for the residents and family members in the two communities were strikingly similar in their tone and subject matter. The concluding sections of this chapter will discuss some of the reasons why.

\section{The Dynamics of Life Transition in LTC}

The multiple perspectives from study participants thus far have spoken to the array of challenges in defining, legislating, and implementing a new model of LTC care in Nova Scotia. 
The Province has spent an enormous amount of money financing the construction of 11 new LTC communities and are rightfully concerned about the outcomes, both in terms of staff and resident satisfaction, and monetarily, in terms of cost to the Province to run the new communities. The management at the Welsh Group has specific outcomes that they are working toward for their company, and their primary focus is to stay on track with their goals of educating both their staff and the general community about the principles of the SH philosophy of care.

With respect to the study family and resident interviews, there was little mention of room layout, staffing levels, management communication, or the use of staff uniforms. What family members did want to talk about is how their relative has gotten to the point where they have needed to move into LTC and the oftentimes confusing and frustrating road to that move. For residents, their concerns run much deeper; these are stories of memories and regrets, about coming to terms with not only where they are, but more importantly, where they aren't, both

physically and emotionally. The qualitative interview is noteworthy in its role as an entry point to the subjectivity of individuals (Rubenstein, 2002), and the interviews in this case study research become a very powerful tool in working toward clarification in the phenomenon of aging and transitions in LTC.

\section{The Process of Change for Family Members}

The study themes for the family members were directly related to the circumstances surrounding the placement of a spouse or parent into LTC (Table 11). The interviews for the most part, took place with the family members of residents with some level of cognitive 


\begin{tabular}{|c|c|c|}
\hline THEME & DEFINITION & EXAMPLE \\
\hline Family Member & $\begin{array}{l}\text { Discussion relating to the } \\
\text { burden and transitions for } \\
\text { family members when a } \\
\text { resident is moved to LTC }\end{array}$ & \\
\hline Caregiver Burden & $\begin{array}{l}\text { Discussion relating to the } \\
\text { burden of caring for a } \\
\text { loved one at home }\end{array}$ & $\begin{array}{l}\text {-And again, you're up all night, you have to work all day, and then } \\
\text { you're up all night again; it's too much after a while. }\end{array}$ \\
\hline Transitions & $\begin{array}{l}\text { Discussion relating to the } \\
\text { circumstances surrounding } \\
\text { the move of a family } \\
\text { member to LTC }\end{array}$ & $\begin{array}{l}\text {-He got out of their house and somebody found him at } 5: 30 \text { in the } \\
\text { morning at the side of the road, he had frost bite on his feet. They } \\
\text { took him to the hospital, adult protection stepped in and two days } \\
\text { later he was here. } \\
\text {-One day my brother came home and Dad had built a fire in the } \\
\text { middle of the living room because he said he was cold. } \\
\text { Pretty soon after that he had to go to the hospital with pneumonia, } \\
\text { that's when we sort of realized that he was not really able to } \\
\text { handle the transition. }\end{array}$ \\
\hline Anger and Guilt & $\begin{array}{l}\text { Discussion relating to the } \\
\text { emotions relating to the } \\
\text { decision to move a loved } \\
\text { one into LTC }\end{array}$ & $\begin{array}{l}\text {-I am still angry that this is happening and the lack of control. I } \\
\text { feel guilty sometimes that I have done something wrong. }\end{array}$ \\
\hline Letting Go & $\begin{array}{l}\text { Discussion of the family } \\
\text { member's need or ability } \\
\text { to move on with life with a } \\
\text { family member in LTC }\end{array}$ & $\begin{array}{l}\text {-I'll get a phone call, which bothered me at first, but now I just } \\
\text { listen and let him rant. } \\
\text {-For the betterment of everybody, he is here. }\end{array}$ \\
\hline
\end{tabular}

impairment and the interview themes describe the resulting family emotional highs and lows

which include : (1) caregiver burden; (2) transitions; (3) anger and guilt; and (4) letting go.

\section{Caregiver Burden}

The caregiver burden experienced and expressed by the family members is often made

more distinct by the cognitive issues of the family member needing care. The majority of the family member interviews in this study related to an individual who had been placed into LTC

due to issues related to dementia. The impact of dementia on the family member in its advanced stages resembles having lost a spouse or parent, making the adjustment to the caregiving role particularly hard (Connidis,2010). 
Rose \& Bruce (1995) describe the emotions that go into caring for family members with dementia as a large part of the invisible work carried out by the care giver and their quality of life. George's son, John, previously described the ups and downs in caring for his father at home, "He was having a really hard time and would have hallucinations at night time, night terrors. You're up all night, you have to work all day, and then you're up all night again, it's too much after a while." For Tina and her brother, fear for the safety of their father Frank at home led them to call adult family services, "In August, we started unplugging the stove and putting things up, it's like he had an inexhaustible supply of things he could hurt himself or other people with." After multiple trips to the hospital, Vincent's wife and son had come to the mutual understanding that he needed to be in a LTC setting, and Elizabeth remembers that, "From September when I brought him home from the hospital down home, from September to December, it was $24 / 7$ care. I was just so exhausted."

\section{Transitions}

The transition period from home or hospital to LTC can be a stressful, trying time, and the dynamics of the move can take its toll on both the care recipient and their family members, because as we have seen, a medical emergency often puts the family in shock mode rather than a planning mode. Residents may wait indefinitely in transitional care, sometimes at the end of that wait to be sent to the wrong community altogether. By the time the permanent move is scheduled to take place, the family members are so exhausted from the inertia of the process that they do not have the emotional resources to have their family member go through another move to get in to a newer or closer facility. 
Once the transition is made, families need a place to be a family. Joan's experiences the first few weeks that Tom moved to Ridgemont were telling; there was no place to sit as a family for important discussions other than a shared bedroom or the noisy parlor. This breakdown in the ability to communicate as a family at such a crucial point in the LTC transition speaks to the importance of providing opportunities for family members who have given up their duties as caregiver, a place where they can return to just being husband, mother, wife, son, or daughter; where they can sit and drink coffee at the kitchen table or watch a movie, or simply sit with the person they love while they are sleeping. These issues appear to have been worked through to some degree at Stonebridge. There is a sense of calm in the cottages that enable residents and their family members to have a discussion in the privacy of the resident's room or around the kitchen table without the unwanted interruption of TVs or roommates or call bells.

\section{Anger and Guilt}

We have heard from the family members that the trauma of going through the process of relocating a family member to LTC can be matched by the burden of a caregiver who is caring for that person at home. There is relief in being able to put the care of a loved one into the trusted hands of someone else and being able to move on with one's life. There is relief, but anger and guilt as well, and all three of these emotions were sensed from the family members in the two communities because the burden of caring for the relative at home is then replaced with guilt at placing that spouse or parent in a care community.

Joan described her guilt with respect to the process of moving her husband Tom into LTC. "I am still angry that this is happening and the lack of control. I feel guilty sometimes that I have done something wrong, especially when he calls me 10-12 times a day." Joan understands 
that it is her role as a family member to just listen because care staff are too busy for resident anger or tears. Similarly, Gill receives the brunt of Terry's anger, and while he has come to accept it as part of his role as her husband, it is still difficult, "The other day I came in and she starts giving me hell and I didn't know what it was for, something that happened about 30 years ago. She just sits there all day and thinks of stuff, she has nothing else to do."

\section{Letting Go}

Despite their grumbling about the cost and the process, the families in this study are grateful that the province is creating opportunities for care and are funding well-designed LTC communities. These are not happy stories, but the family interviews demonstrate the ability to let go a little bit. Joan will continue to visit Tom, at the same time moving on with her life as a mother and grandmother while her husband of 50+ years continues his slide into the depths of a place where she can no longer reach him. Garney will keep the home that he and his wife Rose shared for almost five decades, while at the same time spending every day with her at Ridgemont. For Vincent's wife, children, and grandchildren who drive an hour each way to visit him, the peace of mind in knowing that he is being well-cared for in a safe environment affords them a sense of closure in knowing that they will not need to move him again.

\section{The Process of Change for Residents}

The resident interviews in this study tell us more about each individual through stories from their past rather than present experiences. This was an unexpected outcome in this study, as the goal of the interview process had originally been to gain a firsthand account of resident life in LTC. However, as Ravdal (2002) explains, through life stories there is an attempt to capture and convey time and the timelessness of the human experience. The importance of life 
stories is two-fold: the act of telling is an experience with a function; and as Kenyon, Ruth, \& Mader (1999) write, there is an inseparability of the Self and the story because human beings not only have a life story, they are the story. The story derives its significance from two sources, both as a symbol of the self and as an external projection for other people to encounter (Rubenstein, 2002). Table 12 outlines the emergent themes from the resident interviews which include: (1) the need for care; (2) individual history; (3) adaptation in LTC; (4) strength and vulnerability; and (5) autonomy and choice.

\section{Need For Care}

The individual resident stories in this study run deep and are stories of loss: lost homes, lost loved ones, and most strikingly, lost capabilities. Physical manifestations of illness, such as mobility limitations and diminished capacity for self-care, may change environmental meanings (Golant, 2003), and the physical reason for leaving a home to move to LTC may be the result of personal declining health, but also of the increasing frailty or ill-health of a family care caregiver (Wilcocks, Peace, \& Kellaher, 1987). These individual stories relate to the wife whose husband has died, the husband whose wife is in the hospital but he can't remember her, the man who never had a wife or children, and the man who is angry at his children for removing him from his home and putting him in a place that bears no resemblance to who he is or what he is about. Then there is the man who started a fire in the middle of his living room because he got cold; now that man sits in a chair in small nurses' station and does nothing, for hours on end.

Each of the interviewees spoke the physical issues which they were living with and of the decision to move, usually due to the concern of their attending physician that they would be unable to care for themselves at home. Others spoke of invitations to live with their children, but 


\begin{tabular}{|c|c|c|}
\hline THEME & DEFINITION & EXAMPLE \\
\hline Resident & $\begin{array}{l}\text { Discussion of the physical } \\
\text { and emotional changes } \\
\text { that occur in a resident's } \\
\text { journey to LTC }\end{array}$ & \\
\hline Need for Care & $\begin{array}{l}\text { Discussion relating to the } \\
\text { residents need to move to } \\
\text { LTC }\end{array}$ & $\begin{array}{l}\text {-I was put here by the mostly by the doctors and the hospital. They } \\
\text { said I could not stay alone. } \\
\text {-I fell and was in the hospital for } 6 \text { months; my daughter has a } \\
\text { silver plate in her back, she couldn't lift me. } \\
\text {-I had cancer, Lymphoma, and three rounds of chemo. }\end{array}$ \\
\hline Individual History & $\begin{array}{l}\text { Discussion relating to the } \\
\text { individuals life story and } \\
\text { personal preferences }\end{array}$ & $\begin{array}{l}\text {-If someone would come and get me and take me out for a couple } \\
\text { hours, to let me get some air, to see the things that I haven't seen } \\
\text { for a long, long time. Like even going over the bridge, you know? } \\
\text { And of course stop into the tavern and have a couple of beers, that } \\
\text { would be beautiful. Honest to God, I would appreciate that so } \\
\text { much, that's who I am. }\end{array}$ \\
\hline Adaptation in LTC & $\begin{array}{l}\text { Discussion relating to the } \\
\text { circumstances behind the } \\
\text { resident's move and } \\
\text { adjustment to LTC }\end{array}$ & $\begin{array}{l}\text {-I was shanghaied. } \\
\text {-You're living here; you've got a long way to being perfect. } \\
\text {-I love this place; I had to wait for a room, you know. }\end{array}$ \\
\hline $\begin{array}{l}\text { Strength and } \\
\text { Vulnerability }\end{array}$ & $\begin{array}{l}\text { Discussion relating to the } \\
\text { personal experiences } \\
\text { impacting individual } \\
\text { coping abilities }\end{array}$ & $\begin{array}{l}\text {-I don't know where I am getting the power to do this. I never in } \\
\text { my life had three things, three smacks in the mouth at one time. } \\
\text { - I told him, 'I'll fix you, one of these days, I'll move somewhere } \\
\text { you can't find me". I don't think he's found me yet. } \\
\text {-The nights were the worst; there isn't any way to describe what } \\
\text { it's like to be in the dark for five and a half days. }\end{array}$ \\
\hline $\begin{array}{l}\text { Autonomy and } \\
\text { Choice in the } \\
\text { Environment }\end{array}$ & $\begin{array}{l}\text { Discussion relating to the } \\
\text { personal decisions for } \\
\text { residents based on their } \\
\text { preferences and the } \\
\text { physical environment }\end{array}$ & $\begin{array}{l}\text {-There are rules and guidelines in place, but at the end of the day, } \\
\text { it's their choice. They are still an individual, they don't lose that. } \\
\text {-We come out of our rooms in the morning, we have something to } \\
\text { eat, and then we go back to our rooms. That's day in and day out, } \\
\text { that's not good. } \\
\text {-I don't get it. We have music, we have Bingo, we have all these } \\
\text { things to do in the community center and then people just don't } \\
\text { come. } \\
\text {-What did she do at home? }\end{array}$ \\
\hline
\end{tabular}

Table 12. Resident Study Themes 
it was clear that they did not want to be a burden on anyone. Margaret made this clear when she discussed her decision to move to Ridgmeont, "I said I would not stay with my children, it is not fair to them because they've got their lives and it's not my daughter-in-law's responsibility to look after me. But I'd sooner be home." Others like Robert, felt that they were not a party to the decision, but they had no other choice, "I had a stroke and that's when they put me in rehab. It didn't work out good, I didn't pass it, so they just put me in a home."

\section{Individual History}

Often, theories for explanation of the flow of lives are concerned with scientific generalizations of the developmental theory about how most people grow up and grow old (Schroots \& Birren, 2002). In these resident interviews, the concern instead was the examination of individual uniqueness or exception. Remembering places from the past can help in redefining aspects of the self in the current changed environmental context.

Chaudhury (2002) writes that through expression of positive or negative life experiences, the associated emotions are regenerated, therefore a person recollecting the pleasant times from his or her past may feel good. These individual stories may be seen as a description of the individual's views of the structure of his or her life and its relationship to the point in time when they have moved to LTC (Schroots \& Birren, 2002. ) Jean spent the majority of her interview talking about the farm where she grew up, the type of work that was done on the farm, and the food that was grown there. For Art, it was important to talk about his teenage days playing ice hockey or about his house by the lake. For Marian, the memories of helping her brother fix his lumber truck allowed her discuss a time when she felt a sense of purpose. 


\section{Adjustment in LTC}

In order to understand what residential care means to a LTC resident, it is important to consider not only the characteristics of the residents, but also to examine the process of becoming a resident and the relationship between the nature of admission and the successful adaptation to a new environment (Wilcocks, Peace e \& Kellaher 1987). In an ideal world, decisions about the care of an older adult are planned with full information, consideration of a range of appropriate choices, and sufficient time to weigh the options of the alternatives (Eckert, et al, 2009). If expectations about the physical options and restrictions in community living are addressed prior to a move to LTC, future residents may be able to be proactive in their planning and alleviate some of the sense of loss. However, as we have seen through the multiple roads taken by the residents in this particular study, it is rare when there is a time for reflection or planning prior to their move.

Daily expectations are minimal for residents in both communities, and for most residents, there is graciousness in the way that they have adapted to their new life. They depend deeply on the caregivers and appreciate the fact that there are people around them that do care, but unfortunately, care is just one piece of the puzzle. Heft (2001) writes that while meaningful features of a common environment are products of individual and collective action, they are, at the same time, fundamental and constitutive of individual knowledge, because individual knowledge grows out of social processes and socio-historical contexts. Some, like Claire, have been able to adapt their daily routine in a way in which the cold burn of grief is a given, but not the focus of her life. Others, like Pala, have had to put their grief into another place, but in doing so, she has numbed herself to the ability to feel at all. 
There were no overwhelming accolades for where the residents are now, in either community, and occasionally there were small complaints about the way that the meals are prepared and served, the cranky neighbor, or the feeling of oppression of having to do the same thing, day in and day out without a break. For others, losing all of their possessions without the chance to go through them has left them with the sense of up-rootedness which Carbioni (1990) described in an earlier section. The Stonebridge CCAs have acknowledged this loss, and the Welsh Group has set a goal to increase public awareness and education into the LTC system.

\section{Strength and Vulnerability}

What was found in both communities is that for LTC residents, there is no appropriate time or place to express emotion, and the scars of lost family, lost homes, and lost capabilities are kept inside; this has to take its toll. Tom expresses his emotion when he shakes the locked Bluebird door at Ridgemont until someone opens it for him. A key lesson learned about the residents in both communities is that there is a strength in vulnerability and frailty, especially amongst the Maritimers in this study. In essence, each of them has said, "Don't judge me by this wheelchair or walker, judge me by what I know, what I've done, and what I care about."

The majority of the residents interviewed wanted to discuss their strengths: where they had lived, worked, and raised their families; the strength that it took to make it back home from the hospital as sick young boy in the midst of the VE day riots; or the strength that it took to make it out of the mines alive after a disaster that had killed multiple friends and coworkers; or to survive the bombings in wartime London. Through these conversations, it was apparent that each individual, despite the trials that their lives had dealt them, was aware of how much they had accomplished in life. More importantly, in the recounting of these past life trials, there lies 
personal proof that they can get through whatever difficulties are handed to them in their current setting, whether in an unruly roommate, a fading memory, or multiple physical restrictions.

\section{Autonomy and Choice in the Environment}

The more control residents have over the timing of going to bed, getting up in the morning, the nature of meals and the way they spend their time may define the individual's level of autonomy or choice in the environment (Kane \& Cutler, 2009). Not only is tolerance of diversity of choice and taste a prerequisite for respecting liberty, but so is acknowledging the irreducible individuality of concrete expressions of autonomy in individuals (Agich, 2003).

Despite the higher levels of choice and autonomy at Stonebridge, there is a missing element which is critical in the outcomes for residents, whether in a traditional institutional environment, a renovated neighborhood environment, or a residentially scaled SH cottage. That missing element is the freedom and ability to be that person from their past. One basic sense of autonomy is freedom of action, but sickness frequently forces an examination of what is commonly termed one's values and places limits on the scope of meaningful action (Agich, 2003). There are no silver bullets; the truth of the matter is that life will never be as it used to be for each individual, their stories have made that clear.

Autonomy is first a problem not because powerful caregivers or institutions limit the freedom of frail elders, but because the existential conditions that create the need for LTC rail against the autonomy of independent self-sufficiency (Agich. 2003). But people adjust, and in 


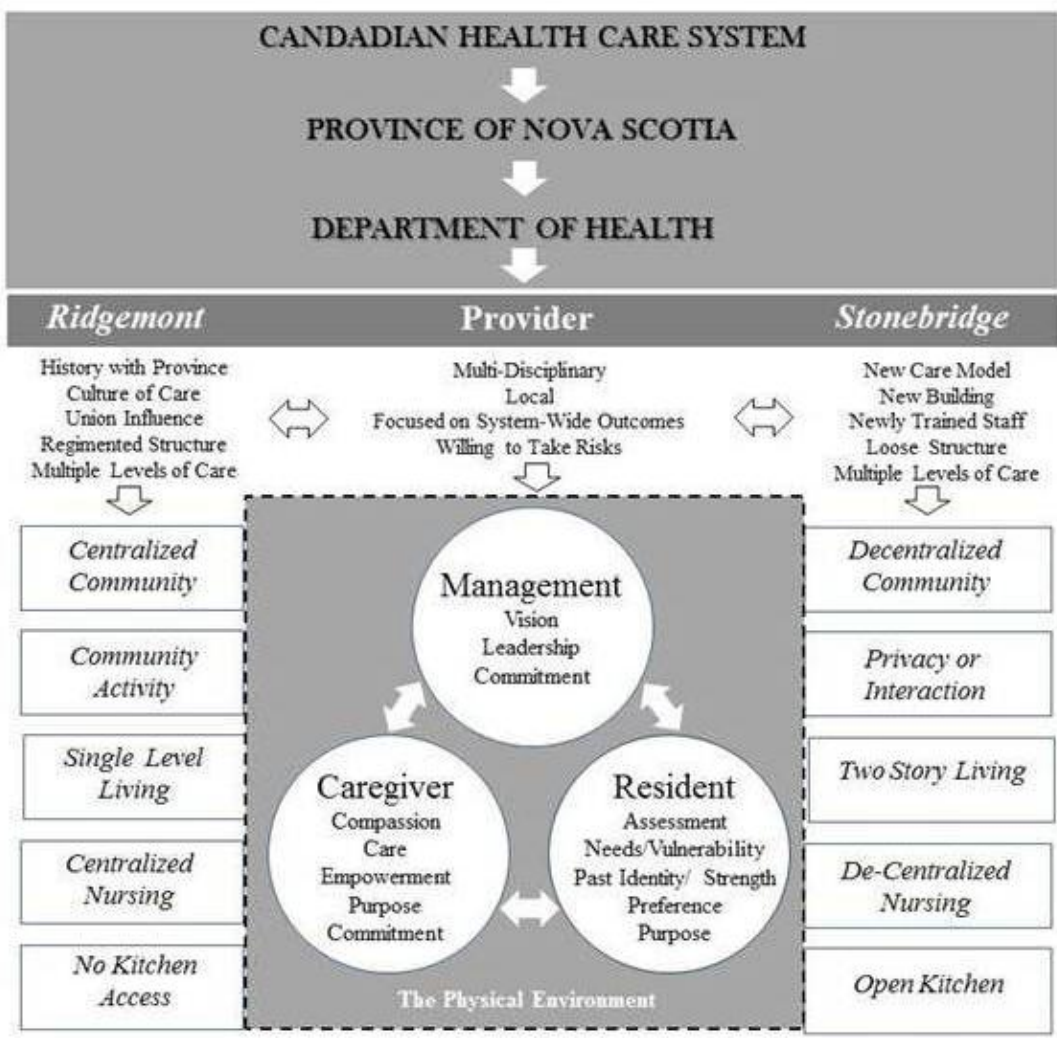

Figure. 110. Cross-Case Study Thematic Relationships

the case of the Maritimers who are used to having to adjust and cope with change, having an environment which is as supportive as their home, if not more so, is a critical element. Having care staff who know them and know their stories is a critical element.

At the outset of this research, it was hypothesized that the differences between the models of care in the two study communities would be clearly articulated in the outcomes, denoting the black and white nature of the two systems of care. Instead of black and white findings, what were found instead were many shades of gray, and this has resulted in multilayered themes relating to not only the physical environment in LTC, but also to the pathways for the creation of those environments, as well as the outcomes for those living and working there (Figure 110). 


\section{Chapter Summary}

Critical social science recognizes that social scientists are participants in the sociohistorical development of human action and understanding. This perspective sees society as humanly constructed and that social science must directly contribute to the revitalization of the moral discourse and revolutionary action by engaging its subjects in a process of active selfunderstanding and collective self-formation (Comstock, 1982). Based on our understanding of the need for change within a system with anomalies, it is clear that the paradigm shift is taking place in the LTC system in Nova Scotia. This appears though to be more of a cultural shift than true culture change, because despite the differences in the organizational or physical structures, the common element in both models remains: the need for care and the provision of care.

The successes and failures in any LTC setting are the result of the relationships created within that setting or the value within the walls. When comparing the two study communities, issues of whether care is inserted into a home-like setting or a home-like setting is inserted into a care environment becomes less important than the universal story of how society provides places for vulnerable, frail individuals to live when they need extra care. The Wyatts and Robins and Joes of the care giving world are driven by their desire to make life better for their residents, whether through a conversation, a new program, or a new building. Though there continue to be frustration for staff at both communities regarding understaffing and underfunding, the CCAs and RNs and LPNs at Ridgemont and Stonebridge are all doing the same thing; each has made a choice, a conscious decision, to be a caregiver. In the case of Stonebridge, the semantics about staffing, communication, and fiscal responsibility will be worked as the organization grows from its experiences, rather than debated in the black hole of conjecture and unknowns. 
It is evident through past discussions that the values that residents bring to the setting are reflected in who they are and their past experiences. According to Heidgegger (1978), the built house does not provide any guarantee that dwelling occurs there; dwelling involves much more than mere inhabitation, suggesting that the dwelling is better understood as that which takes place in terms of relations rather than being defined in terms of a fixed abode. The design of LTC group settings requires an understanding of environmental behavior, i.e. who does what with whom, within what relationship context, and physical setting (Zeisel, 1984), but just as important is the understanding of individual residents attachments to their current place based on the experiences from their past. This does not mean physically doing all of the things that the individual used to do, it means living in a place where there is freedom to be the person who did those things; an individual with an individual life story. 


\section{CHAPTER TEN: FINAL THOUGHTS AND LESSONS LEARNED}

Kruger (1991) writes that in almost all practical questions of life, truth is, at best, the final product of a chain of questions, investigations, doubts, errors, and renewed attempts at reaching it. Even opinions that count as settled are preliminary and subject to revision, at least so far as their deeper significance and wider context is concerned, a context within which they may always change considerably in meaning and function. It is now apparent that Nova Scotia's search for appropriate living situations for individuals in need of LTC has been such a process and has included both positive and negative themes and outcomes for those involved.

The overarching goal for this study has been to use the voices of the stakeholders to answer the study research questions and to enumerate the unique issues and themes relating to physical and philosophical programmatic change in LTC. This has been done through multiple orientations in the hopes of producing a framework for other regional organizations working toward change in their LTC systems (Figure 111).

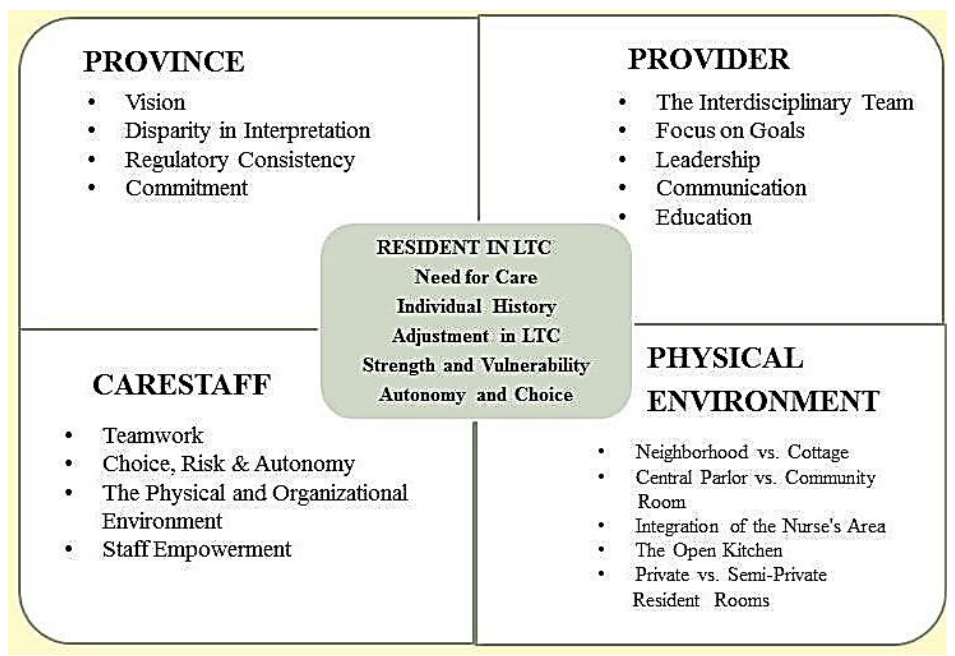

Figure 111. Case Study Thematic Relationships 
While the resident responses at the Stonebridge community have been mixed, the consensus amongst the staff and family members is that the cottage model has multiple benefits for both staff and residents. Reports from the 10 other communities funded through the RFPs have been less positive, in many cases with staff and management reverting back to past habits and organizational structures in the way they provide care. Through their interpretations of the RFP guidelines, they have in essence missed the point of the philosophy of the new model of care. In addition, backups in the transitional care system have not been alleviated, as more individuals put themselves on the waiting list for care in the new communities. The result is that the province is questioning the future of the CCS and is currently assessing how to use the remaining funds which had been earmarked for the construction of over 600 new LTC beds.

\section{Research Questions}

At the outset of this study, three principle research questions were presented. The first related specifically to the impact of the policies and physical guidelines of the SH model on the philosophy of care, service delivery, and staffing patterns in the new Nova Scotia facilities, with particular attention paid to Stonebridge. Care staff at Stonebridge report that, due to the philosophy behind the model, they have a clearer understanding of their role in the lives of the residents. There are highly motivated teams working in each of the cottages, with shared goals of consistency and a person-centered approach to the care that they give. Tensions do exist relating to staff workloads and staffing ratios because of the multiple roles that each team member plays in the cottage, but as, Dana, one of the care staff pointed out, "It's a lot to do, but it's worth it."

The delicate balance of risk and autonomy is another issue raised specifically by the $\mathrm{RN}$, Jill. She understands the philosophy of choice in person centered care, but because of her 
medical training, is also acutely aware of the risk in allowing a resident to do as they please with respect to health and medication issues. This philosophical debate between allowing residents autonomy in their daily choices and the resulting health implications reflects back to the entanglement of the logics of space introduced in the opening chapters.

The management team has tackled multiple hurdles in the first two years of operation and continues to address ongoing issues of staff/management communication as well as the integration of care staff trained in two distinct models of care. One specific outcome of the decentralization of the nursing care at Stonebridge is that the RNs have not had a clear way to communicate with the care staff in the cottages. The gaps in communication have made care planning and implementation difficult, and the ensuing problems have, in some cases, magnified the perception of the differences between the new and the more seasoned staff.

The residents report satisfaction with the care they are receiving at Stonebridge, but there is an ambivalence toward the new model care. The care staff believe that the residents do not truly understand the power of the model because, for many, this is their introduction into LTC. The preference in the residents' interviews was to discuss their life as it had been prior to their move and their individual path to LTC based on an illness or disability. The actual discussion of daily life in the community revolved around the little things which bothered them, but there were no complaints of noise levels, neglect, or concerns for safety. Further discussion of the implications of resident life in LTC will occur in the concluding portions of this chapter.

The second research question was concerned with the ways in which older LTC communities in the province have been transitioning to meet the challenges of the $2006 \mathrm{CCS}$ programming. This question has been addressed using the past and present experiences at 
Ridgemont which have brought to light many of these challenges, including the inconsistency of government funding and the ensuing strengthening of the union influence as a result of the ARC closedown. The issues surrounding the successful transitioning of an institutional model, both physically and organizationally, are multi-fold. With respect to the original Ridgemont nursing home renovation in 1995, committees were formed with staff and management to help design the new central nurses' station. The Welsh Group management had an early understanding of the necessity for care staff buy-in with respect to change, and as Wyatt reported, "We were dealing with nurses at the time who had never heard of anything like the team station, so we had to develop a whole planning team around that." While there are current goals for Ridgemont to be the first existing nursing home in the province to be transformed into an Edenized community, the management understands that staff buy-in will be the deciding factor in to that change. Pushback from the nurses' union is strong and there is a reticence of the staff at Ridgemont to educate themselves about the new model. Other communities in the province have received funding to replace existing beds with new facilities, but the organizational structure and care procedures of these communities reflect care models of the past.

The final research study question asked about the differences in the physical environment of the two study communities in order to gain a clearer understanding of the impact of the new model on resident socialization. This question has been addressed through an environmental analysis of the principle social spaces in the two communities. The differences between the neighborhood design and the cottage design are multi-faceted and ultimately speak to the differences in the care models in general. Due to the physical layout of the building, the majority of the organizational aspects at Ridgemont revolve around the work routines of the staff, including when residents are woken up, meal time schedules, and shower and bathing schedules. 
The focus of community activity is in the nurses' area and parlor at the entrance of the community. In contrast, the Stonebridge care model revolves around the residents and their choices for the day. Staff are there to provide care and support, but do not dictate resident routines. Residents may make choices about their meal and shower times, as well as their levels of privacy or interaction throughout their day.

Through the changes in the spatial configuration of the SH model, there is a decentralization of the principle areas for socialization. This has led to marked changes in the socialization patterns in the shared community spaces, ultimately leading to questions about the "success" of the model by providers and provincial leadership. CCS funds have been put on hold as further analysis is done in the 11 new communities. The remaining sections of this dissertation will explore the meanings and interpretations of this phenomena, as well as an apparent need for a new definition of success in the SH model of care.

\section{Study Orientations}

In addition to the principle study research questions and themes, other topics emerged during the two month case study site visits and the ensuing analysis of the coded data. These were multidimensional orientations relating to the development and assessment of the policy behind this research. This study has focused on a single provider running two very different models of care; therefore, the study findings provide an opportunity to address a variety of universal topics which relate to how we care for those individuals in society who can no longer care for themselves. Because of these multidimensional orientations, it became necessary to develop a framework for the multiple perspectives. 
Altman (1973) has described the environment and behavior field in terms of three orientations: orientation to design and practice, orientation to place, and orientation to psychological and social processes. Lawton, Altman and Wohwill (1984) added a fourth orientation of environmental policy, because policy determination is often the explicit reason for conducting research and it deserves consideration as a separate perspective in environmentbehavior relations and the elderly. They write that there are natural links between place, process, design and policy orientation, because environmental policy often represents an institutional (national, state, or local government) decision about the forms that places should assume and the rules that govern their use (Lawton, Altman \& Wohwill, 1984).

With the application of this framework, four key topics were identified as divergent but connected orientations to clarify the study findings: (1) The orientation to policy- findings in this research relating directly to the political synergy of policy implementation for vulnerable populations; (2) The orientation to design and practice- relating to the impact of changes in building spatial configuration to the socialization patterns in the SH model, this orientation became helpful in answering some of the design-oriented hypothesis associated with the physical characteristics of the SH model. (3) The orientation to place-relating to the individuality of each resident's response to and attachment in a specific environment, in this case the LTC setting; and (4) The orientation to social and psychological processes- relating to resident cognitions, perceptions, and feelings in the LTC environment, particularly how cognitive appraisal processes mediate some person-environment transaction. Moos \& Lemke (1984) write that these processes influence efforts to adapt (coping) and the results of such efforts (outcomes). The use of these four E-B orientations became a helpful tool in examining the universality of the philosophies, values systems and themes associated with LTC change. 


\section{Orientation to Policy-Power Games}

The administrator who hired me back in ' 77 said something that's stuck with me. He said, "The field that we work in, you have to be able to accept change. Change is the rule, not the exception. You've got to be willing to go with it. If you become too set in your ways, you develop problems." (Joe, CCA at Ridgemont)

A critical orientation is preferable where transformative action needs to be preceded by critical thinking and reflection in cases where unequal and invisible power relations need to be unveiled before they can be transformed (Johansson \& Lindhult, 2008). Because this study was driven by a distinct policy orientation, this discussion addresses the necessity of political synergy related to policy implementation for vulnerable populations. Throughout the course of this study, we have seen the impact that provincial legislation has had on care models for vulnerable populations in Nova Scotia. These historical developments have led to an array of social and medical programs designed to support the provincial healthcare system. Examples from previous chapters have shown that, for decades, the process of institutionalization of vulnerable populations has been dictated by whomever was in political power at the time.

Power appears to be a concept that, if not understood, would make it impossible to understand what a society is (Hoy, 1986). This distinction is important when there is an attempt to describe the conflicting political views of the historical role of society in assigning characteristics and attributes to certain individuals (Cousin, \& Hussain, 1984). In the 1960's and 70's, special needs residents in the community had been moved to the ARC at Ridgemont because of the politics behind institutionalization; these were the individuals removed from society by those in power in order that they receive care together in one place, or as Wyatt remembers it, the ARC was considered the "dumping ground for a population that nobody cared about." 
Institutionally oriented settings have been characterized by greater social distance between residents and staff (Willcocks, Peace \& Kellaher, 1987), and in institutions, the needs of the organization to adhere to routines trump personal preferences for how individuals spend their time and take priority over privacy and choice issues (Kane \& Cutler, 2009). While these descriptions refer to institutions of all kinds, there are many similarities found in the type of settings and conditions which individuals with special needs have historically been asked to live with in Nova Scotia.

But as documented in the newspaper articles relating to the ARC closing at Ridgemont, political change swept through the provincial Community Services organization at the beginning of the $21^{\text {st }}$ century, and deinstitutionalization became the new direction with respect to special needs populations. These events were politicized and polarizing, often becoming more about the nature of power relations than about the actual individuals in need of care. A case in point with respect to the historical timeline of the Ridgemont is that while funds to successfully renovate the nursing home were available through the $\mathrm{DoH}$, its sister Community Services organization made the decision to shut down a similar building at the same location, displacing over a hundred residents, rather than provide the funds for a renovation. This polarization could only be the result of inconsistency in the political will in representing the populations being served.

One of the principle outcomes of the closure of the $\mathrm{ARC}$ at Ridgemont was that the union influence at the nursing home was strengthened in order to protect the rights of staff working there. This, in turn, resulted in the strengthening of regimented organizational polices that were more about the staff and cost-efficiency than about the quality of life for the residents at the newly renovated nursing home. These policies, like structured mealtimes and staff hierarchy, were to become the source of many of the anomalies in the system which the DoH were 
addressing when they formed the focus group for the CCS and built their pre-CCS community in Cape Breton in 2005.

\section{Consistency in Leadership}

The history that the Welsh Group has had with the provincial government at Ridgemont is important because it sets the stage for what was to come in the province as changes began to occur in the LTC sector with the 2006 CCS. Commitment and continuity in leadership is a critical element to any system-wide change, and a key disconnect in an organizational system that is moving toward change is the lack of resolve to see change through. In a twist similar to the nursing home renovation/ARC closing, in the time that it has taken for the $2006 \mathrm{CCS}$ standards to become reality, the leadership that formulated the legislation has either lost interest or lost power. An inconsistency in leadership has resulted in the necessity for the re-education of key players in order to keep any long range goal setting and implementation on track, and while the CCS was a 10 year plan, at the halfway point of its implementation, there are already questions surrounding its success. It is important to look at why these value shifts may have taken place.

\section{Shared Program Interpretation and Expectations}

The policies behind the funding for the CCS were developed by a provincial steering committee and legislated by policy makers with the hopes that the 11 new communities would (a) relieve the bottleneck and pressures in the LTC system and (b) encourage relationship building and improved outcomes for residents in the smaller care settings. The 2006 CCS describes the reasoning behind these smaller settings: 
A key feature to the success of these and other innovative approaches to long term care is the reduction in the number of residents living in one 'home area' or 'neighborhood'. Smaller numbers of individuals encourage relationship building between and among residents, families and staff. The more familiar staff are with the residents, the better they can understand the person and the individual's unique needs (CCS, 2006).

The importance of shared expectations and perspectives in a goal setting stage is to ensure similar interpretations of those goals. In this particular case, the reasoning behind the guidelines for the SH physical and organizational model were never fully described. In the 2006 CCS document, the desired outcomes were outlined, i.e., smaller settings, private rooms, resident choice, and well-articulated room sizes, but there was no insight into the relationships of the desired outcomes to the physical and organizational changes that were being proposed. While there was an acknowledgment of the CCS programmatic intricacies, a deeper understanding of the important nuances of the model were left to the provider with the expectation that each would be able to work toward a "successful project outcome" as stated in this excerpt from the CCS document:

Implementation of a multi-million dollar capital project is a complex activity with very high risks requiring careful consideration and management. It is the responsibility of Service Providers to ensure that the necessary resources and management structures are in place that will result in a successful project outcome (CCS, 2006).

Due to a lack of a full understanding of the philosophies behind the changes in the structure of care, there has been an inconsistent approach to the policy interpretations by the providers in the other 10 communities funded by the $2006 \mathrm{CCS}$.

\section{Policy Interpretation}

Hojlo (2010) writes that there are four guiding principles that are essential for LTC transformation to continue: commitment, conflict, competence, and a community of committed 


\begin{tabular}{|c|c|}
\hline $\begin{array}{l}\text { Implementation of the } \\
\text { SH model }\end{array}$ & Stonebridge Provider \\
\hline $\begin{array}{l}\text { Core understanding of } \\
\text { philosophy behind the SH } \\
\text { Model }\end{array}$ & $\begin{array}{l}\text { - History of care for multiple populations needs } \\
\text { - Recognition of anomalies in the LTC system } \\
\text { - } \quad \text { Earticipated in Eden Training } \\
\text { model community }\end{array}$ \\
\hline $\begin{array}{l}\text { Cross-disciplinary } \\
\text { management team }\end{array}$ & $\begin{array}{l}\text { - } \quad \text { Former Director of Care of a nursing home } \\
\text { - } \quad \text { Former nursing home administrator } \\
\text { - } \quad \text { Former frontline nursing home care staff } \\
\text { - Current C.O.O. of parent construction company }\end{array}$ \\
\hline The design process & $\begin{array}{l}\text { - Design-build firm which resulted in consistency in the design goals and } \\
\text { the end product } \\
\text { - Direct relationships with the provincial individuals and committees } \\
\text { involved in the RFPs } \\
\text { - Unwavering consistency in the design goals } \\
\text { - Followed provincial guidelines }\end{array}$ \\
\hline Staff hiring & $\begin{array}{l}\text { - Very selective hiring process based on presentation of the model to } \\
\text { potential care staff } \\
\text { - Decision to keep union hiring out of the new community }\end{array}$ \\
\hline Staff education & $\begin{array}{l}\text { - Partnered with the local community college to provide educational } \\
\text { opportunities for newly hired staff } \\
\text { - In-house continuing education opportunities for care staff }\end{array}$ \\
\hline Shared Goals & - $\quad$ Cohesive management team \\
\hline Consistent leadership & $\begin{array}{l}\text { - Unwavering dedication to staff and residents } \\
\text { - } \quad \text { Understanding of need for flexibility in leadership }\end{array}$ \\
\hline
\end{tabular}

Table 13.

Provider Goals and Outcomes

people. With respect to moving from the care model at Ridgemont to the new model at

Stonebridge, the Welsh Group had all of the essential elements for change. The bonds that

formed the management team that helped design, build, and run Stonebridge were created due to

the commonalities of the team; they were willing to take the risks to address the anomalies they

saw in not only the provincial LTC system, but also what they saw occurring in the Ridgemont

transitions over the years (Table 13). 
The interpretations of the CCS by the other providers awarded the RFPs varied. This was mentioned by the DoH administrator in her discussions about staffing ratios and the decision by some of the providers to build the households for 15-16 residents rather than the 12-13 laid out in the RFP. Staffing ratios are tight even at the lower numbers, and, as she pointed out, those communities have had to bring in support staff to cover the shortages care staff. By doing so, they have missed the point of the model, or as Wyatt said, "they are missing the whole philosophy." In addition, the cottages at Stonebridge are the only ones of the 11 communities with open kitchens. The other ten communities either share a kitchen (meaning shared kitchen staff) or have a completely enclosed kitchen.

While there is a need for some flexibility in interpretation of regulatory standards, as evidenced in this study, outcomes can differ substantially when there are multiple groups of providers involved. The issue with regulated conformity is that it has to be enforced. Unless the presiding leadership is willing to take steps to follow through with regulation of the key elements of the model, they will be faced with the many shades of gray in interpretation found in Nova Scotia. In this case, the multiple interpretations of the CCS have led to an uncertainty about the strength of the model. There are natural links between policy and design, and legislators are taking a step back from the multi-million dollar building project. This uncertainty is directly related to the consistency, leadership, goal setting, and expectations laid out by the province.

Another related topic is the question of how success in the new communities is being measured. It appears that the providers are working under assumptions about outcomes reflecting the only model they really understand, the traditional, institutional model of care. Residents are not spending as much time in the shared community areas in the new communities, and the changes in resident participation in social activity are confusing to staff and 
management. This is the issue that the DoH had raised in their analysis of the 2005 community in Cape Breton. The restructuring of the physical layout of the environment in the SH model has led to the restructuring of the social environment, specifically, what area of the building is used as the center of the community for residents.

\section{Orientation to Design-The Center of the Community}

Previous discussions have addressed the environmental differences in the Ridgemont neighborhood and Stonebridge cottage models. Within a design orientation, it is important to take this a step further to understand the impact of these differences on past expectations and new realities of the social environment in the SH model.

When developing a balanced housing community, there is a recognition that each individual has both a need for support and for challenge. Merely because they have more environmental options built into their setting, the residents in the cottages are more inclined than those in a traditional setting to make the decisions of what to do with their day, giving them a higher level of autonomy because each individual has personal preferences for privacy or interaction: "Should I sit in my room, because it's really my own little apartment; or should I sit in the living room; or should I sit in the kitchen; or should I go down and see what's happening in the activity room?" Because there are more options on how residents are able to spend their day, residents do not spend as much time in the shared community areas. This became clear in the Chapter 9 descriptions of the two buildings and is reflected in Table 14 community comparisons.

In the open neighborhood model at Ridgemont, the central area of the building is the parlor/open nursing area; this is the gathering point for socialization, and residents use the 


\begin{tabular}{|c|c|}
\hline RIDGEMONT-NEIGHBORHOOD & STONEBRIDGE-COTTAGE \\
\hline 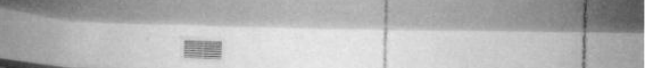 & \\
\hline EAliny & $\frac{17}{2+1}$ \\
\hline $\begin{array}{l}\text { No front door for neighborhoods other than } \\
\text { locked Bluebird doors }\end{array}$ & Front door for each cottage \\
\hline $\begin{array}{l}\text { Private and semi-private resident rooms } \\
\text { connected to public corridors }\end{array}$ & $\begin{array}{l}\text { Private resident rooms directly } \\
\text { connected to semi-private living area }\end{array}$ \\
\hline Lounge/dining areas connected by corridors & $\begin{array}{l}\text { Living/dining areas directly adjacent to } \\
\text { each other }\end{array}$ \\
\hline Necessity to leave group area for meals & $\begin{array}{c}\text { Not necessary to leave the cottage for } \\
\text { meals }\end{array}$ \\
\hline $\begin{array}{l}\text { Care staff/nurses' station central and } \\
\text { adjacent to activity parlor }\end{array}$ & $\begin{array}{l}\text { Care staff/nurses' station decentralized } \\
\text { and integrated into each cottage kitchen }\end{array}$ \\
\hline $\begin{array}{l}\text { Socialization options in activity area or in } \\
\text { semi-private room }\end{array}$ & $\begin{array}{c}\text { Socialization option in kitchen, living } \\
\text { room, private resident room, shared } \\
\text { community room }\end{array}$ \\
\hline $\begin{array}{l}\text { View of comings and goings of building } \\
\text { from the activity area }\end{array}$ & $\begin{array}{l}\text { View of comings and goings from the } \\
\text { cottage from kitchen/dining area }\end{array}$ \\
\hline Noise levels high in community spaces & Noise levels low in the cottages \\
\hline
\end{tabular}

Table 14.

A Change in the Center of the Community

environment in multiple ways. It is important to point out that residents are brought to the activity areas by the care staff, so if a resident is not in their room, it is most probable that they will be in one of the sitting arrangements in this central area. This allows them either a general visual perspective of the entire community area or an opportunity to participate in an ongoing activity where care staff are always at hand. This area is also connected to the building foyer, so 
there is visual connection for residents to watch the comings and goings at the building entrance. The three neighborhood dining areas, on the other hand, are dispersed throughout the building, requiring a trip down a corridor to get to a meal.

As previously pointed out, the central point for socialization at Stonebridge is in each of the cottage kitchens; this is where the action is throughout the day. Within the cottage, residents can choose to be a part of the action or sit back as their cottage mates and staff interact over coffee, conferences, and or a meal. They can also choose to sit in the living room and watch TV, or spend time in their room. There is visual connection throughout the cottage and opportunities for withdrawal or engagement. The noise levels are low except at mealtimes because of the multiple conversations going on at once in the dining area. Reasons to leave the cottage then are reduced to a trip either to an activity at the community room or a trip outside of the building with a visitor. Once an activity is over in the community room, there are no reasons to stay, because other than the receptionist in the front foyer, the rest of the care staff are in the cottages.

\section{Community Integration}

For the casual observer at Stonebridge, the first impression of the shared community environment is that it is subdued. This impression relates directly to the norms dictated by the physical environment of the medical model of the past; in communities like Ridgemont, there were no other places to spend one's time other than one's shared room and the community area. This absence of choices resulted in the appearance of a cohesive social environment. That community ideal is understandable within the context of an institutional setting. Goffman (1961) describes institutions using four main characteristics:

First, all aspects of life are conducted in the same place and under the same single authority. Second, each phase of the member's daily activity is carried on in the 
immediate company of a large batch of others, all of whom are treated alike and required to do the same things together. Third, all phases of the day's activities are tightly scheduled, with one activity leading at a pre-arranged time into the next, the whole sequence of activities being imposed from above by a system of explicit formal rulings and a body of official. Finally, the various enforced activities are brought together into a single rational plan purportedly designed to fulfill the official aims of the institution (Goffman, 1961, Pg. 17).

Yet the extent to which all residents in a setting are involved in community activities as a group is a relatively weak measure of community integration, because such mass activity tends to reflect professional programming rather than person-centered, individualized planning (Kane \& Cutler, 2009).

The implications of the changes in the configurations of the two communities speak to a need to change expectations and the interpretation of community and individual socialization patterns in the new model. There is a presumption that if a resident has chosen to stay in their semi-private room, that is not a sociable person. Information from the care staff interviews has informed us that, with respect to the cottages at Stonebridge, this is not the case. This is pointed out by the caregiver, Annette, who refers to one of the residents in her cottage who prefers being in her room. "She keeps busy, she’s super friendly, she just doesn't like being around a huge group of people." The activity directory, Noreen, also has an understanding that the environmental choices that are now available in the SH model weren't available in the previous model of care.

There is a concern that the provincial leadership is using this change in community social patterns to determine the successes or failures in their new communities. A new sensibility in the communities will be required to allow for an understanding that the residents now have the opportunity to create their own social patterns, and those patterns will be based on the environmental preferences of the individual. Each resident's experiential environment, including 
dwelling or community satisfaction, is based on a number of factors relating to past history and place attachment (Golant, 1984).

\section{Orientation to Place-Individual Response to the Physical Environment}

By calling for a restructuring of the systems of LTC, including the physical and organizational aspects of the care environment, there is the suggestion that the new LTC environments will create new outcomes, and it is assumed that the previous settings will be rejected as unnecessary and useless. However, as Hillier (1980) points out, you cannot see a theory, only its consequences, so you cannot verify a theory, only phenomena that are consistent with it. Therefore, while the residents' need for care is evident in both of the study communities, this case study has revealed that resident responses to their environment are determined more by the resident in the setting than by the setting itself. This orientation to place has emerged in a number of ways throughout this case study research.

Low \& Altman (1992) refer to place as a space that has been given meaning through personal, group, or cultural processes. What makes a place special is not necessarily any intrinsic qualities of the locale itself, it may also be the particularity of lineage to the outside world which is in part what constitutes place (Massey, 1994). How an individual views their place in the world therefore plays a large role in their response to a LTC setting.

For the most part, the decision to move into LTC follows a series of changes, including an individual's declining health or diminished memory, changes in support systems, or a development of new conditions that raise concerns about safety or well-being (Eckert, 2009). In the case of the resident and family stories that we have heard, the primary route to LTC has been hospital stay, either for some type of trauma or illness. Once the individual has been admitted to 
the hospital, it may be clear that the individual can no longer take care of themselves at home. Marcus (1992) writes that an elderly person who is moved from a much-loved home may yearn both for its familiar rooms, views, and furniture and for the feeling of comfort and security it evokes. Feelings occur in space and inevitably become associated with various highly charged places. Thus any discussion of emotion and place must return to the observation that the two are inexplicably connected, not in a causal relationship, but in a transactional exchange unique to each person.

\section{Place Satisfaction}

The environment is meaningful because, within it, we directly experience environmental connections, meaningful events, meaningful places, and social actions (Heft, 2001). Residents in congregate living situations are part of a social entity; they share common experiences and are exposed to common environmental factors. Symbolic meanings about place can be translated into cognitions or beliefs, descriptive statements, rooted in symbols about what kind of place this is (Stedman, 2002). Stokols and Sjumaker (1981) define place as the entity between aspects of meaning, physical properties, and relative activity, and emphasize the collective perceptions of place, proposing that place has a social image-ability. This image-ability is the collectively held social meanings that the place has among its occupants or users.

Kaplan (1988) describes preference as the relationship between cognition and affect and believes that one cannot function without the other in order to understand the importance of preference and judgment in the human psychological makeup. One misconception about the $\mathrm{SH}$ settings is that, because the cottages are residential in scale, the individuals living there will feel 'at home'. However, place theory also tells us of the duality of social worlds which insulate one 
world from another. It allows varied participants to operate in seemingly contradictory worlds that look and sound quite reasonable from a position within each world (Gubrium, 1975). In other words, there can be as many meanings to a place as there are those experiencing it.

\section{Place Attachment}

Mesch and Manor (1998) assert that it is possible to be satisfied with where one lives and not be particularly attached to place. The resident interviews have provided examples of this through their multiple, individual perspectives. Art knows that he is supposed to appreciate Stonebridge, but has related that the physical environment does nothing for him. Robert is clear in his ambivalence about life at Stonebridge, "Well, it's supposed to be (home), it's a long way from being home." Ridgemont for Claire, on the other hand, is the only place she has to call home, "You can't exactly make it your home. But you've got no other home, so this is your home."

Personal identity is also central to attachment to place in later life and is individually distilled from events significant in the framework of the normatively defined life course; it is within this insider's perspective that we discover the roots of place attachment (Rubenstein \& Parmelee, 1992). If an individual has come from home, there are different environmental expectations than if they have come from another care community. Edna was the only resident interviewed who had lived in both Ridgemont and Stonebridge, and while she is not particularly happy with either environment, her perspective allows her to appreciate the subtle differences in her daily choices in what to do and when. For Art, who had come to Stonebridge from home, the transition has been more difficult; he has given up the key activities in his life that he values, therefore does not have Edna's perspective to understand the value of where he is now. For 
Edward, the loss of his belongings is a severing of his roots to an attachment to home of any kind, and this may result in a continuing sense of homelessness. For Elsie, life at Stonebridge affords her independence and safety from an abusive partner.

The SH setting has as many functions as there are individuals experiencing it: a place to receive care, a place for safety, and/or a place for independence. A key study finding is the importance of the setting as a place to give care; the care staff at Stonebridge have formed attachments to their workplace within the context of home. This attachment stems directly from the physical and organizational model of the community, as well as the freedom they have in their scheduling and the consistency of their roles in the lives of the residents. The care staff have a clear understanding of their role in the lives of the residents and have a vested interest in creating a place for positive individual outcomes within the context of a shared lived experience.

\section{Orientation to Social and Psychological Processes-Finding Home}

The resident and family interviews have clarified the fact that despite goals of residential or homelike settings, the reality of home for each individual is a very personal setting related to individual social and psychological processes. This distinction is important for all stakeholders to take in to consideration as the future of the CCS program is assessed by the Province. It may be necessary to change the way that success is measured in the SH model, with the bar of success adjusted to reflect the individuality of resident responses to the physical and social changes in the SH setting. While it remains the role of society to create places where accessibility and principled core vision are designed to meet the needs for individual autonomy, there is a necessity to cut through the veneer of terms such as 'homelike' and 'residential' in the description of new LTC environments. Residents who have moved into LTC are not concerned 


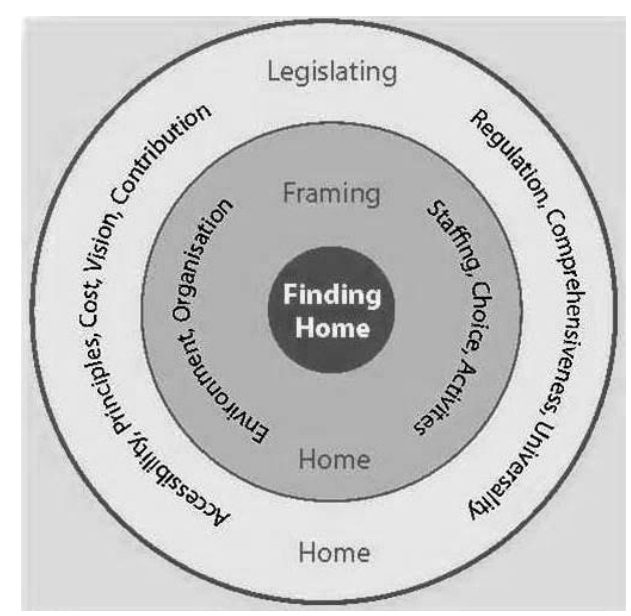

Figure 112. Finding Home in LTC

about the history of the place type, or the legislation which has put them there. What they do care about is their own history, their perception of who they are, and especially for Maritimers, where they come from. Success therefore reflects the seamlessness of each individual's transition into care.

Agich (2003) writes that it is a mistake to think that caring for elders can involve only saving or preserving some remnant trace of past self. For the individual resident, there is necessity to redefine the personal identity, allowing their former selves to change as their bodies and life situations have (Rubenstein \& Parmelee, 1992). The mature self is not a finished product, but a subject who actively experiences the world on the basis of formed identifications. Stonebridge still provides Art a place where he can find purpose and meaning. Music and an opportunity to play Jeopardy in the community room are the things that he gets out of bed for every morning. Home has a personal meaning for each individual, and the multiple rings in Figure 112 speak to the spheres of influence on a resident's ability to find home in LTC. 
The legislator's role is to fund settings where there is accessibility and principled core vision with comprehensiveness in regulation. The second ring reflects the care setting, where the provider and staff create a physical and organizational environment that allows resident choice and autonomy in their daily life. But ultimately for some residents, the very personal search for home in LTC may never be realized, and the notion of a restorative environment goes the direction of the miracle of happy marriage with an abusive spouse or moving back to an apartment filled with a life's possession which are long gone.

As human beings, we live with possibilities, aspirations, dreams, the hope of bettering one's lot, the hope of achieving goals or success - the hope for improvement. It is our environment and individual experience which give us our window on life (Groene, 1966). For an older adult in a residential care, all of the noise, pain, sorrow, and joy from one's life becomes fixated in one place, and everything else is gone. The internal drive, perhaps propelled by one's no longer to be denied awareness of the imminence of death, almost insists on a new or intense meaning to one's life, some new direction leading to the future (Friedan, 1993). But the reality of life in LTC is that meaning for the future is, for the most part, formed in the past. This excerpt from a poem by Sue Elkind describes the search for that meaning:

I wanted the past to go away To leave it as I would in my house, Shutting the door on it.

I wanted the past to go away now it's tomorrow, the future, whatever, And my life has exploded,

Shards flying through the air.

Now I'm living in the past every word is another dab on the palette for the picture painted with memories. I keep going backward until I know

I'll end up a child waiting for a life of tomorrows (Elkind, 1988, p.8) 
For a lifetime, we shut out the noise of life, and now, as we age, that noise is our world. Each memory is singularly painted in one's mind eye until the picture is complete of what this life has been; those are the connections from past to present. After months of daily conversations with staff and residents in her small group home setting, in the last days of her life, my aunt confided in me the story which had been carried with her for 60 years. She described the unexpected and tragic death of a young, vibrant sister, and I saw her weep for the first time, sitting propped up by her pillows in her little bed in her little room. She was in a place both physically and psychologically where she finally felt the security to share those last brush strokes of her life story. This is where our goals should direct us, to provide each individual in LTC a place to finish the very individual painting of their life, with ease and with grace.

\section{Future Study and Conclusion}

Through multiple perspectives, this case study research has determined that the issues relating to the successful implementation of LTC reform within the SH model are complex and relate to the core themes of leadership consistency, staff empowerment, changes in the social environment, and an individual resident's needs and adjustment to their setting. The purpose of this research has been to provide insight into the research questions as well as to provide new areas for future study in the development of the SH model of care. Some important questions remain regarding the long term implications of staff empowerment and satisfaction in the cottage work settings. Does this empowerment translate to staff retention and lower turnover? Is there a way to measure how staff satisfaction impacts resident satisfaction?

Another important question relates to the impact of public education about the realities of LTC on resident preparedness and acceptance of transitions into a new LTC community. Is there 
a distinction in expectations and outcomes for residents moving directly to LTC from home vs. those moving from another community setting?

Other questions relate to the steps being taken in Nova Scotia to expand and update their transitional care units. Would a change in the assessment process alleviate some of the back-ups in the system and could CCS funds be better spent on short stay care settings? Finally, with respect to the physical layout of SH settings, questions remain as to the ways to break up shared community spaces to result in more resident traffic during the day. As the design of large communities with multiple cottages or households becomes more frequent, it is important to look at ways of reducing the building footprint while still retaining appropriate layout and scale in the community. This may require study of resident preference with respect to single level vs. multilevel building arrangements.

The frailties and incapacities associated with old age challenge families, friends, health care institutions, health care professionals, and contemporary societies to respond with compassion and understanding (Agich, 2003). The multiple perspectives in this study have informed us that despite the challenges and hurdles for all stakeholders involved, through the drafting and funding of the Continuing Care Strategy, the Province of Nova Scotia has taken a large step toward the enhancement of opportunities for future individuals in SH settings with the need for long term care. 


\section{Institutional Review Board Approval}

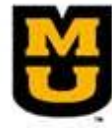

\author{
Campus Institutional Review Board \\ University of Missouri-Columbia
}

485 . MeReytuolds J Jall

Columbia, MO $65211-1150$

TI TONE: (573) $882-4585$

TAX: $(573) 88440663$

Devember 8,2011

Trincipal Investigator: Roberts, Emily

Department: Architectural Stud ies

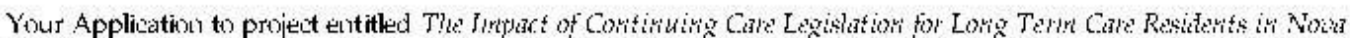

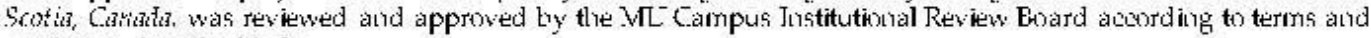
conditions described behow:

\begin{tabular}{|c|c|}
\hline TRE Trtoject Number & 12121242 \\
\hline Tunding . Source & Voute \\
\hline Initial Application Approval Date & December 8,2011 \\
\hline TRE Expiratiory Date & Decimber is 2012 \\
\hline Level of Review & Expedited \\
\hline Expedited Cattegrites & 45 (TR $46.176 . a(n)(7)$ \\
\hline Project Status & Active - Opeir to Eurrollment \\
\hline Risk Level & Mituimal Risk \\
\hline Type of Cousent & Written Cousent \\
\hline
\end{tabular}

The principal investigator (TI) is responsible for all aspects and sonduct of this study. The PT must comply witly the following conditions of the approval:

1. No subjects may be involved in any study procedure pror to the TRE approwal date or after the expiration date.

2. All unanticipated problems, serhous adverse events, and deviations must be reported to the TRE within 5 days.

3. All modifications must be TRE approved pror to implementation utless they are intended to reduce risk

4. All recruitment materials and methods must be approved by the TRE prior to being used.

5. The Continuing Review Status Report must be submitted to the TRE for review and approval at keast 30 days prior to the project expiration date.

6. Vaintain all restarch reards for a period of seven years from the project cumpletion date.

7. Litive the TRE stamped consent documents and other approved research documents boated within the document storage section of eJRE.

If you liave any questions, please contact the Campus TRE at 573-882-4585 or umeresear dheirbomissturiedu.

Thatk you,

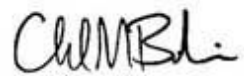

Glarkes Ehorduitr, PlhD

Campus TRE Chair 


\section{Informed Consent}

\section{RESIDENT/FAMILY MEMBER INFORMED CONSENT}

Investigator Name:

Faculty Advisor:
Emily Roberts

Dr. Benyamin Schwarz, PhD

Study Title: Regulation of Small House Settings for Continuing Care Residents in Nova Scotia, Canada IRB Project: \#1200242

\section{INTRODUCTION}

I would like to ask you to participate in a study that involves research. The Department of Architectural Studies at the University of Missouri-Columbia supports the practice of protection for human subjects participating in research. The following information is provided for you to decide whether you wish to participate in the present study. You may refuse to sign this form and not participate in this study. You should be aware that even if you agree to participate, you are free to withdraw at any time. If you do withdraw from this study, it will not impact you in any way.

\section{PURPOSE OF THE STUDY}

The purpose of this study is to better understand how the small house model of continuing care may impact resident daily social engagement and interaction with staff, other residents and family members.

\section{PROCEDURES}

This research will be conducted as a qualitative comparative case study, using multiple sources in data collection to provide an in-depth picture of the daily life in two continuing care facilities in Nova Scotia. Case study research holds a long disguised history across psychology, medicine, lay and political science. Sources of information will come from researcher observations and interviews. If you agree to be interviewed, the interview will be pre-arranged and will last for approximately 30-45 minutes.

\section{RISKS}

There are no risks associated with participation in this study. There will be questions asked regarding the length of time of your residency in this setting, typical daily activities, and the impact choices in the small house model of care. Sample questions include: How important is it for you to be able to choose when to get up in the morning and when to go to bed at night? and Do you feel at home here, if so, what makes it feel like your home; if not, what would make you feel more like at home? 


\section{BENEFITS}

There will be no direct benefit to you for agreement to participate in this study. However, there is a hope that the information obtained from this study may further the understanding of the needs of residents and their families that reside in long term care.

\section{PAYMENT TO PARTICIPANTS}

There will be no monetary compensation for participation in this study.

\section{PARTICIPANT CONFIDENTIALITY}

Your name will not be associated in any publication or presentation with the information collected about you or with the research findings from this study. Instead, the researcher will use a study number or a pseudonym rather than your name. Your identifiable information, or that of any of the other residents or care facility, will not be shared in any form.

Permission granted on this date to use any information from this study remains in effect indefinitely. By signing this form, you give permission for the use of information gathered for purposes of this study at any time in the future.

\section{REFUSAL TO SIGN CONSENT AND AUTHORIZATION}

You are not required to sign this Consent and Authorization form and your refusal to do so will have no impact on your rights of any kind with you or your family members place of residence.

\section{CANCELLING THIS CONSENT AND AUTHORIZATION}

You may withdraw your consent to participate in this study at any time. You also have the right to cancel your permission to use and disclose further information collected about you, in writing, at any time, by sending your written request to the address for the researcher.

\section{QUESTIONS ABOUT PARTICIPATION}

Questions about procedures should be directed to the researcher listed at the end of this consent form.

\section{PARTICIPANT CERTIFICATION:}

I have read this Consent and Authorization form. I have had the opportunity to ask, and I have received answers to any questions I had, regarding the study. I understand that if I have any additional questions about my rights as a research participant, I may call 573-882-9585, write the Campus Institutional Review Board, 483 McReynolds, University of Missouri, Columbia, MO 65211, or email umcresearchcirb@missouri.edu 
I agree to take part in this study as a research participant. By my signature, I affirm that I have received a copy of this Consent and Authorization form.

Print Participant's Name

Date

Participant's Signature

\section{RESEARCHER CONTACT INFORMATION:}

Emily Roberts

Principal Investigator

Department of Architectural Studies

137 Stanley Hall

University of Missouri

Columbia, MO 65211

828-275-5212
Benyamin Schwarz, $\mathrm{PhD}$

Faculty Supervisor

Department of Architectural Studies

137 Stanley Hall

University of Missouri

Columbia, MO 65211

573-882-4904 


\section{Letter of Introduction}

\section{Memo}

To: $\quad$ Residents, Staff and Families

From:

$\mathrm{CC}$ :

Date: $12 / 18 / 2012$

Re: $\quad$ PhD Student Emily Roberts

\section{Hello Everyone,}

We are pleased to welcome Emily Roberts M. Arch (PhD Candidate, Architectural Studies, Masters Student Gerontology) from North Carolina through the University of Missouri-Columbia.

Emily is examining the organizational and architectural set up of $(\quad)$ and $(\quad)$ to compare the effects each environment and model of care has on day to day living and social interactions of the elders living within them. Emily will be present over the next eight weeks beginning tomorrow in the common areas of each community and very much looks forward to meeting everyone.

If you have questions regarding the parameters of her research at any time, Emily will be happy to discuss this with you.

We look forward to reviewing the results of Emily's research to gain further insight into how our models of care affect the quality of life of our elders. 
Interview Protocol- Family Member

\section{Continuing Care Interview Questions}

Sample Family Member Interview Questions

Time In: 10:15 am

\begin{tabular}{lll}
\hline Site: $\quad$ Ridgemont & \\
Field Contact Type: Interview $\quad \uparrow$ & Date: $1 / 04 / 12$ \\
& Researcher: ER
\end{tabular}

1. How often are you able to visit your family member who is a resident here?

2. Can you describe your activities with your family member when you visit?

3. Did you help your family member make the choice to move to this LTC facility? If so, what were the other choices which were available at the time?

4. If your family member had previously been at another facility, how has this model of care changed their daily routines?

5. How much time does your family member spend outside of the household in community activities and with residents from one of the other households?

6. Do you feel comfortable when visiting your family member in this setting? Do you have a positive relationship with the other residents and the staff members?

7. Do you feel that your family member's physical and emotional needs are being met in this particular household?

8. Does your family member feel at home in this setting? If not, what do you think would help them feel at home?

9. Explain what you think works best in this household and this LTC facility.

10. If you were making the decision to move into a LTC facility, would you prefer to live in this type of setting or a traditional institutional setting? Why? 


\section{Interview Protocol-Resident}

\section{Continuing Care Interview Questions}

Sample Resident Interview Questions

Time In: 10:15 am

\begin{tabular}{lll}
\hline Site: $\quad$ Ridgemont & \\
Field Contact Type: Interview $\quad \uparrow$ & Date: $1 / 04 / 12$ \\
& Researcher: ER
\end{tabular}

1. How long have you lived in this care facility?

2. Can you tell me about your typical daily activities?

3. If you were previously living in another facility, can you describe to me your feelings about this moving to a facility with this model of care?

4. What do you like best about this setting? What would you like to see changed?

5. Tell me about how you and your housemates interact socially.

6. Tell me about how you and the care staff interact socially.

7. How important is it for you to have a private bedroom?

8. How important is it for you to be able to choose when to get up in the morning and when to go to bed at night?

9. How much time do you spend outside of the household in community activities or visiting other households?

10. Do you feel at home here? If so, what makes it feel like your home? If not, what would make it feel more like your home? 


\section{Continuing Care Interview Questions}

Sample Staff Interview Questions

Time In: 10:15 am

\begin{tabular}{lll}
\hline Site: $\quad$ Ridgemont & \\
Field Contact Type: Interview $\quad \uparrow$ & Date: $1 / 04 / 12$ \\
& Researcher: ER
\end{tabular}

1. What contributed to your decision to work in this care facility?

2. Can you tell me about your typical workday activities?

3. If you were previously working at another facility, can you describe to me your feelings about working in a facility with this model of care?

4. If you previously worked in a traditional institutional care setting, tell me if and how your job satisfaction has changed since working here.

5. Tell me about how you work with residents to get them involved in social activities.

6. What are the social patterns of behavior that you believe to be related to small household environments for resident and staff interactions?

7. How much time do residents spend outside of the household in community activities and at other households? Would you like to see more social interaction between residents in the different households?

8. Explain what you think needs to be changed in this household and this LTC facility.

9. Explain to me what you think works best in this household and this LTC facility.

10. If you had a family member moving into a LTC facility, would you prefer to live in this type of setting or the traditional institutional setting? Why? 


\begin{tabular}{lll}
\hline Site: & Ridgemont & \\
Field Contact Type: Observation $\quad \uparrow$ & Date: $1 / 04 / 12$ \\
& Researcher: ER
\end{tabular}

Who was involved in the field contact? What was the situation or event? Observed lunch being served in Bluebird Dining Area.

\section{Summarize the information on the research aim/questions below:}

Residents: Cora -Waiting at her table in the dining room. Hears the sound of a rolling cart, "The dinner truck, the dinner truck." Lunch is served first here, there are 15 residents, two have someone there to feed them. Cora and her table mate are answering a woman who is inaudible. "Can you understand her?" "Just say yes, Cora." "I can't do that cause I don't know what she's saying."

Staff: One food server has worked there for 47 years and one for 31 years. She states that "it's changed, it used to be better."

"We used to be a total of 205 because there were apartments across the road (ARC). Now we're down to 51. Those were good times."

"I worked here and then retired until my husband retired. When he did, my house didn't get any bigger. He needed to understand that this wasn't his ship and I wasn't his subordinate. We worked through it and I went back to work."

1. What were the main issues that struck you in this contact? Lunch time at Bluebird, the residents are sitting waiting for the food which is prepped, panned, and carted between three dining rooms with the same staff serving. Little conversation among the residents, although the staff are busy talking with each other.

2. How does this contribute to the research project-Mealtime protocols

3. What new questions do you have in considering the next contact? -Observe the other neighborhood dining areas

Large open room with lots of natural light

No visual of kitchenette, door remains closed

Serving staff rushed, not particularly helpful, but accommodating

Serving staff leave as soon as everyone has been served

Meal-soup, crackers, and sliced cheese 


\section{REFERENCES}

Agich, G. (2003). Dependence and autonomy in old age: An ethical framework for long-term care. Cambridge University Press: Cambridge, England.

Altman, I. (1975). The environment and social behavior. Monterey, CA: Brooks/Cole Publishing.

Altman, I. (1977). Privacy regulation: Culturally universal or culturally specific? Journal of Social Issues, 33, 66-83.

Altman, I., and Rogoff, B. (1987). World views in psychology: Trait, interactional, organismic, and transactional perspectives. In D. Stokols \& I. Altman (Eds.), Handbook of Environmental Psychology (Vol. I, pp. 7-40). New York: Wiley-Interscience.

Altus, D.E., Engleman, K.K., \& Matthew, R.M. (2002). Using family-style meals to increase participation and communication in persons with dementia. Journal of Gerontological Nursing, 28(9), 47-54.

Amella, E., Grant, A. \& Mulloy, C. (2008). Eating behavior in persons with moderate to late-stage dementia: Assessment and intervention. Journal of the American Psychiatric Nurses Association, 13, 360-367.

Angelelli, J. (2006). Promising models for transforming long-term care. Gerontologist 46, 428-430.

Angus, J., Kontos, P., Dyck, I., McKeever, P., \& Poland, B. (2005). The personal significance of home: Habitus and the experience of receiving long-term home care, Sociology of Health and Illness, 27(2), 166-187.

Bachelard, G. (1964). The poetics of space (Excerpt), in Leach, N. (Ed.) Rethinking architecture. London: Routledge.

Baker, B. (2007). Old age in a new age: The promise of transformative nursing homes. Vanderbilt University Press: Nashville.

Banjerjee (2009). Long-term care in Canada: An overview. In P. Armstrong, et al. (Eds.), A place to call home: Long term care in Canada. Nova Scotia: Fernwood Publishing.

Barker, P. (2003). The tidal model: Psychiatric colonization, recovery and the paradigm shift in mental health care. International Journal of Mental Health Nursing, 12(2), 96-102.

Barker, R. (1963). On the nature of environment. Journal of Social Issues, 19(4), 17-38.

Barker, R. (1968). Ecological psychology: Concepts and methods for studying environmental behavior. Stanford University Press: Stanford, California. 
Barnes, S. (2006). Space, choice and control, and quality of life in care settings for older people. Environment and Behaviour, 38, 589-603.

Bergsma, J. \& Thomasma, D. (1982). Health care: Its psychosocial dimensions. Pittsburgh, PA: Duquesne University Press.

Bowman, C. (2008). The environmental side of the culture change movement: Identifying barriers and potential solutions to furthering innovation in nursing homes. Presymposium background paper to the 2008 Creating home in the nursing home: A national symposium on culture change and the environmental requirements.

Brawley, Elizabeth C. (2006). Design Innovations for Aging and Alzheimer's: Creating Caring Environments. John Wiley \& Sons, Inc.: Hoboken, New Jersey.

Brown, M. (2001). Residents' lives places at risk-nurses' union. Province plans to shut down special-needs home. The Daily News, January 2001.

Bruce, H. (1988). Down home: Notes of a maritime son. Key Porter Books: Ontario, Canada.

Buckley, C. \& McCarthy, G. (2009). An exploration of social connectedness as perceived by older adults in a long-term care setting in Ireland. Geriatric Nursing, 30(6), 390-396.

Buhr, G., Kuchibhatla, M., \& Clipp, E. (2006). Caregivers' reasons for nursing home placement: Clues for improving discussion with families prior to the transition. The Gerontologist $46(1), 52-61$.

Calkins, M. (2003). Powell Lawton's contributions to long-term settings. Journal of Housing for the Elderly, 17(1/2), 67-84.

Calkins, M. (2005). Learning from doing: Conducting a SAGE post occupancy evaluation, Alzheimer's Care Quarterly, 6 (4), 357-365.

Calkins, M., and Marsden, J. (2000). Home is where the heart is: Designing home-like settings. Alzheimer's Care Quarterly, 1 (1), 8-16.

Campbell, S. L. (2003). Empowering nursing staff and residents in long-term care. Geriatric Nursing, 24, 170-175.

Carboni, J. (1990). Homelessness among the institutionalized elderly. Journal of Gerontological Nursing, 16(7).

Caron, C., Duncharme, F. Griffith, J. (2006). Deciding on institutionalization for a relative with dementia: The most difficult decision for caregivers. Canadian Journal of Aging, 25(2), 193-205. 
Carradice et al. (2002). A qualitative study of the theoretical models used by UK mental health nurses to guide their assessments with family caregivers of people with dementia. International Journal of Nursing Studies. 39, 17-26.

The Center for Excellence in Assisted Living (2005). Making quality assisted living an affordable community-based care option: Identifying roles, risks and recommendations for Medicaid and other public subsidies.

Chaudhury, H. ( 2002). Journey back home, Journal of Housing for the Elderly, 16(1-2), 85-106.

Chaudhury, H. (2003). Quality of life and place-therapy. Journal of Housing for the Elderly, $17(1), 85-110$.

Cole, T. (1992). The journey of life: A cultural history of aging in America. Cambridge University Press: United Kingdom.

Cohen \& Eisdorfer (2001). The loss of self. International Journal of Geriatric Psychiatry 17(7). 689.

Cohen, U. \& Weisman, G.D. (1991). Holding on to home: Designing environments for people with dementia. Baltimore, MD: Johns Hopkins University Press.

Comstock (1982) A method for critical research, in Bredo, E. and Feinberg, W., (Eds.), Knowledge and values in social and educational research. Philadelphia: Temple University Press.

Connidis, I.A. (2010) Family ties and aging. Los Angeles: Pine Forge Press.

Cousins, M. \& Hussain, A. (1984). Michel Foucault. New York: St Martin’s Press.

Creswell, J. (1998). Qualitative inquiry and research design: Choosing among five traditions. Thousand Oaks: Sage Publications.

Creswell, J. (2009). Research design: Qualitative, quantitative and mixed methods approaches. Los Angeles: Sage Publications.

Csikzentimihayli, M. \& Rochberg-Halton, E. (1981). The meaning of things: Domestic symbols and the self. Cambridge: Cambridge University Press.

Dahlin-Ivanoff, Haak, M. (2007). The multiple meaning of home as experienced by very old Swedish people, Scandinavian Journal of Occupational Therapy, 14, 25-32.

Day, K., Carreon, D., \& Stump, C. (2000). Therapeutic design of environments for people with dementia: A review of the empirical research, The Gerontologist, 40(4), 397-416. 
Diaz-Moore, K. (1999). Dissonance in the dining room: A study of social interaction in a special care unit. Qualitative Health Research, 9(1), 133-155.

Division of Aging and Seniors (2002) Canada's Aging population: A report by Health Canada in collaboration with the interdepartmental committee on aging and seniors issues.

Doty, M., Koren, M.J., \& Sturla, E. (2008). Culture change in nursing homes: How far have we come? Findings for the Commonwealth Fund 2007 national survey of nursing homes.

Dykstra, P.A. and Van Wissen, L.J.G. (1999). Introduction: The life course approach as an interdisciplinary framework for population studies in: P.A. Dykstra and L.J.G. Van Wissen (Eds.), Population Issues: An Interdisciplinary Focus, 1-22, New York: Kluwer Academic.

Eckert J.K., Carder, P, Morgan, L., Frankowski, A.C. \& Roth, E.G. (2009). Inside assisted living: The search for home. Balimore, Maryland: The Johns Hopkins University Press.

Elkind, S. (1988) Another language, California: Papier-Mache Press.

Erickson, P.A. (2004). Historic north end Halifax. Nimbus Publishing Limited: Halifax, Nova Scotia.

Flyvbjerg, B. (2006). Five misunderstandings about case-study research. Qualitative Inquiry, 12(2), 219- 245.

Fried, L., Ferrucci, L. Darer, J. Williamson, J. \& Anderson, G. (2004). Untangling the concepts of disability, frailty, and comorbidity: Implications for improved targeting and care. Journal of Gerontology Medical Science, 59(3), 255-263.

Friedan, B. (1993). The Fountain of Age, New York: Simon and Schuster.

Fuller, S. (2004). Kuhn vs. Popper: The struggle for the soul of science. New York: Columbia.

Gobbens, R.J., Luijkx, K.G., Wijnen-Sponselee, M.T., \& Schols, J.M. (2010). In search of an integral conceptual definition of frailty: Opinions of experts. Journal of the American Medical Association, 11, 338-343.

Gobbens, R.J., van Assen, M., Luijkx, K., \& Schols, J.M. (2012). The predictive validity of the Tilburg Frailty Indicator: Disability, health care utilization, and quality of life in a population at risk. The Gerontologist, p. 1-13.

Gilmore, H., Gibson, F., \& Campbell, J. (2003). Living alone with dementia: A case study approach to understanding risk. Dementia, 2, 403-420.

Goffman, E. (1961). Asylums. New York: Doubleday Anchor Books. 
Golant, S. (1984). The effects of residential and activity behaviors on old people's experiences, in Altman, I., Lawton, M.P., Wohlwill, J., (Eds.) Elderly people and the environment. New York: Plenum Press

Golant, S. (1998). Changing an older person's shelter and care setting: A model to explain personal and environmental outcomes, in Scheidt, R. \& Windley, P., (Eds.) Environment and aging theory: A focus on housing. Westport, Connecticut: Greenwood Press.

Golant, S. (2003). Conceptualizing time and behavior in environmental gerontology: A pair of ideas issues deserving new thought. The Gerontologist, 43(5), 638-648.

Gold, M.F. (2002). Freeing the human spirit. Provider Magazine, 21-32.

gov.ns.ca/health .(2007) District Health Authorities. Retrieved from: http://www.gov.ns.ca/DHW/about/DHA.asp.

Groene, T. ( 1966). The harvest years. Boston: The Christopher Publishing House.

Gubrium, J. (1975). Living and dying at Murray Manor. New York: St. Martin's Press.

Gutman, R. (1972). People and buildings. University of California: Basic Books.

Haggerty, B., Lynch-Sauer, J., Patusky, K., \& Bouwsema, M. (1993). An emerging theory of human relatedness. Image-Journal of Nursing Scholarship, 25, 291-296.

Harasim, L. (2000). Shift happens: Online education as a new paradigm in learning. The Internet and Higher Education, 3(1-2), 41-61.

Hayden, D. (1995). The power of places: Urban landscapes as public history. Cambridge, MA: The MIT Press.

Health Canada (2002). Canada's aging population. A report prepared by Health Canada with the interdepartmental committee on aging and senior issues.

Heft, H. (2001) Ecological psychology in context. Mahwah, New Jersey: Lawrence Erlbaum Associates.

Heidgegger, (1978). Building dwelling thinking. In Basic Writings. David Farrell Krell (Ed). New York: Harper \& Row, 319-339.

Hillier, B. (1996). Space is the Machine. Cambridge: Cambridge University Press.

Hojlo, C. (2010). The VA's transformation of nursing home care: From nursing homes to community living centers. Generations -Journal of the American Society on Aging. 34(2), 43-48. 
Hoy, D.C. (1986). Power, repression, progress: Foucault, Lukes and the Frankfurt School in D.C. Hoy (Ed.) in Foucault: A critical reader. New York: Basil Blackwell.

Hoyningen-Huen, P. (2000). Paul Feyerabend and Thomas Kuhn in Lamb (Ed.) The worst enemy of science? Essays in memory of Paul Feyerabend. New York: Oxford University Press.

Imamoglu, C. (2007). Assisted living as a new place schema; A comparison with homes and nursing homes. Environment and Behaviour, 39(2), 246-268.

Imershein, A.W. (1977). Organizational change as a paradigm shift. The Sociological Quarterly, 18(1), 33-43

Johansson, A. \& Lindhult, E., (2008). Emancipation or workability? Critical versus pragmatic scientific orientation in action research. Action Research, 6(1), 95-115.

Kane, R. (2009). Post occupancy evaluation of a transformed nursing home: The first four Greenhouse settings. Journal of Housing for the Elderly, 23, 304-334.

Kane, R. \& Cutler, L. (2009). Promoting homelike characteristics and eliminating institutional characteristics in community-based residential care settings: Insights from an 8-state study. Seniors Housing \& Care Journal, 17(1), 15-35.

Kane, R.A., Lum, T.Y., Cutler, L.J., Gegenholtz, H.B., \& Yu, T. (2007). Resident outcomes in small-house nursing homes: A longitudinal evaluation of the initial Greenhouse program. Journal of the American Geriatrics Society, 55, 832-838.

Kaplan, S. (1988). Where cognition and affect meet: A theoretical analysis of preference: Environmental aesthetics. Cambridge: Cambridge University Press.

Kaup, M. (2007). Rethinking nursing home architecture: Why skilled care environments don't really feel like home (and what we can do about it), In design and social justice: Proceedings from the Interior Design Educators Council $44^{\text {th }}$ Annual International Conference. 196-

Kearney, M.H. (1998). Truthful self-nurturing: A grounded formal theory of women's addiction. Qualitative Health Research, 8, 495-512.

Keefe, J., Stadnyk, R., White, E., Fancey, P. (2009). Building research capacity for examining the impact of developments on quality of life for nursing home residents and their families. Background document Nova Scotia Center on Aging.

Kendig, H. (2003). Directions in environmental gerontology: A multidisciplinary field. The Gerontologist, 43(5), 611-615. 
Kennedy, J. (1963). In Koff, T. \& Park, R. (1999) Aging public policy: Bonding the generations. (JFK Aging Speech p. 86). New York: Baywood Publishing.

Kenyon, G.M., Ruth, J.E. \& Mader, W. (1999). Elements of a narrative gerontology. In (Eds.) V.L. Bengtson \& K.W. Schaie, Handbook of theories of aging. New York: Springer Publishing Company.

Kirby, M.J. (2002). The health of Canadians- The federal role. Volume one: The story so far. Ottawa: The Standing Senate committee on Social Affairs, Science and Technology.

Kitwood, T. (1997). Dementia reconsidered: The person comes first. Buckingham: Open University Press.

Koncelik, J. (1976). Designing the open nursing home. Stroudsburg, Pennsylvania: Dowden, Hutchinson \& Ross.

Koncelik, J. (2003). The human factors of aging and the mico-environment: Personal surroundings, technology and product development. Journal of Housing for the Elderly, 17(1), 117-134.

Konetzka, T. (2006). Changing economic incentives in long-term care. Center for Policy Research: Maxwell School of Citizenship and Public Affairs: Syracuse University.

Korpela, K.et al. (2001). Restorative experience and self-regulation in favorite places. Environment and Behavior, 33, 572-598.

Kruger, L. (1991). Culture and modernity. University of Hawaii Press: Honolulu.

Kuhn, T. (1970). Logic of discovery or psychology of research, in Lakatos, I. and Musgrave, A. (Eds), Criticism and the growth of knowledge. Cambridge: University Press.

Lang, J. (1987). Creating architectural theory. New York: Van Nostrand Reinhold.

Larvor, B. (2003). Why did Kuhn's Structure of Scientific Revolution cause a fuss? Studies in History and Philosophy of Science, 34(2), 369-390.

Lawton, M.P. (2001). The physical environment of the person with Alzheimer's disease. Aging and Mental Health, 5(1), 56-64.

Lawton, M.P., Altman, I. \& Wohwill, J. (1984). Dimensions of environment-behavior research: Orientations to place, design, process, and policy, in Altman, I., Lawton, M.P., Wohlwill, J., (Eds.) Elderly people and the environment. New York: Plenum Press

Lawton, M.P. \& Nahemow, L. (1973). Ecology and the aging process. In C. Eisdendorfer \& M. P. Lawton (Eds). The psychology of adult development and aging. Washington, DC: American Psychological Association. 
Lee, R, Draper, M. \& Lee, S. (2001). Social Connectedness, dysfunctional interpersonal behaviors, and psychological distress: Testing mediator model. Journal of Counselling Psychology, 48(3), 310-318.

Lewin, K. (1951). Field theory in social science: Selected theoretical papers. In D. Cartwright (Ed.), New York: Harper \& Row.

Lewin, F. (2001). The meaning of home among elderly immigrants: Directions for future research and theoretical development, Housing Studies, 16 (1) 353-370.

Marcus, C. (1992). Environmental memories. In (Eds. I. Altman \& S.M. Low) Place attachment. New York: Plenum Press.

Massey, D. (1994). Space, place and gender. Minneapolis: University of Minnesota Press.

Mayer, K.U. (1986). Structural constrains on the life course, Human Development, 29, 163-170.

MetLife (2005). Mature market institute: The MetLife Survey of nursing home \& home care costs. Westport, CT: MetLife Mature Market Institute. http://www.metlife.com.

McLellan, D. (1975). Karl Marx. Glasgow: Fontana.

McLughlin, P. (2001). Nurses: Closing center a mistake. Health of residents at home compromised, opposition charges. The Daily News, January 2001.

Mesch, G.S. \& Minor, O. (1998). Social ties, environmental perception and local attachment, Environment and Behaviour, 30(4), 504-519.

Miles, M.B. \& Huberman, A.M. (1994). Qualitative Data Analysis. Thousand Oaks, CA : Sage Publications.

Mirowsky, J. (1995). Age and the sense of control. Social Psychology Quarterly, 58, 31-43.

Molony, S., Evans, L., Jeon, S., Rabig, J., \& Straka, L. ( 2011). Trajectories of at-homeness and health in usual care and small house nursing homes. The Gerontologist 15 (4), 504-515.

Moore, G.T., Tuttle, D.P., \& Howell, S.C. (1985). Environmental design research directions: Process and prospects. New York: Praeger.

Moos, R.H. (1976). The human context: Environmental determinants of behaviour. New York: John Wiley \& Sons.

The National Post (2001) Nova Scotia: Adult center to close. January 2001. 
Norberg-Shulz, C. ( 1993). Heidegger's thinking in on architecture in K. Nesbit (Ed.) Theorizing a new agenda for architecture. An anthology of architectural theory. New York:

Princeton Architectural Press.

Nova Scotia Department of Health. (1995). From blueprint to building: Renovating Nova Scotia's health system. Nova Scotia Department of Health.

Nova Scotia Department of Health (2000). Transitions in care: Nova Scotia Department of Health facilities review summary: Prepared for the Honourable Jamie Muir, Minister of Health, Nova Scotia Department of Health.

Nova Scotia Department of Health (2006). Shaping the future of continuing care in Nova Scotia: To have every Nova Scotian live well in a place they can call home. Report from the Provincial Steering Committee.

Nova Scotia Department of Health (2007). Continuing Care Strategy: Long term care facility requirements. RFP 60131637.

Parker, C., Barnes, S., McKee, K., Morgan, K., Torrington, J., \& Tregenza, P. (2005). Quality of life and building design in residential and nursing homes for older people. Aging \& Society, 24, 941-962.

Parker, L., Kirchner, J., Bonner, L., Fickel, J., Ritchie, M., Simons, C., \& Yano, E. (2009). Creating a quality improvement dialogue: Utilizing knowledge from frontline staff, managers, and experts to foster health care quality improvement. Qualitative Health Research, 19, 229-242.

Partridge, J.S., Harari, D., Dhesi, J.K. (2012). Frailty in the older surgical patient: A review. Age and Ageing, 41(2), 142-'47.

Patton, M.Q. (1990). Qualitative evaluation and research methods. Newbury Park: Sage Publications.

Perez de Vega, (2010). Experiencing built space: Affect and movement. Proceedings of the European Society of Aesthetics, 2, 386-409.

Propp, K., Apker, J., Ford, W., Wallace, N., Serbenski, M., \& Hofmeister, M. (2010). Meeting the complex needs of the health care team: Identification of nurse-team communication practices perceived to enhance patient outcomes. Qualitative Health Research, 20, 15-28.

Raina, P., O’Donnell, M., Schwellnus, H., Rosenbaum, P., King, G., Brehaut, J., Russell, D., Swinton, M., King, S., Wong, M., Walter, S., \& Wood, E. (2004) Caregiving processes and caregiver burden: Conceptual models to guide research and practice. BMC Pediatrics $4(1)$.

Rabig, J. (2009) Home again, small houses for individuals with cognitive impairment. Journal of Gerontological Nursing, 35(8), 10-15. 
Rader, J. (1995). Moving away from the hospital model to an individualized resident-centered model. Individualized dementia care: Creative, compassionate approaches. New York: Springer.

Rahman, A. N., \& Schnelle, J. F. (2008). The nursing homes culture-change movement: Recent past, present, and future directions for research. The Gerontologist, 48, 142- 148.

Rapoport, A., (2000). Science, explanatory theory, and environment-behavior studies. In (Eds. Wapner et al. )Theoretical perspectives in environment-behavior research. New York: Plenum Publishers.

Regnier, V. (2002). Design for assisted living: Guidelines for housing the physically and mentally frail. New York, John Wiley \& Sons.

Ravdal, H. (2002) Telling stories: Introduction . In (Eds. Rowles \& Schoenberg) Qualitative gerontology: A contemporary perspective. New York: Springer Publishing.

Richards, S. (1987). Philosophy and sociology of science: An introduction. Oxford: Basic Blackwell.

Ridgemont Community News (1998). From the Administrator. 4(1), 1.

Ridgemont ARC News (2001). Ridgemont ARC: Keeping you informed. 1 (1), 1-4.

Rochberg-Halton (1981). In Csikzentimihayli, M. \& Rochberg-Halton, E. The Meaning of Things: Domestic symbols and the self. Cambridge: Cambridge University Press.

Rockwood, R., Fox, R. Stolee, P. and Robertson, D. (1994). Frailty in elderly people: An evolving concept. Canadian Medical Association 150(4), 489-495.

Rubenstein, R.L. (1990). Culture and disorder in the home care experience: The home as sickroom, in J.F. Gubrium and A. Sankar (Eds.) The home care experience: Ethnography and policy. Newbury Park, CA: Sage.

Rubinstein, R.L. (2002). The qualitative interview with older informants: Some key questions, in G. Rowles and N. Schoenberg (Eds.) Qualitative gerontology: A contemporary perspective. New York: Springer Publishing Company.

Rubenstein, R.L. \& Parmelee, P.A. (1992). Attachment to place and the representation of the life course by the elderly. In I. Altman \& S.M. Low (Eds.) Place attachment, New York: Plenum Press.

Scheidt, R. \& Norris Baker, C. (2003). Many meanings of community: Contributions of M. Powell Lawton. Journal of Housing for the Elderly, 17(1/2), 55-66. 
Schein, EH (1985). Organizational culture and leadership: A dynamic view. San Francisco: Jossey-Bass Inc.

Schroots, J.J. \& Birren, J.E. (2002). The study of lives in progress: Approaches to research on life stories. In G. Rowles \& N. Schoenberg (Eds.) Qualitative gerontology: A contemporary perspective, New York: Springer Publishing Company.

Schwarz, B. (1992). Designing public places for private lives: A study of the design process of long-term care settings. Dissertation-The University of Michigan.

Schwarz, B. (2003). M. Powell Lawton's three dilemmas in the field of environment and aging. Journal of Housing for the Elderly, 17(1/2), 5-22.

Shiner, D., Stadnyk, R., daSilva, Y., \& Cruttenden, K. (2010). Senior housing: Challenges, issues and possible solutions for Atlantic Canada. Final report of the Atlantic Seniors Housing Research Alliance. Mount Saint Vincent University. Halifax, Nova Scotia.

Schillmeier, M. \& Heinelin, M. (2009). From house to nursing home and the (un-) canniness of being at home. Space and Culture, 12(2), 218-231.

Schoeneman, K.(2007). Culture change in nursing homes: How far have we come? Picker Commonwealth Fund.

Smith, A. (2001). Nova Scotia closing residence for disabled: 139 adults will be moved to small options, nursing homes. The Mail Star, January, 2001.

Stadnyk, R. (2002). The status of Canadian nursing home care: Universality, accessibility and comprehensiveness. For the Atlantic Centre of Excellence for Women's Health: Halifax, Nova Scotia.

Stake, R. (1995). (1995). The art of case study research. Thousand Oaks: Sage Publication.

Strawbridge, W., Sherma, S., Balfour, J., Higby, H. \& Kapllan, G. (1998). Antecedents of frailty over three decades in an older cohort. The Journals of Gerontology, 53(1). S9-S16.

Stedman, R. (2002). Toward a social psychology of place: Predicting behavior from place-based cognitions, attitude, and identity. Environment and Behavior, 34, 561-581.

Stokols, D., (1988). Transformational processes in people-environment relations. In McGrath, J.E. (Ed.), The social psychology of time: New perspectives. Newbury Park, CA: Sage Publications.

Stokols, D., \& Shumaker, S. (1981). People in place: A transactional view of settings. In J. Harvey (Ed.), Cognition, social behavior and the environment. Hillsdale, NJ : Lawrence Erlbaum. 
Thomas, W.H. (2003). Evolution of Eden. In A. Weiner \& J. Ronch (Eds). Culture change in long-term care. Birmingham, NY: Haworth Social Work Practice Press.

Tirado, F., Calle, B., \& Cassian, N. (2009). The question of movement in dwelling: Three displacements in the care of dementia. Space and Culture, 12, 371-382.

Townsend, K. \& McWhirter, B. (2005). Connectedness: A review of the literature with implications for counseling, assessment, and research. Journal of Counseling and Development, 83(2), 191-201.

Tyler, D. \& Parker, V. (2011). Nursing home culture, teamwork, and culture change. Journal of Research in Nursing, 16, 37-49.

UWM Center on Aging (2010). Next steps think tank: Culture change consensus and the household model. For the University of Wisconsin Milwaukee: Center on Age and Community.

Van Schaik, L. (2008) Spatial intelligence: New futures for architecture. Great Britain, John Wiley and Sons.

Verbeek, H., van Rossum, E., Zwakhalen, S., Kempen, I., Hamers, J. (2009). Small, homelike care environments for older people with dementia: A literature review. International Psychogeriatrics, 21(2), 252-264.

Verbeek, H., van Rossum, E., Zwakhalen, S., Ambergen, T., Kempen, I., Hamers, J. (2009). The effects of small-scale, homelike facilities for older people with dementia on residents, family caregivers and staff: Design of a longitudinal, quasi-experimental study. $B M C$ Geriatrics, 9(3), 1-13.

Vikko, A. (1996). In Lewin, F. (2001). The meaning of home among elderly immigrants: Directions for future research and theoretical development, Housing Studies, 16 (1) 353-370.

Wahl, H. \& Weisman, G.D. (2002). Environmental gerontology at the beginning of the new millennium: Reflections on its historical, empirical, and theoretical development. The Gerontologist, 43, 616-627.

Wallace, C., Chandler, L., Rogers, A., Crosby, K., Joshi, N., Spriggs, T. \&Hill, C. (2012). Caring for frail patients: Best practices. Nursing Standards, 26(28), 50-56.

Willcocks, D., Peace, S. \& Kellaher, L. (1987) Private lives in public places. University Press: Cambridge.

Wood, W., Harris, S. Snider, M. \& Patchel, S. (2005). Activity situations on an Alzheimer's disease special care unit and resident environmental interaction, time use, and affect. American Journal of Alzheimer's Disease and Other Dementias. 20, 105-118. 
Yin, R. (1994). Case study research: Design and methods. Newbury Park, CA: Sage.

Zeisel, J. (1984). Inquiry by design: Tools for environment-behavior research. Monterey, California: Brooks/Cole Publishing Company.

Zeisel, J., Hyde, J. \& Levkoff, S. (1994). Best practices: An environment-behavior (E-B) model of Alzheimer special care units. The American Journal of Alzheimer's Care and Related Dementias \& Research, 4-21. 


\section{VITA}

Emily Roberts was born in Santa Barbara, California in 1960. At the age of nine, she and her family moved to further south to Orange, California where she attended public schools, graduating from high school in 1977. She then attended California State University Fullerton where she attained a Bachelor's Degree in Environmental Design in 1981. Ms. Roberts made the decision to apply for architecture school the same year, after attending a summer architecture workshop at the Harvard Graduate School of Design. She went on to receive a Masters of Architecture with distinction from the University of New Mexico in 1987. Upon return to California, Ms. Roberts worked for several prominent architectural firms in the Santa Barbara area, at which time she met her husband. Throughout the years of raising three children, she worked as a consultant in construction administration, doing presentation work, and in the production of working drawings. During this period, she also developed and ran several architectural workshops for $4^{\text {th }}$ and $5^{\text {th }}$ grade elementary school children. In 2009, after sending her eldest son off to architecture school, Ms. Roberts made the decision to continue her schooling with a Master's degree in Gerontology and a $\mathrm{PhD}$ in Architectural Studies. Ms. Roberts has presented her research at both the Environmental Design Research Association (EDRA) and Gerontological Society of America (GSA) annual conferences and is currently cochair of the Environment-Gerontology network of EDRA. 